(6)

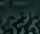
ory

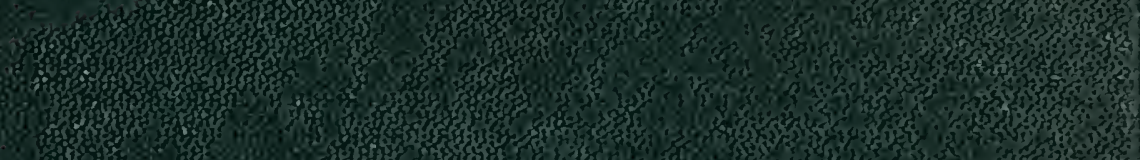

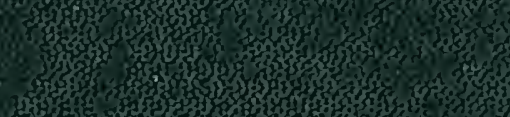

4 a

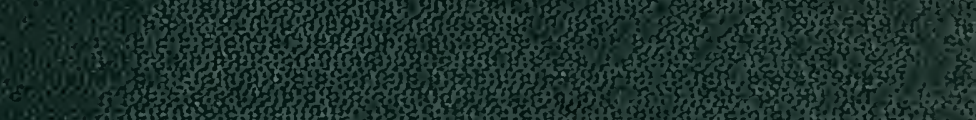

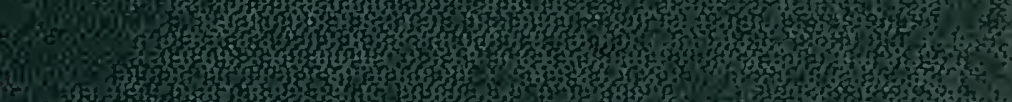

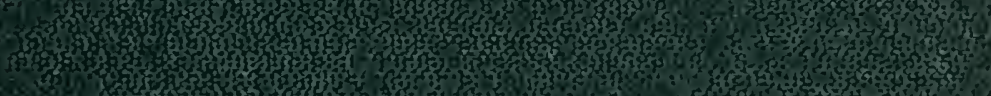

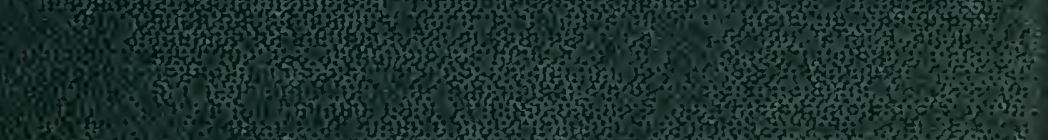

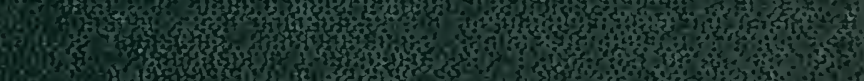

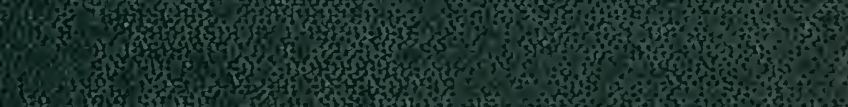

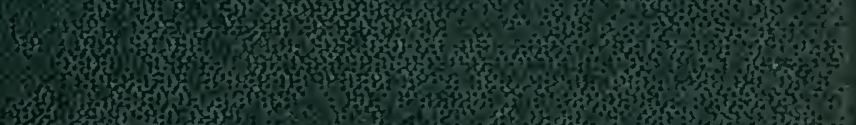
W.

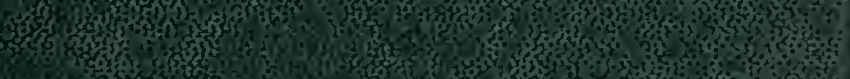

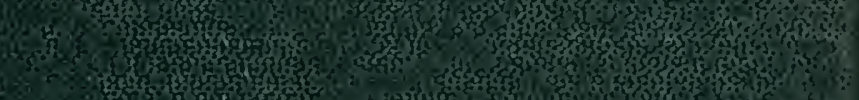

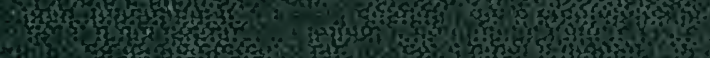
की

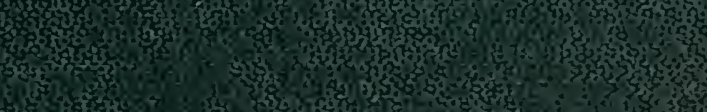

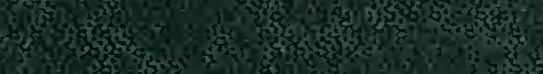
Q6. (1) 


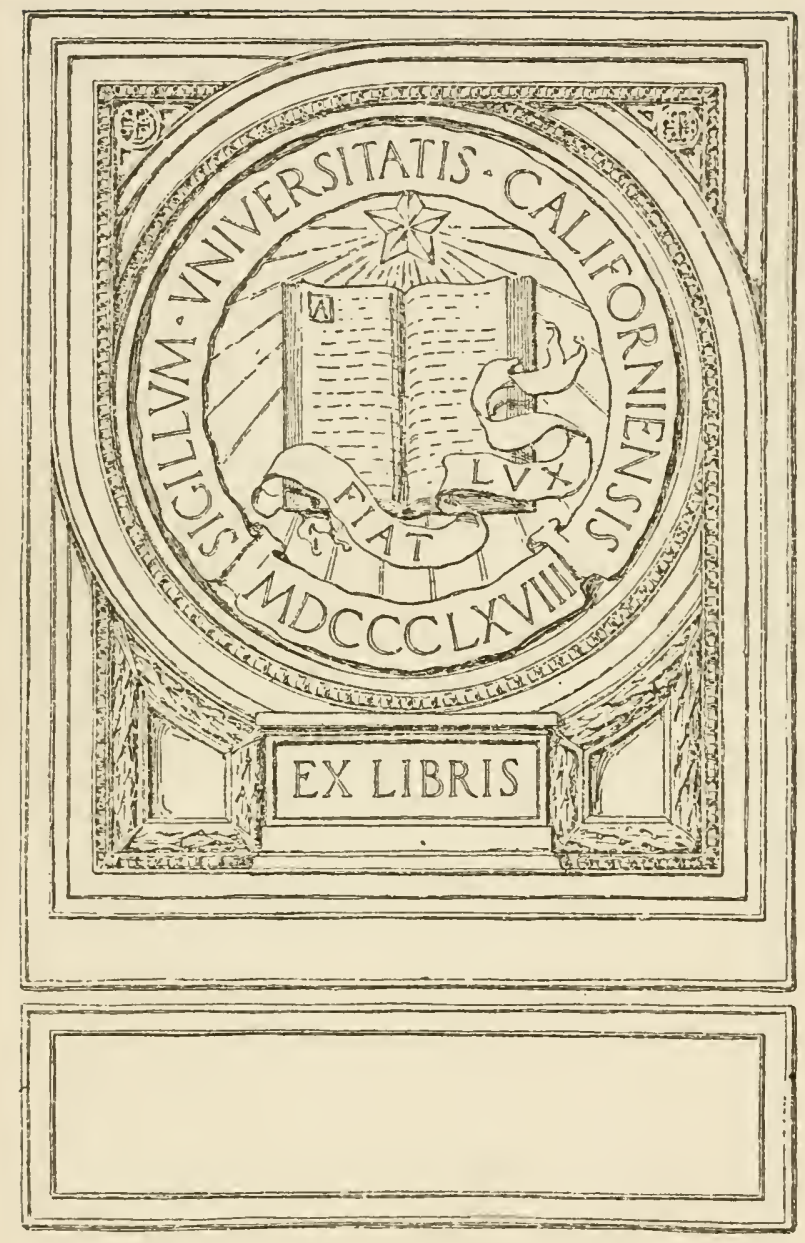



Digitized by the Internet Archive in 2008 with funding from Microsoft Corporation 


\section{ORGANIC AGRICULTURAL CHEMISTRY}




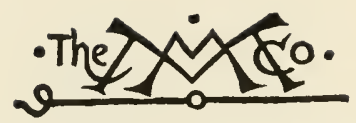

THE MACMILLAN COMPANY

NEW YORK - BOSTON - CHICAGO - DALLAS ATLANTA - SAN FRANCISCO

\section{MACMILLAN \& CO., Limited \\ LONDON - BOMBAY - CALCUTTA \\ MELBOURNE}

THE MACMILLAN CO. OF CANADA, LTD. TORONTO 


\section{ORGANIC}

\section{AGRICULTURAL CHEMISTRY}

(The Chemistry of Plants and Animals)

A TEXTBOOK

OF GENERAL AGRICULTURAL CHEMISTRY OR ELEMENTARY BIO-CHEMISTRY FOR USE IN COLLEGES

BY

JOSEPH SCUDDER CHAMBERLAIN, PH.D. PROFESSOR OF ORGANIC AND AGRICULTURAL CHEMISTRY IN THE MASSACHUSETTS AGRICULTURAL COLLEGE

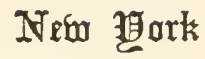

THE MACMILLAN COMPANY I9I9 


\section{Copyright, I9i6, \\ BY THE MACMILLAN COMPANY.}

Set up and electrotyped. Published May, rgr6. Reprinted February, I9r7. 


\section{$\mathbb{T a}$ \\ MY FATHER \\ W. I. CHAMBERLAIN}

WHO HAS SPENT HIS LIFE IN AND FOR AGRICULTURE, THIS BOOK IS

LOVINGLY DEDICATED 



\section{PREFACE}

Agricultural chemistry is a subject presenting two quite distinct lines of study. The study of soils and fertilizers, including the relation of the plant to its soil food, is almost wholly inorganic and physical. On the other hand, the study of plants and animals as living organisms is as distinctly organic and physiological, embracing the greater part of what is termed Biochemistry.

This has led the author to prepare one part of a textbook of General Agricultural Chemistry with this distinction in view, and to designate it as Organic Agricultural Chemistry - The Chemistry of Plants and Animals. The companion volume on Inorganic Agricultural Chemistry - The Chemistry of Soils and Fertilizers - is being prepared by the author's associate, Dr. Ernest Anderson.

The author believes that there is a place in our Agricultural Colleges for a course covering the work included in these two volumes with the definite aim of giving to students of practical agriculture enough general scientific instruction in chemistry to enable them to understand and correlate the broad problems of agricultural practice. The course covered by the two books has been planned to follow a course in general chemistry such as is given in the Freshman year in most colleges, and assumes a knowledge represented by such work.

The present volume does not pretend in any sense to replace the more thorough study of both organic and physiological chemistry by those students preparing to be chemists or other scientific workers in agriculture. Assuming that the student has not had a special course in systematic organic chemistry, there is included, as Section I, the essentials of such a study as related directly to agriculture. Following this systematic study of organic chemistry the treatment in Section II is largely 
physiological, and centers around the general subjects of food and nutrition as applies to both animals and plants and photosynthesis in plants. In the last section on Crops, Foods and Feeding the effort has been to present the chemical basis for the valuation of animal foods, but without entering into the discussion of the practical operation and results of animal feeding.

In presenting the physiological chemistry of plants and animals a departure has been made from the usual custom, and the detailed study of animals and animal nutrition is considered before that of plants. The author believes that this procedure presents bio-chemistry in such a way that the student gains the correct view of plants and animals as living organisms. It also emphasizes the real differences between these two forms while retaining the idea of fundamental similarity.

There has been no effort to make the book a handbook of facts in regard to the subjects treated, and it is not a textbook of agricultural analysis, the methods mentioned being considered only as to the fundamental principles. The presentation is general and is in the lecture style with the underlying purpose of making a book of the most value to students as a text for class use. Laboratory experiments have been incorporated in the text as this has seemed to be desirable. Except in connection with the tables practically no references to literature have been cited, but at the end of each section a list is given of reference books which cover the subjects discussed. The author wishes to give full credit to all of these books as sources of the material presented.

The book is the result of five years' experience in giving a course in general agricultural chemistry to students in practical agriculture and horticulture in the Massachusetts Agricultural College, the work in the present volume being carried in a course of two lectures and one laboratory per week for one semester.

While intended primarily for use in Agricultural Colleges, the author hopes that the book may be found of value in other colleges where an elementary presentation of bio-chemistry is desired. 
Finally the author wishes to acknowledge the assistance and coöperation of his associate, Dr. Ernest Anderson, and of all others who have in any way aided him in the work.

\section{JOSEPH S. CHAMBERLAIN.}

Massachusetts Agricultural College,

Amherst, Massachusetts.

November 15, 1915 . 



\section{TABLE OF CONTENTS}

INTRODUCTION

\section{SECTION I. SYSTEMATIC • •}

PAGES

I-2

Chapter I. Hydrocarbons

Experiment Study I; Hydrocarbons from wood and coal, 7. Methane, 7. Occurrence, properties, constitution, 7, 8. Structural formula, 8. Experiment Study II; Methane, 9. Substitution, Io. Synthesis of higher hydrocarbons, I3. Isomerism, I5.

Chapter II. Substitution Products of the Hydrocarbons

Halogen compounds, I8. Chloroform, iodoform, carbon tetrachloride, I8. Experiment Study III; Halogen substitution products, I9. Halogen ethanes, I9. Isomerism of di-brom-ethane, 20. Cyanides and amines, 2r. Cyanamide, 23. Calcium cyanamide, 23. Experiment Study IV; Cyanides, 25. Hydroxy substitution products or alcohols, 25. Alcohol series, 26. Experiment Study V; Distillation of alcohols, Fractional distillation, 26. Table I; Alcohol per cent and specific gravity, 28. Methyl alcohol, 29. Experiment Study VI; Methyl alcohol, 30. Ethyl alcohol, 3I. Experiment Study VII; Ethyl alcohol, 3I. Alcoholic fermentation, 32. Enzymes, zymase, 33. Experiment Study VIII; Alcoholic fermentation, 34. Diastase, 34. Absolute alcohol, 36. Alcoholic beverages, 36 . Industrial uses, 37 . Taxation, 37. Denatured alcohol, 38. Higher alcohols, 39. Experiment Study IX; Amyl alcohol, 40. Polyhydroxy alcohols, 40. Glycol, 40. Glycerol, 4I. Higher polyhydroxy alcohols, $4 \mathrm{I}$.

Chapter III. Oxidation Products of Alcohols .

Aldehydes, 42. Formaldehyde (formalin), 43. Acetaldehyde, 44. Aldehyde reactions; addition compounds, oximes, 
hydrazones, 44. Experiment Study X; Aldehydes, 45. Acids, 46. Acetic acid series, 47. Formic acid, 48. Experiment Study XI; Formic acid, 48. Acetic acid, 49. Glacial acetic acid, 49. Vinegar, 50. Experiment Study XII; Acetic acid and vinegar, 5I. Polycarboxy acids, 5I. Oxalic acid, 52. Experiment Study XIII; Oxalic acid, 53. Succinic acid, 53.

\section{Chapter IV. Derivatives of Alcohols and Acids}

Ethers, 54. Ethyl ether, 54. Experiment Study XIV; Ether, 55. Acid chlorides and acid amides, 55. Esters, 56. Simple esters, 56. Fruit flavors, 56. Fats, oils and waxes, 57. Fatty acids, 57. Glycerol esters, 58. Esterification, 58. Hydrolysis, 59. Soap, 60. Saponification, 60. Important fats and oils, 6o. Physical constants, 6I. Chemical constants, 6r. Table II; Fats and oils, 62. Experiment Study XV; Esters, 62. Experiment Study XVI; Fats and soap, 63 .

Chapter V. Mixed Compounds . . . . . $66-8 I$

Halogen-aldehydes, 66. Tri-chlor-aldehyde, chloral, 66. Halogen-acids, 67. Hydroxy-acids, 67. Lactic acid, 68. Stereoisomerism, 69. Optical activity, 69. Asymmetric carbon, 7I. van't Hoff-Le Bel, 7 7 . Tetrahedral theory, 72. Inactive lactic acid, 73. Dextro lactic acid, 74. Levo lactic acid, 74. Malic acid, 75. Tartaric acid, 76. Cream of tartar, 76. Rochelle salt, 77. Tartar emetic, 77. Stereoisomerism of tartaric acid, 78. Dextro-, levo-, racemic- and meso-tartaric acids, 78. Citric acid, 8o. Experiment Study XVII; Lactic, malic, tartaric and citric acids, 80.

Chapter VI. Amino-acids, Proteins, Urea, Uric Acid .

Amino-acids, 82. Glycine, 84. Hippuric acid, 84. Alanine, 85. Higher amino-acids, 85. Proteins, 87. Physical properties, 88. Chemical properties, 90. Composition, 90. Analysis, 90. Kjeldahl method, 90, 93. Molecular weight, 9o. Hydrolytic decomposition, 9r. Polypeptides, 92. Experiment Study XVIII; Proteins, 93. Urea, uric acid and purine bases, 97. Urea, 97. Biuret, Ior. Experiment Study XIX; Urea, IоI. Uric acid and purine bases, 102. Xanthine, caffeine, theobromine, I03. 


\section{Chapter ViI. Carbohydrates}

Composition, 104. Experiment Study XX; General properties of carbohydrates, 105. Constitution, 105. Classification, 107. Trioses, I09. Pentoses, IIO. Experiment Study XXI; Pentosans and pentoses, iro. Hexoses, iro. Glucose, III. Determination, III. Fermentation of glucose, II3. Fructose, II3. Galactose, II4. Experiment Study XXII ; Hexoses, II4. Disaccharoses, II5. Sucrose or cane sugar, II5. Hydrolysis, II7. Inversion, II7. Invert sugar, II7. Sugar analysis, ir8. Maltose or malt sugar, iI8. Lactose or milk sugar, IIg. Experiment Study XXIII; Disaccharoses, I20. Polysaccharoses, I 20. Hydrolysis, I 20. Source of alcohol, I21. Starch, I21. Hydrolysis, I 22. Source of glucose, I23. Determination, I23. Experiment Study XXIV ; Starch, I 23. Dextrin, Glycogen, I 24. Inulin, Cellulose, 125. Paper, I26. Mercerized cotton and artificial silk, I27. Explosives and celluloid, 127. Experiment Study XXV; Cellulose, I28. Table III; Summary of carbohydrates, I29. Unsaturated compounds, I30. Conclusion, I34. References to Section I, I35.

\section{SECTION II. PHYSIOLOGICAL • .}

Chapter Vili. Enzymes and Enzymatic Action .

Enzymes and fermentation, I39. Definition, 140. General nature of enzymes, I40. Reactions brought about by enzymes, I4I. Hydrolyzing enzymes, I4I. Oxidizing enzymes, I42. Reducing enzymes, I42. Coagulating enzymes, 142. Decomposing and splitting enzymes, I42. Character of enzyme action, I42. Specific, I42. Reversible, 143. Zymogens, I43. Co-enzymes and anti-enzymes, I44. Names of enzymes, I44. Table IV; Enzymes, I45.

Chapter IX. Composition of Plants and Animals I $46-153$

Organic and inorganic constituents, I46. Volatile and nonvolatile constituents, I47. Ash, I49. Table V; Volatile and nonvolatile constituents, I50, I51. Experiment Study XXVI; Organic and inorganic constituents, I52.

Chapter X. The Living Celi and its Food $154^{-1} 5^{8}$

Plant and animal cell alike, I54. Composition of the cell, 154. Cell energy and cell food, I55. Food as energy ma- 
terial, $\mathrm{x}_{55}$. Oxidation of food, $\mathrm{I}_{5} 6$. Heat and work, $\mathrm{I}_{5} 6$. Food as building material, 157. Function of food, 157. Plants and animals compared, 157 .

Chapter Xi. Animal Food and Nutrition; Digestion and ABSORPTION .

Animal food, I59. Definition, I59. Utilization of food, I60. Mastication, I6r. Digestion, I62. Digestive region, I63. Digestion of carbohydrates, I63. Monosaccharoses, final product of digestion, I64. Hydrolysis of di- and polysaccharoses, 164. The mouth, I65. Saliva, I65. Enzymes of saliva, I66. Ptyalin and maltase, I66. Conditions of salivary action, 167 . Salts in saliva, 167 . Organic compounds in saliva, I68. Experiment Study XXVII; Salivary digestion, I68. The stomach, I69. The small intestine, I70. Pancreatic juice, amylopsin, I70. Intestinal juice, I70. Sucrase, maltase and lactase, I7I. Digestion of proteins, I7I. The stomach, I72. Gastric juice, I72. Rennin, I73. Pepsin, I73. Hydrochloric acid, I73. Experiment Study XXVIII; Gastric digestion, I74. The small intestine, I75. Pancreatic juice, I76. Hormones, I76. Pancreatic rennin, I77. Trypsin, I77. Trypsinogen, 177. Enterokinase, I77. Intestinal juice, I78. Erepsin, I78. Digestion of fats, I79. Hydrolysis of fats, I79. The stomach, gastric lipase, $\mathrm{x} 8 \mathrm{o}$. The small intestine, pancreatic lipase, I80. The bile, I8r. The large intestine, I82. Absorption of food, 183 . Absorption of carbohydrates, 183. Absorption of proteins, I84. Absorption of fats, I85. Résumé of digestion and absorption, r86. Time for food passage, $\mathrm{I} 88$.

Chapter XII. Antmal Food and Nutrition; Metabolism

Metabolism, Anabolism, Katabolism, I90. Metabolism of carbohydrates, I9I. Direct metabolism, I9I. Glycogen, 192. Conversion of glycogen into glucose, I92. Amount of glycogen in the liver, I92. Oxidation of glucose, 193. Muscle glycogen, I94. Conversion of carbohydrates into fats, I95. Feeding experiments, I95. Respiratory quotient, I96. Metabolism of fats, r98. Body fat and milk fat, I99. Conversion of fats into carbohydrates, 200. Metabolism of proteins, 20I. Amino-acids, 20I. Polypeptide nucleus, 202. Serum albumin, 202. Body protein, 203. Oxidation of protein, 203. Katabolism of protein, 204. Katabolic products, 
204. Nitrogen excretion in urine, 205. Formation of urea, etc., 205. Conversion of proteins into carbohydrates, 206. Conversion of proteins into fats, 207.

Chapter XIII. Milk, Blood and Urine

Milk, 209. Constituents, 209. Carbohydrates, 209. Fats, 210. Proteins, 21 I. Casein, 212. Lactalbumin, 2 I2. Inorganic salts, 212. General properties, 214. Analysis, 215. Preservatives, 216. Butter, 216. Cheese, 217. Whey, 217. Food value, 218. Experiment Study XXIX; Milk, 218. Blood, 219. Properties, 220. Constituents, 220. Erythrocytes, 220. Hæmolysis and hæmagglutination, 220. Hæmoglobin and oxyhæmoglobin, 22I. Leucocytes, 222. Blood plasma, 223. Blood serum, 223. Serum albumin, 224. Fibrinogen and fibrin, 224. Clotting, 224. Experiment Study XXX; Blood, 226. Urine, 226. Constituents, 227. Nitrogen compounds, 227. Urea, 227. Isolation and determination, 227. Uric acid, 228. Creatinine, 228. Ammonia, 228. Hippuric acid, 229. Pathological constituents, 229. Glucose, 229. Albumin, 230. General properties, 230. Experiment Study XXXI; Urine, 231 .

Chapter XiV. Plant Physiology .

Plants and animals compared, 232. Similarity, 232. Differences, 235. Exothermic and endothermic reactions, 235. Animals liberate energy, 236. Plants store energy, 236. Photosynthesis, 237. Source of energy, 237. Chlorophyll bodies and chlorophyll, 238. Products of photosynthesis, 238. Function of products of photosynthesis, 24I. Carbohydrates, 241. Carbohydrates present in plants, 242. Metabolic transformations, 242. Sugars, 243. Translocation material, 243. Cell food, 243. Starch, 244. Reserve food, 244. Diastase and maltase, 244. Germination, 245. Experiment Study XXXII; Diastase and starch, 246. Building material, 246. Cell wall, 247. Cellulose, 247. Fats and proteins, 248. Synthesis of fats and proteins, 248. Location of fats, 249. Location of proteins, 249. Source of nitrogen, 249. Nitrogen cycle, 250. Fixation of atmospheric nitrogen, 25I. Metallic nitrides, 25I. Electrical discharges, 251. Nodule bacteria, 252. Reactions of nitrogen cycle, 254. Diagram of nitrogen cycle, 255. Résumé, 255. References to Section II, 257. 


\section{SECTION III. CROPS, FOODS AND FEEDING}

Chapter XV. Occurrence and Uses of Important ConStituents in Agricultural Plants.

Carbohydrates, 26r. Cellulose, 262. Forms of cellulose, 262. Normal celluloses, 262. Hemicelluloses, 263. Lignocelluloses, 264. Pectocelluloses, 264. Cellulose as food, 265. Crude fiber, 265. Table VI; Cellulose content of crops, 266. Experiment Study XXXIII; Cellulose and crude fiber, 267. Starch, 267. Starch as food, 268. Industrial uses, 268. Table VII; Starch content of crops, 269. Experiment Study XXXIV; Starch, 270. Dextrin, Glycogen, Inulin, Mannan, Galactan, 270. Pentosans, 272. Experiment Study XXXV ; Pentosans, 273. Sugars, 274. Sucrose, 274. Maltose, 275. Monosaccharoses, 275. Table VIII; Sugar content of crops, 276 .

Chapter XVI. Occurrence and Uses of Important Constituents in Agricultural Plants (Continued)

Fats and waxes, 277. Plant fats as food, 277. Occurrence, 277. Oil-yielding plants, 278. Table IX; Fat content of crops, 280. Lecithin and phytosterol, 280. Phytosterol and cholesterol, 280. Lecithin, 282. Physiological function, 283. Proteins, 283. Forms of protein, 283. Occurrence, 284. Table $\mathrm{X}$; Protein content of crops, 285. Amino-acids, Alkaloids, Essential Oils, Terpenes, Tannins, etc., 286. End products of metabolism, 286.

\section{Chapter XVII. Animal Foods and Feeding}

Food value, 288. Quantitative relation of food to energy, 288. Digestibility, 289. Coefficient of digestibility, 289 . Table XI; Coefficients of digestibility, 29o. Application of coefficients of digestibility, 29I. Table XII; Digestibility of foods, 292. Energy value of food constituents, 293. Fuel value, 293. Bomb calorimeter, 293. Calorie, 294. Fuel values in calories, 294. Corrected fuel values, 295. Metabolizable or available energy, 295. Table XIII; Fuel values of food constituents, 296. Fuel values for cattle, 296. Table XIV; Fuel values and metabolizable energy for cattle, 298. Food requirement, 298. Energy requirement, 298. Maintenance requirement, 298. Respira- 
tion calorimeter, 299. Production value, 299. Energy rePAGES quirement for man, 300. Table XV; Production values for cattle, 30r. Summary, zor. Table XVI; Digestibility and energy values for cattle, 302. Nutritive ratio, 302. Protein requirement, 303. References to Section III, 305. 


\section{SECTION III. CROPS, FOODS AND FEEDING}

Chapter XV. Occurrence and Uses of Important Constituents in Agricultural Plants.

Carbohydrates, 26r. Cellulose, 262. Forms of cellulose, 262. Normal celluloses, 262. Hemicelluloses, 263. Lignocelluloses, 264. Pectocelluloses, 264. Cellulose as food, 265. Crude fiber, 265. Table VI; Cellulose content of crops, 266. Experiment Study XXXIII; Cellulose and crude fiber, 267. Starch, 267. Starch as food, 268. Industrial uses, 268. Table VII; Starch content of crops, 269. Experiment Study XXXIV; Starch, 270. Dextrin, Glycogen, Inulin, Mannan, Galactan, 270. Pentosans, 272. Experiment Study XXXV; Pentosans, 273. Sugars, 274. Sucrose, 274. Maltose, 275. Monosaccharoses, 275. Table VIII; Sugar content of crops, 276 .

Chapter XVI. Occurrence and Uses of Important Constituents in Agricultural Plants (Contimued)

Fats and waxes, 277. Plant fats as food, 277. Occurrence, 277. Oil-yielding plants, 278. Table IX; Fat content of crops, 280. Lecithin and phytosterol, 280. Phytosterol and cholesterol, 280. Lecithin, 282. Physiological function, 283. Proteins, 283. Forms of protein, 283. Occurrence, 284. Table X; Protein content of crops, 285. Amino-acids, Alkaloids, Essential Oils, Terpenes, Tannins, etc., 286. End products of metabolism, 286.

\section{Chapter XVII. Animal Foods and Feeding}

Food value, 288. Quantitative relation of food to energy, 288. Digestibility, 289. Coefficient of digestibility, 289 . Table XI; Coefficients of digestibility, 290. Application of coefficients of digestibility, 29I. Table XII; Digestibility of foods, 292. Energy value of food constituents, 293. Fuel value, 293. Bomb calorimeter, 293. Calorie, 294. Fuel values in calories, 294. Corrected fuel values, 295. Metabolizable or available energy, 295. Table XIII; Fuel values of food constituents, 296. Fuel values for cattle, 296. Table XIV; Fuel values and metabolizable energy for cattle, 298. Food requirement, 298. Energy requirement, 298. Maintenance requirement, 298. Respira- 
tion calorimeter, 299. Production value, 299. Energy requirement for man, 300. Table XV; Production values for cattle, 30r. Summary, 30r. Table XVI; Digestibility and energy values for cattle, 302. Nutritive ratio, 302 . Protein requirement, 303. References to Section III, 305 . 



\section{INTRODUCTION}

That part of Agricultural Chemistry which we may term Organic has to do with living plants and animals. Considered agriculturally as farm products, animals and plants have three general uses: (I) as servants of man in performing work, (2) as food for animals including man, (3) as material, or for furnishing material for the use of man in other ways than as food. A knowledge of the chemistry of plants and animals is of value in understanding their uses in these various ways and in showing how their economic value may be increased by greater production, greater conservation or the development of new uses.

The chemistry of living organisms is termed bio-chemistry and as a whole includes all of their physico-chemical relationships, especially those connected with the inorganic soil food of plants. This latter part of bio-chemistry we shall not consider, as it belongs to the inorganic division of agricultural chemistry.

The present study will treat of the composition of plants and animals and later of the physiological processes by which their body substance is built up and the energy of their living processes is produced. It will thus be largely physiological, with especial attention to the general subjects of food and nutrition and photosynthesis.

In order to understand the composition of plants and animals and the chemical reactions involved in their living processes, it is necessary to know the nature of the individual compounds of which they are constituted. As the greater part of these are what we term organic, and as these alone are related directly to the energy of the living organism, we shall take up first a brief study of systematic organic chemistry, discussing only such compounds as are directly related to agriculture.

We shall then be in a position to study the fundamental processes and reactions of living things and those particular physiological processes which differentiate plants from animals. 
Finally, as the agricultural problems with animals are largely those connected with animal feeding and as plants are the main food supply of domestic animals, we shall consider the distribution of food constituents in plants and the fundamental principles of animal foods and feeding together with the use of certain plants or plant products for other purposes than feeding, such as the manufacture of various materials of economic value.

Our entire study will thus be divided into three sections, as follows :

Section I. Systematic. The study of the composition, constitution, character and relationship of the more important organic compounds occurring in plants and animals.

Section II. Physiological. The study of the chemical reactions involved in the fundamental processes of living organisms, in the utilization of food by animals and in photosynthesis in plants.

Section III. Crops, Foods and Feeding. The study of the distribution of food constituents in agricultural crops and the principles of animal foods and feeding. 


\section{SECTION I \\ SYSTEMATIC}

THE CHEMISTRY OF THE MORE IMPORTANT ORGANIC COMPOUNDS FOUND IN PLANTS AND ANIMALS 
ஊ 


\section{CHAPTER I}

\section{H Y D R O C A R B O N S}

A SYSTEMATIC study of organic chemistry directly connected with agriculture should embrace the study of those organic compounds which are of primary importance either as constituents of plants and animals or as products formed from them either naturally or artificially. In order to understand these compounds in their character and their relation to each other, it will be necessary to consider also a few typical ones which are not directly connected with plants or animals in any general agricultural sense.

Organic chemistry was originally so termed because the compounds included in it were produced by living organisms (plants and animals). With the development of this branch of the science of chemistry, many compounds have become known which are truly organic in their character and relationships, but have never been associated with either plants or animals; that. is, they are still solely laboratory products. This has destroyed the original significance of the term organic. The word is still used, however, but in a broader sense.

All compounds which we class as organic are compounds of carbon, but a few carbon compounds are still held as truly inorganic, so that to term organic chemistry the chemistry of the compounds of carbon is not strictly true. However, all organic compounds are derivatives of certain fundamental compounds of carbon and hydrogen so that the best definition of organic chemistry is: the chemistry of the hydrogen compounds of carbon and their derivatives.

The hydrogen compounds of carbon will then be the start- 
ing point for the development of our study. As these com. pounds consist of the two elements, hydrogen and carbon, they are known as hydro-carbons. The hydrocarbons themselves are not found in either plants or animals. A few compounds of hydrogen and carbon do occur as plant constituents, e.g. turpentine, but these do not belong to the primary group of hydrocarbons.

The hydrocarbons are, however, a product of the decomposition of plant or animal substances. Plant and animal bodies consist largely of complex compounds of the elements carbon, hydrogen, oxygen, nitrogen, and sometimes sulphur and phosphorus. These compounds on decomposing, either by slow natural processes, as have taken place geologically in the formation of coal and petroleum, or by rapid artificial processes as in the distillation of wood, break down and yield eventually much more simple compounds. In the artificial distillation, some of the compounds obtained, e.g. wood alcohol and acetic acid, still contain carbon, hydrogen and oxygen, while others are gases containing carbon and hydrogen only, part of the oxygen going off in the form of water $\left(\mathrm{H}_{2} \mathrm{O}\right)$. The nitrogen is volatilized in the form of ammonia or ammonia-like compounds containing also carbon and hydrogen. In the natural geological decomposition of plant and animal substances the greater part of the carbon and hydrogen, however, remains in coal and petroleum and is easily volatilized from them, in the form of compounds containing only these two elements. Therefore we may say that petroleum, natural gas, coal and the gases formed by the natural decomposition of plant remains (marsh gas), all contain, or at least yield by distillation, products which contain true hydrocarbons.

Although there are different theories as to the origin of such substances as petroleum, we may consider it as probably true that some at least of the petroleum and other materials, which are the sources of hydrocarbons, have been produced by the decomposition of plant and animal bodies from which the carbon and hydrogen have been derived. 


\section{EXPERIMENT STUDY I}

\section{Hydrocarbons from Wood and Coal}

(I) (a) Place a few dry wood shavings in a hard glass test tube. Fit the test tube with cork, glass and rubber tubing connections with a glass jet at the end. Heat the tube slowly and notice the moisture given off before the wood begins to char in case the wood was not perfectly dry. As the temperature becomes high enough to char the wood, notice the collection of moisture on the cool parts of the tube. This moisture comes from the decomposed wood. What two elements are, therefore, present in the wood? (b) When gas is being generated fast enough ignite it at the jet. Note character of flame. (c) Hold the burning jet inside a cool, dry, empty bottle. Let the jet burn in the bottle as long as possible. What does the moisture here prove? After the flame ceases to burn in the bottle pour into the bottle 25 c.c. limewater, and shake. The white precipitate proves that carbon dioxide $\left(\mathrm{CO}_{2}\right)$ is present. What does this mean? (d) Hold the burning jet against a cold piece of porcelain. What does this show? What do all these tests prove as to the elements contained in wood?

(2) Repeat (I), using powdered soft coal instead of wood. The gas produced here is crude illuminating coal gas.

(3) Mix in a mortar I gram of wheat flour and an equal volume of fine soda lime. Heat the mixture in a test tube, and hold a piece of moist, red litmus paper at the mouth of the tube. Smell the gas given off. What is it? What element does this prove to be present in the flour?

\section{MARSH GAS - METHANE}

Occurrence. - The gas rising from stagnant pools of water which contain decaying organic substances, commonly known as marsh gas, is known chemically as methane. It has also been obtained from petroleum and from coal and is found naturally in pockets and crevices in coal strata. It is prepared in the laboratory from a salt of acetic acid, a related compound, but it will not be necessary at this time to give the reactions involved in the preparation. (See Exp. II, I, a.) 
Properties. - By analysis the composition of methane has been shown to be 12 parts by mass of carbon to 4 parts by mass of hydrogen. Its molecular mass equals $\mathrm{I} 6$. It is represented, therefore, by the chemical formula $\mathrm{CH}_{4}$, or one atom of carbon to four atoms of hydrogen. It is a colorless gas lighter than air. It burns in the air with a yellow flame which deposits carbon on a cold surface. Mixed with air or with oxygen in the proportion of one volume of methane to two volumes of oxygen it explodes on ignition. Such an explosive mixture in coal mines is known as fire damp and is the cause of mine explosions.

Constitution. - It will not be necessary to consider in each case the proofs or reasons for conceptions which we shall bring forth, but merely state them, assuming that the proofs not here given have been fully developed.

In considering methane as a chemical compound three facts are at the foundation of our conceptions in regard to it, and these conceptions will lead to an understanding of the definite relationship between all of the organic compounds which we shall study. These three facts are as follows:

Methane, $\mathrm{CH}_{4}$, is (I) A saturated compound.

(2) A symmetrical compound, in which all four of the hydrogen atoms stand in exactly the same relation to the carbon atom.

(3) The carbon atom in methane and in practically all organic compounds is tetravalent, i.e. it has the power of holding four and only four hydrogen atoms, or any other univalent element, or group of elements, in combination.

Structural Formula. - The result of these facts is expressed in what is termed the structural or constitutional formula for methane, i.e. a formula which indicates the way in which the compound is built up or constituted. The geometrical figure which can represent perfect symmetry of one body joined to four others is the regular tetrahedron, and in all space relation formulas carbon is considered as being at the center of such a 
tetrahedron with one hydrogen (in the case of methane) situated at each apex.

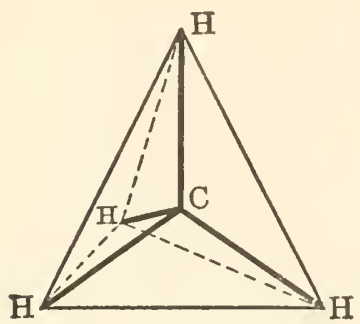

Methane

Such a formula was suggested by van't Hoff and is, because of the wonderful way in which it explains and agrees with facts, universally accepted as the complete structural or stereochemical (space relation) formula for methane. For the sake of expression on a plane surface in writing, this formula is modified to show only two dimensions, but retaining the ideas of symmetry, tetravalence and saturation:

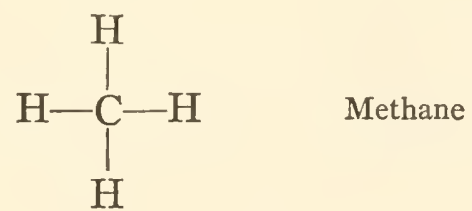

This formula is the plane structural formula to represent methane and to indicate the three facts previously mentioned: (I) saturation of carbon, (2) symmetry of the compound, i.e. all the hydrogen atoms are alike in relation to the carbon, and (3) tetravalence of carbon.

\section{EXPERIMENT STUDY II Methane, Marsh Gas}

(1) (a) Mix in a mortar Io grams fused, dry sodium acetate and 20 grams fine soda lime. Fill a test tube (hard glass) about half full, and hold horizontally and tap until the contents lie in the tube leaving a space along the top. Incline the tube slightly downward when heating. Connect the tube by means of glass and rubber tubing so as to generate gas and collect over water in small bottles or test 
tubes. Heat the tube slowly and thoroughly until all the gas is evolved. Collect three or four bottles or tubes of gas. (b) While the gas is generating freely insert a glass jet at the end and ignite the gas, and repeat Experiment I, I, b.c. $d$.

(2) (a) Bring a flame to the mouth of one of the bottles of gas. (b) Mix one bottle with an equal volume of air and ignite the mixture.

(c) Mix one volume of gas with ten volumes of air and ignite. (d) Mix one volume of $d r y$ gas with two volumes of $d r y$ chlorine gas and ignite. Note character of flame and residue of carbon in the bottle after ignition. After ignition add a little water to the bottle and shake. Test water in bottle for hydrochloric acid. (e) Mix one volume of dry gas with two and one half volumes of $d r y$ chlorine gas. Allow the mixture to stand in the light for several days. Test for hydrochloric acid and examine for carbon residue. (Note. - These last two experiments are better performed in the lecture room. If they have been done there omit, but write up the results in the notebook.)

\section{SUBSTITUTION}

For the most part the hydrocarbons are characterized as inactive compounds. This is indicated by the name given to those similar to methane, viz. parafins, from "parum affinitas," little affinity. This property of inactivity shows itself toward almost all ordinary reagents, such as acids, alkalies, oxidizing and reducing agents, etc. Toward only one group of elements does methane show any reactivity. The halogen elements, chlorine and bromine, do react with methane when brought in contact with it.

When chlorine reacts with methane suddenly at high temperatures, as when a mixture of the two gases is ignited, the methane is decomposed and all of the hydrogen unites with the chlorine, forming hydrogen chloride, and the carbon is left free. (See Exp. II, 2, d.) This is represented by the following reaction:

\section{$\mathrm{CH}_{4}+{ }_{2} \mathrm{Cl}_{2} \rightarrow \mathrm{C}+{ }_{4} \mathrm{HCl}$ \\ Methane}

If, however, the action takes place slowly, as in case a mixture of the two gases is allowed to stand in diffused light, then 
another reaction takes place by which the four hydrogen atoms are removed by the chlorine atom by atom, and each time a hydrogen atom is removed a chlorine atom takes its place. (See Exp. II, 2, e.) The steps in this series of reactions are as follows :

$$
\begin{aligned}
& { }_{\text {Methane }}^{\mathrm{CH}_{4}}+{ }_{4} \mathrm{Cl}_{2} \rightarrow{ }_{4} \mathrm{CH}_{3} \mathrm{Cl}+4 \mathrm{HCl} \\
& 3 \mathrm{CH}_{3} \mathrm{Cl}+3 \mathrm{Cl}_{2} \rightarrow 3 \mathrm{CH}_{2} \mathrm{Cl}_{2}+3 \mathrm{HCl} \\
& 2 \mathrm{CH}_{2} \mathrm{Cl}_{2}+2 \mathrm{Cl}_{2} \rightarrow 2 \mathrm{CHCl}_{3}+2 \mathrm{HCl} \\
& \mathrm{CHCl}_{3}+\mathrm{Cl}_{2} \rightarrow \mathrm{CCl}_{4}+\mathrm{HCl}
\end{aligned}
$$

or ${ }_{4} \mathrm{CH}_{4}+$ Io $\mathrm{Cl}_{2} \rightarrow\left(\mathrm{CH}_{3} \mathrm{Cl}+\mathrm{CH}_{2} \mathrm{Cl}_{2}+\mathrm{CHCl}_{3}+\mathrm{CCl}_{4}\right)+$ Io $\mathrm{HCl}$ Methane

Such products formed from the hydrocarbons or other compounds by substituting for one or more of the hydrogen atoms an equivalent number of atoms of other elements are known as substitution products, and the phenomenon is called substitution. We shall find that numerous series of substitution products are known which have different groups acting as substitutes. The most important ones are those in which one of the halogen elements $(\mathrm{Cl}, \mathrm{Br}, \mathrm{I})$, the hydroxyl group $(\mathrm{OH})$, the amino group $\left(\mathrm{NH}_{2}\right)$, the nitro group $\left(\mathrm{NO}_{2}\right)$, the sulphuric acid group $\left(\mathrm{SO}_{2} \mathrm{OH}\right)$, the cyanogen group (CN) become substituted for a hydrogen atom of a hydrocarbon. Also one oxygen atom $(\mathrm{O})$ may take the place of two hydrogen atoms.

Of the substitution products just described as obtained from methane by the action of chlorine two are well-known substances, viz. $\mathrm{CHCl}_{3}$, chloroform, and $\mathrm{CCl}_{4}$, carbon tetrachloride. Collectively they are known as the chlor-methanes and they are distinguished by prefixes denoting the number of chlorine atoms substituted. The condensed structural formulas and also the full structural formulas together with the names are shown as follows:

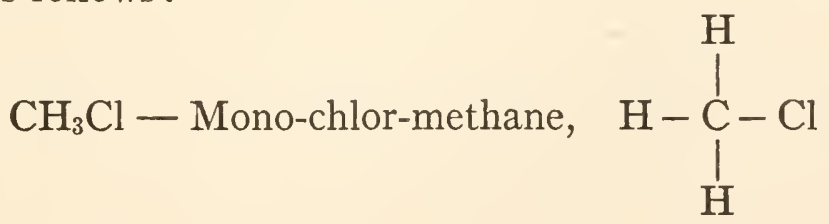


$\mathrm{CH}_{2} \mathrm{Cl}_{2}$ - Di-chlor-methane,

$\mathrm{CHCl}_{3}$ - Tri-chlor-methane,<smiles>ClCCl</smiles>

$\mathrm{CCl}_{4}$ - Tetra-chlor-methane,<smiles>ClC(Cl)Cl</smiles><smiles>ClC(Cl)(Cl)Cl</smiles>

In these compounds and similar ones the groups $\left(\mathrm{CH}_{3}\right),\left(\mathrm{CH}_{2}\right)$, $(\mathrm{CH})$ or others containing several carbon groups, which will be found running unchanged through a series of related compounds, are termed radicals. The radical $\mathrm{CH}_{3}$ is called methyl and $\mathrm{CH}_{3} \mathrm{Cl}$ is known as methyl chloride as well as mono-chlormethane.

By reactions which we shall not now discuss there have been produced other mono substitution products of methane in which the hydroxyl, amino, nitro, cyanogen, etc., groups have been substituted for a hydrogen and they are known by analogous names. The relationship between them and methane itself may be grasped by considering them together.

$\mathrm{CH}_{3}-\mathrm{H}$, Methyl hydride (Methane)

$\mathrm{CH}_{3}-\mathrm{Cl}$, Methyl chloride (Mono-chlor-methane)

$\mathrm{CH}_{3}-\mathrm{Br}$, Methyl bromide (Mono-brom-methane)

$\mathrm{CH}_{3}-\mathrm{I}$, Methyl iodide (Mono-iodo-methane)

$\mathrm{CH}_{3}-\mathrm{OH}$, Methyl hydroxide (Mono-hydroxy-methane)

$\mathrm{CH}_{3}-\mathrm{NH}_{2}$, Methyl amine (Mono-amino-methane)

$\mathrm{CH}_{3}-\mathrm{CN}$, Methyl cyanide (Mono-cyano-methane)

The group of substitution products of methane in which one halogen element is substituted for a hydrogen atom is known by 
the name of mono-halogen methanes or methyl halides. The reactions of these methyl halides lead to conceptions in regard to the structure and relationship of other hydrocarbons and other substitution products.

\section{SYNTHESIS OF HIGHER HYDROCARBONS}

Methane, $\mathrm{CH}_{4}$, is the simplest of a long series of similar compounds which increase gradually both in carbon and hydrogen content. The first six members of this series together with a few of the highest may be given as an illustration.

Methane or Paraffin Series of Hydrocarbons, $\mathrm{C}_{n} \mathrm{H}_{2 n+2}$.
$\mathrm{CH}_{4}$, Methane
$\mathrm{C}_{6} \mathrm{H}_{14}$, Hexane
$\mathrm{C}_{2} \mathrm{H}_{6}$, Ethane
$\mathrm{C}_{7} \mathrm{H}_{16}$, Heptane
$\mathrm{C}_{3} \mathrm{H}_{8}$, Propane
$\mathrm{C}_{10} \mathrm{H}_{22}$, Decane
$\mathrm{C}_{4} \mathrm{H}_{10}$, Butane
$\mathrm{C}_{20} \mathrm{H}_{42}$, Eicosane
$\mathrm{C}_{5} \mathrm{H}_{12}$, Pentane
$\mathrm{C}_{60} \mathrm{H}_{122}$, Hexacontane

Above the fourth member the prefix of the name denotes the number of carbon atoms in the compound. It will be seen that the successive compounds differ in composition by one carbon and two hydrogens, i.e. by $\mathrm{CH}_{2}$, and that for the whole series the general formula, $\mathrm{C}_{n} \mathrm{H}_{2 n+2}$, holds.

What are these compounds as to structure and constitution? When methyl iodide, $\mathrm{CH}_{3} \mathrm{I}$, is treated with sodium, ethane is formed and the iodine unites with the sodium, forming sodium iodide. The reaction takes place in the proportion of two molecules of methyl iodide to one molecule (two atoms) of sodium and yields one molecule of ethane and two molecules of sodium iodide as follows:

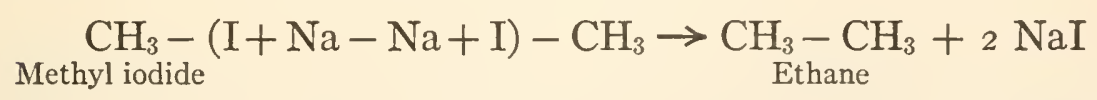

This reaction means that ethane, $\mathrm{C}_{2} \mathrm{H}_{6}$, must be considered as composed of two methyl radicals joined together, viz. $\mathrm{CH}_{3}-\mathrm{CH}_{3}$. Using the complete structural formulas, we write the reaction: 


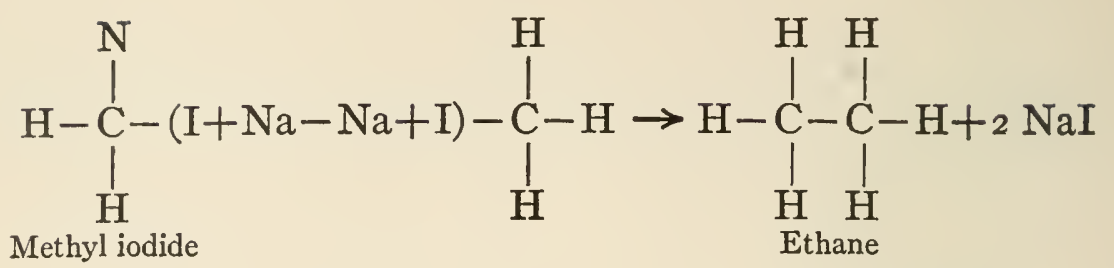

Ethane, $\mathrm{C}_{2} \mathrm{H}_{6}$, is therefore $\mathrm{CH}_{3}-\mathrm{CH}_{3}$, or $\mathrm{H}-\mathrm{C}-\mathrm{C}-\mathrm{H}$<smiles>CC</smiles>

The monohalogen ethanes are exactly analogous to the monohalogen methanes and are, e.g.,<smiles>[3H]CCCCCCC</smiles>

In an exactly analogous way propane, $\mathrm{C}_{3} \mathrm{H}_{8}$, may be made from ethyl iodide (monoiodo-ethane) and methyl iodide in the presence of sodium.

$\mathrm{CH}_{3}-\mathrm{CH}_{2}-(\mathrm{I}+\mathrm{Na}-\mathrm{Na}+\mathrm{I})-\mathrm{CH}_{3} \rightarrow \mathrm{CH}_{3}-\mathrm{CH}_{2}-\mathrm{CH}_{3}+2 \mathrm{NaI}$ Ethyl iodide Methyl iodide Propane

or

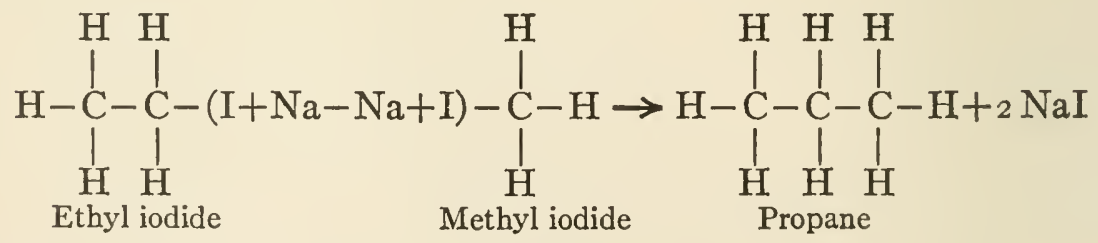

By this same general reaction each of the successive hydrocarbons may be synthesized, and we find that the structure of each is represented by a continually elongated chain of carbon groups, the two end carbon groups being $\mathrm{CH}_{3}$ and all of the intermediate groups $\mathrm{CH}_{2}$. Also each hydrocarbon is the methyl substitution product of the one preceding it. 

$\mathrm{CH}_{3}-\mathrm{H}$,
$\mathrm{CH}_{3}-\mathrm{CH}_{3}$,
$\mathrm{CH}_{3}-\mathrm{CH}_{2}-\mathrm{CH}_{3}$,
$\mathrm{CH}_{3}-\mathrm{CH}_{2}-\mathrm{CH}_{2}-\mathrm{CH}_{3}$,
$\mathrm{CH}_{3}-\mathrm{CH}_{2}-\mathrm{CH}_{2}-\mathrm{CH}_{2}-\mathrm{CH}_{3}$,
Methane
Ethane (Methyl methane)
Propane (Methyl ethane)
Butane (Methyl propane)
Pentane (Methyl butane)
$\mathrm{CH}_{3}-\mathrm{CH}_{2}-\mathrm{CH}_{2}-\mathrm{CH}_{2}-\mathrm{CH}_{2}-\mathrm{CH}_{3}$, Hexane (Methyl pentane)
$\mathrm{CH}_{3}-\left(\mathrm{CH}_{2}\right)_{58}-\mathrm{CH}_{3}$,
Hexacontane

From each one of these hydrocarbons substitution products may be formed containing various elements or groups, $\mathrm{Cl}$, $\mathrm{Br}, \mathrm{I},(\mathrm{OH}),\left(\mathrm{NH}_{2}\right),(\mathrm{CN})$, etc.

\section{ISOMERISM}

When we come to study the substitution products of propane we find a new phenomenon. When propane, $\mathrm{C}_{3} \mathrm{H}_{8}$, or $\mathrm{CH}_{3}-\mathrm{CH}_{2}-\mathrm{CH}_{3}$, is converted into monoiodo-propane or propyl iodide, there are formed two compounds of identical composition but of distinctly different properties. Such compounds of like composition but different properties are known as isomeric compounds and the phenomenon is known as isomerism. Isomerism we shall find is a most striking and important phenomenon of organic compounds.

The explanation of the formation of two propyl iodides is derived from our idea of the structure of propane. By examining the formula of propane,

$$
\mathrm{CH}_{3}-\mathrm{CH}_{2}-\mathrm{CH}_{3} \text { or } \mathrm{H}-\stackrel{\mathrm{C}}{\mathrm{C}}-\mathrm{C}-\mathrm{C}-\mathrm{C}-\mathrm{H} \text { Propane }
$$

we see that the six hydrogens in the two end carbon groups may be considered to be in a different relation, in the compound, to the two hydrogens united to the middle carbon. If then one hydrogen of each of these two sets is substituted, one at one time and the other at another time, by iodine, we can represert the resulting compounds by the following structural formulas: 
<smiles>CCCCCCCCCCCCCCCCCCCCC</smiles>

\section{or $\mathrm{CH}_{3}-\mathrm{CH}_{2}-\mathrm{CH}_{2} \mathrm{I}$ and $\mathrm{CH}_{3}-\mathrm{CHI}-\mathrm{CH}_{3}$}

These two iodine atoms are evidently in different positions in the compound, i.e. have different relations to the rest of the compound. The fact that two propyl iodide compounds exist isomeric with each other indicates that our supposition of the difference of the two substituted hydrogen atoms is correct.

The two isomeric propyl iodides are known as propyl iodide and as iso-propyl iodide (isomeric propyl iodide).

If now by the reaction with sodium a new methyl group is placed in the position of the iodine in these two propyl iodides, we shall have two hydrocarbons formed each of the composition $\mathrm{C}_{4} \mathrm{H}_{10}$, and in which a difference in structure exists like that in the isomeric propyl iodides, i.e.:

$$
\underset{\text { Propyl iodide }}{\mathrm{CH}_{3}-\mathrm{CH}_{2} \mathrm{I}} \rightarrow \underset{\text { Butane }}{\mathrm{CH}_{3}-\mathrm{CH}_{2}-\mathrm{CH}_{3}}
$$

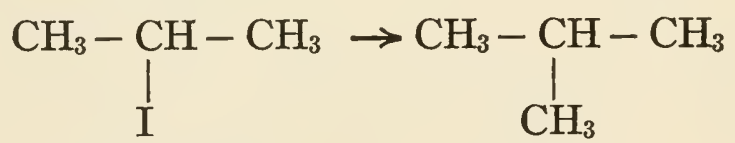

Iso-propyl iodide

Iso-butane

Here also fact and theory agree, for there are known two butane hydrocarbons isomeric with each other. Without developing the idea further we can gain some conception of the meaning of isomerism and the possibility of the existence of isomeric compounds both among the hydrocarbons themselves and among all the different classes of substitution products. Such isomerism, when the difference in the isomeric compounds is explained by difference in structure or by difference in the position which a substituting element or group takes, is known as structural or position isomerism. We shall later have to do with a further development of the idea of isomerism when we consider the space relationship of the molecule in connection 
with the tetrahedral formula for methane or for the carbon atoms in organic compounds. This new isomerism is known as space or stereo isomerism.

Having thus developed, through a consideration of a few compounds, some of the fundamental theoretical conceptions of organic chemistry we shall now consider the compounds themselves.

The hydrocarbons are of importance to agriculture as constituents of products which possess great value because of extensive general use, such as gasoline, kerosene, lubricating . oils and greases, vaseline and paraffin, all of which are obtained by the fractional distillation of petroleum. Also illuminating gas obtained by distilling coal. They have an indirect value also in the theoretical ways just explained, and in the fact that they are products of the decomposition of plant and animal bodies. An interesting fact is that the lower hydrocarbons, $\mathrm{CH}_{4}$, methane, $\mathrm{C}_{2} \mathrm{H}_{6}$, ethane, $\mathrm{C}_{3} \mathrm{H}_{8}$, propane and $\mathrm{C}_{4} \mathrm{H}_{10}$, butane, are gases, the next few liquids, and the higher members solids. The solid members are contained in paraffin and, like it, are wax-like substances. 


\section{CHAPTER II}

\section{SUBSTITUTION PRODUCTS OF THE H Y D R O C A R B O N S}

\section{HALOGEN COMPOUNDS}

\section{Halogen Methanes}

As already explained, the halogen substitution products or alkyl halides result from the substitution of one of the halogens for an equivalent amount of hydrogen of the hydrocarbon. This substitution does not take place directly except in a few cases, and methods of preparation usually start with other compounds than the hydrocarbons themselves. It is not necessary for us to consider these reactions of preparation, as they involve the alcohols, which we shall study later, and they are not essential to an understanding of the group as a whole and the special properties of a few common representatives. The chief importance of these compounds is in synthetic reactions. Of the halogen substitution products of methane, three are common substances. These are:

Tri-chlor-methane, chloroform, $\mathrm{CHCl}_{3}$

Tri-iodo-methane, iodoform, $\mathrm{CHI}_{3}$

Tetra-chlor-methane, carbon tetrachloride, $\mathrm{CCl}_{4}$

Chloroform is a heavy, colorless liquid possessing a sweet, suffocating odor. It is non-inflammable and only slightly soluble in water. It is one of the two most common anæsthetics, its use as such being discovered in 1848 by Simpson, an Englishman. It is made from alcohol or from acetone by the action of chlorine.

Iodoform is a yellow, crystalline solid almost insoluble in 
water and soluble in alcohol. It is a very important disinfectant and antiseptic used especially in the dressing of wounds. It also is made from alcohol and its formation is a test for the presence of alcohol. (See Exp. VII, 4.)

Carbon Tetrachloride, or tetra-chlor-methane, is a heavy liquid resembling chloroform in appearance and general character, but is non-anæsthetic. Its chief use is as a solvent for fats and oils. It is non-inflammable and is used as a constituent of non-inflammable cleaning liquids and also of some fire-extinguishing liquids.

\section{EXPERIMENT STUDY III}

\section{Halogen Substitution Products}

(I) Chloroform, $\mathrm{CHCl}_{3}$, Tri-chlor-methane. (a) Using 2 to 3 c.c. chloroform, test the compound for general properties, e.g. color, odor, inflammability (pour a few drops on a watch glass and apply flame), solubility in water, in alcohol, specific gravity (heavier or lighter than water), etc. (b) Test solvent action on (I) iodine, (2) fats or oils, (3) sulphur.

(2) Iodoform, $\mathrm{CHI}_{3}$, Tri-iodo-methane. Examine iodoform as to general character and crystal form (microscope or lens). Test for color, odor, and solubility in water and alcohol.

(3) Carbon Tetrachloride, $\mathrm{CCl}_{4}$, Tetra-chlor-methane. Repeat the chloroform tests with carbon tetrachloride.

\section{Halogen Ethanes}

Mono-halogen Ethanes. - The halogen ethanes or ethyl halides are analogous to the halogen methanes, e.g.:

$\begin{array}{ll}\mathrm{CH}_{4}, \text { Methane } & \mathrm{CH}_{3} \mathrm{I}, \text { Methyl iodide } \\ \mathrm{C}_{2} \mathrm{H}_{6}, \text { Ethane } & \mathrm{C}_{2} \mathrm{H}_{5} \mathrm{I}, \text { Ethyl iodide } \\ & \mathrm{C}_{2} \mathrm{H}_{5} \mathrm{Br}, \text { Ethyl bromide } \\ & \mathrm{C}_{2} \mathrm{H}_{5} \mathrm{Cl}, \text { Ethyl chloride }\end{array}$

These mono-halogen ethanes are all known and are important synthetic reagents. Ethyl chloride and ethyl bromide are also used as anæsthetics. 
Di-halogen Ethanes. - The di-halogen ethanes are significant as introducing to our consideration a new type of isomerism. Analogous to di-chlor-methane and di-brom-methane, we have the corresponding di-halogen ethanes:
$\mathrm{CH}_{2} \mathrm{Cl}_{2}$
Di-chlor-methane
$\mathrm{C}_{2} \mathrm{H}_{4} \mathrm{Cl}_{2}$
Di-chlor-ethane
$\mathrm{C}_{2} \mathrm{H}_{4} \mathrm{Br}_{2}$
Di-brom-ethane

Isomerism of Di-substituted Ethanes. - Not only do we know di-brom-ethane, but there are two isomeric compounds of this same composition, $\mathrm{C}_{2} \mathrm{H}_{4} \mathrm{Br}_{2}$. We should mention the fact that only one mono-substituted ethane of any kind is known, and from this we gain the idea that all six of the hydrogen atoms in ethane are alike. When, however, we consider the entrance into the ethane molecule of two substituting elements in place of two hydrogen atoms, we see at once, from our constitutional formula of ethane, that two products are possible. The fact as already stated is that two are known. By examining the formula for ethane, we see that it would be possible to substitute two hydrogens united to the same carbon atom or two hydrogens one of which is united to one carbon and the other united to the second carbon. Expressing this idea by our structural formulas we have:

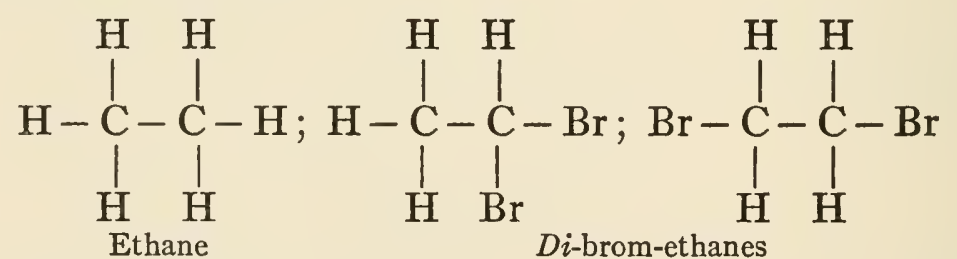

This, then, explains the existence of two isomeric di-bromethanes. From the fact that one structure represents a symmetrical compound while the other represents an unsymmetrical one, the two compounds are known as symmetrical di-bromethane and unsymmetrical di-brom-ethane. The symmetrical di-brom-ethane is directly related to a new kind of hydrocarbon called ethylene $\left(\mathrm{C}_{2} \mathrm{H}_{4}\right)$, and the bromide is therefore known as ethylewe bromide. The unsymmetrical compound is also known as ethylidene bromide. We shall mention ethylene again 
later and show how its relation to symmetrical di-brom-ethane leads to ideas in regard to the structure of ethylene. Writing the condensed structural formulas for these compounds we have :

\begin{tabular}{cll}
$\mathrm{CH}_{3}-\mathrm{CH}_{3}$ & \multicolumn{1}{c}{$\mathrm{CH}_{3}-\mathrm{CHBr}_{2}$} & $\mathrm{CH}_{2} \mathrm{Br}-\mathrm{CH}_{2} \mathrm{Br}$ \\
Ethane & Unsymmetrical & Symmetrical \\
& di-brom-ethane & di-brom-ethane \\
& Ethylidene bromide & Ethylene bromide
\end{tabular}

This isomerism, as illustrated by the two di-brom-ethanes, applies to all di-substituted ethanes so that for each class we have unsymmetrical or ethylidene and symmetrical or ethylene di-substituted ethanes.

\section{CYANIDES AND AMINES}

Cyanides. - When a halogen substitution product reacts with potassium cyanide, $\mathrm{KCN}$, a compound is formed in which the halogen is replaced by the group or radical, $\mathrm{CN}$.

\section{$\mathrm{CH}_{3}(\mathrm{I}+\mathrm{K}) \mathrm{CN} \rightarrow \mathrm{CH}_{3}-\mathrm{CN}+\mathrm{KI}$ \\ Methyl iodide Methyl cyanide}

This new compound is $\mathrm{CH}_{3}-\mathrm{CN}$ and is known as methyl cyanide just as $\mathrm{CH}_{3}-\mathrm{I}$ is methyl iodide. This cyanogen group may be substituted in practically any position where a halogen atom is present and we therefore have a large number of cyanide compounds. As we shall find, the simple cyanides are directly related to the acids, and on that account are known as acid nitriles.

Among the compounds studied in inorganic chemistry the cyanides occupied an important place. The cyanides of iron, in particular the double cyanides, are noticeable for their color and are important as dyes. The name cyanide comes from a Greek word (cyanos) meaning blue.

Amines. - By an analogous reaction to the one just described, ammonia reacts with a halogen substitution product and a compound is formed in which the halogen is replaced by the group or radical, $\mathrm{NH}_{2}$, which is the radical of ammonia. 


\section{$\mathrm{CH}_{3}(\mathrm{I}+\mathrm{H}) \mathrm{NH}_{2} \rightarrow \mathrm{CH}_{3}-\mathrm{NH}_{2}+\mathrm{HI}$ \\ Methyl iodide \\ Methyl amine}

This new compound is known as amino-methane or methyl amine. These names are significant and are exactly analogous to those of the halogen substitution products. The group, $\mathrm{NH}_{2}$, is known as the amine or amino group, and the general name for compounds containing this group is amines or amino compounds. Practically in all places in which we may substitute halogens we may likewise substitute the amino radical, and the amines constitute a large and important group of compounds. Several of these compounds which we shall consider later are directly connected with animal and vegetable life. Some of them are found naturally in herring brine, in the distillation products of beet sugar residues, in certain plants and in other places.

The importance of amino compounds in connection with agriculture is that in all of their characters they are ammonia derivatives. Methyl amine may be looked upon either as a derivative of methane or of ammonia.

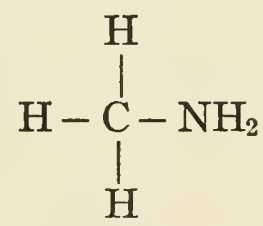

Amino-methane

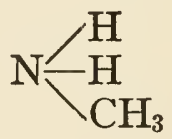

Methyl ammonia (amine)

In fact it is the ammonia character of these compounds which is the striking thing. They are alkaline in reaction, have an ammoniacal odor and form salts with acids just as ammonia does. In the conversion of ammonia into ammonium salts the trivalent nitrogen in ammonia becomes pentavalent in the salts as follows:

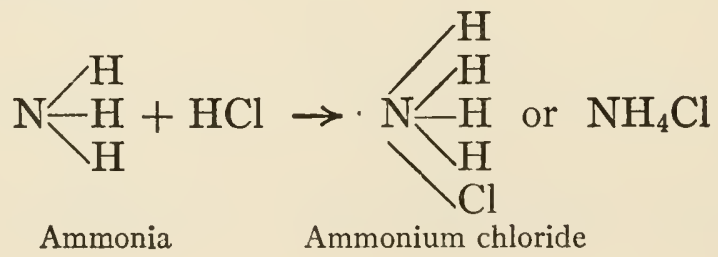




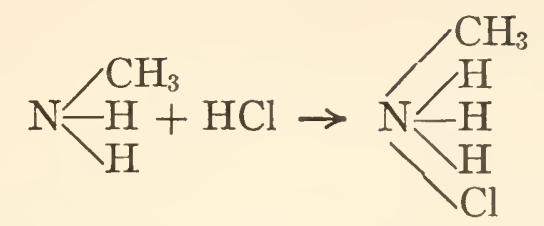

Methyl amine Methyl ammonium chloride

On decomposition the amines yield their nitrogen as ammonia, and it is their ammonia relationship which connects them with agriculture. The most complex nitrogen compounds of the animal body, the proteins, are unquestionably amino compounds, and on breaking down they yield simpler amino compounds, one of these being urea, and these in turn yield the nitrogen finally as ammonia, in which form it begins its connection with plant life as plant food in the soil. These complex amino compounds will be considered later.

Cyan-amide. - One amino compound should now be considered in more detail. We have just discussed first the cyanides and then the amines. A compound is known in which this cyanide radical is substituted in ammonia just as, in methyl amine, methyl is substituted in ammonia.

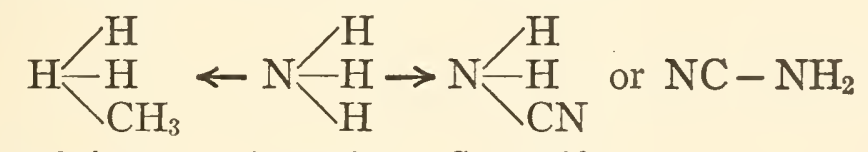

Methyl amine Ammonia Cyanamide

The compound is known as cyan-amide. It forms salts with metals such as silver and calcium in which the metal replaces an equivalent amount of hydrogen of the amino group.

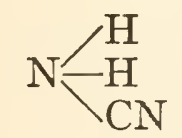

Cyanamide

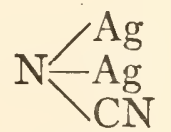

Silver cyanamide

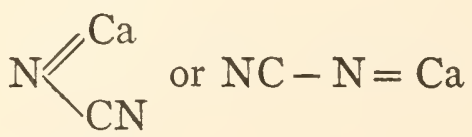

Calcium

cyanamide

Calcium Cyanamide. - This calcium salt or calcium cyanamide is a new and, without doubt, a very important nitrogen fertilizer. Its value to plants is due to its ammonia character, as the nitrogen in this new compound in which no hydrogen is 
left retains its original ammonia nature. On decomposition with water it goes back to ammonia.

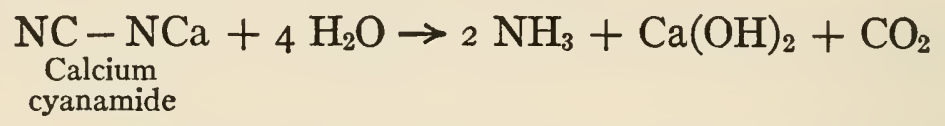

This decomposition takes place in steps which cannot be well explained here. The exact character of the reaction, at least the extent to which it is completed, probably varies under different conditions in the soil. The nature of its action is still subject to investigation, but there is no doubt that the compound will eventually be one of the important forms of nitrogen fertilizers. Its common commercial name is limenitrogen. Its value and importance is largely in connection with its commercial method of preparation.

When carbon (coal) is heated in an electric furnace with lime, $\mathrm{CaO}$, the common substance calcium carbide is produced.

$$
\mathrm{CaO}+3 \mathrm{C} \rightarrow \underset{\substack{\text { Calcium } \\ \text { carbide }}}{\mathrm{CaC}_{2}}+\mathrm{CO}
$$

This calcium carbide with water yields the common illuminating gas acetylene. When, however, it is heated with atmospheric nitrogen calcium cyanamide is formed.

$$
\underset{\substack{\text { Calcium } \\
\text { carbide }}}{\mathrm{CaC}_{2}}+\mathrm{N}_{2} \rightarrow \mathrm{NC}-\underset{\begin{array}{c}
\text { Calcium } \\
\text { cyanamide }
\end{array}}{\mathrm{NCa}}+\mathrm{C}
$$

The source of the nitrogen, therefore, is the atmosphere, and we are converting atmospheric nitrogen into a plant fertilizer. The utilization of atmospheric nitrogen for the manufacture of agricultural nitrogen fertilizers is the great chemical problem in relation to agriculture which chemists have been investigating, especially during the last quarter of a century, and this compound, calcium cyanamide, is one of the three important results of this work.

The more detailed study of this compound, including its practical application as a fertilizer, belongs to the study of soils and fertilizers and not to our present study. 


\section{EXPERIMENT STUDY IV}

\section{Cyanides}

Caution. Potassium cyanide is an exceedingly strong POISON. Examine potassium cyanide very cautiously for color, odor and solubility in water. Make a solution of about I g. in Io c.c. water. Take ro c.c. silver nitrate and add I drop of the cyanide solution. Note precipitate. Add a few more drops and note result.

$$
\begin{gathered}
\mathrm{AgNO}_{3}+\mathrm{KCN} \rightarrow \underset{\mathrm{AgCN}}{\mathrm{AgNO}} \mathrm{KNO}_{3} \\
\text { insol. } \\
\mathrm{AgCN}+\mathrm{KCN} \rightarrow \underset{\text { sol. }}{\mathrm{AgCN}-\mathrm{KCN}}
\end{gathered}
$$

Double Cyanides. Examine crystals of potassium ferrocyanide, $\mathrm{K}_{4} \mathrm{Fe}(\mathrm{CN})_{6}$, or $\mathrm{Fe}(\mathrm{CN})_{2} \cdot{ }_{4} \mathrm{KCN}$, and of potassium ferricyanide, $\mathrm{K}_{3} \mathrm{Fe}(\mathrm{CN})_{6}$, or $\mathrm{Fe}(\mathrm{CN})_{3} \cdot 3 \mathrm{KCN}$, as to general character and solubility. Add a few drops of each to some ferrous sulphate, $\mathrm{FeSO}_{4}$, and to some ferric chloride, $\mathrm{FeCl}_{3}$.

Calcium Cyanamide, $\mathrm{CaN}-\mathrm{CN}$. Examine calcium cyanamide for general properties. Add Io g. to roo c.c. water in a flask. Boil the contents of the flask and pass the steam through glass and rubber tubing into a beaker containing water and some red litmus paper. What gas is produced after considerable boiling (one half hour)? Add hydrochloric acid to residue in flask. Filter and test filtrate for calcium by means of ammonia and ammonium oxalate, $\left(\mathrm{NH}_{4}\right)_{2} \mathrm{C}_{2} \mathrm{O}_{4}$.

\section{HYDROXY SUBSTITUTION PRODUCTS OR ALCOHOLS}

When the monohalogen substitution products of the methane hydrocarbons are treated with silver hydroxide, $\mathrm{Ag}(\mathrm{OH})$, the halogen is replaced by the $(\mathrm{OH})$ group or radical. This group is known as hydroxyl and the compound resulting is a hydroxy substitution product.

$$
\underset{\text { Methyl iodide }}{\mathrm{CH}_{3}(\mathrm{I}+\mathrm{Ag})-\mathrm{OH} \rightarrow \underset{\text { Methyl hydroxide }}{\mathrm{CH}_{3}-\mathrm{OH}}+\mathrm{AgI}}
$$

When methyl iodide is used the product of the reaction is methyl hydroxide. It is, however, a common substance known 
as wood alcohol or methyl alcohol. It is the first or lowest member of a large group of similar compounds to which we give the class name of alcohol. All alcohols are characterized by this hydroxyl group and are hydroxy substitution products of the hydrocarbons. They are an exceedingly important class of compounds, and are related to agriculture in that they are produced from agricultural products, and because they possess properties which make them possible of important uses in agriculture.

The second member of the series, viz., the hydroxy-ethane, or ethyl hydroxide, $\mathrm{CH}_{3}-\mathrm{CH}_{2}-\mathrm{OH}$, is known chemically as ethyl alcohol and commonly as grain alcohol, fermentation alcohol or simply as alcohol. The first five members of the alcohol series, together with two of the higher members, are as follows:

\section{Alcohols}

\section{$\mathrm{CH}_{3}-\mathrm{OH}$}

$\mathrm{CH}_{3}-\mathrm{CH}_{2}-\mathrm{OH}$

$\mathrm{CH}_{3}-\mathrm{CH}_{2}-\mathrm{CH}_{2}-\mathrm{OH}$

$\mathrm{CH}_{3}-\mathrm{CH}_{2}-\mathrm{CH}_{2}-\mathrm{CH}_{2}-\mathrm{OH}$

$\mathrm{CH}_{3}-\mathrm{CH}_{2}-\mathrm{CH}_{2}-\mathrm{CH}_{2}-\mathrm{CH}_{2}-\mathrm{OH}$

$\mathrm{C}_{16} \mathrm{H}_{33}-\mathrm{OH}$

$\mathrm{C}_{30} \mathrm{H}_{61}-\mathrm{OH}$
Methyl alcohol (Wood alcohol)

Ethyl alcohol (Alcohol)

Propyl alcohol

Butyl alcohol

Amyl alcohol

Cetyl alcohol

Myricyl alcohol

We shall now consider the first two common alcohols, and one or two of the others, more at length in connection with their production from agricultural products and their uses.

\section{EXPERIMENT STUDY V}

\section{Alcohols, Distillation}

Set up apparatus for distillation consisting of (a) distilling flask, (b) stopper and thermometer, $(c)$ condenser, $(d)$ adapter, $(e)$ receiver. (See drawing on laboratory blackboard.) 
(I) Methyl Alcohol, Wood alcohol. In a 250 c.c. flask place Ioo c.c. of methyl alcohol. Heat the flask gradually until the liquid begins to distill over and note the temperature at this instant. Continue slowly until about $30 \mathrm{cc}$. have distilled over. Determine the specific gravity of the original alcohol and of the distillate.

(2) Repeat (I) using ethyl alcohol.

(3) Repeat (I) using amyl alcohol.

(4) Fractional Distillation. Measure out Ioo c.c. of ethyl alcohol. Determine the specific gravity. Add Ioo c.c. water and mix thoroughly. Determine the specific gravity of the mixture. Place the mixture in a $500 \mathrm{cc}$. distilling flask, heat gradually and distill very slowly. Note the temperature at the beginning of the distillation. Distill over 30 c.c. and note temperature at this time. Without stopping the distillation change receiver and collect a second 30 c.c. fraction, noting temperature as before. In the same way collect a third, fourth and fifth fraction, noting temperature carefully at the end of each fraction which is also the beginning temperature of the next higher fraction. Cease the distillation at the end of the fifth 30 c.c. fraction. Determine the specific gravity of each fraction and of the residue. Calculate the per cent of alcohol in each fraction and in the residue from the table (Table I) and tabulate the results as follows:

\section{Fractional Distillation of Ethyl Alcohol}

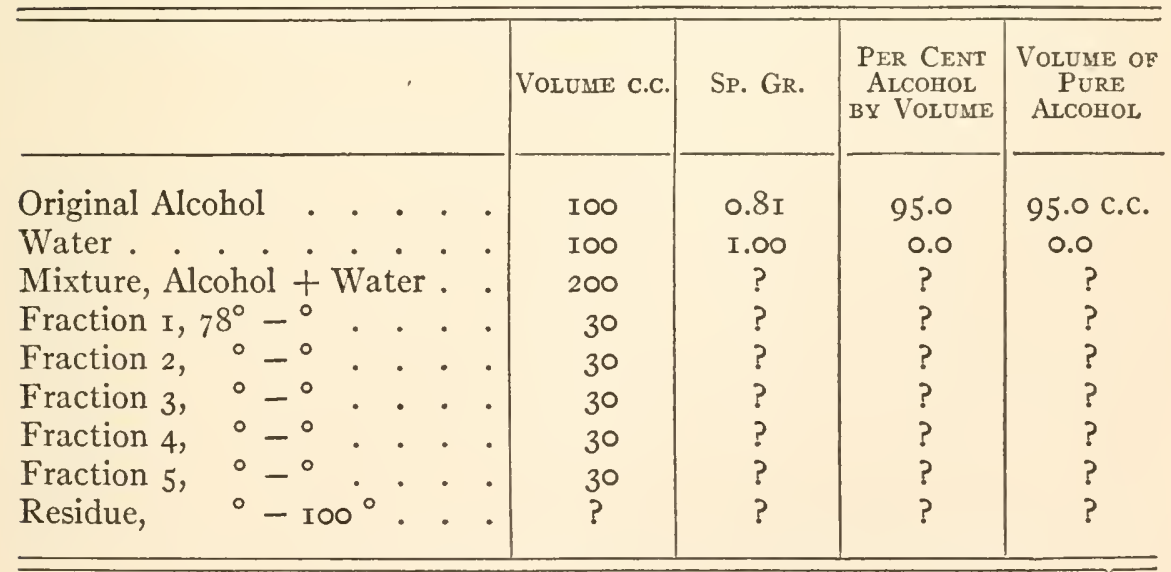

What has been effected by this distillation? If repeated several times with each fraction, what would the result. be? 


\section{TABLE I}

\section{Alcohol}

Alcohol in Per Cent. by Volume Corresponding to Specific Gravities at $\frac{15.56^{\circ}}{15.56^{\circ}}$ of Mixtures of Water and Ethyl Alcohol. (From Landolt's 'Tables, p. 226.)

\begin{tabular}{|c|c|c|c|c|c|}
\hline$d \frac{\mathrm{r} 5.56^{\circ}}{\mathrm{r} 5.56^{\circ}}$ & $\begin{array}{l}\text { VOLUME } \\
\text { PER CENT } \\
\text { ALCOHOL }\end{array}$ & $d \frac{\mathrm{I} 5.56^{\circ}}{15.56^{\circ}}$ & $\begin{array}{l}\text { VolUMe } \\
\text { PER CENT } \\
\text { ALCOHOL }\end{array}$ & $d \frac{15.56^{\circ}}{15.56^{\circ}}$ & $\begin{array}{l}\text { VOLUME } \\
\text { PER CENT } \\
\text { ALCOHOL }\end{array}$ \\
\hline 1.000 & 0 & \multirow{6}{*}{0.9592} & \multirow{6}{*}{35} & \multirow{6}{*}{0.8900} & \multirow{6}{*}{70} \\
\hline 0.9985 & I & & & & \\
\hline 0.9970 & 2 & & & & \\
\hline $0.995^{6}$ & 3 & & & & \\
\hline 0.9942 & 4 & & & & \\
\hline 0.9928 & 5 & & & & \\
\hline 0.99I 5 & 6 & \multirow[t]{5}{*}{0.9519} & \multirow[t]{5}{*}{40} & \multirow[t]{5}{*}{0.8773} & \multirow[t]{5}{*}{75} \\
\hline 0.9902 & 7 & & & & \\
\hline 0.9890 & 8 & & & & \\
\hline 0.9878 & 9 & & & & \\
\hline 0.9866 & IO & & & & \\
\hline 0.9854 & II & \multirow[t]{3}{*}{0.9435} & \multirow[t]{3}{*}{45} & \multirow[t]{3}{*}{0.8639} & \multirow[t]{3}{*}{80} \\
\hline 0.9843 & I 2 & & & & \\
\hline 0.9832 & I3 & & & & \\
\hline 0.9821 & I4 & \multirow[t]{2}{*}{0.9343} & \multirow[t]{2}{*}{50} & \multirow[t]{2}{*}{0.8496} & \multirow[t]{2}{*}{85} \\
\hline 0.98 I I & I5 & & & & \\
\hline \multirow[t]{4}{*}{0.9760} & \multirow[t]{4}{*}{20} & \multirow[t]{4}{*}{0.9242} & \multirow[t]{4}{*}{55} & 0.8339 & 90 \\
\hline & & & & 0.8306 & $9 I$ \\
\hline & & & & 0.8272 & 92 \\
\hline & & & & 0.8237 & 93 \\
\hline \multirow[t]{4}{*}{0.9709} & \multirow[t]{4}{*}{25} & \multirow[t]{4}{*}{0.9134} & \multirow[t]{4}{*}{60} & 0.8201 & 94 \\
\hline & & & & $\begin{array}{l}0.8 \text { I } 64 \\
0.8 \text { I } 25\end{array}$ & $\begin{array}{l}95 \\
06\end{array}$ \\
\hline & & & & 0.8084 & 97 \\
\hline & & & & $0.804 \mathrm{I}$ & 98 \\
\hline \multirow[t]{2}{*}{0.9655} & \multirow[t]{2}{*}{30} & \multirow[t]{2}{*}{0.9021} & \multirow[t]{2}{*}{65} & 0.7995 & 99 \\
\hline & & & & 0.7946 & 100 \\
\hline
\end{tabular}




\section{Methyl Alcohol (Wood Alcohol)}

Methyl alcohol, $\mathrm{CH}_{3} \mathrm{OH}$, which is hydroxy-methane, is commonly known as wood alcohol because it is produced by the destructive distillation of wood. When wood, better the hard woods such as beech or maple, is heated in closed retorts, or in compact piles covered with earth, so that no air, or only a small amount, has access to it, the wood is not burned but is decomposed by the heat. Such a process is termed destructive distillation. As a result of this heating the wood is decomposed into gaseous and liquid products and a residue of carbon or charcoal is left. The gaseous products contain some ammonia, but mostly mixtures of gaseous hydrocarbons. The liquid distillate contains methyl alcohol together with other compounds to be considered later, of which acetic acid (vinegar acid) is the most important. The crude distillate is acid in character and is known as pyroligneous acid. It is dark colored because of tarry compounds contained in it, most of which separate as an oily layer, and can be removed as such. To obtain the methyl alcohol alone from this crude acid distillate the latter is neutralized with alkali (lime or caustic soda) and redistilled. The neutralization converts the acetic acid into a non-volatile salt so that by the redistillation the alcohol is separated from this compound. By further purification from the other compounds present, and by fractional distillation through what is known as a column still, methyl alcohol of 95 per cent purity is obtained. Such high grade methyl alcohol is known in this country as Columbian Spirits. Absolute or roo per cent methyl alcohol may be obtained by forming a crystalline compound with calcium chloride; and this, when filtered off and air dried, is decomposed with sulphuric acid and distilled.

Another source of methyl alcohol is the dry residue obtained in the manufacture of beet sugar. When the juice of the sugar beet is concentrated and then the sugar crystallized out as much as possible, a sirupy residue containing considerable solid matter remains. This still contains more or less sugar, 
and by fermentation yields ethyl alcohol, as will be presently discussed. After fermentation, and the distillation of the ethyl alcohol, the dry residue remaining is destructively distilled and methyl alcohol is obtained. Another product obtained, as was referred to recently, is methyl amine, $\mathrm{CH}_{3} \mathrm{NH}_{2}$.

Methyl alcohol is a water-like liquid boiling at $64.5^{\circ} \mathrm{C}$. and has a specific gravity of $0.8 \mathrm{I} 2$ at $0^{\circ} \mathrm{C}$. It burns with a nonluminous flame, and is soluble in water in all proportions. It has a characteristic, rather disagreeable odor, and is poisonous if taken internally. When so taken it generally affects the eyes, and people have been known to be made blind by drinking methyl alcohol. Its odor and poisonous properties make it useful as a denaturant of ordinary alcohol, i.e. to make ordinary alcohol unfit for use as a beverage.

The chief use of methyl alcohol industrially is as a solvent, It is a good solvent of many organic substances which are insoluble in water such as shellac, varnish, celluloid, etc. It is also used in the preparation of certain dyes. As its cost of manufacture is not great and as it is not subject to taxation, being unfit for beverage uses, it is much cheaper than ordinary alcohol on which a tax has been paid. Until the passage of the denatured alcohol law, it was therefore the chief alcohol used for industrial purposes. When slowly oxidized, as when its vapor mixed with air is passed over heated copper, it yields a compound soon to be considered, known as formaldehyde or formalin, a common disinfectant.

\section{EXPERIMENT STUDY VI}

\section{Methyl Alcohol}

(r) Determine (a) color, $(b)$ odor, $(c)$ inflammability (I cc. on a watch glass), and (d) miscibility with water. (2) Test the solvent power of methyl alcohol on the following substances and compare it with water as a solvent: ${ }^{1}(a)$ sodium chloride, $(b)$ sugar, $(c)$ camphor,

1 The best way to perform the solubility tests is as follows: With each substance take three very small pieces (just a crystal or two or an amount about the size of half a pea) and place in three clean, dry test tubes. Then add to one test tube 
(d) shellac, $(e)$ rosin, $(f)$ chloroform, $(g)$ iodoform, $(h)$ iodine, $(i)$ sulphur, $(j)$ lard or tallow, $(k)$ cottonseed oil.

\section{Ethyl Alcohol (Common Alcohol)}

Properties. - Ethyl alcohol, $\mathrm{CH}_{3} \mathrm{CH}_{2} \mathrm{OH}$ or $\mathrm{C}_{2} \mathrm{H}_{5} \mathrm{OH}$, is the common alcohol of commerce, and is contained in a greater or less amount in alcoholic beverages. It bears the same relation to methyl alcohol that ethane does to methane. It is a waterlike liquid similar to methyl alcohol in general appearance and properties. It boils at $78^{\circ}$ and has a specific gravity of 0.806 at $0^{\circ} \mathrm{C}$. It differs from methyl alcohol in having a pleasant odor. It burns with a non-luminous flame and mixes with water in all proportions. It resembles methyl alcohol in its solvent properties, but is stronger in this action toward most organic substances. It forms crystalline compounds with certain salts, e.g. calcium chloride, $\mathrm{CaCl}_{2}$.

In dilute form, as it is found in beverages, alcohol has been known from ancient times and in nearly all countries. It was first obtained in concentrated pure form in the Middle Ages, and absolute or Ioo per cent alcohol was made first in I796, and its composition determined in 1808 .

\section{EXPERIMENT STUDY VI}

\section{Ethyl Alcohol}

(I) (2) Perform all of the tests under Experiment VI, I, 2, with ethyl alcohol. (3) To a little absolute ethyl alcohol in a test tube, which is fitted to generate gas and collect it over water in another tube, add a small piece of metallic sodium the size of half a pea. Note generation of gas. The gas is hydrogen, as may be proven by testing. Repeat addition of sodium if necessary to collect enough gas to test. How does the reaction eompare with that of sodium and water? After the reaction is over evaporate the alcohol in a small about 2 or 3 c.c. of water; to the second about the same amount of methyl alcohol, and to the third ethyl alcohol. Shake each tube, and notice solubility of the substance. If it does not dissolve, warm the tube a little. If it is doubtful whether any solution has occurred, filter the clear liquid into a watch glass and let it evaporate. A residue will show solubility of the original substance. 
evaporating dish or watch glass. Remember alcohol volatilizes completely. What is the residue like? It is known as sodium ethylate and has the composition $\mathrm{C}_{2} \mathrm{H}_{5} \mathrm{ONa}$. By quantitative determination it has been proven that only one hydrogen is replaced by sodium. This proves that one hydrogen is combined as in water in the form of hydroxyl ( $-\mathrm{OH})$.

(4) Test for ethyl alcohol. Prepare two solutions of ethyl alcohol in water approximately I.O per cent and o.I per cent strength. (95 per cent alcohol I.o c.c. + water 99 c.c. = approximately I.o per cent alcohol. I.o per cent alcohol ro.o c.c. + water 90 c.c. $=$ approximately o.I per cent alcohol.) Test each of the solutions as follows: - Take Io c.c. of the dilute alcohol in a test tube. Add two or three small crystals of iodine. Add 5.0 c.c. dilute $\mathrm{KOH}$ or $\mathrm{NaOH}$. Warm the mixture. A yellow crystalline precipitate giving the odor of iodoform is proof of the presence of alcohol in the original solution. Dilute the o.I per cent solution Io times, and repeat the test.

(5) Test for water in ethyl alcohol. To 5.0 c.c. of 95 per cent ethyl alcohol add about I g. of anhydrous copper sulphate. Shake and let stand. Note change in the copper sulphate. Anhydrous copper sulphate is almost white. When it takes up water it is converted into the ordinary copper sulphate which is blue and has $5 \mathrm{H}_{2} \mathrm{O}$ as water of crystallization, $\left(\mathrm{CuSO}_{4} \cdot 5 \mathrm{H}_{2} \mathrm{O}\right)$. If in the test the copper sulphate remains white, the alcohol has no water, i.e. it is absolute alcohol. If water is present even in small proportions, the copper sulphate will turn blue.

Alcoholic Fermentation. - It was early discovered that when the juice of grapes and other sweet fruits was allowed to ferment it took on a sharp taste and affected the body in a stimulating manner. This property was found to be due to the presence of alcohol in the fermented liquid. In I 836 Cagniard de la Tour and von Schwann showed that the alcohol in such fermentation was produced by the action of a living plant organism upon sugar solutions. This organism is the common yeast plant, Saccharomyces cerevisia. Liebig held the view known as the mechanical chemical theory of fermentation according to which the action was due to some catalytic substance. The views of von Schwann and de la Tour were later thoroughly established by the work of Pasteur, and it became an accepted idea that 
the life process of the yeast plant was directly connected with alcoholic fermentation. Pure yeast is able to ferment only certain sugars, the two most common ones being glucose, or grape sugar, and fructose, or fruit sugar. In the grape juice both glucose and the yeast cells are present, the latter occurring naturally on the bloom of the grape.

Enzymes, Zymase. - The recent work of Buchner has shown that the fermentation is due not to the living action of the yeast cell but to a substance known as zymase, which is secreted by the cell. A number of substances are known which act catalytically in producing chemical changes of the same nature, and which are termed in general fermentations. Ptyalin, the active substance in saliva, which converts starch into sugar; pepsin, the active substance in gastric juice converting proteins into simpler compounds; and diastase, a constituent of sprouting grain which also converts starch into sugar, - are examples of these substances. They are known as ferments. Because alcoholic fermentation, which is the most common process of this nature, was supposed, until Buchner's time, to be due to a living cell, these other substances which could be obtained in a more or less pure condition were distinguished from the yeast plant ferment by the name unorganized ferment and later as enzymes, the alcoholic ferment being known as an organized ferment.

Buchner, however, proved that the living yeast cell could be entirely destroyed and an unorganized ferment which he called zymase obtained from it which in itself possessed the power of fermenting grape sugar. Thus alcoholic fermentation is of the same nature as these other fermentations, and is due like them to the catalytic action of an unorganized ferment or enzyme. Thus both of the old views of Liebig and Pasteur may be considered as in a way true. The action, as Liebig claimed, is catalytic, i.e. depending upon the mere presence or contact of the enzyme, not upon its mass, while the living yeast cell is necessary, not directly to the fermentation itself, as Pasteur claimed, but to the formation of the enzyme, a chemical substance which produces the fermentation. 
The alcoholic fermentation of sugar, then, is due to the action of the enzyme zymase which is secreted by the yeast cell. In grapes both the sugar and enzyme are present and the juice therefore ferments naturally with the formation of alcohol, the resulting alcoholic liquid being known as wine. As wine has considerable commercial value in itself it is not the source from which pure or high percentage alcohol is obtained.

\section{EXPERIMENT STUDY VIII}

\section{Alcoholic Fermentation}

Place 150 c.c. of glucose sirup (Karo Corn Sirup) in a rooo c.c. flask with 500 c.c. of water. Add 20 c.c. of nutritive solution ${ }^{1}$ (a solution of salts for the nutrition of the yeast plant). Mix about $\frac{1}{8}$ cake of yeast with a little water to make a thin mixture. Add this yeast to the sugar solution and place stopper in flask with bent glass and rubber connection. Connect the rubber tube with a straight glass tube and introduce this glass tube into a graduated cylinder containing 50 c.c. of limewater, $\mathrm{Ca}(\mathrm{OH})_{2}$. Pour about I c.c. of kerosene upon the surface of the limewater to exclude air. Set the whole apparatus on the shelf and let it remain at $25^{\circ} \mathrm{C}$. until the next exercise, examining in the interval if possible. What is the precipitate formed in the cylinder? What gas does this prove to be given off? After the fermentation is over pour off 150 c.c. of the clear liquid into a 300 c.c. distilling flask and distill over roo c.c. Test the distillate for alcohol as in VII, 4. What are the two products of the yeast fermentation of sugar? Test the specific gravity of the distillate and calculate the amount of alcohol present in it. As this distillate contains all of the alcohol present in the 150 c.c. of the fermentation liquid calculate the amount of alcohol present in the fermentation liquid. This is the method of determining the alcohol content of alcoholic liquors.

Diastase. - The chemical substance which is the ultimate source of industrial alcohol is starch. Recently cellulose has

1 Pasteur salt solution is made as follows:

$\left.\begin{array}{l}\text { Potassium phosphate, } 2.0 \text { parts } \\ \left.\text { Calcium phosphate, } \begin{array}{l}0.2 \text { parts } \\ \text { Magnesium sulphate, } \\ \text { Ammonium tartrate, } 10.0 \text { parts }\end{array}\right\} \text { parts }\end{array}\right\}$ water, 857.6 parts


also been used, as will be referred to later. The material from which the starch is obtained is generally one of the cereal grains or potatoes. Starch, however, is not acted upon by the enzyme zymase, so that it cannot be used directly for the alcoholic fermentation. When one of the cereal grains, or in general any starch-containing seed, sprouts or begins to grow, there is a gradual conversion of the starch present in the grain into sugar. This change is brought about by the presence in the germinating grain of two other enzymes, viz. diastase and maltase. The diastase converts the starch into a sugar, maltose, and maltase converts the maltose into glucose. When, therefore, these enzymes have acted upon starch, it is converted into a sugar upon which the alcoholic enzyme zymase can act. In practice the grain, usually corn, rye or barley, is allowed to sprout in a warm room $\left(60^{\circ}-63^{\circ}\right)$, ground, and water added, making a thin mush or mash. This is next treated with yeast and allowed to stand at about $25^{\circ}$. Temperatures above $33^{\circ}$ are injurious to the enzyme. After the fermentation the mash, or wort as it is now called, is either placed in retorts and the alcohol distilled off directly or the liquid of the wort is separated by filtration. The amount of alcohol present in the liquid of the wort is usually about 5 per cent, but in some fermenting liquids as in grape juice it may reach as high as I4 per cent. Above this it cannot go because a stronger solution of alcohol is destructive to the enzyme. The distillation of the fermented liquid takes place in a still built in several sections so that the alcoholic vapor is continually condensed and redistilled (fractionated). By a direct distillation from such an apparatus a solution of alcohol is obtained of about 90 per cent. This may contain small amounts of higher boiling alcohols, propyl and amyl alcohols. The non-volatile substances present in the fermentation liquid, the principal ones being glycerol and succinic acid, are left behind in the retort. For the still greater purification of the alcohol it is first mixed with water, making about a 50 per cent solution. This allows the separation of some of the amyl alcohols as an oily layer. After separation it is now distilled 
again through a rectifying or column still. This is a tall still containing many condensing plates so that the alcohol is still more perfectly fractionated. By this second distillation the purest and strongest alcohol of commerce is obtained. It is about 95 per cent, by weight, and is commercially known as Cologne spirits.

Absolute Alcohol. - For the preparation of absolute or 100 per cent alcohol the 95 per cent product is placed over quicklime, $\mathrm{CaO}$, and after standing to allow the lime to remove all water the whole mass is heated and alcohol passes over as roo per cent. Anhydrous copper sulphate may also be used as a dehydrating agent, but this is common only in laboratories and not in commercial practice.

Absolute alcohol, because of its affinity for water, acts as a dehydrating agent, and is used to remove the last traces of water from some substances, especially animal and plant tissues. It can be kept only in bottles well stoppered.

Alcoholic Beverages. - The use of alcoholic beverages is an ancient and very general custom. The natural alcoholic beverages are the weaker in alcoholic content and are simply the undistilled fermentation liquids. They are wine, beer, ale, stout and others similar in character, but with different names. Wine is the simple fermented grape juice and contains 7 per cent to 20 per cent alcohol. Those above I4 per cent are termed fortified wines because they have alcohol added to them. Beer, ale and stout are fermented liquors obtained by filtering or decanting off the fermented liquid made from barley in the general manner described in the manufacture of alcohol. These are still lower in alcohol content than wine, being between 2 per cent in pale beers to 5 or 6 per cent in ales and porters. The characteristic taste or flavor of wines and the names given to them depend upon the variety of grape used, the locality where the wine is made, or the particular processes involved in its manufacture. The same general facts determine the quality and name of the beers and ales.

When a fermented mash prepared from grain or from fruits 
is distilled without attempting to secure complete purification of the distillate or the highest per cent of alcohol possible, there is obtained a strong alcoholic distillate possessing certain characteristic properties due to the original material used. These liquids constitute the distilled liquors known as whisky, brandy, cognac, gin, rum, etc. These liquors are much stronger in alcohol than either wine or beer and contain usually from 35 per cent to 40 per cent alcohol.

Industrial Uses. - The importance of alcohol is not, however, in its use in one of these various forms as a beverage, but in its wide application in the arts as a solvent or as a substance from which other valuable compounds are made. In some of its industrial uses it may be replaced by its methyl homologue, but not in all, at least to advantage. In its synthetical uses it, of course, cannot be replaced by the other.

Taxation. - Because of its use in beverages, which are almost wholly luxuries, nearly all civilized countries have considered alcohol as a proper article for taxation and for government control. The tax is also usually high, so that the cost of pure alcohol is far above its cost of actual manufacture. Alcoholic beverages, and pure alcohol, that are subject to such taxation are taxed according to the amount of pure alcohol present. It therefore becomes necessary to determine the strength of alcoholic liquids and also to have a fixed standard of strength. The analysis of such liquids for per cent. of alcohol has had much attention paid to it in order to make the methods reliable and applicable to every varying condition. The general method is to take a definite amount of the liquid, e.g. Ioo c.c. (this will be smaller the higher the alcohol content of the liquid), dilute to a definite volume (I50 c.c.) and then distill off about two thirds ( Ioo c.c.). The distillate contains the entire amount of alcohol present in the liquid and, in case necessary precautions have been taken, contains only water in addition. Mixtures of pure water and alcohol possess a definite specific gravity for each variation in concentration (see Table I), so that the determination of the specific gravity of the distillate defines the exact 
amount of alcohol present, and if this is the entire amount pres. ent in the original liquid, we have an exact determination of the factor desired.

The standard of strength upon which alcohol is taxed is not, as might seem natural, Ioo per cent or absolute alcohol, but something less than this. In this country the standard strength is a 50 per cent by volume alcoholic solution or 42.7 per cent by weight. This is termed proof spirit, and tax is always made according to per cent proof spirit.

Denatured Alcohol. - Because of the extremely high tax (in the United States the tax equals \$I.Io per proof gallon) and, therefore, the high price of pure alcohol, also the fact that methyl alcohol which has no tax cannot always be substituted for it, it is of the utmost importance that alcohol which is to be used industrially, not as a beverage, should be removed from taxation and thus greatly cheapened in price. In order to make this possible it is necessary to render the alcohol for industrial uses unfit for beverage purposes. Alcohol so treated is termed denatured. Germany and England have had laws in operation for some time by means of which alcohol to be used industrially is freed from taxation, but it was not until I906 that the United States had a law of this kind. Alcohol to be used industrially is denatured by the addition of some substance which does not interfere with its use, but makes it unfit for internal consumption. For example, alcohol to be used in the manufacture of ether is denatured by the addition of sulphuric acid which is the reagent necessary when the ether is made. For ordinary solvent purposes the denaturant is usually methyl alcohol, while a little pyridine is often used to give it an offensive odor, and sometimes a colored substance to give it a noticeable color. The denatured alcohol law has two advantages. It cheapens the cost of alcohol so that things made by its use can be cheapened. It also makes it possible to manufacture alcohol more generally and to use in its manufacture a great many starch, sugar or cellulose-containing materials which have heretofore been simply waste products of the farm. The sub- 
stances generally used are fruit, most vegetables, especially potatoes, inferior grain, sawdust, etc. The utilization of cellulose, the carbohydrate constituent of sawdust and other woody material, for the production of alcohol has been recently developed and several processes have been patented. The general principle of all of them is to first hydrolyze the cellulose to glucose sugar, usually by acid hydrolysis, and then to ferment the glucose to alcohol by means of yeast, as already described.

\section{The Higher Alcohols}

Amyl Alcohols. - The only alcohols, in addition to the two already described, which we shall consider are the amyl alcohols which contain five carbon atoms, i.e. $\mathrm{C}_{5} \mathrm{H}_{11} \mathrm{OH}$. There are eight different isomeric amyl alcohols, all of which are fully explained by our ideas of structure which will not be discussed here but will be taken up again under lactic acid, p. 69. Two of these are found in the products of distillation when a fermented liquor is distilled. They are known together as fermeniation amyl alcohol. These two alcohols with propyl alcohol and butyl alcohol, the two preceding members, constitute the greater part of what is commonly known as fusel oil and on account of which the oil is also called crude amyl alcohol.

Amyl alcohol as it is ordinarily obtained, which is a mixture of at least tro of the eight isomers, is a heavy liquid boiling at about $130^{\circ}$, sp. gr. about $0.8 \mathrm{r}$. It shows a marked difference from methyl, ethyl and propyl alcohols in not being soluble in water. It is a striking fact that the solubility in water decreases as the amount of carbon in the alcohol increases, and at the same time the specific gravity increases and the boiling point rises. The lower alcohols are thus water-like volatile liquids soluble in water. The intermediate members from 5 to Io carbon atoms are heavy liquids, difficultly volatile and insoluble in water, while the higher members are solid, waxlike compounds, non-volatile and insoluble in water. 


\section{EXPERIMENT STUDY IX}

\section{Amyl Alcohol}

Perform experiments I, $a, b, c, d$ under Experiment Study VI, using amyl alcohol.

\section{Polyhydroxy Alcohols}

In our study of the halogen substitution products we considered the products formed by substituting more than one element in place of hydrogen. These compounds, e.g. chloroform, $\mathrm{CHCl}_{3}$, iodoform, $\mathrm{CHI}_{3}$, and ethylene bromide, $\mathrm{CH}_{2} \mathrm{Br}-\mathrm{CH}_{2} \mathrm{Br}$, are termed polyhalogen substitution products.

In considering the alcohols thus far only the monosubstitution products have been taken up. Exactly analogous to the polyhalogen substitution products we have polyhydroxy alcohols. The polyhydroxy alcohols are analogous as bases to the polyhydroxy bases of the metals, e.g. calcium hydroxide, $\mathrm{Ca}(\mathrm{OH})_{2}$, aluminium hydroxide, $\mathrm{Al}(\mathrm{OH})_{3}$, etc. They are, therefore, often termed polyacid alcohols and will be diacid alcohols, triacid, tetraacid, etc., depending upon the number of hydroxyl groups present. These polyhydroxy compounds which act as bases are termed polyacid because they react with more than one molecule of univalent acids, i.e. the metal or radical in them will replace two, three, four, etc., acid hydrogens.

Dihydroxy Alcohols. - It is a fact which has been pretty well established that when two hydroxyl groups are united to one carbon, the result is, in almost all cases, an unstable compound which loses water, the hydroxyl groups being thus broken.

In agreement with these ideas is the fact that no dihydroxy derivative of methane is known and also that the unsymmetrical dihydroxy ethane, $\mathrm{CH}_{3}-\mathrm{CH}(\mathrm{OH})_{2}$, is unknown, except as derivatives. This will be taken up later.

The simplest dihydroxy alcohol is the symmetrical dihydroxy ethane known as glycol, $\mathrm{CH}_{2} \mathrm{OH}-\mathrm{CH}_{2} \mathrm{OH}$. This compound is called glycol, because it has a sweet taste, as indicated by the 
prefix "glyc" and is an alcohol as the termination "ol " signifies. It is also termed ethylene glycol because as a symmetrical disubstituted ethane it is related to ethylene (see p. 132). It is a thick liquid soluble in water. Its application in our study is as an introduction to the polyhydroxy alcohols. The dihydroxy products of the hydrocarbons above ethane will not be mentioned.

Trihydroxy Alcohols. - The simplest trihydroxy product is the symmetrical trihydroxy substitution product of propane:

\section{$\mathrm{CH}_{3} \mathrm{CH}_{2} \mathrm{CH}_{3} \rightarrow \mathrm{CH}_{2} \mathrm{OH}-\mathrm{CHOH}-\mathrm{CH}_{2} \mathrm{OH}$}

Propane

Trihydroxy propane

Glycerol (Glycerin). - This trihydroxy propane is the wellknown compound glycerin. Its better name is glycerol, which signifies its alcohol character. It is important to remember that these compounds are true alcohols in their chemical character and also in many of their physical properties, such as solubility. Glycerol is a thick, clear liquid, of sweet taste, soluble in water. The importance of glycerol in agricultural chemistry is in its relation to the fats and oils as we shall explain later.

Higher Polyhydroxy Alcohols. - The higher polyhydroxy alcohols are known in the tetra (4), penta (5) and hexa (6) hydroxyl compounds. The tetrahydroxy alcohols are represented by erythritol or erythrite, the penta by arabitol or arabite and the hexa by dulcitol or dulcite, sorbitol or sorbite and mannitol or mannite. The striking fact which has already been referred to is that as the number of hydroxyl groups increases the compounds possess a sweeter taste. Glycol, glycerol, erythritol, mannitol, each is sweeter than the one preceding it. We shall find when we study the carbohydrates (sugars) that these polyhydroxy alcohols are directly related to them. 


\section{CHAPTER I I I}

\section{OXIDATION PRODUCTS OF ALCOHOLS}

\section{ALDEHYDES}

Oxidation may be either the addition of oxygen to a compound or the removal of hydrogen from it. When primary alcohols are oxidized, both of these reactions take place successively, and two important classes of compounds are obtained.

Compounds in the first of these classes are known as aldehydes from the two words al(cohol) dehyd(rogenatum).

\section{Formaldehyde}

When methyl alcohol, $\mathrm{CH}_{3} \mathrm{OH}$, is oxidized, the following is the reaction :

$$
\mathrm{CH}_{3}-\mathrm{OH} \text { or } \mathrm{H}-\mathrm{C} \underset{\mathrm{OH}}{-} \frac{\mathrm{H}}{\mathrm{H}}+\mathrm{O} \rightarrow \mathrm{H}-\mathrm{C}=\stackrel{\mathrm{O}}{\mathrm{O}}+\mathrm{H}_{2} \mathrm{O}
$$

\section{Methyl alcohol Formic aldehyde}

The resulting compound is formic aldehyde or formaldehyde.

This reaction probably takes place in two steps. First, the oxygen converts one of the hydrogen atoms of the alcohol into a hydroxyl group. The compound resulting contains two hydroxyl groups united to one carbon atom and by loss of water would yield the aldehyde as follows:

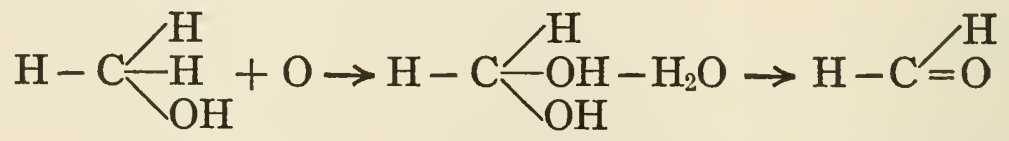

Methyl alcohol Intermediate compound Formaldehyde

The fact that the oxidation of hydrogen united to carbon results in the conversion of the hydrogen into hydroxyl is proven by other reactions and is the probable result here. The fact 
also that the intermediate product above is unknown leads to the view previously referred to (p. 40) that when two hydroxyl groups are united to one carbon an unstable compound is formed which loses water, yielding a stable product.

Formic aldehyde or, as it is better known, formaldehyde is a common disinfectant and germicide. It is ordinarily used in the form of a 40 per cent water solution under the name of formalin. It is used extensively to disinfect after sickness, and as a germicide in connection with numerous plant diseases such as potato scab, oat smut, etc. It is also used as a food preservative and to preserve anatomical or biological specimens. One of the most common uses as a food preservative has been in preserving milk. Milk so preserved is especially injurious to infants and is strictly prohibited by all health and pure food regulations. The compound is a gas, and when used as a disinfectant in case of sickness it is generally freshly prepared in this form. The formaldehyde gas is usually generated by pouring ordinary formalin upon potassium permanganate. The permanganate acts violently upon the formaldehyde, oxidizing part of it while the heat of the reaction volatilizes the greater part, which goes off as a gas rapidly penetrating all parts of a room. The formalin is also often sprinkled on a hanging sheet, when vaporization of the formaldehyde occurs. When methyl alcohol is burned with a small amount of air, or when a mixture of air and methyl alcohol vapor is passed over heated copper, formaldehyde is the result. This principle is used in making alcohol lamps which produce formaldehyde. The odor observed when a methyl alcohol lamp is blown out is due to formaldehyde. It has a sharp, penetrating, suffocating odor.

The most important fact in regard to formaldehyde, agriculturally considered, is its biological relation to the synthesis of carbohydrates in plants from carbon dioxide and water. Formaldehyde may be formed from these two simple compounds, and we may represent the reaction empirically as follows:

$$
\mathrm{CO}_{2}+\mathrm{H}_{2} \mathrm{O} \rightarrow \mathrm{H}-\mathrm{CHO}+\mathrm{O}_{2}
$$


This will be referred to again when we discuss photo-synthesis (p. 239).

\section{Acetaldehyde}

Ethyl alcohol similarly oxidized yields acetic aldehyde or acetaldehyde.

$$
\mathrm{CH}_{3}-\mathrm{C} \underset{\mathrm{OH}}{-} \underset{\mathrm{H}}{-}+\mathrm{O} \rightarrow \mathrm{CH}_{3}-\mathrm{C}=\mathrm{O}+\mathrm{H}_{2} \mathrm{O}
$$

Ethyl alcohol

Acetaldehyde

These two aldehydes are known as formic and acetic aldehydes because, on further oxidation, with the taking up of oxygen, they yield formic acid and acetic acid respectively.

\section{Aldehyde Reactions}

Addition Compounds. - Some of the reactions of aldehydes are important and should be mentioned, as they will be referred to later. When acetaldehyde is treated with ammonia or with hydrogen cyanide, addition products are formed probably as follows :

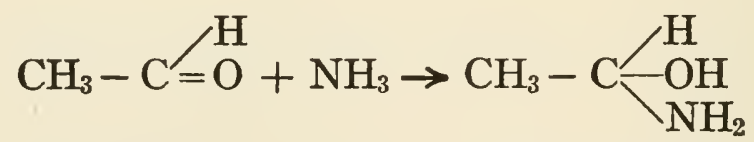

$$
\begin{aligned}
& \text { Acetaldehyde } \\
& \text { Aldehyde ammonia }
\end{aligned}
$$

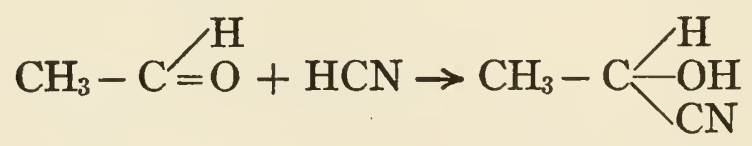

Oximes. - When aldehydes are treated with hydroxyl amine (hydroxyl ammonia), $\mathrm{H}_{2} \mathrm{~N}-\mathrm{OH}$, the two amine hydrogens of the latter compound unite with the oxygen of the aldehyde, forming water, the following reaction taking place:

$$
\underset{\text { Aldehyde }}{\mathrm{CH}_{3}-\mathrm{C}=} \stackrel{\mathrm{H}}{\left.\stackrel{\mathrm{H}}{\mathrm{H}}+\mathrm{H}_{2}\right) \mathrm{N}-\mathrm{OH}} \rightarrow \underset{\text { Hyoxyl amine }}{\mathrm{CH}_{3}}-\underset{\text { Ald-oxime }}{\mathrm{C}=\mathrm{H}}-\mathrm{OH}+\mathrm{H}_{2} \mathrm{O}
$$

The product is known as an oxime. 
Phenyl Hydrazones. - An exactly analogous reaction takes place with a benzene derivative known as phenyl hydrazine which has the formula $\mathrm{H}_{2} \mathrm{~N}-\mathrm{NH}-\mathrm{C}_{6} \mathrm{H}_{5}$. The reaction is :

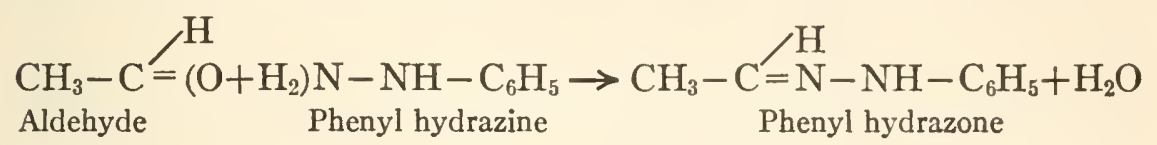

The product is known as a phenyl hydrazone.

Both of these last reactions are due to the presence in aldehydes of the group $-\stackrel{\mid}{\mathrm{C}}=\mathrm{O}$ called the carbonyl group. This group is characteristic of aldehydes and ketones, the latter being very similar to the aldehydes. In aldehydes the carbonyl carbon has one valence satisfied by a carbon radical, the other by hydrogen. In ketones both are satisfied by radicals.

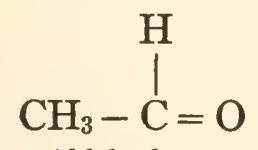

Aldehydes

(Acetaldehyde)

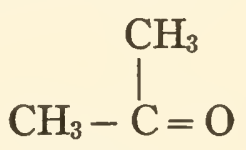

Ketones

(Acetone)

This will be sufficient reference to ketones as we shall wish simply to understand them as a class.

The hydrogen cyanide, hydroxyl amine and phenyl hydrazine reactions just discussed are of especial importance in connection with the study of the carbohydrates and will be referred to again when we consider these compounds.

\section{EXPERIMENT STUDY $\mathrm{X}$}

\section{Aldehydes}

(I) Formaldehyde. (a) Place 5.0 c.c. of methyl alcohol in a large test tube. Heat a spiral coil of copper wire red-hot, and without cooling drop it carefully into the tube of alcohol. When the flame dies out notice the odor of formaldehyde in the tube.

(b) Observe general properties of formalin, which is a 40 per cent water solution of formaldehyde.

(c) (Do this in a hood.) To about $5.0 \mathrm{~g}$. of potassium permanganate in a beaker add 5-Io c.c. formalin. Note odor of formalde- 
hyde and rapid evolution as a gas. This is the best method of using formaldehyde as a disinfectant.

(2) Acetaldehyde. Place 5.0 c.c. of ethyl alcohol in a test tube. Add a few crystals (3.0 g.) potassium dichromate $\left(\mathrm{K}_{2} \mathrm{Cr}_{2} \mathrm{O}_{7}\right)$. Mix I5.0 c.c. water +5.0 c.c. sulphuric acid (concentrated). Add the mixed acid slowly to the alcohol and dichromate. Warm if necessary. Note the action and the sweet odor. The odor is due to acetaldehyde. The green color is due to chromium sulphate. Explain.

\section{ACIDS}

When the oxidation of primary alcohols proceeds to its limit, the second stage of the reaction occurs, oxygen is added to the aldehyde, and an acid results. From formaldehyde, formic acid is obtained, and from acetaldehyde, acetic acid. The composition and constitution of these two acids is shown by the following reactions :

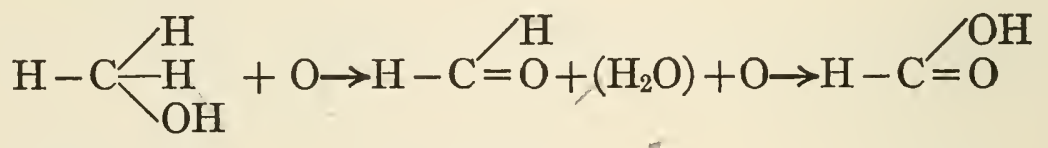

Methyl alcohol

Formaldehyde

Formic acid

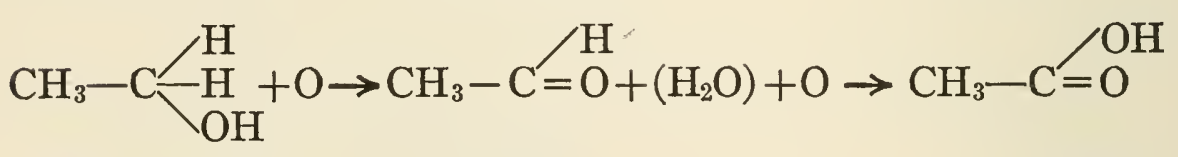

Ethyl alcohol

Acetaldehyde

Acetic acid

The formulas just given represent the constitution of the aldehydes and acids as proven by experimental evidence. The acids, like the alcohols, contain a hydroxyl group $(\mathrm{OH})$, while the aldehydes do not, the hydrogen and oxygen being each united directly to carbon. The common way of writing the formulas is :

Formaldehyde, $\mathrm{H}-\mathrm{CHO} \quad$ Formic acid, $\mathrm{H}-\mathrm{CO} O \mathrm{H}$ Acetaldehyde, $\mathrm{CH}_{3}-\mathrm{CHO}$ Acetic acid, $\mathrm{CH}_{3}-\mathrm{COOH}$ Any aldehyde, $\mathrm{R}-\mathrm{CHO} \quad$ Any organic acid, $\dot{\mathrm{R}}-\mathrm{COOH}$

It is this $\mathrm{COOH}$ group, known as the carboxyl group, which is characteristic of acids, and it is the hydroxyl group within this 
group that gives to acids their distinctive acid properties. The organic acids, like the inorganic, are neutralized by bases forming salts. In organic acids it is always this hydroxyl hydrogen which is replaced by metals in forming salts and also this hydroxyl hydrogen which becomes the positive ion (kation) when the acid dissociates in water solution. The formation of salts by neutralization of an acid by a base may be illustrated by the following reactions:

$$
\begin{array}{cc}
\mathrm{H}-\mathrm{COOH}+\mathrm{KOH} & \rightarrow \mathrm{H}-\mathrm{COOK}+\mathrm{H}_{2} \mathrm{O} \\
\text { Formic acid } & \text { Potassium formate } \\
\mathrm{CH}_{3}-\mathrm{COOH}+\mathrm{NaOH} & \rightarrow \underset{\text { Sodium acetate }}{\mathrm{CH}_{3}-\mathrm{COONa}+\mathrm{H}_{2} \mathrm{O}} \\
\text { Acetic acid } & \text { Any salt }
\end{array}
$$

Acetic acid series. - The monobasic acids derived from the hydrocarbons of the paraffin series which are of especial importance in our study are given below. They are known as the acetic acid series and also as fatty acids as explained later.

\section{Acetic Acid Series}

Formic acid

Acetic acid

Propionic acid

Butyric acid

Valeric acid

Caproic acid

Caprylic acid

Capric acid

Lauric acid

Myristic acid

Palmitic acid

Stearic acid

Arachidic acid
$\mathrm{H}-\mathrm{COOH}$

$\mathrm{CH}_{3}-\mathrm{COOH}$

$\mathrm{CH}_{3}-\mathrm{CH}_{2}-\mathrm{COOH}$

$\mathrm{CH}_{3}-\mathrm{CH}_{2}-\mathrm{CH}_{2}-\mathrm{COOH}$

$\mathrm{C}_{4} \mathrm{H}_{9}-\mathrm{COOH}$

$\mathrm{C}_{5} \mathrm{H}_{11}-\mathrm{COOH}$

$\mathrm{C}_{7} \mathrm{H}_{15}-\mathrm{COOH}$

$\mathrm{C}_{9} \mathrm{H}_{19}-\mathrm{COOH}$

$\mathrm{C}_{11} \mathrm{H}_{23}-\mathrm{COOH}$

$\mathrm{C}_{13} \mathrm{H}_{27}-\mathrm{COOH}$

$\mathrm{C}_{15} \mathrm{H}_{31}-\mathrm{COOH}$

$\mathrm{C}_{17} \mathrm{H}_{35}-\mathrm{COOH}$

$\mathrm{C}_{19} \mathrm{H}_{39}-\mathrm{COOH}$
BoIring PoInT IOI ${ }^{\circ} \mathrm{C}$. $\mathrm{I} 20^{\circ}$

$140.2^{\circ}$

$\mathrm{I} 62.5^{\circ}$ I $86^{\circ}$

$205^{\circ}$

$236^{\circ}$

$270^{\circ}$

Melting Point

$43.6^{\circ}$

$53.8^{\circ}$

$62^{\circ}$

$69.2^{\circ}$

$75^{\circ}$ 
The same general relations in their physical properties exist between the successive members of the acid series as were found in the case of the hydrocarbons, alcohols and other homologous series. The lower members are liquids easily distilled, the intermediate members are heavier, not easily volatile liquids, while the higher members are non-volatile solids. The lower members are soluble in water; the higher members are not soluble in water, but are usually soluble in alcohol.

\section{Formic Acid}

Formic acid is found free naturally in certain ants, bees and nettles. It is a water-like liquid with a very sharp, irritating odor. It produces blisters on the skin. In ants and bees it is used as a poison in killing their prey.

\section{EXPERIMENT STUDY XI}

\section{Formic Acid}

Note. - In testing the action of acids on indicators proceed as follows: (a) Test the acid with blue litmus paper. (b) To r.o c.c. of acid add to c.c. water, and then 2 drops of phenolphthalein solution. Add $\mathrm{KOH}$ or $\mathrm{NaOH}$ drop by drop until the color changes.

(I) Test formic acid for color, odor, action toward litmus and phenolphthalein. (2) Shake up about I.o g. of mercuric oxide with 2 or 3 c.c. of acid plus an equal volume of water. After 5 minutes filter and heat the filtrate in a test tube connected with delivery tube which is immersed in another tube containing a little limewater. What gas is evolved? What is the residue? The reaction is as follows :

$$
\begin{aligned}
& { }_{2} \mathrm{H}-\mathrm{COOH}+\mathrm{HgO} \rightarrow(\mathrm{H}-\mathrm{COO})_{2} \mathrm{Hg}+\mathrm{H}_{2} \mathrm{O} \\
& \text { Formic acid Mercuric formate (soluble) } \\
& 2(\mathrm{H}-\mathrm{COO})_{2} \mathrm{Hg}+\text { heat } \rightarrow 2 \mathrm{H}-\mathrm{COOHg}+\mathrm{CO}_{2}+\mathrm{HC}-\mathrm{OOH} \\
& \text { Mercurous formate (insoluble) } \\
& 2 \mathrm{H}-\mathrm{COOHg}+\text { heat } \rightarrow 2 \mathrm{Hg}+\mathrm{CO}_{2}+\mathrm{H}-\mathrm{COOH}
\end{aligned}
$$

(3) Dilute 2 c.c. formic acid with an equal volume of water. Add a few drops of dilute sulphuric acid. Now heat and add, drop by drop, 
a solution of potassium permanganate. What does the loss of color of the permanganate show? When formic acid is heated to decomposition with dehydrating agents, it breaks up as follows:

$$
\mathrm{H}-(\mathrm{CO}) \mathrm{OH} \rightarrow \mathrm{CO}+\mathrm{H}_{2} \mathrm{O}
$$

In the presence of an oxidizing agent like potassium permanganate this decomposition takes place more easily, the $\mathrm{CO}$ being oxidized to $\mathrm{CO}_{2}$.

\section{Acetic Acid}

Acetic acid in addition to its occurrence in nature in the form of esters is produced on a large scale by the oxidizing fermentation of the alcohol obtained as the result of fermenting fruit juices, especially apple juice or cider. When cider ferments, due to the action of the enzyme zymase, alcohol is produced. This alcohol is then oxidized through the activity of bacterial organisms, acetic acid bacteria, which are present naturally in the fruit juice, and the product is acetic acid.

$$
\begin{array}{ccc}
\text { Sugar }+ \text { Zymase } \rightarrow \text { Alcohol }+\mathrm{CO}_{2} \\
\mathrm{CH}_{3}-\mathrm{CH}_{2} \mathrm{OH}+\mathrm{O}_{2} \rightarrow \mathrm{CH}_{3}-\mathrm{COOH}+\mathrm{H}_{2} \mathrm{O} \\
\text { Alcohol } & \begin{array}{l}
\text { Atmospheric } \\
\text { oxygen }+ \\
\text { bacterial action }
\end{array}
\end{array}
$$

Glacial Acetic Acid. - This form of the acid has the same relation to ordinary acetic acid that absolute alcohol has to ordinary alcohol, i.e. it is Ioo per cent pure. It is obtained from strong acetic acid by fractional distillation. Pure acetic acid crystallizes at $16.7^{\circ}$, and hence its name glacial acetic acid. It is a liquid, boiling point $\mathrm{I} 20^{\circ}$, with a sharp odor and irritating effect upon the skin similar to formic acid, but not so strong. The salts of acetic acid are mostly crystalline compounds, the important ones being those of sodium, potassium, ammonium, calcium, iron, aluminium, copper and lead. The iron and aluminium acetates are used as mordants in dyeing. The copper acetate is a constituent of several insecticides (Paris green, etc.), and the lead acetates are used in medicine. 
When acetic acid or the sodium salt of the acid is heated, especially in the presence of a base such as lime, $\mathrm{Ca}(\mathrm{OH})_{2}$, or sodium hydroxide, $\mathrm{NaOH}$, the acid loses carbon dioxide, $\mathrm{CO}_{2}$, and methane, the hydrocarbon next lower to ethane from which the acetic acid is derived, is formed, as follows:

$$
\underset{\text { Acetic acid }}{\mathrm{CH}_{3}-\mathrm{COOH}} \rightarrow \underset{\text { Methane }}{\mathrm{CH}_{4}}+\mathrm{CO}_{2}
$$

The lime or sodium hydroxide absorbs the carbon dioxide. This reaction is a general one for organic acids by which hydrocarbons are obtained. The hydrocarbon in each case contains one less carbon atom than the acid. This reaction occurs in Experiment II in the preparation of methane.

Vinegar. - Acetic acid produced by the natural fermentation process is known as vinegar. As vinegar may be produced by the acetic fermentation of any alcoholic liquid, it will possess characteristic properties depending upon its source. Naturally this process is slow, the cider being allowed to stand for a long time with access to the air. Industrially the process is much hastened by allowing the weak alcoholic liquid to flow slowly over beechwood shavings which are covered with the acetic bacteria while the whole is kept at a temperature of about $33^{\circ}$, well aërated. These processes all produce a vinegar which contains from about 4.6 per cent (U.S.) to 8.0 per cent (France) of pure acetic acid.

Wood Vinegar. - Acetic acid of greater strength than this is made by the destructive distillation of wood. This process was described under the preparation of methyl alcohol (wood alcohol). The distillate obtained from the wood and known as pyroligneous acid contains about 4 to 8 per cent of pure acetic acid. This is separated from the alcohol, acetone and other substances present by conversion into its metallic salts (calcium, sodium) and the distillation of the alcohol, acetone, etc. The acid is again set free by treatment of the calcium acetate with sulphuric acid and distilling off the acid. In this way acid of about $9 \circ$ per cent is obtained. 


\section{EXPERIMENT STUDY XII}

\section{Acetic Acid and Vinegar}

(I) (a) Cool 5 c.c. of roo per cent acetic acid in running water to at least $15^{\circ} \mathrm{C}$. Note crystallization. (b) Dilute the acid with equal volume of water and cool again. (2) Test the dilute acetic acid for color, odor, taste and action toward indicators. (3) To a little sodium carbonate on a watch glass add a few drops of dilute acetic acid. What causes the effervescence? (4) Test acetic acid as in (2) and (3) Exp. XI. What does this prove as to ease of oxidation of acetic acid? (5) Examine the following salts of acetic acid as to general character and solubility in water: (a) sodium acetate, (b) lead acetate, (c) copper acetate. (6) Examine pyroligneous acid as to general character. Test acidity by means of litmus paper. (7) Test for acetic acid, or its salts. (See Experiment XV.) (8) Examine cider vinegar as to color, odor, taste, acidity. (9):Measure out in a pipette 5.0 c.c. vinegar. Dilute to 50 c.c. Add a few drops of phenolphthalein. Now add from pipette, carefully, with stirring, $\mathrm{N} /$ Io $\mathrm{NaOH}$ until color changes. Calculate acidity of vinegar. I c.c. $\mathrm{N} /$ ro $\mathrm{NaOH}$ is equivalent to $.006 \mathrm{~g}$. $\mathrm{CH}_{3}-\mathrm{COOH}$.

\section{POLYCARBOXY ACIDS (POLYBASIC ACIDS)}

Primary alcohols on oxidation yield aldehydes and acids. A dihydroxy alcohol, therefore, should yield a dicarboxy acid, provided both hydroxyl groups are in a $\left(-\mathrm{CH}_{2} \mathrm{OH}\right)$ grouping for this only yields the carboxyl group on oxidation. These polycarboxy acids possess polyacid properties depending upon the number of carboxyl hydrogens present. They are termed polybasic because they react with more than one molecule of a monoacid base, e.g NaOH. They are analogous to the polybasic inorganic acids, e.g. sulphuric acid,

$\mathrm{H}_{2} \mathrm{SO}_{4}$ or $\mathrm{O}_{2} \mathrm{~S}\left\langle\frac{\mathrm{OH}}{\mathrm{OH}}\right.$ and phosphoric acid, $\mathrm{H}_{3} \mathrm{PO}_{4}$ or $\mathrm{OP} \underset{\mathrm{OH}}{-} \stackrel{\mathrm{OH}}{-\mathrm{OH}}$

Two dibasic acids are common and more or less widely distributed in nature. 


\section{Oxalic Acid}

Oxalic acid occurs free in certain plants such as sorrel and in combination as calcium salts in the leaves and roots or tubers of others (such as jack-in-the-pulpit, elephant ears, etc.) and in animal urine.

Oxalic acid is the dicarboxy derivative of ethane, corresponding to acetic acid, the monocarboxy acid derived from ethane.

\section{$\mathrm{CH}_{3}-\mathrm{CH}_{3} \rightarrow \mathrm{CH}_{3}-\mathrm{COOH} \rightarrow \mathrm{COOH}-\mathrm{COOH}$ \\ Ethane \\ Acetic acid \\ Oxalic acid}

Oxalic acid is, therefore, simply dicarboxyl, and is the simplest representative of the polybasic acids. When oxalic acid is heated, it reacts as acetic acid does, it loses $\mathrm{CO}_{2}$. Acetic acid by such loss of $\mathrm{CO}_{2}$ yields methane while by loss of $\mathrm{CO}_{2}$ oxalic acid yields formic acid, our simplest monobasic acid.

$$
\underset{\text { Acetic acid }}{\mathrm{CH}_{3}-\mathrm{COOH}} \rightarrow \underset{\text { Methane }}{\mathrm{CH}_{3}-\mathrm{H}}+\mathrm{CO}_{2}
$$$$
\mathrm{COOH}-\mathrm{COOH} \rightarrow \mathrm{H}-\mathrm{COOH}+\mathrm{CO}_{2}
$$

Oxalic acid

Formic acid

Now formic acid when heated with dehydrating agents yields $\mathrm{CO}+\mathrm{H}_{2} \mathrm{O}$

$$
\underset{\text { Formic acid }}{\mathrm{H}-\mathrm{COOH}} \rightarrow \mathrm{H}_{2} \mathrm{O}+\mathrm{CO}
$$

Therefore the decomposition of oxalic acid when similarly heated may be represented by the double reaction:

$$
\underset{\text { Oxalic acid }}{\mathrm{COOH}-\mathrm{COOH} \rightarrow \underset{\text { Formic acid Carbon monoxide }}{\mathrm{H}}-\mathrm{COOH} \rightarrow \mathrm{CO}+\mathrm{H}_{2} \mathrm{O}}
$$

Oxalic acid is a poison and it is possible that this action is due to decomposition in the body similar to this decomposition by heat, thus forming carbon monoxide, which is a poison. 


\section{EXPERIMENT STUDY XIII}

\section{Oxalic Acid (Poison)}

(I) (a) Examine oxalic acid as to its nature and solubility in water. (b) Add a little oxalic acid to limewater and note precipitate of calcium oxalate. (c) Fit up a test tube for generating gas and collecting over water. Heat $5 \mathrm{~g}$. of oxalic acid and sulphuric acid in the test tube and collect two small bottles or tubes of the gas. To one introduce by means of a bent tube some $\mathrm{NaOH}$. What gas is absorbed? Now remove tube and test remainder with lighted match. What gas is proven here?

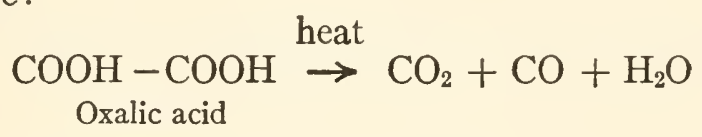

(2) Dissolve a few crystals of oxalic acid in water. To this solution of oxalic acid add drop by drop a solution of potassium permanganate, $\mathrm{KMnO}_{4}$, to which two or three drops of sulphuric acid have been added. The loss of color shows that the permanganate is reduced by the oxalic acid. The oxalic acid is oxidized, yielding $\mathrm{CO}_{2}+\mathrm{H}_{2} \mathrm{O}$. Compare with the preceding reaction and with Exp. XI, 3.

\section{Succinic Acid}

Succinic acid occurs naturally in amber. Derivatives of it are important in animal physiology and also as tartaric and malic acids. Its formula is

\section{$\mathrm{CH}_{2} \mathrm{COOH}$ $\mathrm{CH}_{2} \mathrm{COOH}$}

It is the symmetrical dicarboxy derivative of butane. 


\section{CHAPTER I V}

\section{DERIVATIVES OF ALCOHOLS ANDACIDS}

\section{ETHERS}

Ethyl Ether. - One derivative of alcohol should be briefly mentioned, as it is such an important compound though not related to agriculture. This is ordinary ether or ethyl ether. It is one of the two most common anæsthetics, chloroform having already been mentioned as the other.

When alcohol is treated with sulphuric acid in a particular way, ether is obtained by the loss of one molecule of water from two molecules of the alcohol, and its constitution has been proven to bear the relation to alcohol that sodium oxide does to sodium hydroxide.

$$
\begin{aligned}
& 2 \mathrm{Na}-\mathrm{OH} \rightarrow \mathrm{Na}_{2} \mathrm{O}+\mathrm{H}_{2} \mathrm{O} \\
& \text { Sodium hydroxide Sodium } \\
& \text { oxide } \\
& { }_{2} \mathrm{C}_{2} \mathrm{H}_{5}-\mathrm{OH} \rightarrow\left(\mathrm{C}_{2} \mathrm{H}_{5}\right)_{2} \mathrm{O}+\mathrm{H}_{2} \mathrm{O} \\
& \text { Alcohol } \\
& \text { (ethyl hydroxide) (ethyl oxide) }
\end{aligned}
$$

Ether is a very volatile, limpid, clear liquid with suffocating odor. It boils at $34.6^{\circ} \mathrm{C}$., is very inflammable, and mixtures of air and ether vapor are explosive. It is lighter than water and does not mix with it. It is a good solvent of fats, oils, waxes, resins, chlorophyll and many other plant constituents. It has been shown to possess certain stimulating effects upon the germination of seeds and the growth of plants.

Ether is typical of a whole group of compounds known as ethers, all of which have the constitution of oxides of hydrocarbon radicals with the general formula $\mathrm{R}_{2} \mathrm{O}$, in which the two radicals may be alike or different. None of the other ethers needs further mention. 


\section{EXPERIMENT STUDY XIV}

\section{ETHER}

Caution. Ether is very inflammable and should be kept away from all flames.

(I) (a) Heat some water in a beaker to about $50^{\circ} \mathrm{C}$. Place Io c.c. of ether in a test tube, and hold the thermometer in the tube with the bulb just touching the ether. Place the test tube in the warm water until the ether boils. Note temperature. B. P. $=34.6^{\circ} \mathrm{C}$. (b) Pour about I c.c. of ether upon the hand. Note the effect. Explain. (c) Pour not over I c.c. of ether into a watch glass. Bring flame to the ether. Note ease of ignition.

(2) Observe the general character of ether and test solvent power upon (a) sodium chloride, $(b)$ sugar, $(c)$ shellac, $(d)$ lard, (e) cottonseed oil.

(3) Make the following mixtures: $(a)$ water 5.0 c.c. + ether 5.0 c.c. (b) Alcohol 5.0 c.c. + ether 5.0 c.c. To (b) add 5.0 c.c. water and explain result.

\section{ACID CHLORIDES AND ACID AMIDES}

These two groups of acid derivatives need be only briefly mentioned. When an acid is treated with phosphorus pentachloride, $\mathrm{PCl}_{5}$, or with the tri-chloride, $\mathrm{PCl}_{3}$, the hydroxyl group of the acid is replaced by chlorine and a compound known as an acid chloride is obtained. The reaction is :

$$
\underset{\text { Acetic acid }}{\mathrm{CH}_{3}-\mathrm{COOH}}+\mathrm{PCl}_{5} \rightarrow \underset{\begin{array}{c}
\text { Acetyl chloride } \\
\text { (an acid chloride) }
\end{array}}{\mathrm{CH}_{3}-\mathrm{COCl}}+\mathrm{POCl}_{3}+\mathrm{HCl}
$$

When an acid chloride is treated with ammonia, the chlorine is replaced by the amine group and an acid amide results:

$$
\underset{\text { Acetyl chloride }}{\mathrm{CH}_{3}-\mathrm{COCl}}+\mathrm{NH}_{3} \rightarrow \underset{\text { Acet-amide }}{\mathrm{CH}_{3}-\mathrm{CONH}_{2}}+\mathrm{HCl}
$$

The acid amides differ from the amines in that in the latter the amine group has been substituted for a hydrogen atom of a hydrocarbon while in the former the amine group replaces a hydroxyl group of an acid carboxyl.

$\mathrm{R}-\mathrm{NH}_{2}$

Amine
$\mathrm{R}-\mathrm{CONH}_{2}$

Acid amide 


\section{ESTERS OR ETHEREAL SALTS}

\section{Simple Esters}

The acids, with the exception of formic acid, do not usually occur free in nature, but are present in combination as a particular kind of salt known as an ester or ethereal salt. When an acid is neutralized by a base, a salt is formed by the hydroxyl hydrogen of the acid being replaced by the metal of the base, as follows :

$$
\left.\underset{\text { Acetic acid }}{\mathrm{CH}_{3}-\mathrm{COO}(\mathrm{H}}+\mathrm{HO}\right) \mathrm{K} \rightarrow \underset{\text { Potassium acetate }}{\mathrm{CH}_{3}-\mathrm{COOK}}+\mathrm{H}_{2} \mathrm{O}
$$

Now alcohols, which in general are neutral substances, when brought in contact with acids act like bases and neutralize the acid. The hydroxyl hydrogen of the acid is replaced by the radical of the alcohol and the resulting compound is termed an ester or ethereal salt.

\section{$\mathrm{CH}_{3}-\mathrm{COO}(\mathrm{H}+\mathrm{HO}) \mathrm{C}_{2} \mathrm{H}_{5} \rightarrow \mathrm{CH}_{3}-\mathrm{COOC}_{2} \mathrm{H}_{5}+\mathrm{H}_{2} \mathrm{O}$ \\ Acetic acid \\ Ethyl \\ Ethyl acetate}

These esters are exactly analogous to the metallic salts, the organic radical taking the place of the metal. They are named like the metallic salts, viz. the radical name joined to that of the acid with the termination ic changed to ate. Ethyl acetate is the ethereal salt of the ethyl radical and acetic acid made by neutralizing acetic acid with ethyl alcohol. Similarly methyl formate is the methyl salt of formic acid, amyl valerate is the amyl salt of valeric acid, etc. The importance of esters is in the fact that they occur very widely distributed in nature in plants, fruits and flowers, and as oils, fats and waxes. Esters of the lower acids and lower alcohols are pleasant-smelling, volatile liquids (hence the name ethereal salts). They are not usually miscible with water, though often slightly soluble in it. The higher members are crystalline solids.

Fruit Flavors. - While it is probably a fact that the odor of fruits is due to the presence of esters, it is not fully established, 
as they are present in exceedingly small amounts. Esters that have been prepared synthetically from some of the middle members of the acid and alcohol series do, however, possess the odors of certain fruits, and on that account are prepared and used as artificial fruit flavors or fruit essences. Some of these are as follows :
Ethyl butyrate, Pineapple essence;
Iso-amyl-iso valerate, Apple essence;
Amyl butyrate, Apricot essence;
Iso-amyl-acetate, Pear essence;
etc.

\section{Fats, Oils and Waxes}

These important plant and animal substances are all true esters of alcohols and organic acids.

Waxes. - The waxes are esters of monohydroxy alcohols, similar to ethyl alcohol but containing a larger number of carbon atoms. Beeswax, for example, is composed mostly of the ester of myricyl alcohol, $\mathrm{C}_{30} \mathrm{H}_{61} \mathrm{OH}$, and palmitic acid, $\mathrm{C}_{15} \mathrm{H}_{31} \mathrm{COOH}$, i.e. myricyl palmitate, $\mathrm{C}_{15} \mathrm{H}_{31} \mathrm{COOC}_{30} \mathrm{H}_{61}$. Spermaceti, a wax obtained from the head of the sperm whale, is mostly the ester of cetyl alcohol, $\mathrm{C}_{16} \mathrm{H}_{33} \mathrm{OH}$, and palmitic acid, i.e. cetyl palmitate, $\mathrm{C}_{15} \mathrm{H}_{31} \mathrm{COOC}_{16} \mathrm{H}_{33}$.

Fats and Oils. - The fats and oils of vegetable or animal origin are true fats and oils as distinguished from numerous compounds commonly termed oils, e.g. petroleum oil, oil of turpentine, oil of bitter almonds, etc. They are composed of mixtures of esters of the trihydroxy alcohol, glycerol and numerous acids, mostly the monobasic acids of the paraffin series of hydrocarbons, which have been given previously. The acids which are most common as constituents of fats and oils are, butyric, capric, lauric, myristic, palmitic, stearic and arachidic. This explains the designation of this series of acids as the fatty acids. The names given to these acids indicate their natural source in plants or animals: 
Butyric acid in butter,

Capric acid in goat milk fat,

Lauric acid in laurel fat,

Palmitic acid in palm oil,

Arachidic acid in peanut oil,

etc.

Glycerol esters. - Glycerol being a trihydroxy alcohol will react with three molecules of a monobasic acid to form an ester. An example may be given of the ester formed from butyric acid, $\mathrm{C}_{3} \mathrm{H}_{7} \mathrm{COOH}$, and glycerol, $\mathrm{C}_{3} \mathrm{H}_{5}(\mathrm{OH})_{3}$.

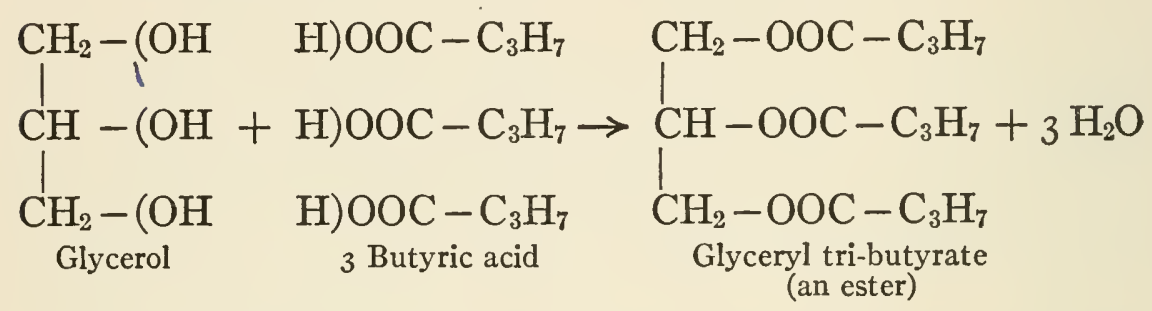

Before considering in further detail the more important vegetable and animal fats, we shall discuss the most important reactions connected with them.

Esterification. - When an alcohol neutralizes an acid, thereby forming an ester, the process is termed esterification.

$\mathrm{CH}_{3}-\mathrm{COO}(\mathrm{H}+\mathrm{HO})-\mathrm{C}_{2} \mathrm{H}_{5} \rightarrow \mathrm{CH}_{3}-\mathrm{COO}-\mathrm{C}_{2} \mathrm{H}_{5}+\mathrm{H}_{2} \mathrm{O}$, esterification Acetic acid Ethyl alcohol Ethyl acetate

In this process water is always lost. This reaction, as written above, does not take place in a satisfactory way unless some other reagent like sulphuric acid is present to remove the water which is the other product of the reaction. If the water is not removed, the reaction soon begins to reverse itself, and the ester by taking up water is split into the alcohol and acid originally used. We express these facts by saying that the reaction is reversible and writing it in this way:

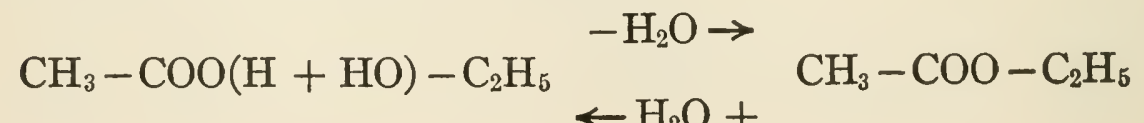


The general reaction of esterification or ethereal salt formation is one of the best examples we have of reversible reactions. By modifying conditions many esterification reactions can be made to go in the reverse way.

On the other hand an ester when boiled with water will take up water and be resolved into its constituent acid and alcohol. This reaction, like that of esterification, does not proceed to completion because as soon as some free acid and alcohol are formed they begin to react in the reverse way and re-form the ester. If, however, some alkali is present to react with the free acid as fast as it is formed, then the decomposition of the ester goes on to completion.

Thus, in esterification, a water absorbing substance must be present and in the decomposition of esters alkali must be present. The reaction in both cases is, however, due to water, i.e. loss of water in esterification and addition of water in the decomposition of the ester.

$$
\begin{aligned}
& \mathrm{CH}_{3}-\mathrm{COO}-(\mathrm{H}+\mathrm{HO})-\mathrm{C}_{2} \mathrm{H}_{5}+\left(\mathrm{H}_{2} \mathrm{SO}_{4}\right) \stackrel{-\mathrm{H}_{2} \mathrm{O}}{\rightarrow} \underset{\mathrm{C}}{\mathrm{C}} \mathrm{H}_{3}-\mathrm{COO}-\mathrm{C}_{2} \mathrm{H}_{5} \\
& \text { Esterification } \\
& +\mathrm{H}_{2} \mathrm{O} \\
& \mathrm{CH}_{3}-\mathrm{COO}-\mathrm{C}_{2} \mathrm{H}_{5}+(\mathrm{KOH}) \rightarrow \mathrm{CH}_{3}-\mathrm{COOH}+\mathrm{HO}-\mathrm{C}_{2} \mathrm{H}_{5}
\end{aligned}
$$

Hydrolysis. - The second reaction, the decomposition of the ester, because it involves the addition of water, is termed hydrolysis. Hydrolysis and esterification are, therefore, respective names for the two forms of this reversible reaction. We have used as our illustration one of the simple esters, viz. ethyl acetate. All esters, however, are subject to these same generalizations.

The esters of glycerol and the fatty acids, i.e. the fats and oils, undergo the reaction of hydrolysis when boiled with water containing an alkali. When the hydrolysis occurs, the alcohol (glycerol) and the acid (butyric, palmitic, stearic, etc.) are re-formed. The glycerol remains free, but the acid reacts 
further with the alkali present and the metal salt of the acid is formed.

Soap. - The sodium and potassium salts of some of the fatty acids, chiefly palmitic and stearic, form the common substance we know as soap. Thus when a fat is boiled with dilute alkali, soap and glycerol are the products.

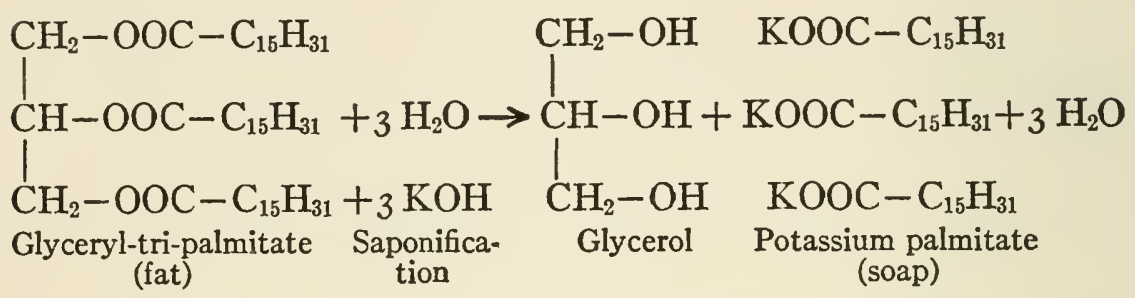

Saponification. - Such an hydrolysis of a fat is therefore termed an action of saponification or soap formation. The saponification of esters is thus a particular form of hydrolysis, viz. in the presence of an alkali, and any alkaline hydrolysis of an ester is termed saponification even though the product is not, strictly speaking, a soap. Its particular importance in our study is in connection with the saponification of the animal and vegetable fats and oils. Industrially this is in the utilization of fats in the manufacture of soap and glycerol. Physiologically it is in connection with the digestion of fats in the animal body which will be considered again in detail when we study animal digestion.

Important Fats and Oils. - Fats differ from oils simply in their physical properties, the former being solid at ordinary temperature, while the latter are liquid. Chemically they are of identical nature, being glycerol esters of the fatty acids, differing from the waxes which are esters of monohydroxy alcohols and fatty acids. They are not chemical individuals, but are mixtures of several, oftentimes many, glycerol esters. Individual fats and oils are characterized by the particular acids present and by their relative proportions. The identification and analysis of fats and oils is by the determination of the physical properties of the fats themselves and of certain 
chemical constants depending upon the amounts of the different acids present.

Physical Constants. - The esters of the different acids have distinctive properties such as melting point, specific gravity, refractive index, etc. The relative amounts of the different esters present give to the fats these definite characters which are termed the physical constants. For example, fats containing large amounts of palmitic or stearic acid esters are solid at ordinary temperatures, as in beef fat, mutton tallow, palm oil, etc. Those containing large amounts of the esters of oleic acid, or linolic acid, eighteen carbon acids of a new series, are liquids as in olive oil, cottonseed oil and linseed oil. Such fats as human fat and butter fat lie between these two extremes.

Chemical Constants. - Oleic acid, linolic acid and linolenic acid not only form esters that are liquid but the acids themselves possess distinct chemical properties which they impart to the esters. They all belong to series of acids differing from the acetic acid series in that while the latter are saturated the former are unsaturated. They are related to unsaturated hydrocarbons like ethylene, which has been referred to in connection with ethylene bromide or symmetrical dibrom ethane. These hydrocarbons, acids and fats containing esters of the latter, all show their property of unsaturation by readily taking up bromine or iodine by addition. The amount of iodine, therefore, which a fat absorbs by addition rests upon the amount of the esters of these acids present. This gives us a chemical constant termed the iodine value by which fats are identified.

Other chemical constants known as saponification value, amount of insoluble acids and amount of volatile acids all depend upon the amount of particular groups of acids combined in the fat, and are used, together with the iodine value and the physical constants already mentioned, for purposes of identification and analysis. This brief mention of the basis of analytical methods applying to fats and oils is all that is is desirable to make.

In connection with plant constituents (p. 278) we shall consider the important vegetable oils as to their occurrence and use. 
The following table of the more important animal and vegetable fats and oils gives their melting points and the esters present.

\section{TABLE II}

Important Fats, Oils and Waxes

\begin{tabular}{|c|c|c|}
\hline & $\begin{array}{l}\text { Melting Point or } \\
\text { Solidifying Point } \\
\text { DEGRE C. }\end{array}$ & Acids of the Princtpal Esters Present \\
\hline Oils & & \\
\hline Olive . . . & $+4^{\circ}$ to $-6^{\circ}$ & Oleic, Palmitic, Arachidic, Linolic \\
\hline Peanut . . & $-5^{\circ}$ & Arachidic, Palmitic, Oleic, Linolic \\
\hline Cottonseed & $+\mathrm{I}^{\circ}$ to $+10^{\circ}$ & Oleic, Palmitic, Linolic \\
\hline Maize . . . & $-10^{\circ}$ to $-20^{\circ}$ & Palmitic, Stearic, Arachidic, Oleic, Linolic \\
\hline Linseed (Flax) & $-20^{\circ}$ to $-27^{\circ}$ & Linolic, Iinolenic, Palmitic, Oleic \\
\hline $\begin{array}{l}\text { Castor . . } \\
\text { Fats }\end{array}$ & $-18^{\circ}$ & Stearic, Ricinoleic \\
\hline Palm . . & $+27^{\circ}$ to $+42^{\circ}$ & Palmitic, Oleic \\
\hline Cacao-butter . & $+30^{\circ}$ to $+34^{\circ}$ & Stearic, Palmitic, Oleic, Lauric, Arachidic \\
\hline Cocoanut . . & $+20^{\circ}$ to $+28^{\circ}$ & Caproic, Capyrlic, Capric, Lauric, Palmitic \\
\hline Laurel . . & $+32^{\circ}$ to $+36^{\circ}$ & Lauric \\
\hline Tallow (Beef) & $+36^{\circ}$ to $+49^{\circ}$ & Palmitic, Stearic, Oleic \\
\hline Lard. . . & $+28^{\circ}$ to $+45^{\circ}$ & Palmitic, Stearic, Oleic \\
\hline $\begin{array}{l}\text { Milk Fat } \\
\text { (Butter) }\end{array}$ & $+29^{\circ}$ to $+35^{\circ}$ & $\begin{array}{l}\text { Butyric, Caproic, Caprylic, Capric, Myris- } \\
\text { tic, Palmitic, Stearic, Oleic }\end{array}$ \\
\hline Human Fat & & $\begin{array}{l}\text { Caprylic, Palmitic, Stearic, Oleic, Butyric, } \\
\text { Caproic }\end{array}$ \\
\hline Waxes & & \\
\hline Spermaceti & $+43^{\circ}$ to $+49^{\circ}$ & Palmitic (Cetyl Alcohol Ester) \\
\hline Beeswax . & $+62^{\circ}$ to $69^{\circ}$ & Cerotic, Palmitic (Myricyl Alcohol Esters) \\
\hline
\end{tabular}

\section{EXPERIMENT STUDY XV}

\section{Esters or Ethereal Salts}

(I) Esterification. Test for acetic acid or its salts. (a) To 5 c.c. of Io per cent acetic acid add an equal volume of ethyl alcohol. Note odor of mixture. Now add about I c.c. of sulphuric acid, shake carefully and warm. Note odor now and compare with the odor of the mixture of acid and alcohol. The fruity odor is due to the formation of the ester ethyl acetate as in the reaction: 


$$
\underset{\text { Acetic acid }}{\mathrm{CH}_{3}-\mathrm{COO}(\mathrm{H}}+\underset{\text { alcohol }}{\mathrm{HO})-\mathrm{C}_{2} \mathrm{H}_{5}} \rightarrow \underset{\text { Ethyl }}{\mathrm{CH}_{3}-\mathrm{COO}-\mathrm{C}_{2} \mathrm{H}_{5}}+\mathrm{H}_{2} \mathrm{O}
$$

The sulphuric acid brings about the loss of the water in the above reaction. (b) To a little of any salt of acetic acid, e.g. sodium acetate, add a little dilute alcohol and then I c.c. of sulphuric acid. Warm and note odor of ethyl acetate. The sulphuric acid first reacts with the salt of acetic acid, forming free acetic acid.

\section{$\mathrm{CH}_{3}-\mathrm{COONa}+\mathrm{HOSO}_{2} \mathrm{OH} \rightarrow \mathrm{CH}_{3}-\mathrm{COOH}+\mathrm{NaOSO}_{2} \mathrm{OH}$ Sodium acetate \\ Acetic acid}

The free acetic acid then reacts with the alcohol in the presence of sulphuric acid and forms the ester.

(2) Hydrolysis. (a) Place Io g. ethyl acetate $\left(\mathrm{CH}_{3} \mathrm{COOC}_{2} \mathrm{H}_{5}\right)$, in a flask and add roo c.c. of so per cent sodium or potassium hydroxide. Connect with a return condenser and boil until no odor of ethyl acetate is noticeable. Change the condenser and distill off about 25 c.c. -50 c.c. Test the distillate for ethyl alcohol as in Experiment VII, 4.

(b) Place the remainder of the solution in the flask in an evaporating dish. Carefully neutralize excess of alkali with hydrochloric acid, avoiding excess of acid by testing with litmus paper. Evaporate to dryness. Test the dry salt for acetates as in (I), $b$. The reactions involved are:

$$
\begin{aligned}
& \mathrm{CH}_{3}-\mathrm{COO}-\mathrm{C}_{2} \mathrm{H}_{5}+\mathrm{KOH} \rightarrow \mathrm{CH}_{3}-\mathrm{COOK}+\mathrm{C}_{2} \mathrm{H}_{5} \mathrm{OH} \\
& \text { Ethyl acetate } \quad \text { Potassium Alcohol }{ }_{j} \\
& \text { acetate } \\
& \mathrm{CH}_{3}-\mathrm{COOK}+\mathrm{H}_{2} \mathrm{SO}_{4} \rightarrow \mathrm{CH}_{3}-\mathrm{COOH}+\mathrm{KHSO}_{4} \\
& \text { Acetic acid } \\
& \mathrm{CH}_{3}-\mathrm{COOH}+\mathrm{HO}-\mathrm{C}_{2} \mathrm{H}_{5} \rightarrow \mathrm{CH}_{3}-\mathrm{COO}-\mathrm{C}_{2} \mathrm{H}_{5}
\end{aligned}
$$

\section{EXPERIMENT STUDY XVI}

\section{Fats and Soap}

(I) Saponification of a Fat. (a) Use Io g. of lard, tallow, cottonseed oil or olive oil. Place in an evaporating dish and add 200 c.c. of 5 per cent $\mathrm{NaOH}$. Heat on water bath until all melted fat has disappeared. Continue to heat until the liquid has evaporated; or 
without evaporating add about $50 \mathrm{~g}$. of common salt, $\mathrm{NaCl}$, and stir thoroughly. The addition of salt causes the soap to separate as a solid layer. (b) Test the residue or the separated cake for its soapy character. (c) Dissolve some of the soap in water and add sulphuric acid until the solution is distinctly acid. The solid separating is the free acid originally combined with the glycerol as an ester in the fat. The reactions are as follows:

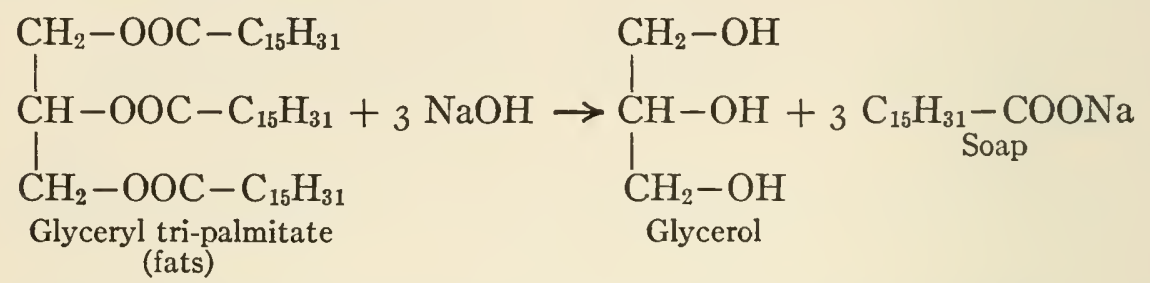

$$
\underset{\text { Soap }}{\mathrm{C}_{15} \mathrm{H}_{31}-\mathrm{COONa}}+\mathrm{H}_{2} \mathrm{SO}_{4}
$$$$
\underset{\text { Palmitic acid }}{\mathrm{C}_{15} \mathrm{H}_{31}-\mathrm{COOH}}+\mathrm{NaHSO}_{4}
$$

(2) Properties of Fats and Soap. (a) Mix 5 c.c. of oil or melted fat with an equal volume of water. Shake and then allow to settle. Explain. (b) Place two filter papers in two funnels. Keep one perfectly dry and moisten one with water. Pour Io c.c. of oil or melted fat upon each paper. Explain. (c) Mix 5 c.c. of oil with an equal volume of soap solution. Shake and allow to stand a few minutes. This mixture is called an emulsion. Filter this emulsion through a wet filter paper. Explain.

(3) Hard Water. (a) Place Io c.c. of limewater, $\mathrm{Ca}(\mathrm{OH})_{2}$, in a test tube. With a glass tube blow your exhaled breath through the limewater. What is the precipitate which forms? Continue to blow through the solution until the precipitate first formed dissolves. What compound is now present in solution? Take one-half of this solution of calcium acid carbonate and boil thoroughly. Explain. Filter or decant off the clear liquid. Boil again to be sure all carbonate has been precipitated. The reactions are as follows:

$$
\begin{aligned}
\mathrm{Ca}(\mathrm{OH})_{2}+\mathrm{CO}_{2} \rightarrow & \mathrm{CaCO}_{3}+\mathrm{H}_{2} \mathrm{O} \\
& \text { Calcium carbonate (insoluble) } \\
\mathrm{CaCO}_{3}+\mathrm{CO}_{2}+\mathrm{H}_{2} \mathrm{O} \rightarrow & \mathrm{Ca}\left(\mathrm{HCO}_{3}\right)_{2} \\
& \text { Calcium acid carbonate (soluble) } \\
\mathrm{Ca}\left(\mathrm{HCO}_{3}\right)_{2}+\text { heat } \rightarrow & \mathrm{CaCO}_{3}+\mathrm{CO}_{2}+\mathrm{H}_{2} \mathrm{O}
\end{aligned}
$$


(b) Add an equal volume of soap solution to the unboiled acid carbonate solution and to the filtrate from the portion that was boiled. Notice the difference. The precipitate formed with the soap and acid carbonate solution is the calcium salt of palmitic or other fatty acid. Water containing calcium acid carbonate in solution is termed hard. This hardness is termed temporary because it is destroyed by boiling and precipitating out the calcium. (c) Test solutions of magnesium sulphate and calcium sulphate in the same way with soap solution without boiling and after boiling. Is there any change in the boiled solution? Water containing these salts in solution is termed permanently hard. 


\section{CHAPTER V}

\section{MIXED C O M P U N D S}

WE have considered polysubstitution products formed by substituting in a hydrocarbon more than one element or group of the same kind.

Similarly there may be substituted in a hydrocarbon two elements or groups, one of one kind and one of another. That is, we may have a halogen and hydroxyl, a hydroxyl and carboxyl, an amine group and carboxyl, etc. We shall mention only a few of the different known compounds of this general class.

\section{HALOGEN-ALDELHYDES AND HALOGEN-ACIDS Halogen-aldehydes}

Tri-chlor-aldehyde. - The mixed halogen and hydroxy compounds are not important here, but the group represented by halogen-aldehydes has an important member.

When chloroform is prepared from alcohol by the action of chlorine, the chlorine first oxidizes the alcohol to aldehyde as follows :

$$
\underset{\text { Ethyl alcohol }}{\mathrm{CH}_{3}-\mathrm{CH}_{2}-\mathrm{OH}}+\mathrm{Cl}_{2}+\mathrm{H}_{2} \mathrm{O} \rightarrow \underset{\text { Acetaldehyde }}{\mathrm{CH}_{3}-\mathrm{C}=\stackrel{\mathrm{H}}{\mathrm{O}}}+\mathrm{H}_{2} \mathrm{O}+2 \mathrm{HCl}
$$

The chlorine then acts upon the aldehyde and is substituted for all three hydrogen atoms of the methyl group.

$$
\begin{aligned}
& \mathrm{CH}_{3}-\mathrm{CHO}+{ }_{3} \mathrm{Cl}_{2} \rightarrow \mathrm{CCl}_{3}-\mathrm{C}=\stackrel{\mathrm{H}}{\mathrm{O}}+{ }_{3} \mathrm{HCl} \\
& \text { Acetaldehyde } \\
& \text { Tri-chlor-aldehyde (chloral) }
\end{aligned}
$$


The product is chloral, an oily liquid boiling at $97^{\circ} \mathrm{C}$. When boiled with alkalies, it breaks down and yields chloroform. It possesses the characteristic property of uniting with water, forming a crystalline compound known as chloral hydrate $\mathrm{CCl}_{3}-\mathrm{CHO} \cdot \mathrm{H}_{2} \mathrm{O}$. The evidence seems to point to the conclusion that in chloral hydrate we have a compound of the constitution, not of an aldehyde, but of a dihydroxy compound, viz. $\mathrm{CCl}_{3}-\mathrm{CH}(\mathrm{OH})_{2}$. This is a marked exception to the general fact before referred to, that compounds containing two hydroxyl groups united to one carbon do not exist.

Chloral hydrate forms clear monoclinic prisms melting at $57^{\circ} \mathrm{C}$. It is a very valuable and commonly used soporific and anæsthetic.

\section{Halogen-acids}

Chlor-acetic Acids. - As illustrations simply of the halogenacids we may mention the halogen substitution products of acetic acid formed by introducing first one, then two, and finally three chlorine atoms in acetic acid.

\footnotetext{
$\mathrm{CH}_{3}-\mathrm{COOH}+\mathrm{Cl}_{2} \rightarrow \mathrm{CH}_{2} \mathrm{Cl}-\mathrm{COOH}+\mathrm{HCl}$ Acetic acid Mono-chlor-acetic acid

$\mathrm{CH}_{2} \mathrm{Cl}-\mathrm{COOH}+\mathrm{Cl}_{2} \rightarrow \mathrm{CHCl}_{2}-\mathrm{COOH}+\mathrm{HCl}$

Di-chlor-acetic acid

$\mathrm{CHCl}_{2}-\mathrm{COOH}+\mathrm{Cl}_{2} \rightarrow \mathrm{CCl}_{3}-\mathrm{COOH}+\mathrm{HCl}$

Tri-chlor-acetic acid
}

This reaction takes place with chlorine alone in the direct sunlight or by means of iodine tri-chloride, $\mathrm{ICl}_{3}$, without sunlight. These three compounds have been of the greatest importance in establishing our ideas of substitution. All of these substituted acetic acids are strongly acid, even more so than acetic acid itself.

\section{HYDROXY-ACIDS}

The polysubstitution products in which both hydroxyl and carboxyl groups are present contain some very important compounds which have direct connection with agriculture. All of 
the mixed compounds are characterized by possessing properties distinctive of both classes of compounds represented. The hydroxy-acids possess the characteristic properties both of the alcohols and the acids. Because alcohols react toward strong bases as acids it was at first supposed that these hydroxy-acids were dibasic. They are not, however, dibasic unless they at the same time contain two carboxyl groups.

\section{Lactic Acid}

The simplest acid of this group of importance to us is the hydroxy-propionic acid, $\mathrm{CH}_{3}-\mathrm{CH}(\mathrm{OH})-\mathrm{COOH}$. It is the common acid produced by the souring of milk and known as lactic acid.

By methods of synthesis, which it will not be necessary to enter into, lactic acid has been clearly proven to have the constitution of hydroxy-propionic acid as given above. It is a fact, however, that another acid known as hydracrylic acid also has the constitution of hydroxy-propionic acid. According to our ideas of isomerism the existence of these two isomeric acids is readily explained. Two positions are possible in which we may substitute the hydroxyl group in propionic acid.

Propionic acid is $\mathrm{CH}_{3}-\mathrm{CH}_{2}-\mathrm{COOH}$ and we might obtain either

$$
\begin{array}{cc}
\mathrm{CH}_{3}-\mathrm{CH}(\mathrm{OH})-\mathrm{COOH} & \text { or } \mathrm{CH}_{2}(\mathrm{OH})-\mathrm{CH}_{2}-\mathrm{COOH} \\
\alpha \text {-hydroxy-propionic acid } & \beta \text {-hydroxy-propionic acid }
\end{array}
$$

These two compounds are distinguished as $\alpha$-hydroxy-propionic acid, in which the hydroxyl group is united to the carbon atom next to the carboxyl group, and $\beta$-hydroxy-propionic acid, in which the hydroxyl is united to the carbon atom second from the carboxyl group. By reactions which leave no doubt it has been shown that hydracrylic acid is the $\beta$-compound and lactic acid is the $\alpha$-compound.

The $\beta$-hydroxy-propionic acid or hydracrylic acid we need not discuss further. Lactic acid, however, possesses properties which need further explanation and which bring us to the con- 
sideration of one of the most striking phenomena of organic chemistry.

\section{Stereo-isomerism or Space-isomerism}

Not only are there known the two structurally isomeric hydroxy-propionic acids which are explained as just described, but there are also known two other acids which are likewise hydroxy-propionic acids and furthermore which are structurally identical with lactic acid, i.e. $\alpha$-hydroxy-propionic acid.

When milk sours, the sugar contained in the milk is converted by means of bacterial organisms into lactic acid or, as it is further distinguished, lactic acid of fermentation or sour milk lactic acid. This acid is inactive toward polarized light. In the flesh of animals another lactic acid has been found which, as just stated, is also $\boldsymbol{\alpha}$-hydroxy-propionic acid or a true lactic acid. This acid, however, possesses the characteristic property of activity toward polarized light and turns the plane of polarization to the right, or as it is termed, it is dextro-rotatory. Also when the lactic acid of sour milk which is inactive toward polarized light is treated in a definite way (conversion of it into its strychnine salt) it has been split into two different lactic acids, one of which is active and dextro-rotatory identical with lactic acid from flesh, and the other is oppositely active, i.e. is left-handed or levorotatory. This levo-rotatory lactic acid is also produced directly when cane sugar is acted upon by a particular form of bacterium. We thus have three isomeric lactic acids all of which are the same structurally, i.e. are $\alpha$-hydroxy-propionic acids, viz. inactive lactic acid found in sour milk, dextro lactic acid found in animal muscle, levo lactic acid produced by bacterial fermentation of cane sugar.

How now can we harmonize the existence of three lactic acids of identical structure, viz. $\alpha$-hydroxy-propionic acids, $\mathrm{CH}_{3}-\mathrm{CH}(\mathrm{OH})-\mathrm{COOH}$, with our previous statements in regard to the structure of carbon compounds and with these definite properties in connection with polarized light?

Optical Activity. - Without explaining the physical action 
let it suffice to state that when light passes through certain crystalline substances, e.g., Iceland spar (crystallized calcium carbonate), it undergoes double refraction, that is, the vibrations are broken into two sets, the planes of which are at right angles to each other. One set of vibrations is called the ordinary ray and the other the extraordinary ray. When another crystal or, in practice, another half of a crystal reversed, is next interposed, the extraordinary ray only passes through the second half of the double crystal. On emerging the light is found to consist of vibrations all in one plane or in parallel planes and is said to be polarized. When such a double crystal has been mounted in a particular form of optical apparatus containing a second double crystal like the first, it is possible to observe this polarized light and note how it is affected by different substances. Such an instrument is known as a polariscope.

Now when certain substances, some in crystalline form and others in solution, are examined in this instrument, they exhibit certain definite characteristic effects upon the polarized light. When a solution of ordinary sour milk lactic acid is so examined, it is found to have no effect upon the polarized light, i.e. it is, as we say, inactive toward polarized light. When, however, the structurally identical substance obtained from flesh is similarly examined, it is found that it turns the plane of the polarized light to the right. It is termed, therefore, dextro (right) rotatory. In the same way when the third structurally identical lactic acid, obtained from cane sugar by the special form of bacterium, is examined, it is found to turn the plane of the polarized light to the left, and is termed levo (left) rotatory. And when sour milk lactic acid, the inactive form, is split by means of its strychnine salt, there are obtained both the dextro-rotatory and the levorotatory compounds. We shall find that other compounds, especially tartaric acid and the sugars, possess these same properties. It should be emphasized that these differences in physical properties as exhibited toward polarized light indicate no difference whatever in the chemical structure of the compounds, 
as represented by the groups present or the order of their arrangement.

Asymmetric Carbon. - On examining the structural formula for the lactic acids, viz. $\alpha$-hydroxy-propionic acid, we find a distinctive fact.

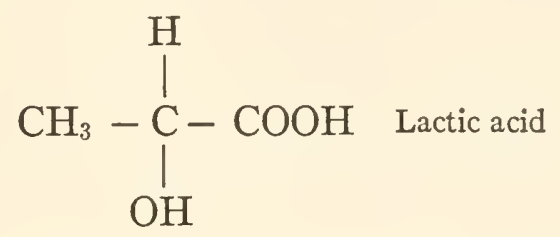

We see that the second carbon atom differs from the other two in this, that it has united to it four different elements or groups, viz., $\mathrm{CH}_{3}, \mathrm{H}, \mathrm{OH}$ and $\mathrm{COOH}$. Now it has been found that all compounds, which when in solution exhibit optical activity toward polarized light, contain at least one carbon atom which is thus united to four different elements or groups. The union of four different groups to one carbon would give to that carbon in its space relations an unsymmetrical arrangement. Such arrangement would make possible an unsymmetrical action such as exhibited toward polarized light in that one form is right-handed or dextro-rotatory and the other form left-handed or levo-rotatory. Such an unsymmetrical arrangement also would be like the unsymmetrical nature of the right and left hand. This complete unsymmetrical nature would be lost whenever any two, or all four, groups united to a carbon atom were the same. Furthermore it was found by Pasteur that certain compounds, e.g. the salts of tartaric acid, crystallized in unsymmetrical or right-and left-handed forms and that these right- and left-handed crystal forms when put into solution exhibit right- and left-handed action toward polarized light.

van't Hoff-Le Bel. - This theory as we have outlined it, which connects optical activity and the existence of structurally identical isomers with the presence in such compounds of an unsymmetrical carbon atom, was advanced simultaneously by two chemists, van't Hoff, a Dutchman, and Le Bel, a Frenchman. It is known as the theory of the asymmetric (unsymmetrical) 
carbon atom. Le Bel went no further than we have stated above. van't Hoff, however, not only assumed this asymmetry of the carbon atom as the explanation of optical activity and of the existence of isomeric structurally identical compounds, but he assumed a definite arrangement for such a carbon atom in space.

Tetrahedral Theory. - He assumed that tetravalent carbon exists in space situated at the center of a regular tetrahedron with the four equal valences directed toward the angles of each apex as follows :

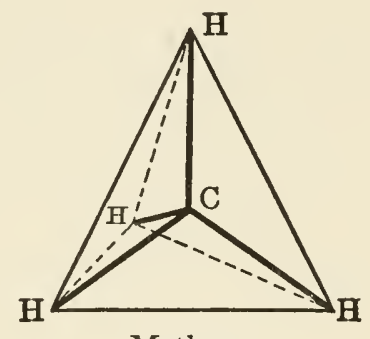

Methane

In methane all four valences are satisfied with hydrogen so that the carbon and the whole compound is completely symmetrical. If, however, as in the lactic acids, these four valences are satisfied by four different groups, then the carbon atom would be asymmetric and the compound would possess asymmetry possible of exhibiting itself in its action toward polarized light. The formula would be:

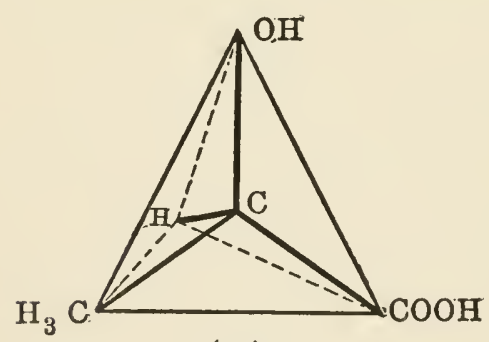

(A)

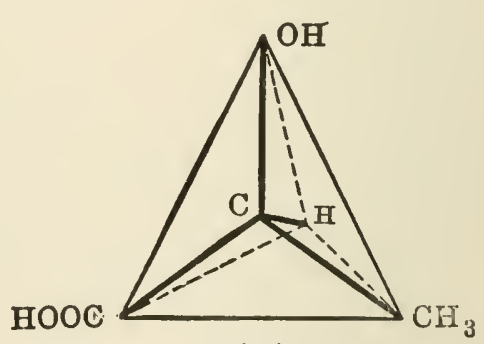

(B)

Lactic acid

Such an arrangement would make possible a compound $A$ and a second compound $B$ which differ in that one is right-handed 
and the other left-handed. They are related to each other as an object and its image, or as the right hand to the left. It can be readily seen that one of these compounds might act one way toward polarized light and the other would possibly act in the reverse way. By one formula, $A$ for example, we can represent the lactic acid of flesh, the dextro-rotatory form, and by the other the lactic acid obtained by bacterial action on cane sugar, the levo-rotatory form. Thus we can explain the two active forms. How about the inactive form? The fact that sour milk lactic acid can be split into the two active forms, and the same is true of inactive tartaric acid and many other inactive compounds which contain an asymmetric carbon atom, gives reason for the view that the inactive compound is composed of equivalent amounts of the active forms which simply neutralize each other as to their effect upon polarized light.

To state it all briefly: van't Hoff and Le Bel's Theory of the Asymmetric Carbon Atom, or, as we also call it, the Tetrahedral Theory, explains the existence of three lactic acids by assuming that one compound, the dextro-rotatory form, has the space arrangement of one of the two formulas just given, say $A$. The other active compound, the levo-rotatory form, has the arrangement of the formula $B$. The third lactic acid, the inactive sour milk acid, is composed of equivalent amounts of the two active forms.

Inactive Lactic Acid. - As has been stated before, the inactive form of lactic acid which is in reality a mixture of the dextro and levo forms is found in sour milk. It is produced in milk by the bacterial fermentation of the milk sugar which is present.

$$
\underset{\text { Milk sugar }}{\mathrm{C}_{12} \mathrm{H}_{22} \mathrm{O}_{11}}+\mathrm{H}_{2} \mathrm{O} \rightarrow \underset{\text { Lactic acid }}{\mathrm{C}_{3} \mathrm{H}_{6} \mathrm{O}_{3}}
$$

This reaction consists both of a hydrolysis and of a splitting of the molecule. It is brought about by a particular group of bacteria, viz. lactic acid bacteria. The acid is also found 
in silage, where it is produced by the bacterial fermentation of the carbohydrates present in corn, clover, etc. These carbohydrates are cane sugar and glucose which are present as such or have been formed by the hydrolysis of starch.

The three carbohydrates, cane sugar, milk sugar and glucose, all yield lactic acid by bacterial fermentation. The form of acid obtained, i.e. inactive, dextro or levo, depends upon the particular bacterial organism which produces the fermentation. It is probably true that lactic acid is an intermediate product in the alcoholic fermentation of glucose into alcohol. Lactic acid itself undergoes further bacterial fermentation and is converted by the butyric acid ferment into butyric acid, $\mathrm{C}_{3} \mathrm{H}_{7}-\mathrm{COOH}$.

$$
\begin{aligned}
& +\mathrm{O}_{2} \\
& { }_{2} \mathrm{C}_{3} \mathrm{H}_{6} \mathrm{O}_{3} \rightarrow \mathrm{C}_{3} \mathrm{H}_{7}-\mathrm{COOH}+{ }_{2} \mathrm{CO}_{2}+{ }_{2} \mathrm{H}_{2} \mathrm{O} \\
& \text { Lactic acid Butyric acid }
\end{aligned}
$$

When milk sours and lactic acid is formed, it is the lactic acid which causes the coagulation of the protein, casein, present in colloidal suspension in the milk and which forms the coagulum or curd from which cheese is made.

When pure, inactive lactic acid is a colorless, sirupy liquid which absorbs water from the air. It decomposes on heating, forming an inner ester called a lactide. It is used as a mordant in dyeing in the form of the antimony salt.

Dextro Lactic Acid (Sarco Lactic Acid). - The dextro-rotatory variety of lactic acid is the form found in the flesh or muscular tissue of animals, from which it gets its name Sarco lactic acid. It is also found in the blood and urine. It may be prepared by the splitting of the inactive form as previously described, or by bacterial fermentation of the sugars previously mentioned.

Levo Lactic Acid. - The levo form of lactic acid is obtained when cane sugar is fermented with certain lactic acid bacteria. It may also be obtained by splitting the inactive form. 


\section{Malic Acid (Mono-hydroxy-succinic Acid)}

We shall now consider three acids which are widely distributed in nature occurring either free or as salts in many of our common fruits. They all belong to this same group of hydroxy-acids to which lactic acid belongs. The first two, malic and tartaric, are derivates of succinic acid.

When succinic acid is converted into mono-brom-succinic acid, this, by replacing bromine with hydroxyl by means of silver hydroxide, $\operatorname{Ag}(\mathrm{OH})$, yields malic acid, thus proving it to be mono-hydroxy-succinic acid. The reactions are as follows:

$$
\begin{aligned}
& \mathrm{CH}_{2}-\mathrm{COOH} \quad \mathrm{CHBr}-\mathrm{COOH} \quad \mathrm{CH}(\mathrm{OH})-\mathrm{COOH} \\
& { }_{\mathrm{CH}_{2}-\mathrm{COOH}}+\mathrm{Br}_{2} \rightarrow \mathrm{HBr}+\left.\right|_{\mathrm{CH}_{2}-\mathrm{COOH}}+\mathrm{Ag}(\mathrm{OH}) \rightarrow \mathrm{CH}_{2}-\mathrm{COOH} \\
& \text { Succinic acid Mono-brom- } \\
& \text { succinic acid }
\end{aligned}
$$

In nature malic acid is found in many acid fruits such as apples, cherries, gooseberries, raspberries, strawberries, currants, pineapples and grapes, and in seeds of some other plants, e.g. pepper and parsley and in unripe berries of the mountain ash. Its name is derived from its being found in apples. It is obtained commercially from the mountain ash berries. It is a solid substance readily soluble in water and melts at $100^{\circ} \mathrm{C}$.

The malic acid found in nature is levo-rotatory in dilute solutions. The dextro-rotatory form and also the inactive form are both known. The existence of these three stereo-chemical isomers is in accord with the theory just discussed in regard to the asymmetric carbon atom, one of the carbon atoms in malic acid being asymmetric.

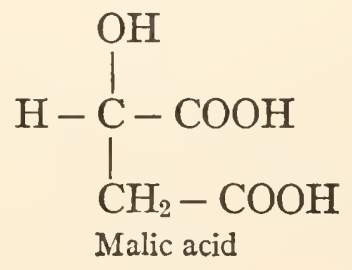




\section{Tartaric Acid (Di-hydroxy-succinic acid)}

Just as we make malic acid from succinic acid through the mono-brom-succinic acid so by converting succinic acid into the symmetrical di-brom-succinic acid we obtain by means of silver hydroxide, $\mathrm{Ag}(\mathrm{OH})$, tartaric acid which has, therefore the constitution of symmetrical di-hydroxy-succinic acid.

$$
\begin{aligned}
& \underset{\mathrm{CH}_{2}-\mathrm{COOH}}{\mathrm{CH}_{2}-\mathrm{COOH}}+{ }_{2} \mathrm{Br}_{2} \rightarrow 2 \mathrm{HBr}+\underset{\mathrm{CHBr}-\mathrm{COOH}}{\stackrel{\mathrm{CHBr}}{l}-\mathrm{COOH}}+2 \mathrm{Ag}(\mathrm{OH}) \rightarrow \underset{\mathrm{CH}(\mathrm{OH})-\mathrm{COOH}}{\mathrm{CH}(\mathrm{OH})-\mathrm{COOH}} \\
& \text { Succinic acid Sym. di-brom- } \\
& \text { succinic acid }
\end{aligned}
$$

Tartaric acid is found naturally in the free condition and as salts in certain fruits, especially in grapes. Being a dibasic acid containing two carboxyl groups or two acid hydrogens, it forms salts with either one or both of these hydrogens replaced by metals.

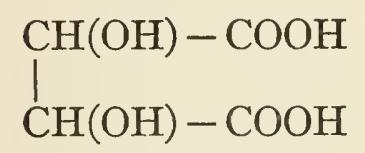

Tartaric acid

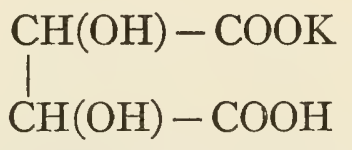

Mono-potassium tartrate (Acid potassium tartrate)
$\mathrm{CH}(\mathrm{OH})-\mathrm{COOK}$

$\mathrm{CH}(\mathrm{OH})-\mathrm{COOK}$

Di-potassium tartrate (Neutral potassium tartrate)

The mono-potassium tartrate or (acid potassium tartrate) is the form in which it occurs in grapes and from which source it is commercially obtained. When grape juice is fermented in preparing wine, there settles out an insoluble material consisting largely of impure acid potassium tartrate and known as argol or crude tartar, the purified acid potassium tartrate being known as cream of tartar. The crude tartar is separated, recrystallized from hot water, converted into the wholly insoluble calcium salt and then back into the free tartaric acid which is then pure. Tartaric acid as thus obtained forms large transparent crystals readily soluble in water or alcohol. Several of the salts of tartaric acid are commonly in use either in cooking or in medicine. They are as follows:

Cream of Tartar, Acid Potassium Tartrate. - This salt of tartaric acid, the formula of which has just been given, is the form 
in which the acid is found in grapes and is the common domestic household article cream of tartar. It is a constituent of most baking powders. Its use in cooking is due to its acid character, one of the acid hydrogens in tartaric acid still remaining. As an acid it reacts in solution with carbonates, such as sodium bicarbonate or baking soda, liberating carbon dioxide; and this evolution of carbon dioxide gas expands or raises the dough of bread or cake and makes a light porous product.

Rochelle Salt. - This compound is the mixed potassium and sodium salt of tartaric acid, i.e. being dibasic the acid has one acid hydrogen replaced by potassium and the other by sodium.

\section{$\mathrm{CH}(\mathrm{OH})-\mathrm{COOK}$<smiles>[CH]=C</smiles>$$
\mathrm{CH}(\mathrm{OH})-\mathrm{COONa}
$$

Potassium-sodium tartrate (Rochelle salt)

The salt forms large crystals containing four molecules of water of crystallization. It is a very important reagent as a constituent of Fehling's Solution. This will be described later in discussing methods of analyzing sugars. It is also used in medicine as a constituent of Seidlitz powders, free tartaric acid and sodium bicarbonate being the other constituents.

Tartar Emetic. - This is a compound of tartaric acid used in medicine as an emetic. It is a mixed potassium and antimonyl salt of tartaric acid, one acid hydrogen being replaced by potassium and the other by the antimonyl group ( $\mathrm{SbO}$ ).

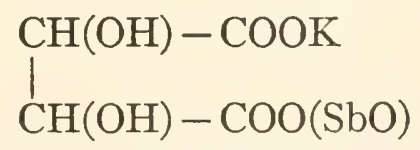

Potassium-antimonyl tartrate (Tartar emetic)

Free tartaric acid, or its salts, have several properties which enable them to be easily detected. When the acid, or a salt plus $\mathrm{H}_{2} \mathrm{SO}_{4}$, is heated it decomposes, chars, and gives forth an odor resembling burnt sugar. When a neutral solution of a tartrate is added to an ammoniacal solution of silver nitrate, 
the silver salt is reduced to metallic silver and a silver mirror is formed. This reaction is similar to that of aldehyde upon silver nitrate.

Stereo-isomerism of Tartaric Acid. - The tartaric acid obtained from grapes, as above described, is optically active, dextro-rotatory. There is also present with it in grapes the inactive form, known as racemic acid, which is also produced when tartaric acid is prepared synthetically from succinic acid. Racemic acid, like the inactive lactic acid, can be split into its two optical components whereby both dextro tartaric acid and levo tartaric acid are obtained. This, however, is not all, for when tartaric acid is prepared synthetically, or when it is heated with water to $165^{\circ}$, a fourth tartaric acid is obtained. This tartaric acid is also inactive, but differs from the racemic acid in that it cannot be split into its two opposite optical components. It is known as meso-tartaric acid.

We have then four stereo-isomeric tartaric acids, as follows:

(I) Dextro tartaric acid in grapes,

(2) Levo tartaric acid,

(3) Racemic acid (inactive tartaric acid) found also in grapes, can be split into dextro and levo acids,

(4) Meso-tartaric acid (inactive), cannot be split into two components.

The explanation of these four forms of tartaric acid is analogous to that of the three lactic acids. The difference between tartaric acid and lactic or malic acids, or any other optically active substance which we have considered thus far, is that while lactic acid has one asymmetric carbon atom, tartaric acid has two and these two are directly joined to each other.

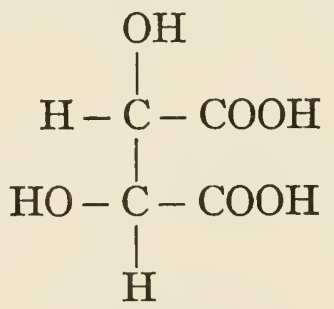

Tartaric acid 
It is considered possible then that the two halves of the compound may be alike in asymmetry and optical power or may be opposite. If the two halves of the compound are alike they may both be dextro, giving dextro tartaric acid, or they may both be levo, making levo tartaric acid. These two in equivalent amounts would make inactive tartaric acid, which could be split into its two components again; that is, racemic acid. If, however, the two halves are different, one dextro and the other levo, an inactive compound would be formed which cannot be split into a dextro and a levo form. This would be meso-tartaric acid.

Thus the existence of four stereo-isomeric tartaric acids is possible in accordance with the van't Hoff - Le Bel theory. These will be more readily comprehended if we examine the four formulas as drawn on a plane surface, or better by an examination of models.

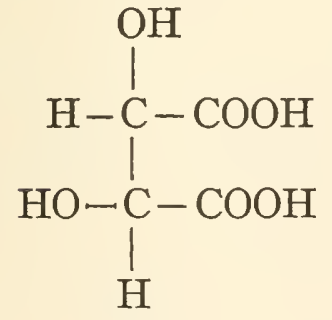

Dextro-

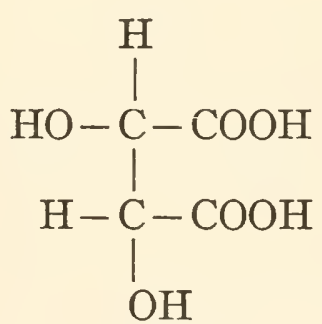

Levo-<smiles>O=C(O)C(O)C(O)C(=O)O</smiles>

Meso-

Racemic

The stereo-isomerism of these acids is especially interesting historically because it was with racemic acid salts that Pasteur made the first separation of an optically inactive compound into its two opposite optical components and also isolated the two enantiomorphic (object and image) forms of crystals, thus demonstrating the nature of inactive compounds of this type. Such inactive compounds which can be split into optical isomers are known now by the general name of racemic compounds. 


\section{Citric Acid}

This is the third hydroxy acid which is found in nature in acid fruits. It is especially abundant in fruits of the citrous family, lemons, oranges, limes, etc., and is present in as much as 6 per cent of the juice. It is also produced by a fermentation of glucose. It is a solid crystalline compound easily soluble in water. The constitution of citric acid is as follows:

\section{$\mathrm{CH}_{2}-\mathrm{COOH}$

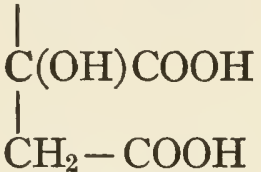

Citric acid

It is thus a mono-hydroxy-tri-carboxy acid, and is tribasic.

Some of the salts of citric acid have important uses. Agriculturally one salt is of importance in a scientific way. A neutral solution of ammonium citrate of approximately 20 per cent strength is used in fertilizer and soil analysis as a solvent for the dicalcium or reverted calcium phosphate, the phosphoric acid salt which is insoluble in water and yet seems to be available to plants. Magnesium citrate is used in medicine, and ferric-ammonium citrate is used in making blue print photographic paper.

\section{EXPERIMENT STUDY XVII}

\section{Lactic, Malic, Tartaric, Citric Acids}

(I) (a) Examine samples of lactic, malic, tartaric and citric acids. (b) Test acidity toward phenolphthalein indicator. (c) Heat a few grams of tartaric acid or a salt of tartaric acid with sulphuric acid in a test tube. Note the odor of burnt sugar. (d) Prepare a little ammoniacal silver nitrate (silver nitrate and just enough $\mathrm{NH}_{4} \mathrm{OH}$ to dissolve the precipitate first formed). To this add a few drops of tartaric acid or a tartrate and warm. Note reduction of silver nitrate to metallic silver. 
(2) (a) Examine samples of

Potassium acid tartrate (Cream of tartar), Potassium sodium tartrate (Rochelle salt), Potassium antimonyl tartrate (Tartar emetic).

(b) Mix about $5 \mathrm{~g}$. each of potassium acid tartrate and sodium acid carbonate, $\mathrm{NaHCO}_{3}$. Add Io c.c. water and warm slightly. What gas is given off? This mixture is the basis of most baking powders. 


\section{CHAPTER VI}

\section{A M I N O-A C I D S, P R O TEINS, UREA A D U R I C A C ID}

\section{AMINO-ACIDS}

THE amino compounds and derivatives which we have thus far considered have been first the alkyl-amines in which an alkyl group (e.g.) methyl, ethyl, propyl, etc., has been substituted in ammonia for one hydrogen yielding a substituted ammonia compound. These show a close relationship to ammonia in many of their reactions, especially the formation of ammonium-like salts. The compounds are also to be considered as amino substitution products of the hydrocarbons in which the amino radical $\mathrm{NH}_{2}$ is substituted for one hydrogen in a hydrocarbon. Methyl amine is also, therefore, amino-methane.

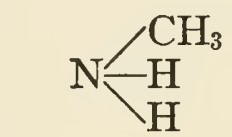

Methyl amine

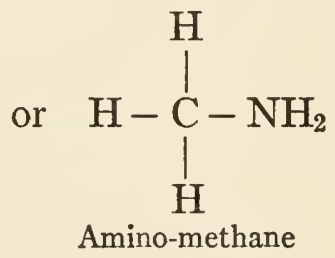

Amino-methane

As amino substituted hydrocarbons, the amines are thus exactly analogous to the halogen and hydroxy substitution products.

$\mathrm{CH}_{3}-\mathrm{Cl}$
Mono-chlor-methane $\quad \begin{gathered}\mathrm{CH}_{3}-\mathrm{OH} \\ \text { Hydroxy-methane }\end{gathered} \quad \begin{aligned} & \mathrm{CH}_{3}-\mathrm{NH}_{2} \\ & \text { Amino-methane }\end{aligned}$

In connection with the derivatives of acids we considered also the acid amides in which the hydroxyl portion of the carboxyl group was replaced by the amino group.

$$
\underset{\text { Acetic acid }}{\mathrm{CH}_{3}-\mathrm{COOH}} \rightarrow \underset{\text { Acet-amide }}{\mathrm{CH}_{3}-\mathrm{CONH}_{2}}
$$

Now just as we have mixed compounds which contain both halogen and carboxyl or both hydroxyl and carboxyl groups, 
the latter of which we have just been considering and which we have termed the hydroxy-acids, so also we have mixed compounds containing amino and carboxyl groups which, similarly, we know as amino-acids.

$\mathrm{CH}_{3}-\mathrm{COOH}, \mathrm{CH}_{2} \mathrm{Cl}-\mathrm{COOH}, \mathrm{CH}_{2}(\mathrm{OH})-\mathrm{COOH}, \mathrm{CH}_{2}\left(\mathrm{NH}_{2}\right)-\mathrm{COOH}$ Acetic acid Chlor-acetic acid Hydroxy-acetic acid Amino-acetic acid

These amino-acids are acids in which a hydrogen of the radical is replaced by the amino group. This substitution may take place in any one of the carbon groups composing the hydrocarbon radical of the acid. The hydroxy-acids are both alcohol and acid compounds and the amino-acids similarly possess the properties of both acids and amines. As acids they form salts, both metallic salts and esters, also acid chlorides and acid amides. As amines they form amine or ammonium salts with acids. They also react like ammonia with acid chlorides, yielding acid amides in which the amino-acid less one of the amine hydrogens replaces the hydroxyl group of another acid. They may be prepared directly from the halogen acids by the action of ammonia.

Taking one of the simpler compounds, e.g. amino-acetic acid, as an illustration, these relations may be clearly shown.

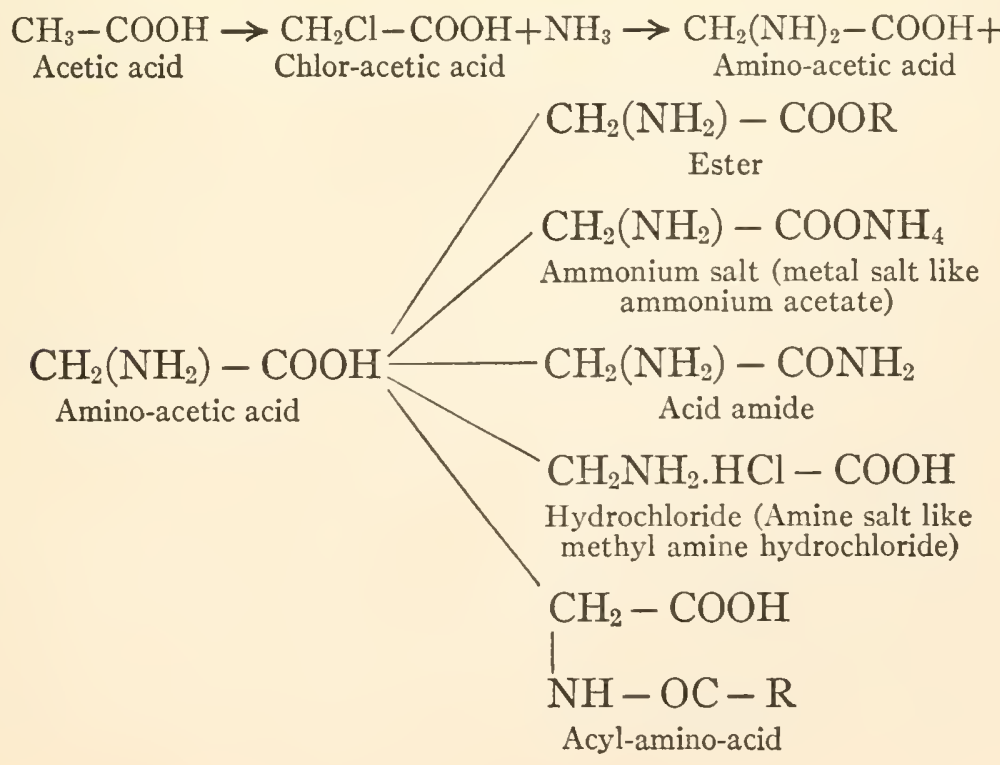




\section{Glycine. Amino-acetic Acid. $\quad \mathrm{CH}_{2}\left(\mathrm{NH}_{2}\right)-\mathrm{COOH}$}

When this compound is prepared from chlor-acetic acid by the action of ammonia, the ammonium salt of the amino-acid is formed.

\section{$\mathrm{CH}_{2} \mathrm{Cl}-\mathrm{COOH}+2 \mathrm{NH}_{3}$}

Chlor-acetic acid

\section{$\mathrm{CH}_{2}\left(\mathrm{NH}_{2}\right)-\mathrm{COONH}_{4}+\mathrm{HCl}$}

Ammonium salt of amino-acetic acid

This salt, when boiled with hydrochloric acid, decomposes and forms the amine hydrochloride of the acid.

$\mathrm{CH}_{2}\left(\mathrm{NH}_{2}\right)-\mathrm{COONH}_{4}+2 \mathrm{HCl} \rightarrow \mathrm{CH}_{2}\left(\mathrm{NH}_{2} \mathrm{HCl}\right)-\mathrm{COOH}+\mathrm{NH}_{4} \mathrm{Cl}$ Ammonium salt of amino-acetic acid

Hydrochloride of amino-acetic acid

Amino-acetic acid is a solid crystalline compound melting at $235^{\circ} \mathrm{C}$. It is readily soluble in water. The hydrochloride salt is also a crystalline solid soluble in water. An important derivative of amino-acetic acid should be mentioned. As previously stated the amino group in the compound acts as ammonia and forms compounds in which the amino residue becomes the amide part of an acid amide. With acetic acid or, better, with the acid chloride of acetic acid, ammonia and amino-acetic acid yield the following:

$$
\underset{\text { Acetyl chloride Ammonia }}{\mathrm{CH}_{3}-\mathrm{COCl}}+\underset{\mathrm{NH}_{3}}{\mathrm{CH}_{3}-\mathrm{CONH}_{2}+\mathrm{HCl}}
$$

$$
\underset{\text { Amino-acetic acid }}{\mathrm{CH}_{3}-\mathrm{COCl}+\left(\mathrm{NH}_{2}\right)-\mathrm{CH}_{2}-\mathrm{COOH}} \rightarrow \underset{\text { Acetyl-amino-acetic acid }}{\mathrm{CH}_{3}-\mathrm{CO}-\mathrm{NHCH}_{2}-\mathrm{COOH}+\mathrm{HCl}}
$$

Benzoic acid is a mono-carboxy acid derived from the hydrocarbon benzene, $\mathrm{C}_{6} \mathrm{H}_{6}$. It is $\mathrm{C}_{6} \mathrm{H}_{5}-\mathrm{COOH}$. This forms a benzoyl $\left(\mathrm{C}_{6} \mathrm{H}_{5} \mathrm{CO}\right)$ derivative of amino-acetic acid.

$$
\mathrm{C}_{6} \mathrm{H}_{5}-\mathrm{COOH} \quad \mathrm{C}_{6} \mathrm{H}_{5} \mathrm{CO}-(\mathrm{NH}) \mathrm{CH}_{2}-\mathrm{COOH}
$$

Benzoic acid

Benzoyl-amino-acetic acid (Hippuric acid)

This compound, benzoyl-amino-acetic acid, is the substance known as hippuric acid. It is a constituent of the urine of man but is more abundant in that of horses and cows and of other herbivorous animals. When hippuric acid is boiled with hydrochloric 
acid it hydrolyzes, forming benzoic acid and amino-acetic acid. The free amino-acetic acid then with the $\mathrm{HCl}$ yields the hydrochloric acid salt.

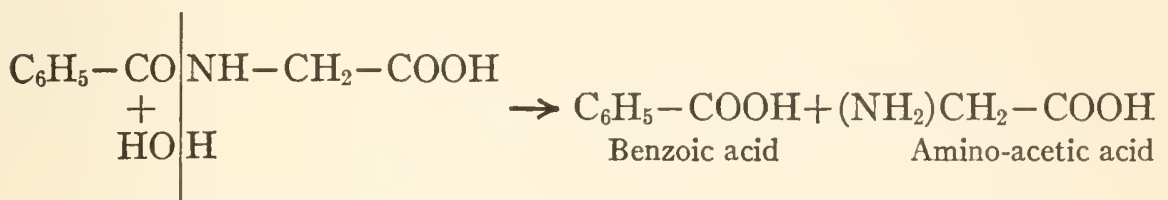

Hippuric acid $+\mathrm{H}_{2} \mathrm{O}$

Hippuric acid is important as a product of animal metabolism and will be considered again under that subject. Aminoacetic acid commonly goes by another name, especially in connection with its physiological relationships. It is known as glycine; the prefix, glyc, of this name indicates its sweet taste, and the termination, ine, its amine nature.

Alanine, $\alpha$-amino-propionic acid : $\mathrm{CH}_{3}-\mathrm{CH}\left(\mathrm{NH}_{2}\right)-\mathrm{COOH}$

This compound, the next higher homologous amino-acid, is the amino analogue of lactic acid.

Lactic acid, $\alpha$-hydroxy-propionic acid: $\mathrm{CH}_{3}-\mathrm{CH}(\mathrm{OH})-\mathrm{COOH}$ Alanine, $\alpha$-amino-propionic acid : $\mathrm{CH}_{3}-\mathrm{CH}\left(\mathrm{NH}_{2}\right)-\mathrm{COOH}$

Like lactic acid, it contains an asymmetric carbon atom (underlined) and possesses optical activity, being known in its dextro, levo and inactive forms. The compound is similar to glycine in its properties, being a solid crystalline compound forming salts with both bases and acids, and also derivatives of the acid amide type as discussed under glycine.

\section{Higher Amino-acids}

A few other amino-acids will be mentioned, simply giving their constitutional formulas, in order that they may be referred to later.

Valine, $\alpha$-amino- $\beta$-methyl-butyric acid :

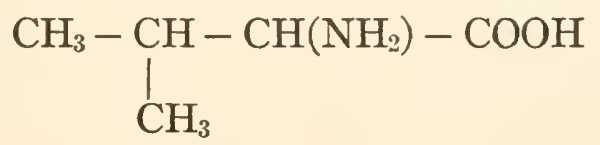


Leucine, $\alpha$-amino- $\gamma$-methyl-valeric acid ( $\alpha$-amino-iso-caproic acid) :

$$
\underset{\mathrm{CH}_{3}}{\mathrm{CH}_{3}}>\mathrm{CH}-\mathrm{CH}_{2}-\mathrm{CH}\left(\mathrm{NH}_{2}\right)-\mathrm{COOH}
$$

Iso-leucine, $\alpha$-amino- $\beta$-methyl-valeric acid :

$$
\mathrm{CH}_{3}-\mathrm{CH}_{2}-\underset{\mid}{\mathrm{CH}}-\mathrm{CH}\left(\mathrm{NH}_{2}\right)-\mathrm{COOH}
$$

Serine, $\alpha$-amino- $\beta$-hydroxy-propionic acid :

$$
\mathrm{CH}_{2}(\mathrm{OH})-\mathrm{CH}\left(\mathrm{NH}_{2}\right)-\mathrm{COOH}
$$

Lysine, $\alpha$ - $\epsilon$-di-amino-caproic acid :

$\mathrm{CH}_{2}\left(\mathrm{NH}_{2}\right)-\mathrm{CH}_{2}-\mathrm{CH}_{2}-\mathrm{CH}_{2}-\mathrm{CH}\left(\mathrm{NH}_{2}\right)-\mathrm{COOH}$

Aspartic acid, amino-succinic acid :

$\mathrm{CH}\left(\mathrm{NH}_{2}\right)-\mathrm{COOH}$

$\stackrel{\text { ! }}{\mathrm{CH}_{2}}-\mathrm{COOH}$

Asparagine, mono-amide of amino-succinic acid:

$\mathrm{CH}\left(\mathrm{NH}_{2}\right)-\mathrm{COOH}$

$\stackrel{\text { ! }}{\mathrm{CH}_{2}}-\mathrm{CONH}_{2}$

This compound is both an amino-acid and an acid amide.

Glutamic acid, $\alpha$-amino-glutaric acid :

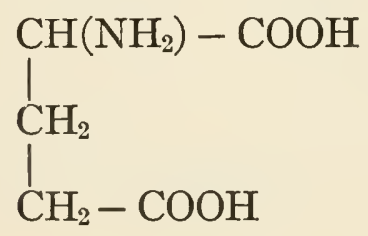

Phenyl-alanine, $\alpha$-amino- $\beta$-phenyl-propionic acid :

$$
\begin{aligned}
& \mathrm{CH}_{2}-\mathrm{CH}\left(\mathrm{NH}_{2}\right)-\mathrm{COOH} \\
& \mathrm{C}_{6} \mathrm{H}_{5}
\end{aligned}
$$


Tyrosine, $\alpha$-amino- $\beta$-hydroxy-phenyl-propionic acid :

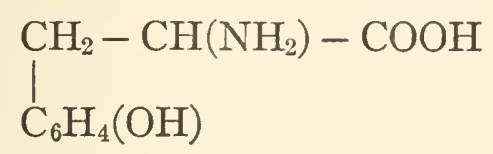

Tryptophane, $\alpha$-amino- $\beta$-indol-propionic acid :

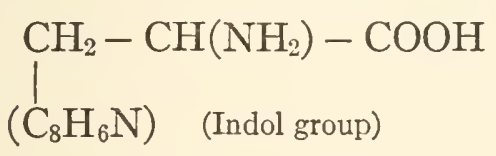

Arginine, $\alpha$-amino- $\delta$-guanidine-valeric acid:

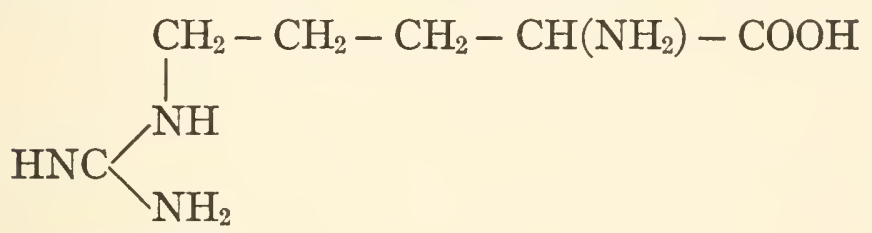

(Guanidine residue)

\section{PROTEINS}

The three essential organic or carbon-containing constituents of animal foods are fats, e.g. lard, tallow, olive oil ; proteins, e.g. egg albumin, cheese casein and wheat gluten; and carbohydrates, e.g. sugar, starch and cellulose. Fats we have already discussed in a preceding chapter. The consideration of proteins should come in connection with the amino-acids which we have just studied. The carbohydrates will be taken up a little later.

The three food constituents above mentioned are alike in that they all contain the three elements, carbon, hydrogen and oxygen. When we come to study the manner in which these foods are used in the animal body, we shall find that this use rests fundamentally upon the property of these compounds to be oxidized, and by means of this oxidation to furnish the energy of the animal body. The oxidation of these substances depends upon the carbon and hydrogen contained in them. As these food constituents are practically the only compounds which the animal body thus uses as a source of energy, they are of the utmost importance, and their presence determines the value 
and use of any foodstuff. All this will be considered again at greater length in the later part of our study.

Now, while proteins are like fats and carbohydrates in containing carbon, hydrogen and oxygen, they differ from them in containing also the element nitrogen. Protein, as the name signifies, is the primary or fundamental substance of living matter. It is one of the chemical constituents of the biological substance protoplasm, which is the essential of all living cells. As we shall find later, animals are unable to use the element nitrogen for the purpose of forming new protein unless that nitrogen is in the form of protein itself or of compounds very closely related to protein. That is, to form animal protein, food protein is essential. We thus see how important a place the substances we call proteins occupy in connection with plant and animal life. What then are these proteins in their chemical nature?

While in most cases proteins contain only the four elements carbon, hydrogen, oxygen and nitrogen, they are among the most complex compounds in organic chemistry. In addition to being very complex, their physical and chemical properties are such that they are among the most difficult of all compounds to study. From the examples of proteins previously given, viz. egg albumin or white of an egg, cheese curd or casein and wheat gluten, the tough elastic constituent of wheat left when the starch is washed away, we see that these substances are of a somewhat different nature from that of ordinary chemical compounds. In fact, we have hardly any evidence that any one of the substances we know as a protein is a single individual compound. Some proteins are definitely known to be complex mixtures of several individuals, and probably no one of them can be definitely considered as an individual.

\section{Physical Properties of Proteins}

The physical properties of proteins are in general those of non-crystallizable (though some have been crystallized) colloidal compounds. They do not have definite melting points or boil- 
ing points, and their chief differences from each other lie in their slightly different solubility. The classification of proteins has thus been based largely upon these slight differences in solubility and upon certain general properties. The differences in solubility are also not sharp, as in the case of many crystalline, gaseous and liquid compounds, so that their sharp separation is an impossibility. Differences in solubility such as have been used to distinguish proteins from each other have given us certain groups such as the following:

Albumins, soluble in water,

Globulins, soluble in dilute salt solutions,

Prolamines, soluble in dilute alcohol,

Albuminoids, insoluble in all neutral solvents, etc.

The solubility in water may be easily tested with such proteins as egg albumin, wheat gluten and milk casein, as in Experiment Study XVIII, I. This is also shown in Experiment Study XXIX, by the separation of the proteins in milk where we obtain milk albumin which is soluble in water, and milk casein, a phospho-protein which is insoluble in water.

A few proteins are more complex than the ones given above, classified by differences of solubility, and these are known as double or conjugated proteins. They contain two distinct parts and are distinguished by the parts shown to be present as follows:

Glyco-proteins, protein and a carbohydrate (mucin in saliva), Nucleo-proteins, protein and nucleic acid,

Phospho-proteins, protein and a phosphorus compound (casein),

Hæmoglobins, protein and an iron-containing compound (blood hæmoglobin).

We thus see how difficult a matter it is to arrive at any conclusion as to the true chemical nature of proteins from a study of their physical properties because they each lack the sharply distinctive properties of ordinary chemical compounds. 


\section{Chemical Properties of Proteins}

Composition. - When we turn to the chemical properties of proteins we find that here too we have much less to work with than in most cases. Chemically proteins are characterized by their inactivity and by the difficulty with which they are converted into other compounds. In their ultimate composition also there is little to aid in their study. The analysis of many proteins has given results as follows:

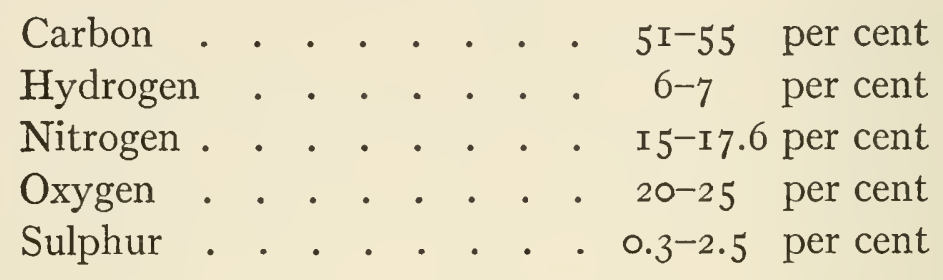

Analysis. - Nitrogen, the characteristic element in proteins which distinguishes them from carbohydrates and fats, may be easily detected by test as in the experiment study following. A positive test for nitrogen does not prove an organic substance to be protein, but it does distinguish proteins from the other two organic food constituents. The quantitative determination of nitrogen in materials which contain protein, such as most plant or animal substances, is the only analytical method known for determining the protein itself. The method universally used is known as the Kjeldahl method for nitrogen as described in the experiment study below.

Qualitative tests are also made for proteins by means of reagents which give color reactions or precipitations. In general all proteins respond to these tests, while in some cases certain non-protein compounds also respond. While some of the color reactions have been shown to be due to certain organic groups it is, nevertheless, impossible to differentiate proteins by these reactions.

Molecular Weight. - When an effort has been made, based upon the percentage composition of the proteins, to arrive at some idea as to the size of the molecule of the compounds, 
some very striking and interesting results have been obtained, but which really give us very little information of value. Molecular weights have been assigned as follows:

Edistin, based on the per cent of sulphur present . . I4,530 Egg albumin, based on the per cent of sulphur present I 5,703 Blood serum albumin (horse) based on the per cent of sulphur present . • • • . . . . . • . . I4,989

Blood oxy-hæmoglobin (horse) based on the per cent of sulphur present . . . . . . . • . . I6,655 Blood oxy-hæmoglobin, based upon iron content . I5,000

This discussion so far, though it gives us no clear idea as to the real chemical nature of the proteins, at least shows us very clearly how complex the compounds are and how difficult the study of them is.

Hydrolytic Decomposition. - Only one line of investigation has resulted in throwing any light on the subject. When proteins are boiled with acids or alkalies, hydrolysis takes place by addition of water and the splitting of the complex compounds into simpler compounds. These simpler compounds are the amino-acids which we have just considered. This explains why the study of the proteins is taken up at this point, immediately following that of the amino-acids. We have given the formulas for thirteen amino-acids. In addition to these thirteen, five others are known, making a total of eighteen, all of which have been isolated as products formed by the hydrolytic cleavage of proteins. These different amino-acids are obtained in varying proportions by the hydrolysis of different proteins. This gives a better basis for separating or distinguishing different proteins than can be obtained from a study of physical properties.

It seems, therefore, that as all proteins yield these aminoacids as cleavage products, some proteins yielding nearly the entire eighteen, the proteins themselves are probably composed of these compounds as constituent parts. 


\section{Poly-peptides}

The question then arises, how may these amino-acids be joined together to form the proteins? In our discussion of amino-acids it was emphasized that the peculiar characteristic of them is that they are both acid and basic compounds in the same molecule. The amino group, acting as ammonia, forms amide compounds with organic acids. This is illustrated by the formation of the benzoyl derivative of amino-acetic acid in which the radical of benzoic acid replaces one of the hydrogens of the amino group. The product, benzoyl-amino-acetic acid, or benzoyl-glycine, is hippuric acid.

\section{$\mathrm{CH}_{2} \mathrm{NH}(\mathrm{H})-\mathrm{COOH}$}

Amino-acetic acid (glycine)

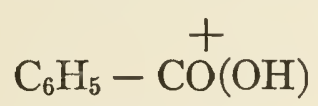

Benzoic acid
$\mathrm{CH}_{2}(\mathrm{NH})-\mathrm{COOH}$

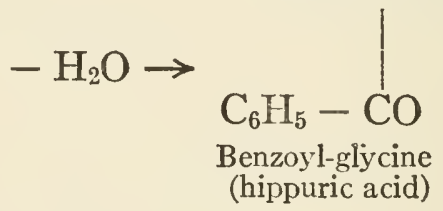

Now it has been found that by certain reactions two molecules of amino-acetic acid react with each other, the amino group in one reacting with the carboxyl group of the other just as above, and a compound is obtained as follows:

$\mathrm{CH}_{2} \mathrm{NH}(\mathrm{H})-\mathrm{COOH}$

$\mathrm{CH}_{2}\left(\mathrm{NH}_{2}\right)-\stackrel{+}{\mathrm{CO}}(\mathrm{OH})$
$\mathrm{CH}_{2}(\mathrm{NH})-\mathrm{COOH}$

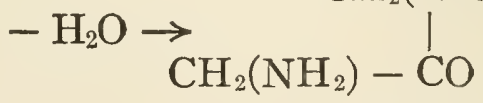

Glycyl-glycine

The compound formed is known as glycyl-glycine, exactly analogous to benzoyl-glycine, and is it called a di-peptide.

In a similar way some 30 compounds have been prepared by joining together certain amino-acids. Not only, however, may two amino-acids be thus united (the amino-acids being the same or different), but $3,4,5,6,8$, 10, 14 and finally I 8 . These are known as tri-peptides, tetra-peptides, deca-peptides, octa-decapeptides, etc., depending upon the number of amino-acids united. As a class they are known as poly-peptides.

Now the important fact is that these poly-peptides exhibit 
characters very similar to those of proteins. By hydrolysis they yield the amino-acids from which they have been prepared. They give color reactions and precipitation tests similar to those given by proteins. Finally they have been obtained as intermediate cleavage products between the proteins themselves and the amino-acids. Absolute identity of a poly-peptide made synthetically and one obtained as a cleavage product of a protein has not yet been established, but the evidence points strongly to the conclusion that proteins are poly-peptides of the various amino-acids obtained as cleavage products.

\section{EXPERIMENT STUDY XVIII}

\section{Proteins}

(I) Solubility. Test solubility of egg albumin, wheat gluten and milk casein in water. Compare also Experiment Study XXIX on the separation and isolation of milk proteins.

(2) Proof of Nitrogen in Proteins. (a) Place about a gram or two of protein (egg albumin) in a dry test tube. Add about an equal volume of fine soda lime. Heat. Hold a piece of red litmus paper at mouth of tube. Also notice odor. Ammonia is liberated, proving nitrogen in the original protein.

(b) Place a small amount of protein (egg albumin) in a small piece of glass tubing closed at one end. Add a piece of metallic sodium. Heat red hot for some time. Place end of hot tube in a little water to crack it and let fused mass into the water. Boil. Add a drop of $\mathrm{HCl}$ and 5 c.c. of $\mathrm{FeCl}_{3}$. Now add a little $\mathrm{FeSO}_{4}$. A blue precipitate proves presence of $\mathrm{CN}$ group as $\mathrm{Na}_{3} \mathrm{Fe}(\mathrm{CN})_{6}$. The $\mathrm{N}$ came from the protein.

(3) Quantitative Determination of Protein. (a) Place 0.5 g. of pure protein, e.g. egg albumin, casein or wheat gluten, or 1.0-5.0 g. of a protein-containing plant or animal substance, e.g. wheat, cottonseed meal, meat, or milk, in a long-necked, round-bottom flask (Kjeldahl flask). Now add 25-30 c.c. concentrated pure sulphuric acid and ro g. crystallized potassium sulphate. Heat gradually in a hood until the acid boils, being careful to avoid frothing. Continue heating until the organic substance is all oxidized and a light straw- 
colored or colorless liquid remains (usually $2-5$ hours' heating is required). Cool the contents of the flask. Add quickly about 200 c.c. water and then about 50 c.c. concentrated ( 50 per cent) sodium hydroxide solution and connect the flask at once with a condenser. The receiver end of the condenser should dip below the surface of the liquid in the receiving flask. This liquid is water plus a known amount of standard ( $N /$ Io usually) hydrochloric acid sufficient to more than neutralize all ammonia distilled over. Distill the contents of the digestion flask long enough to drive over all ammonia (usually $\frac{1}{2}$ to $I$ hour). Titrate back excess of acid and calculate the amount of ammonia, or of nitrogen, obtained from the original protein substance used.

(b) Reactions of I Jjeldahl Determination of Nitrogen in Protein. The Kjeldahl method for determining nitrogen is applicable to all protein substances and has been modified in various ways to adapt it to various nitrogen compounds such as nitrates, etc. It is the universal method for determining nitrogen in practically all agricultural analysis of such materials as plant and animal substances, fertilizers, soils, etc. The details in regard to the method and its modifications will be found in any book on analytical chemistry or agricultural analysis.

The modification given in this study is known as the Gunning modification. The principle of the method is in general as follows: When an organic nitrogen-containing compound, such as a protein, is heated to the boiling point with concentrated sulphuric acid, the protein is completely decomposed and all carbon and hydrogen are oxidized. All of the nitrogen is converted into ammonia, which in the presence of the sulphuric acid forms ammonium sulphate, which is non-volatile and is thus not lost in the digestion. The potassium sulphate added to the sulphuric acid in the Gunning modification is for the purpose of raising the boiling point of the acid, thus increasing the oxidation power or its rapidity. When the digestion begins much carbon is set free which gradually disappears as oxidation proceeds. When the digested material is colorless or straw color, the carbon is all oxidized and usually all nitrogen compounds have by this time been converted into ammonia and the digestion is complete. At the completion of digestion, therefore, all of the protein nitrogen is in the digestion liquid in the form of ammonium sulphate. After cooling and dilution, strong sodium hydroxide is added sufficient to more 
than neutralize the excess of the sulphuric acid. The sodium hydroxide reacts with the ammonium sulphate, setting free the ammonia. This ammonia is then distilled into standard acid and the amount of standard acid which is thus neutralized by the ammonia is determined by titration against a standard alkali. From the amount of standard acid neutralized the amount of ammonia is calculated. From this amount of ammonia, the amount of nitrogen is calculated, and this amount of nitrogen is the whole of the nitrogen contained in the original protein.

On the average, as previously stated, proteins contain I 6 per cent nitrogen. Therefore, multiplying the amount of nitrogen by the factor 6.25 gives us the amount of protein in the original substance. This factor, 6.25, is the one commonly used for converting nitrogen into protein, and agricultural analyses in general are calculated with this factor which may be understood unless otherwise stated. Some proteins contain more than 16 per cent nitrogen, e.g. the proteins of wheat gluten contain 17.6 per cent nitrogen. The factor for converting into protein would be, then, 5.68. The following typical analysis may be given as an illustration of the calculation.

(c) Calculation of a Kjeldahl Nitrogen Determination.

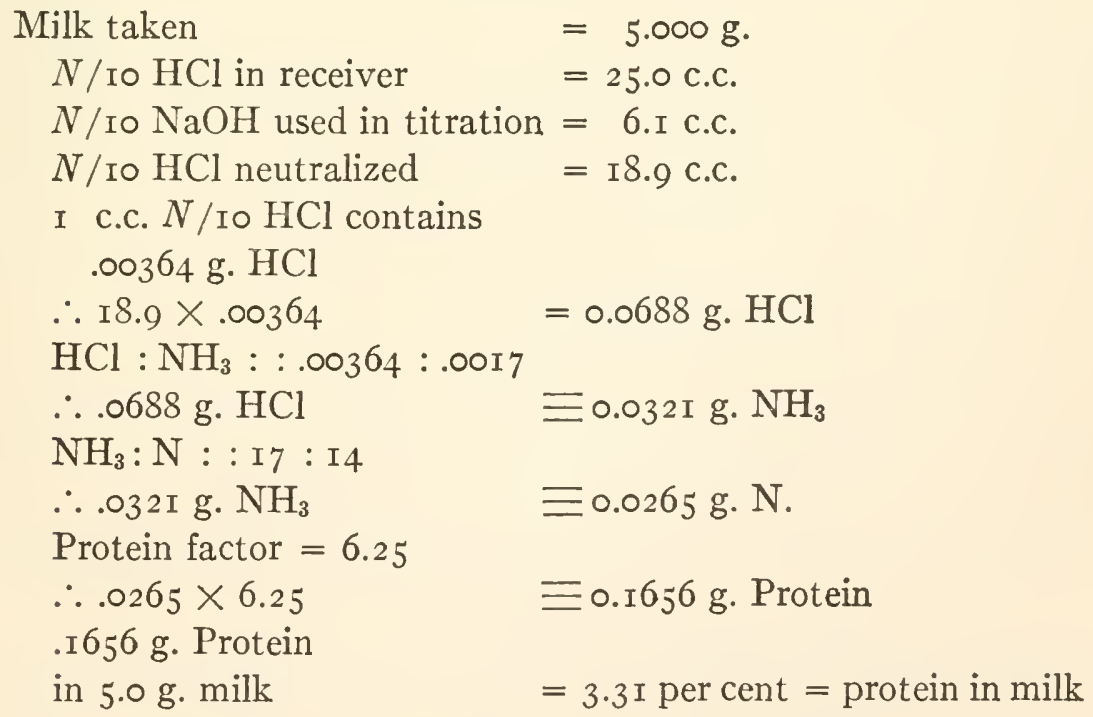

(4) Color Reactions of Proteins. (See list of proteins at end of this experiment.) (a) Millon's Reaction. Millon's Reagent is prepared as follows: Dissolve one part by weight of mercury in two 
parts by weight of concentrated $\mathrm{HNO}_{3}$ (sp. gr. I.42) and then dilute with two vol. $\mathrm{H}_{2} \mathrm{O}$. To a small amount of solid protein in a test tube add a few drops of Millon's reagent. Warm. A yellow or white color which turns red on heating indicates protein. The test works best on solid protein. The test is obtained with any substance containing the hydroxy-phenyl group $\left(\mathrm{C}_{6} \mathrm{H}_{4}(\mathrm{OH})\right)$ so that nonproteins like tyrosine, phenol or carbolic acid $\left(\mathrm{C}_{6} \mathrm{H}_{5} \mathrm{OH}\right)$ and thymol give a positive test.

(b) Xanthoproteic Reaction. To a small amount of protein in a test tube add concentrated nitric acid. A white precipitate turning yellow indicates protein. Cool and add ammonium hydroxide. The color changes to orange. The reaction depends upon the presence of the phenyl group $\left(\mathrm{C}_{5} \mathrm{H}_{5}-\right)$ so that any phenyl-containing compound such as tyrosine, phenylalanine and tryptophane, phenol, etc., gives a positive test. The yellow color produced when nitric acid stains the flesh is due to this reaction.

(c) Biuret Reaction. To a 5 c.c. solution of protein add an equal volume of concentrated $\mathrm{KOH}$ or $\mathrm{NaOH}$. Mix thoroughly. Make a very dilute solution of copper sulphate by adding a few drops ( 2 to 5 ) of ordinary ro per cent solution copper sulphate to a test tube full of water. The dilute $\mathrm{CuSO}_{4}$ should be only very faintly blue. Now add a few drops of this dilute $\mathrm{CuSO}_{4}$ to the alkaline protein solution and warm. A pink-violet color indicates protein. The reaction is due to substances containing two amino $\left(\mathrm{NH}_{2}\right)$ groups. These groups may be joined together directly or with an intermediate carbon group. Biuret, the substance which gives the name to the reaction, is formed from urea by the loss of ammonia (see Experiment XIX).

Test by the above reagents :
(a) Egg albumin, fresh,
(e) Milk casein or curd,
(b) Dilute solution of egg albumin,
(f) Wheat gluten,
(c) Egg albumin, dry,
(g) Dried blood,
(d) Egg albumin, coagulated
(h) Horn or hair or finger nail. (cooked),

(5) Precipitation Tests. (a) To 5.0 c.c. of dilute mercuric chloride (corrosive sublimate) solution, add a little egg albumin solution. Note the precipitation of mercury albuminate. (b) Repeat the experiment, using lead acetate solution instead of mercuric chloride. The precipitate here is lead albuminate. These two experiments 
illustrate the property of proteins to form salts known as albuminates, and on this property is based the use of egg albumin as an antidote for poisoning with mercuric chloride or lead salts.

\section{UREA, URIC ACID AND PURINE BASES}

Urea is one of the end products of the metabolism of protein in the animal body. When body protein, having been built up from food protein, is burned in the body for the production of muscular energy or of body heat, part of the carbon is oxidized to carbon dioxide, part of the hydrogen to water, and the rest of the carbon, hydrogen and oxygen are eliminated through the kidneys in the form of urea, uric acid, creatinine, purine bases (xanthine), etc. These compounds in addition to carbon, hydrogen and oxygen contain all of the nitrogen of the original . food or body protein. Their importance in animal physiology is, therefore, apparent.

\section{Urea}

What now is urea? The composition is $\mathrm{CH}_{4} \mathrm{~N}_{2} \mathrm{O}$ and it has been shown to have the constitution of a di-amide of hypothetical carbonic acid.<smiles>NC(N)=O</smiles>

Urea<smiles>O=C(O)O</smiles>

Carbonic acid

The compound may also be defined or considered as aminoformamide.

$\mathrm{H}-\mathrm{COOH}$

Formic acid
$\mathrm{NH}_{2}-\mathrm{COOH}$

Amino-formic acid or $\mathrm{H}_{2} \mathrm{CO}_{3}$

This constitution may be proven in several ways. Aminoformic acid is the very simplest of the amino-acids.

\section{$\mathrm{H}-\mathrm{COOH}$}

Formic acid
$\mathrm{NH}_{2}-\mathrm{COOH}$

Amino-formic acid 
This acid is not known as the free acid, but is known both in the form of its ammonium salt and also of its ethyl ester.

$$
\mathrm{NH}_{2}-\mathrm{COONH}_{4}
$$

Ammonium amino-formate
$\mathrm{NH}_{2}-\mathrm{COOC}_{2} \mathrm{H}_{5}$

Ethyl amino-formate

Now when ammonium amino-formate is heated, water is lost and urea results. Also when ethyl amino-formate is treated with ammonia, urea is formed and ethyl alcohol is the other product. These reactions leave no doubt as to the structure of urea and its relation to formic acid.

$$
\mathrm{NH}_{2}-\mathrm{CO}(\mathrm{O}) \mathrm{NH}_{2}\left(\mathrm{H}_{2}\right) \rightarrow \mathrm{NH}_{2}-\mathrm{CO}-\mathrm{NH}_{2}+\mathrm{H}_{2} \mathrm{O}
$$

Ammonium amino-formate

Urea

$\mathrm{NH}_{2}-\mathrm{CO}\left(\mathrm{OC}_{2} \mathrm{H}_{5}+\mathrm{H}\right) \mathrm{NH}_{2} \rightarrow \mathrm{NH}_{2}-\mathrm{CO}-\mathrm{NH}_{2}+\mathrm{HO}-\mathrm{C}_{2} \mathrm{H}_{5}$

Ethyl amino-formate

Urea

Alcohol

The relation of urea to carbonic acid is also shown by this first synthesis above, for the ammonium amino-formate is produced when carbon dioxide and ammonia are brought together.

$$
\mathrm{CO}_{2}+2 \mathrm{NH}_{3} \rightarrow \mathrm{C} \stackrel{\stackrel{/ \mathrm{NH}_{2}}{=}=\mathrm{O}}{\mathrm{O} \mathrm{ONH}_{4}}
$$

Ammonium amino-formate Ammonium carbamate

As this compound in its relation to carbonic acid is both an acid amide and an ammonium salt, it is known also as ammonium carbamate. This with a molecule of water forms ammonium carbonate.

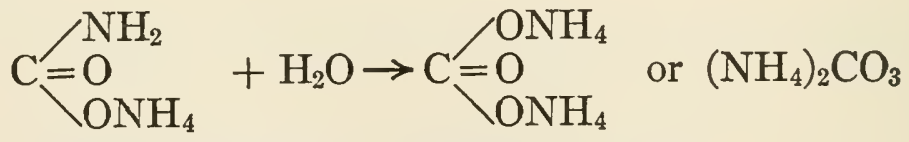

Ammonium carbamate Ammonium carbonate

Carbonic acid though not existing free is known as its di-ethyl ester.

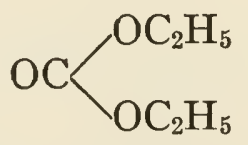

and this compound with ammonia forms urea and alcohol. 


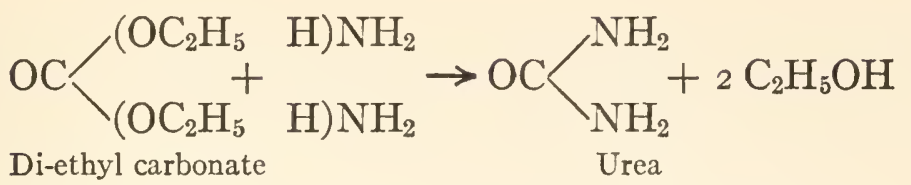

Also carbonyl chloride (phosgene), $\mathrm{COCl}_{2}$, yields urea with ammonia.

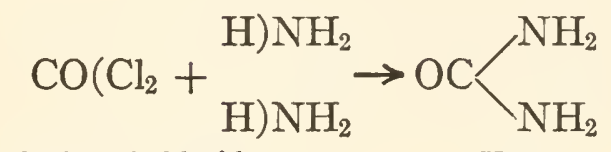

Carbonyl chloride

Urea

Thus the relationship of urea to both carbonic acid and formic acid is established.

The most interesting synthesis of urea is one which shows little as to its constitution, but which is important because it was the first preparation, from purely inorganic substances, of a compound found in animals or plants. In I 828 the German chemist Wöhler obtained urea by simply heating the inorganic salt ammonium cyanate. In this conversion no other substance was added or produced, there simply being a rearrangement of the atoms.

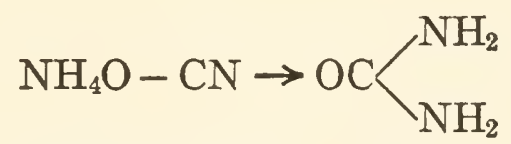

Ammonium cyanate Urea

Up to the time of this historic synthesis no substance known only as a product of living organisms or, as they were termed, vital products, had ever been prepared in the laboratory. This caused the abandonment of the view that organic substances belonged to a different class, and needed the presence of a different kind of chemical reaction than inorganic substances. The vital force, as it was called, was not essential to the formation of organic compounds. This is not saying, however, that living matter itself can be produced from nonliving matter. Wöhler's synthesis of urea thus stands as an epoch-making discovery, and marks the real beginning of a new era in organic chemistry. 
Urea occurs in considerable amounts in the urine of all animals. In man the amount is about 25 grams or one ounce per day. It is present in urine in a much larger quantity than any of the other nitrogenous constituents, all of which, as previously stated, result from the metabolism of body protein or food protein, and they contain all of the nitrogen of the protein metabolized. They are true excretion or waste products.

Urea is a beautiful crystalline compound forming needle-like prisms, melting at $132^{\circ} \mathrm{C}$. It is readily soluble in water and in alcohol. It may easily be isolated from urine, first as the nitric acid salt, and this converted into free urea (Exp. XXXI). When urea is heated with water to $180^{\circ} \mathrm{C}$. or when it is boiled with acids, hydrolysis occurs, and ammonium carbonate is first formed, which then breaks up into ammonia and carbon dioxide.

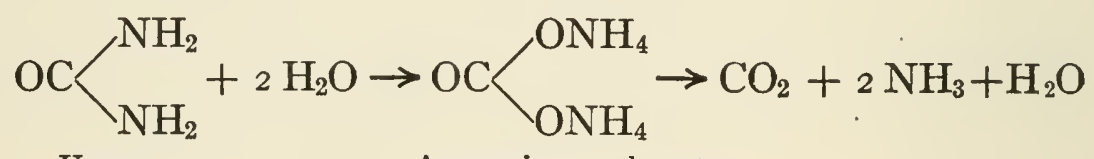

Urea

Ammonium carbonate

Probably ammonium carbamate (ammonium amino-formate) is the intermediate product between urea and ammonium carbonate. This decomposition is the reverse of the reaction of synthesis of urea from ammonia and carbon dioxide. The importance of this decomposition is that it takes place naturally due to the action of bacterial organisms, urea bacteria. When urine undergoes fermentation, this reaction occurs and the nitrogen of the urea, which is the nitrogen of the original body or food protein, is thus set free in the form of ammonia. This ammonia, which in some cases is useful as a plant food, becomes readily converted by bacterial organisms into nitric acid and its salts, in which form all plants can utilize it. Thus, by these fermentation changes, nitrogen of urine, the chief nitrogenous substance in ordinary manure, and which has derived its nitrogen from the protein food, becomes converted into forms directly available to plants. 
Biuret. - This compound, as the name indicates, is a derivative of two molecules of urea from which it is formed by the loss of one molecule of ammonia. The reaction is as follows:

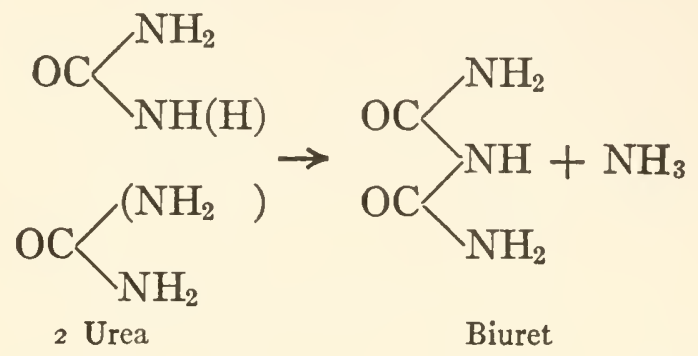

The substance is colored pink by a very dilute solution of copper sulphate, and the biuret test for proteins (Experiment Study XVIII, $4, c$ ) derives its name from this compound.

\section{EXPERIMENT STUDY XIX}

\section{Urea}

(I) Determination of Urea. (a) Make a 2 per cent solution of urea. (b) Prepare an alkaline solution of sodium hypobromite as follows :
$\mathrm{NaOH}$, to per cent solution, roo c.c.
Bromine
2 c.c.
$2 \mathrm{NaOH}+\mathrm{Br} \rightarrow \mathrm{NaOBr}+\mathrm{NaBr}+\mathrm{H}_{2} \mathrm{O}$

(c) Fill the ureometer tube with the hypobromite solution and then add, by means of a small I c.c. bent pipette, I c.c. of urea solution to the ureometer tube. Allow to stand and measure the gas evolved. The gas is nitrogen according to the following reaction:

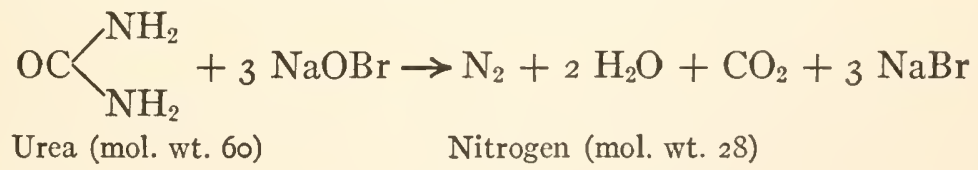

The $\mathrm{CO}_{2}$ evolved is absorbed by the alkali of the solution. This reaction is quantitative and the amount of nitrogen gas evolved is an exact measure of the urea decomposed as 60 parts by mass of urea yield 28 parts by mass of nitrogen. The ureometer used in this test is a piece of clinical apparatus so graduated that for I c.c. of urine the nitrogen evolved is read directly in per cent of urea in the urine. 
(2) Preparation of Biuret. Place a small amount of urea in a dry, small test tube. Heat carefully until the urea melts. Continue to heat slowly as long as gas is evolved. What is the gas? Test with red litmus paper and by odor. After all ammonia is expelled, cool and dissolve in water. Now add to the solution an equal volume of strong $\mathrm{KOH}$ and a few drops of very dilute $\mathrm{CuSO}_{4}$ solution as described under Experiment XVIII, 4, c. The pink color is due to the reaction of the biuret, formed from the urea, and the copper sulphate.

\section{Uric Acid and Purine Bases}

Uric acid is a much more complex compound related to urea. It contains two urea residues joined together by a carbon nucleus.

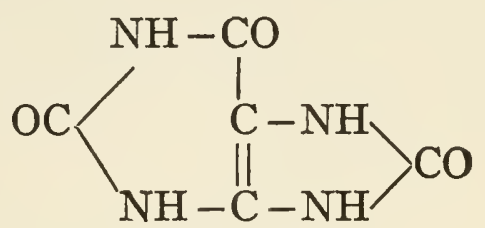

Uric acid

It is what is known as a tautomeric compound, i.e. it exists in either of two forms depending upon the conditions and the character of the substance acting upon it. The tautomeric form is represented by the following formula:

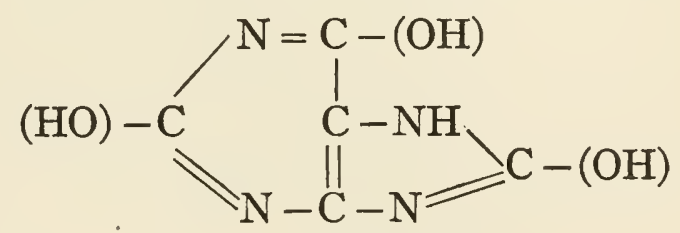

Uric acid

This is a tri-hydroxy derivative of a hypothetical compound known as purine which has the formula,

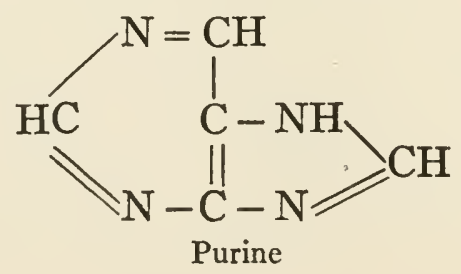


Several well-known and commonly occurring substances have been shown to be derivatives of this same hypothetical compound purine. The simplest of these is xanthine, which is a di-hydroxy-purine. It is present in urine and in animal tissues. Theobromine, the active constituent of the cocoa bean and present in chocolate and cocoa, is the di-methyl derivative of xanthine, i.e. di-methyl-di-hydroxy-purine. Caffeine, or thein, the active constituent of coffee and tea, is a tri-methyl derivative of xanthine or tri-methyl-di-hydroxy-purine. Writing the formulas all together will show their relationship.
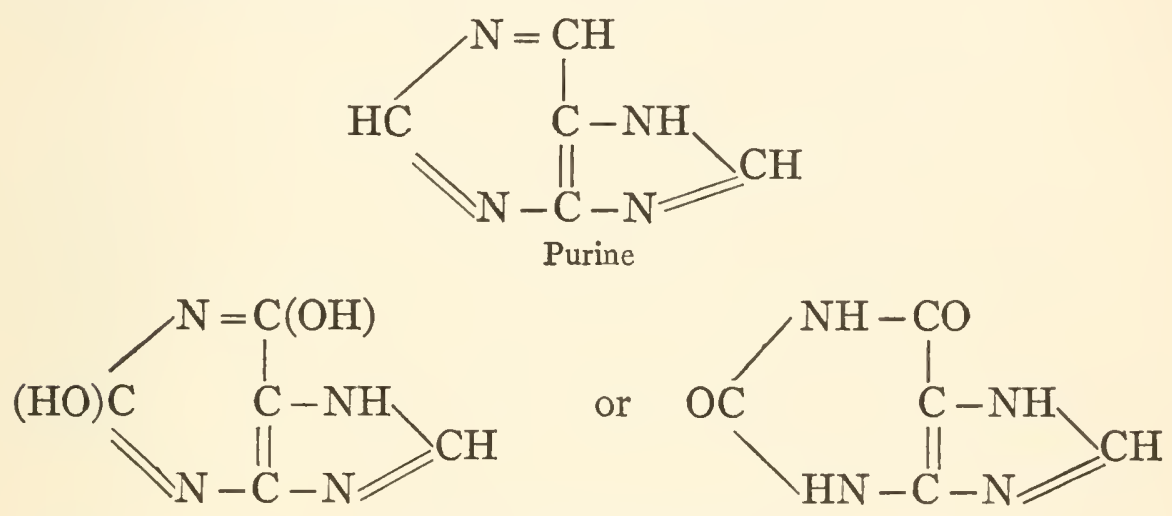

Xanthine, Di-hydroxy-purine
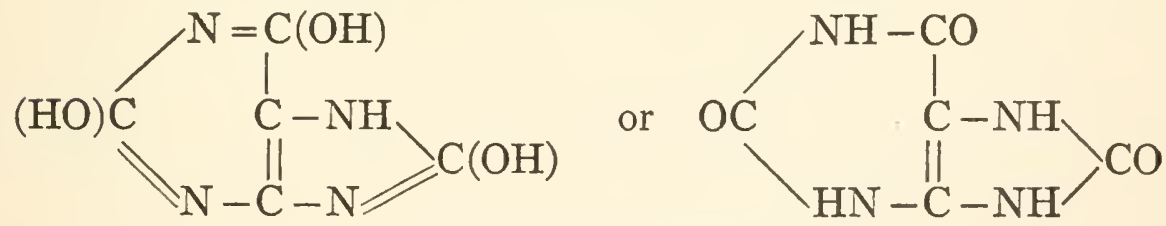

Uric acid, Tri-hydroxy-purine

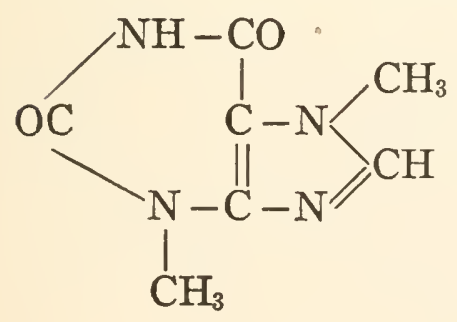

Theobromine

Di-methyl xanthine

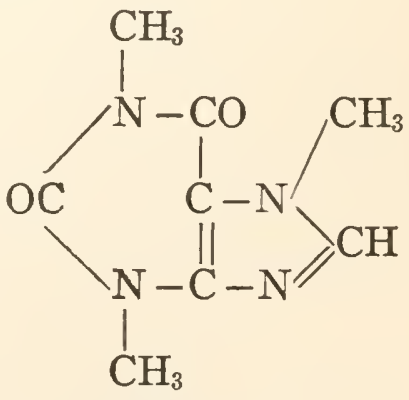

Caffeine

Tri-methyl xanthine 


\section{CHAPTER VII}

\section{A R B O Y D R A T E S}

WE come now to the consideration of the third essential organic constituent of animal foods, the carbohydrates. The other two, viz. fats and proteins, have already been discussed. We shall find that the group of compounds known as carbohydrates contains some of the most important substances that have to do with plant and animal life and also some which have a very great value industrially in other ways than as food. We shall confine ourselves now to the study of these compounds as to their chemical nature, their classification and relationship to each other and their general relation to plants and animals and to manufactured products. Their physiological relation to plants and animals, their special occurrence in plants and their specific industrial uses will be considered later.

Composition. - The name carbohydrates was originally given because it was supposed that they were carbon and water compounds. It is now known that they bear no direct relation to these two substances other than the fact that they contain carbon plus hydrogen and oxygen with these last two elements in the same proportion in which they are present in water, i.e. $\mathrm{H}_{2}: \mathrm{O}$ or two atoms of hydrogen (two parts by mass) to one atom of oxygen (sixteen parts by mass). A fact which led to the belief that the carbohydrates contain carbon and water, is that when they are thoroughly dried and freed from all hygroscopic water and also from all water of crystallization and then heated out of contact with oxygen they are decomposed and water is driven off while carbon remains,

$$
\text { Carbohydrates }+ \text { heat } \rightarrow \text { carbon }+ \text { water }
$$

This same decomposition occurs when some carbohydrates, e.g. cane sugar, are treated with concentrated sulphuric acid 
which absorbs water and leaves a residue of pure carbon. The general formula for all carbohydrates, with one exception, which need not be discussed here, is $\mathrm{C}_{n}\left(\mathrm{H}_{2} \mathrm{O}\right)_{x}$. In this formula $x$ may have the same value as $n$ or it may be equal to one less than $n$.

\section{EXPERIMENT STUDY XX \\ General Properties of Carbohydrates}

(I) (a) Dry some cane sugar at $100^{\circ} \mathrm{C}$. until all hygroscopic moisture has been driven off. (b) Heat about a gram of dry cane sugar in a test tube. Notice moisture given off as the sugar decomposes. What is the residue in the tube? This proves carbon, hydrogen and oxygen as constituents of sugar. (c) To $5 \mathrm{~g}$. of dry cane sugar in a test tube add about 5 c.c. concentrated sulphuric acid (c. p.). Without heating notice decomposition due to the removal of water by the sulphuric acid and the residue of pure carbon. This is a method of preparing chemically pure carbon.

(2) Make the soda lime test for nitrogen, Experiment XVIII, 2. This proves absence of nitrogen.

(3) Moore's Test. To 5 c.c. of a sugar solution add a little $\mathrm{KOH}$ and warm. A yellow and then brown color is characteristic of carbohydrates.

\section{Constitution. Mixed Alcohol-aldehyde or Alcohol-ketone} Compounds. - Without entering into a detailed discussion in regard to the constitution of these compounds, with the proofs for each of the views advanced, we may simply state the fundamental facts necessary for understanding their relation to each other. The simple carbohydrates which are known as mono-saccharoses undergo reactions which indicate that they contain both alcoholic hydroxyl groups and also an aldehyde or ketone group. Furthermore each carbon atom but one has one and only one alcoholic hydroxyl joined to it. This remaining carbon atom is in the condition of either an aldehyde or ketone group. The group characteristic of aldehydes and ketones is

$$
\stackrel{\mathrm{C}}{\mathrm{C}}=\mathrm{O} \text {, i.e. } \mathrm{R}-\stackrel{\mathrm{H}}{\mathrm{C}}=\mathrm{O} \text { in aldehydes and } \mathrm{R}-\stackrel{\mathrm{R}}{\mathrm{C}}=\mathrm{O} \text { in }
$$
ketones (see p. 42). 
The carbohydrates are also directly related to the polyhydroxy alcohols containing the same number of carbons with a hydroxyl joined to each carbon. By the oxidation of these polyhydroxy alcohols, with the conversion of one alcoholic group only into an aldehyde group or a ketone group, we obtain the carbohydrates.

This will be clear if we illustrate with a concrete example. The common sugars glucose and fructose each contain six carbon atoms, their formula being $\mathrm{C}_{6} \mathrm{H}_{12} \mathrm{O}_{6}$. They are both related to the hexa-hydroxy-hexane which is known as sorbitol and which has the constitution as follows:

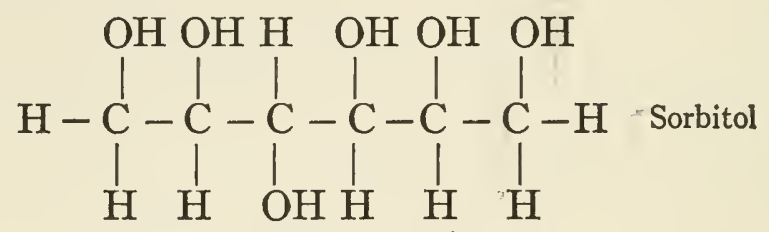

When this is oxidized with the conversion of one of the end primary alcohol groups into an aldehyde group, we obtain the compound :

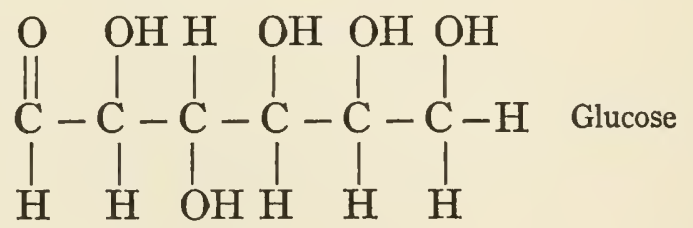

The compound so obtained is the sugar glucose. When, however, the oxidation results in the conversion of one of the secondary alcohol groups into a ketone group, we obtain the compound:

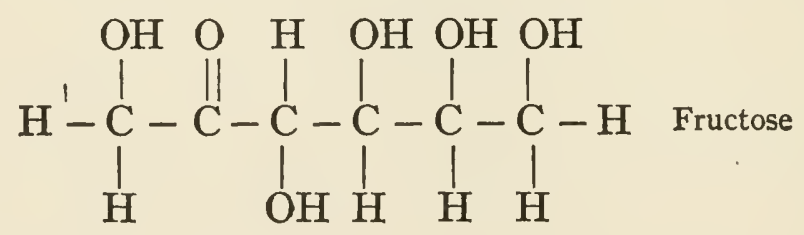

This compound is the sugar known as fructose. These two formulas agree with the composition of the two sugars, viz. $\mathrm{C}_{6} \mathrm{H}_{12} \mathrm{O}_{6}$ or $\mathrm{C}_{6}\left(\mathrm{H}_{2} \mathrm{O}\right)_{6}$. The sugars themselves undergo the 
distinctive reactions characteristic of aldehydes and ketones, viz. they form addition producis with hydrogen cyanide, $\mathrm{HCN}$, they yield oximes with hydroxyl amine, $\mathrm{H}_{2} \mathrm{~N}-\mathrm{OH}$, and they form hydrazones when treated with phenyl hydrazine, $\mathrm{H}_{2} \mathrm{~N}-\mathrm{NH}-\mathrm{C}_{6} \mathrm{H}_{5}$. These reactions were referred to in connection with aldehydes (p. 44) and they have been of the greatest importance in the study of the carbohydrates.

It will not be necessary to discuss these reactions more in detail nor to dwell further upon ideas in regard to the constitution of the carbohydrates, for these facts are not essential to an understanding of their agricultural importance. The more important study for us is the occurrence and distribution of the carbohydrates in nature, their relation to each other and to a few other compounds such as alcohol and lactic acid, and their economic uses. Before dismissing the question of constitution, however, it should be stated that recent work has shown that the aldehyde and ketone structure is probably not the form in which the carbohydrates actually exist, but that they take this form when acted upon by the reagents considered.

Classification. - The carbohydrates are subdivided into several smaller groups, depending both upon the number of carbon atoms in the molecule and upon their general complexity and relation to each other. In the first place there are two main groups which are known as simple carbohydrates and compound carbohydrates. The simple carbohydrates, or, as they are more generally termed, the simple sugars, are known more definitely as mono-saccharoses. The name signifies the fact that the compounds of this subgroup are the unit sugars. This is shown by the fact that they cannot be split or broken down by hydrolysis into any simpler units and also because they are the unit parts of more complex carbohydrates. The general formula is $\mathrm{C}_{n}\left(\mathrm{HO}_{2}\right)_{n}$. Typical examples of monosaccharoses are the two common sugars already mentioned, glucose and fructose. These both have six carbon atoms in the molecule and their formula is, therefore, $\mathrm{C}_{6}\left(\mathrm{H}_{2} \mathrm{O}\right)_{6}$ or $\mathrm{C}_{6} \mathrm{H}_{12} \mathrm{O}_{6}$. While all the monosaccharoses are alike in this unit character, the 
subgroup is further divided into smaller groups depending upon the number of carbon atoms in the molecule. The number of carbon atoms varies from two to nine and the names indicate the number of carbon atoms. Monosaccharoses which contain two carbons are called bi-oses and have the formula $\mathrm{C}_{2} \mathrm{H}_{4} \mathrm{O}_{2}$; those containing three carbons are called tri-oses with the formula $\mathrm{C}_{3} \mathrm{H}_{6} \mathrm{O}_{3}$. Similarly, the other subgroups of monosaccharoses are tetr-oses, $\mathrm{C}_{4} \mathrm{H}_{8} \mathrm{O}_{4}$, pent-oses, $\mathrm{C}_{5} \mathrm{H}_{10} \mathrm{O}_{5}$, hex-oses, $\mathrm{C}_{6} \mathrm{H}_{12} \mathrm{O}_{6}$, hept-oses, $\mathrm{C}_{7} \mathrm{H}_{14} \mathrm{O}_{7}$, oct-oses, $\mathrm{C}_{8} \mathrm{H}_{16} \mathrm{O}_{8}$, and non-oses, $\mathrm{C}_{9} \mathrm{H}_{18} \mathrm{O}_{9}$. Those of special importance and which we shall study further are the trioses, pentoses and hexoses.

The compound carbohydrates are known as poly-saccharoses, which signifies that they are made up of more than one unit sugar. This is proven by the fact that on hydrolysis they split and yield two or more molecules of the monosaccharoses. They are further divided into smaller groups according to the number of monosaccharose molecules which they yield. Di-saccharoses are those polysaccharoses which yield two molecules of monosaccharoses. Their formula is $\mathrm{C}_{n}\left(\mathrm{H}_{2} \mathrm{O}\right)_{n-1}$, or $\mathrm{C}_{12} \mathrm{H}_{22} \mathrm{O}_{11}$, and they are typified by the common sugar of commerce, cane sugar. Tri-saccharoses are polysaccharoses which yield three molecules of monosaccharoses. Their formula is $\mathrm{C}_{18} \mathrm{H}_{32} \mathrm{O}_{16}$ and an example is the sugar raffinose. Poly-saccharoses, specifically so called in distinction from the two subgroups just mentioned, are those polysaccharoses which yield an indefinite number of molecules of monosaccharoses. This group is typified by the common substances, starch and cellulose, with the formula $\left(\mathrm{C}_{6} \mathrm{H}_{10} \mathrm{O}_{5}\right)_{x}$. A tabular presentation of the classification of carbohydrates will perhaps make the whole matter clearer. 


\section{CARBOHYDRATES}

Simple carbohydrates

or

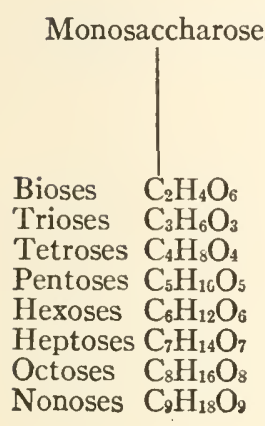

Compound carbohydrates

Polysaccharoses

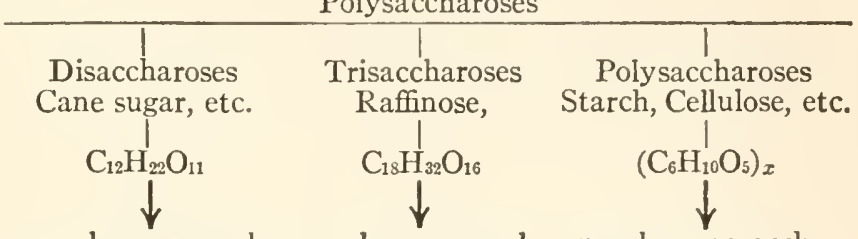

$2 \mathrm{~mol}$. monosacch. $3 \mathrm{~mol}$. monosacch. $x$ mol. monosacch.

TRIOSES, $\mathrm{C}_{3} \mathrm{H}_{6} \mathrm{O}_{3}$

In discussing the constitutional formula for the carbohydrates, as previously given, we showed the relation between the six-carbon sugar glucose (a hexose) and the six-carbon hexahydroxy alcohol sorbitol. The triose sugar bears exactly the same relation to the three-carbon tri-hydroxy alcohol which we have considered before, viz. glycerol (glycerin).<smiles>OCC(O)CO</smiles>

Glycerol

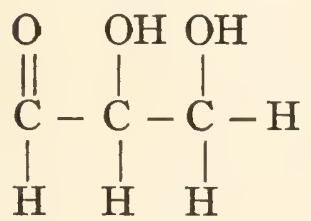

and

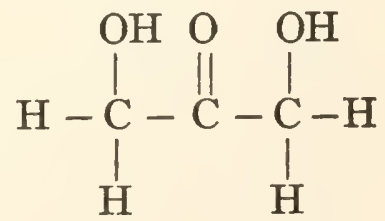

Glycerose

The importance of this simple sugar, which is a mixture of both the aldehyde and ketone compounds, is that it can be made from glycerol and that it undergoes polymerization and yields fructose sugar. 


\section{PENTOSES, $\mathrm{C}_{5} \mathrm{H}_{10} \mathrm{O}_{5}$}

The four-carbon monosaccharoses or tetroses are not important, but the five-carbon compounds, pentoses, are commonly occurring substances in many plants. When certain gums such as gum arabic, cherry gum or wood gum, are boiled with acids, sugars known as arabinose and xylose are obtained which are pentoses, and have the formula $\mathrm{C}_{5} \mathrm{H}_{10} \mathrm{O}_{5}$.

These sugars are contained in the gums, not as sugars, but as complex compounds which, because they yield pentose sugars, are known as pentosans. The substances occur in the woody or cellular parts of many plants which are used as animal foods, and are directly utilizable by the animal as food nutrients. The amount of pentosan compounds in an animal food is, therefore, an important item. We shall consider pentosans more at length as constituents of plants in Chapter XV, p. 272 .

The only carbohydrates which do not contain the elements hydrogen and oxygen in the proportion $\mathrm{H}_{2}: \mathrm{O}$ are the substituted sugars. The best known is rhamnose, which has the composition $\mathrm{C}_{6} \mathrm{H}_{12} \mathrm{O}_{5}$. It is a methyl substitution product of a pentose, i.e. $\left(\mathrm{CH}_{3}\right)-\mathrm{C}_{5} \mathrm{H}_{9} \mathrm{O}_{5}$.

\section{EXPERIMENT STUDY XXI}

\section{Pentosans and Pentoses}

(I) (a) Place about $2.0 \mathrm{~g}$. of wheat bran in a flask and boil with Ioo c.c. of dilute $\mathrm{HCl}$ (sp. gr. I.I 5), distilling through a condenser until about 25 c.c. of distillate have collected. Now add to the distillate some phloroglucinol solution. A green precipitate turning black shows the presence of furfural. The furfural has been produced from the pentose carbohydrates obtained by hydrolysis of the pentosans present in the bran. (b) The same experiment may be performed, using gum arabic instead of bran.

\section{HEXOSES, $\mathrm{C}_{6} \mathrm{H}_{12} \mathrm{O}_{6}$}

By far the most important group of monosaccharose sugars is that of the hexoses which have six carbon atoms and the formula $\mathrm{C}_{6} \mathrm{H}_{12} \mathrm{O}_{6}$. The most common members of this group are: 
Glucose, dextrose or grape sugar,

Fructose, levulose or fruit sugar,

Galactose.

These hexose monosaccharoses all have the formula $\mathrm{C}_{6} \mathrm{H}_{12} \mathrm{C}_{6}$. They differ in constitution in ways that need not be entered into here, but we shall consider in detail their relation to the polysaccharose carbohydrates.

We have given to the whole class of simple sugars the name of monosaccharoses. This name is given in distinction to those of disaccharoses, trisaccharoses and polysaccharoses, and because they are the simplest of the entire group of carbohydrates. This simple nature is shown by the fact that they do not split up by hydrolysis into any simpler carbohydrate compounds. The disaccharoses and all polysaccharoses are known as such because on hydrolysis they do split up and yield two or more molecules of these monosaccharoses.

\section{Ghucose or Dextrose, $\mathrm{C}_{6} \mathrm{H}_{12} \mathrm{O}_{6}$}

Occurrence and Properties. - The most important and most common of the hexose sugars is glucose, also known as dextrose and grape sugar because it occurs naturally in ripe grapes. It is found also in all other ripe fruits and in honey. It is present in small amounts in many plants. It occurs in the blood of all animals and in urine in the disease known as Diabetes. As we shall find when we study animal nutrition, it is the final form into which most of the carbohydrate food is changed in the process of digestion, and the form in which it is burned in the blood to furnish heat to the animal body. It occurs also in combination in plants in the form of complex compounds known as glucosides. These glucosides upon hydrolytic decomposition yield glucose. An example may be mentioned, viz. amygdalin, a glucoside found in bitter almonds and in cherry kernels, which by fermentation yields glucose, hydrogen cyanide, and a substance known as benzaldehyde, or oil of bitter almonds.

Determination. - Glucose possesses optical activity as explained in connection with lactic acid. It turns the plane of 
polarized light to the right, i.e. it is dextro-rotatory and on this account is known also as dextrose. This physical property, being constant and definite in amount, is used as a means of determining the quantity of glucose in a solution. That is, the amount in a solution can be calculated by measuring the angle through which it turns the plane of polarized light to the right. This will be referred to again when we consider ordinary or cane sugar. It is also a strong reducing agent. An ammoniacal solution of silver nitrate is reduced to metallic silver and an alkaline solution of copper sulphate is reduced to red cuprous oxide, $\mathrm{Cu}_{2} \mathrm{O}$. This last reaction is also used as a method of quantitatively determining the amount of glucose in solution by weighing the cuprous oxide formed. The copper solution used in this determination is made up of definite amounts of copper sulphate, $\mathrm{CuSO}_{4}$, potassium sodium tartrate or Rochelle salt, $\mathrm{KNaC}_{4} \mathrm{H}_{4} \mathrm{O}_{6}$, and sodium hydroxide, $\mathrm{NaOH}$. It is known as Fehling's solution, ${ }^{1}$ and may be used volumetrically by titration, as in urine analysis, or gravimetrically by weighing the cuprous oxide formed, as is done in the case of ordinary solutions containing glucose. Fehling's solution may be used in determining the amount of one of the other monosaccharoses, viz. fructose, and also the two disaccharoses, malt sugar and milk sugar. Glucose is a solid, crystallizing in masses more or less wax-like and containing one molecule of water of crystallization. As ordinarily obtained under the name of glucose sirup it is a thick, viscous liquid. It is readily soluble in water and almost insoluble in absolute alcohol. It tastes only slightly sweet. It has numerous industrial applications, in dyeing, in the making of confectionery and jellies and in pharmaceutical preparations. It is not ordinarily obtained from its natural sources, but is made by chemical transformation from other members of the carbohydrate group. All three of the common

1 Allihn's modification of Fehling's solution is made as follows:

Solution A: $\mathrm{CuSO}_{4} \cdot{ }_{5} \mathrm{H}_{2} \mathrm{O}, 69.2$ g. per litre.

Solution B : (Rochelle salt, $346 \mathrm{~g} .+\mathrm{KOH}, 250 \mathrm{~g}$.) per litre.

$\mathrm{A}$ and $\mathrm{B}$ are mixed in equal volumes and the mixed solution used freshly prepared. 
disaccharose sugars, viz. cane sugar, malt sugar and milk sugar, when acted upon by enzymes or when boiled with acids, yield glucose. Starch also by similar reactions is broken down into glucose, and this is the commercial method of preparing it. These reactions will be more fully considered later.

Fermentation of Glucose. - By far the most important reaction of glucose is its fermentation. When a solution of glucose is acted upon by the plant organism yeast (saccharomyces), it yields alcohol and carbon dioxide.

$$
\mathrm{C}_{6} \mathrm{H}_{12} \mathrm{O}_{6}+\text { yeast (zymase) } \rightarrow{ }_{2} \mathrm{C}_{2} \mathrm{H}_{5} \mathrm{OH}+{ }_{2} \mathrm{CO}_{2}
$$

This fermentation, as has been fully described under alcohol, is due to an enzyme known as zymase, which is secreted by the yeast cell. Alcoholic fermentation takes place in all glucosecontaining solutions whether the glucose is present in such solutions naturally, as in grape juice and apple juice, or whether it has been formed by a preceding decomposition of malt sugar or starch, as in the case of malted grain.

\section{Fructose or Levulose, $\mathrm{C}_{6} \mathrm{H}_{12} \mathrm{O}_{6}$}

Fructose or levulose is also known as fruit sugar, and is found usually associated with glucose in fruits such as grapes, and in honey. As its name, levulose, signifies, it is oppositely active toward polarized light to dextrose, being levo-rotatory. It does not crystallize easily, being more soluble than glucose both in water and in alcohol. It is like glucose in fermenting with yeast zymase, though less rapidly, and in reducing Fehling's solution. In their constitution glucose and fructose differ in that the former is an aldehyde-alcohol compound and the latter a ketone-alcohol compound. In the decomposition of cane sugar by enzymes or by boiling with acids not only glucose but also fructose is formed, and in equal molecular amounts, one molecule of glucose and one of fructose. In the decomposition of starch and malt sugar, however, only glucose is formed. Fructose is the direct product of a laboratory synthesis of sugars. Formaldehyde when treated with alkali is converted into this 
sugar. Also the three-carbon sugar glycerose, which may be made from glycerol, condenses and yields fructose. As fructose may be converted into glucose, we may say that both of the hexose monosaccharoses have been synthesized in the laboratory. There is pretty general belief that this formaldehyde synthesis of glucose and fructose represents part of the process by which carbohydrates are photo-synthesized in green plants.

\section{Galactose, $\mathrm{C}_{6} \mathrm{H}_{12} \mathrm{O}_{6}$}

Galactose, the third monosaccharose hexose sugar, may be simply mentioned. It is obtained together with glucose when milk sugar is hydrolyzed by enzymes or acids. It is dextrorotatory and ferments with yeast zymase. It has not been found free in either plants or animals, but occurs in combination in certain glucosides, especially one known as cerebron found in the brain. In plants it occurs also as polysaccharose derivatives known as galactans. These latter will be referred to again.

\section{EXPERIMENT STUDY XXII}

\section{Hexoses}

(r) Examine for general properties, such as solubility in water and in alcohol, taste, etc., (a) Glucose or dextrose; (b) Fructose or levulose.

(2) To 5 c.c. Fehling's solution add about r c.c. of glucose solution. Warm. Notice reduction of the copper sulphate to red $\mathrm{Cu}_{2} \mathrm{O}$. Allow to settle. If a blue color remains, add a little more sugar solution and repeat until all copper sulphate has been reduced.

(3) Repeat the Fehling's solution test with a solution of levulose.

(4) Perform Experiment XX, 3, with both glucose and fructose.

(5) To 5 c.c. of ammoniacal silver nitrate solution add a little glucose solution and warm in hot water. Notice formation of silver mirror due to the reduction of the silver solution.

(6) Make up a I.o per cent solution of glucose. Mix this solution with $\mathrm{I} . \mathrm{Og}$. yeast and fill a Fermentation tube with the mixture. Allow to stand 24 hours, and determine the amount of $\mathrm{CO}_{2}$ evolved. This fermentation tube is a form of clinical apparatus known as a Sac- 
charometer. It is so graduated as to read directly, from the volume of $\mathrm{CO}_{2}$, the per cent sugar in the original solution. The calculation is based on the following reaction:

$$
\begin{aligned}
& \mathrm{C}_{6} \mathrm{H}_{12} \mathrm{O}_{6} \rightarrow 2 \mathrm{CO}_{2}+{ }_{2} \mathrm{C}_{2} \mathrm{H}_{5} \mathrm{OH} \\
& \text { I80 } 88
\end{aligned}
$$

(7) Ferment glucose on a larger scale and obtain the alcohol as a distillation product. (See Experiment VIII.)

\section{DISACCHAROSES, $\mathrm{C}_{12} \mathrm{H}_{22} \mathrm{O}_{11}$}

The disaccharoses are sucrose or cane sugar, maltose or malt sugar and lactose or milk sugar. All of these compounds split by hydrolysis when acted upon by enzymes or when boiled with acids and yield two molecules of monosaccharoses, hence their name, disaccharoses. They possess the composition $\mathrm{C}_{12} \mathrm{H}_{22} \mathrm{O}_{11}$ and the reaction by which they split up into monosaccharoses is as follows:

$$
\begin{aligned}
& \mathrm{C}_{12} \mathrm{H}_{22} \mathrm{O}_{11}+\mathrm{H}_{2} \mathrm{O} \rightarrow{ }_{2} \mathrm{C}_{6} \mathrm{H}_{12} \mathrm{O}_{6} \\
& \text { Disaccharose } \\
& \text { Mono- }
\end{aligned}
$$

The disaccharoses may thus be considered as anhydrides of two molecules of monosaccharoses. The conversion of disaccharoses into monosaccharoses, involving simply the addition of a molecule of water, is termed a reaction of hydrolysis. We thus speak of hydrolyzing disaccharoses to monosaccharoses. This hydrolysis, as has been stated, takes place either through the agency of chemical substances known as enzymes or when the disaccharoses are boiled with dilute acids.

\section{Sucrose or Cane Sugar, $\mathrm{C}_{12} \mathrm{H}_{22} \mathrm{O}_{11}$}

Occurrence. - The most important of the disaccharoses is sucrose, or as it is known because of its most important source, cane sugar. It is very widely distributed in nature and occurs in almost all plants in greater or less amounts. The two most abundant sources from which it is obtained are the sugar cane, from which it derives its name of cane sugar, and the beet, in 
which it occurs in exactly the same form as in the sugar cane. It is also found in considerable amount in sorghum cane and in the sap of maple trees, especially the hard or sugar maple (Acer saccharum). Other rather abundant sources are vegetables such as carrots, parsnips, artichokes, in such fruits as strawberries and pineapples, in the sap of some other trees such as beech, and in some nuts such as chestnuts.

Properties. - Cane sugar is a crystalline solid, forming monoclinic prisms. It is easily soluble in water and slightly so in alcohol. It melts at $\mathrm{r} 60^{\circ} \mathrm{C}$, and when melted and allowed to cool it forms a transparent vitreous-like mass known as barley sugar, which gradually becomes crystalline. When heated to $210^{\circ} \mathrm{C}$., it loses water and is converted into a brown amorphous mass known as caramel which is used as a brown coloring agent, and as a flavoring substance of a characteristic taste. Heated still higher it decomposes, yielding finally a residue of carbon and giving off water and a mixture of volatile products containing several hydrocarbons, aldehydes and acids. When sugar is treated with concentrated sulphuric acid, it is decomposed with the evolution of heat and a residue of carbon is left. (See Experiment $\mathrm{XX}, \mathrm{I}, c$.) If this is washed to remove the acid, pure carbon is obtained, and this is used as a method of making pure carbon. Cane sugar is dextro-rotatory, but it does not reduce Fehling's solution. When pure cane sugar is treated with Fehling's solution, reduction often occurs after some minutes' boiling, because the sugar is first hydrolyzed into glucose and fructose which then reduce the Fehling's solution.

Cane sugar does not undergo alcoholic fermentation by the action of the enzyme zymase as do glucose and fructose. Yeast contains not only the alcoholic enzyme zymase but also enzymes which hydrolyze cane sugar and the other disaccharoses. When, therefore, cane sugar is subjected to yeast fermentation, alcohol is produced, due to a double process. First the cane sugar is hydrolyzed by the yeast enzyme sucrase or invertase and converted into glucose and fructose. These monosaccharoses are 
then fermented by the alcohol producing enzyme zymase, and alcohol results,

$$
\begin{aligned}
& \mathrm{C}_{12} \mathrm{H}_{22} \mathrm{O}_{11}+\text { sucrase }+\mathrm{H}_{2} \mathrm{O} \rightarrow{ }_{2} \mathrm{C}_{6} \mathrm{H}_{12} \mathrm{O}_{6} \\
& \text { Cane sugar } \\
& \mathrm{C}_{6} \mathrm{H}_{12} \mathrm{O}_{6}+\text { zymase }
\end{aligned}
$$

Glucose and Fructose

Hydrolysis. - When sucrose is hydrolyzed by enzymes or by boiling with acids, it yields two molecules of monosaccharoses. One molecule, however, is dextro-rotatory glucose and the other is levo-rotatory fructose.

$$
\underset{\text { Cane sugar }}{\mathrm{C}_{12} \mathrm{H}_{22} \mathrm{O}_{11}}+\mathrm{H}_{2} \mathrm{O} \rightarrow \underset{\text { Glucose }}{\mathrm{C}_{6} \mathrm{H}_{12} \mathrm{O}_{6}}+\underset{\text { Fructose }}{\mathrm{C}_{6} \mathrm{H}_{12} \mathrm{O}_{6}}
$$

Inversion. - As fructose is more strongly levo-rotatory than glucose is dextro-rotatory, a mixture of equal molecules of each is not inactive like equal molecules of dextro and levo lactic acid or tartaric acid, but is levo-rotatory. As the sucrose itself is dextro-rotatory, the hydrolysis thus changes or inverts the solution as to the direction in which it rotates the plane of polarized light. The process of converting sucrose into a mixture of glucose and fructose is, therefore, known as inversion, and the mixture of glucose and fructose obtained is called invert sugar. Invert sugar then is the mixture of equal molecules of glucose and fructose obtained by the hydrolysis or inversion of sucrose.

$$
\begin{aligned}
& \mathrm{C}_{12} \mathrm{H}_{22} \mathrm{O}_{11}+\mathrm{H}_{2} \mathrm{O} \rightarrow \mathrm{C}_{6} \mathrm{H}_{12} \mathrm{O}_{6}+\mathrm{C}_{6} \mathrm{H}_{12} \mathrm{O}_{6}
\end{aligned}
$$

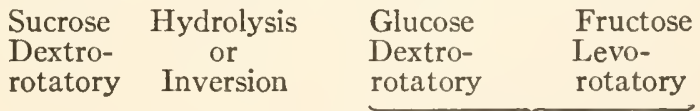

Invert sugar, levo-rotatory

The similar hydrolysis of the other disaccharoses, maltose and lactose, yields products of the same direction of optical rotation. These hydrolyses do not, therefore, result in inversion.

Invert Sugar. - Invert sugar may be separated by crystallization into the more readily crystallized glucose and the less 
readily crystallized fructose, but the crystallization is difficult and it is not a practical method for obtaining glucose. Invert sugar occurs in honey together with sucrose. As both glucose and fructose reduce Fehling's solution, invert sugar also reduces it and in a definite amount. The determination of the amount of sucrose in a solution by inverting it and then determining by Fehling's solution the amount of invert sugar present is a practical laboratory method of analysis. As sucrose is dextro-rotatory and invert sugar is levo-rotatory the determination of the optical rotation both before and after inversion gives a second practical method for determining the amounts of sucrose and invert sugar present in a mixture of the two substances.

Sugar Analysis. - This is in brief the principle of methods of analysis of all sugar-containing liquids such as are dealt with in all sugar-producing and refining processes, or in the study of plant constituents. Details of methods will be found in books on analytical chemistry or sugar analysis.

\section{Maltose, Malt Sugar, $\mathrm{C}_{12} \mathrm{H}_{22} \mathrm{O}_{11}$}

Maltose or malt sugar is the second of the important disaccharoses. It is present in malted grain, or malt, where it is produced from starch. When malt is extracted with water and the extract evaporated, a sirup is obtained containing maltose in solution. From such solution maltose may be obtained as a crystalline substance. It forms needle crystals with one molecule of water. It is easily soluble in water, and only slightly so in alcohol. It reduces Fehling's solution, but is not fermentable by zymase. It is optically active, being dextrorotatory. After hydrolysis to a monosaccharose, as in the case of cane sugar, the product is fermentable. When hydrolyzed by enzymes or by boiling with acids, two molecules of glucose are obtained. This reaction is not accompanied with optical inversion as in the case of cane sugar, as both the maltose and the hydrolytic product, glucose, are dextro-rotatory. 


\section{Lactose, Milk Sugar, $\mathrm{C}_{12} \mathrm{H}_{22} \mathrm{O}_{11}$}

Lactose or milk sugar. - The third disaccharose, as its name signifies, is found in the milk of mammals. It is not found in any plants. In milk, it is present to the extent of about 4-5 per cent. When both the fat and the protein have been separated from the milk, the remaining liquid on evaporation yields lactose (see Experiment XXIX). This separates as a crystalline substance, often in large crystal masses resembling cane sugar crystals or rock candy. The crystals contain one molecule of water. It also crystallizes with three molecules of water. It is soluble in six parts of water, and is slightly sweet. Like maltose, lactose reduces Fehling's solution, and both of these sugars may be determined quantitatively by means of this reagent, as in the case of glucose and fructose. It is optically active, being dextro-rotatory. When hydrolyzed by enzymes or boiling acids it yields one molecule of glucose and one of galactose, both being also dextro-rotatory so that no inversion takes place. It is not fermented by zymase. With yeast alcoholic fermentation occurs slowly after the lactose is first hydrolyzed by another enzyme of the yeast, probably lactase.

Lactose differs from the other two disaccharoses in readily undergoing a bacterial fermentation by which lactic acid is produced. As explained in connection with lactic acid, lactose is fermented by the lactic acid bacteria and inactive lactic acid, or fermentation lactic acid, is obtained. These bacteria are naturally present in milk, and after standing fermentation takes place, the lactic acid is formed and the milk, as we say, sours. The chemical reaction in the conversion of lactose into lactic acid is first one of hydrolysis into glucose and galactose, and then one of simplifying the molecule without hydrolysis, oxidation or any other chemical reaction.

$$
\begin{aligned}
& \mathrm{C}_{12} \mathrm{H}_{22} \mathrm{O}_{11}+\mathrm{H}_{2} \mathrm{O} \rightarrow{ }_{2} \mathrm{C}_{6} \mathrm{H}_{12} \mathrm{O}_{6} \\
& \text { Lactose } \\
& \text { Glucose and } \\
& \text { Galactose } \\
& \mathrm{C}_{6} \mathrm{H}_{12} \mathrm{O}_{6} \rightarrow{ }_{2} \mathrm{C}_{3} \mathrm{H}_{6} \mathrm{O}_{3} \\
& \text { Glucose Lactic acid }
\end{aligned}
$$




\section{EXPERIMENT STUDY XXIII}

\section{Disaccharoses}

(I) Sucrose or Cane Sugar. (a) Test a ro per cent cane sugar solution with Fehling's solution as in Experiment XXII, 2. (b) To 5 c.c. of sugar solution, add I.O c.c. of dilute ( $\mathrm{I}: \mathrm{I}) \mathrm{HCl}$, boil for 5 minutes. Neutralize excess of acid with $\mathrm{Na}_{2} \mathrm{CO}_{3}$ and then test with Fehling's solution. (c) Heat a little cane'sugar carefully in a test tube. Notice darkening in color and characteristic odor (caramel).

(2) Repeat (I, a) and XX, 3 with maltose (malt sugar).

(3) Repeat ( $x, a$ ) and XX, 3 with lactose (milk sugar).

\section{POLYSACCHAROSES (NOT SUGARS), $\left(\mathrm{C}_{6} \mathrm{H}_{10} \mathrm{O}_{5}\right)_{x}$}

The polysaccharoses, or more strictly speaking those polysaccharoses not sugars, for the disaccharoses are of course polysaccharoses, include the common and very widely distributed substances, starch, dextrin, cellulose, and the less common glycogen found in animals.

Hydrolysis. - The formula for the polysaccharoses is $\left(\mathrm{C}_{6} \mathrm{H}_{10} \mathrm{O}_{5}\right)_{x}$. The size of the molecule is unknown, but it is probably quite large. Like the disaccharoses these polysaccharoses are hydrolyzed by enzymes, and by boiling with acid. They each yield the monosaccharose glucose.

This hydrolysis of polysaccharoses to monosaccharoses is connected with several very important processes both natural and industrial. The natural processes occur in both plants and animals. In the green leaves of plants the carbohydrate, starch, which has been built up by the photosynthetic action of the leaves is converted by means of the enzyme diastase into maltose, and then by maltase enzyme into glucose. In all starch-containing seeds, when germination begins, the starch is converted by the same enzymes into these products. This process when produced artificially is known as malting, and the germinated seed or grain containing both glucose and maltose sugars is known as malt. By a completion of the enzyme action by means of zymase alcoholic fermentation takes place and the glucose 
formed yields alcohol. This, as has been discussed under alcohol, is the source of most of the industrial alcohol and of the alcohol in both malt and distilled beverages.

In the animal body two hydrolytic conversions of polysaccharoses occur. First, the digestive process by which starch food is hydrolyzed by the enzyme ptyalin, found in the saliva, and converted into maltose sugar. This is then further hydrolyzed by the enzyme maltase, found in the saliva and also in the intestinal juice, and yields glucose. Second, the metabolic conversion of glycogen in the liver and in the muscle cells into glucose also probably by enzyme action.

Source of Alcohol. - The industrial processes by which polysaccharoses are hydrolyzed to monosaccharoses, in addition to the natural process of malting grain already referred to, are: First, the hydrolysis of starch by means of boiling dilute acid into glucose for the purpose of obtaining the sugar or sirup known as glucose. Second, the hydrolysis of cellulose by means of acid to obtain glucose which by alcoholic fermentation then yields alcohol. This process of obtaining alcohol from cellulose material is being developed at the present time as a means of securing cheap alcohol for industrial purposes. All of these processes of hydrolyzing the polysaccharoses will be considered in detail later in this study in connection with the plants and animals concerned.

\section{Starch, $\left(\mathrm{C}_{6} \mathrm{H}_{10} \mathrm{O}_{5}\right)_{x}$}

Occurrence and Properties. - Starch is a constituent of some part of practically all plants. It occurs in especially large amounts in such plants as potato tubers, wheat, corn and other cereal grains, arrowroot, certain palms (sago), cassava, etc. In its general properties and relation to water, starch belongs to the class of bodies known as colloids. It does not dissolve in water, but may be so mixed with it as to remain suspended indefinitely in the form of an emulsion. In such form it is known as starch paste. It is non-diffusible through a semipermeable membrane. When dry, starch is a fine powder and 
is composed of small pieces or grains. These grains possess a definite microscopical structure which is different for the starch obtained from different plants. This makes possible the identification of starches as to their source, and is used in detecting adulteration of starches or starch-containing materials. When placed in cold water these starch grains remain unbroken and the starch does not mix with the water, but settles out on standing. If, however, the starch is boiled in water the grains are ruptured and the contents then mix with the water as an emulsion or colloidal suspension known as starch paste. In this form starch is adhesive, and is used as a substitute for gums and in sizing cloth and paper. When starch is brought in contact with a solution of iodine, a blue compound is formed. This blue color of iodine and starch is used in a number of ways as a test for starch or for free iodine. Starch grains treated with iodine take on a beautiful blue color under the microscope. The structure of the grains is shown very clearly so that starch grains and other similar granular substances are readily distinguished. Paper moistened with a starch paste to which potassium iodide has been added turns blue as soon as any iodine is liberated from the potassium iodide. This paper is thus a test for ozone, hydrogen peroxide, nitrous oxide or any other oxidizing substance which will set iodine free from its iodide salts. When starch is hydrolyzed by enzymes or by boiling with acids, a test with iodine solution readily indicates when all starch has been hydrolyzed. Starch does not reduce Fehling's solution, is non-fermentable by zymase and is inactive optically.

Hydrolysis. - When hydrolyzed by acids or enzymes, starch yields glucose only. In the enzymatic hydrolysis, two enzymes are chiefly concerned. In plants, both in green leaves and in seeds, the enzyme diastase converts starch into maltose sugar. In the animal body the saliva contains the enzyme ptyalin and the pancreatic juice contains the enzyme amylopsin both of which similarly hydrolyze starch into maltose. Associated with diastase in plants and with ptyalin in saliva and also pres- 
ent in the intestinal juice is another enzyme maltase which hydrolyzes maltose into glucose. This enzyme is also present in yeast. The complete enzymatic hydrolysis of starch therefore yields glucose as the final product. In the acid hydrolysis of starch glucose is also the final product, the intermediate products being probably the same as in the case of enzymatic hydrolysis.

Source of Glucose. - The acid hydrolysis of starch is employed in the manufacture of commercial glucose from starch. The starch is boiled with dilute sulphuric acid until a test with iodine for starch and with Fehling's solution for glucose shows that all starch has been converted into the sugar. The excess of sulphuric acid is then removed by precipitation and the sugar-containing filtrate is evaporated to a thick sirup known as glucose sirup (Karo Corn Sirup). In making Karo Corn Sirup the hydrolysis is not carried to completion, a good deal of maltose and dextrin being present which prevents the crystallization of the sirup. By complete hydrolysis and subsequent evaporation the glucose sugar crystallizes out as a solid. Glucose so obtained is a commercial product used as described under glucose sugar.

Determination. - Starch may be determined quantitatively by converting it into glucose either by means of diastase and maltase, by boiling with acids or by heating with steam under pressure. The resulting glucose is then determined by means of Fehling's solution or by its optical rotation.

\section{EXPERIMENT STUDY XXIV}

\section{Starch}

(I) Test corn, potato and wheat or rice starch for general character, and under the microscope for shape of starch grains. While under microscope add a drop of iodine solution.

(2) Test solubility of starch (any variety) in cold water.

(3) Mix a little starch ( 2.0 g.) with cold water to make a thin paste. Heat a liter of water to boiling. While boiling add the cold starch 
mixture and continue to boil a few minutes. This is a colloidal suspension of starch and is known as starch paste.

(4) Test this starch paste solution with iodine solution. Dilute the starch paste 10, 100 and rooo times, and test each with iodine solution.

(5) Dilute 5 c.c. starch paste, with roo c.c. water, add 5 c.c. of concentrated $\mathrm{HCl}$ and boil for Io to I 5 minutes. Neutralize excess acid with $\mathrm{Na}_{2} \mathrm{CO}_{3}$ and test a little with iodine solution, and another portion with Fehling's solution. The starch is hydrolyzed by boiling with acids as follows:

$$
\underset{\text { Starch }}{\left(\mathrm{C}_{6} \mathrm{H}_{10} \mathrm{O}_{5}\right)_{x}}+x \mathrm{H}_{2} \mathrm{O} \rightarrow \underset{\text { Glucose }}{\mathrm{C}_{6} \mathrm{H}_{12} \mathrm{O}_{6}}
$$

\section{Dextrin}

When starch is hydrolyzed by diastase or ptyalin, and also probably by acids, dextrin is formed as an intermediate product between starch and maltose. Dextrin is soluble in cold water, forming a sirup with adhesive properties, and is used commercially in several ways. It is optically active, being dextrorotatory, and reduces Fehling's solution. It is non-fermentable with zymase. Toward iodine, dextrin acts in different ways indicating the existence of several varieties. One form, known as erythro-dextrin, is colored reddish brown with iodine. Another form known as achroö-dextrin is colorless with iodine. Achroö-dextrin is also known in three varieties called $\alpha$-, $\beta$ - and $\gamma$-achroö-dextrin. All of these varieties of dextrin have been proven as intermediate between starch and maltose in the enzymatic hydrolysis of starch.

\section{Glycogen}

Glycogen is known as animal starch. It resembles starch and is found in the animal body. It is present in the liver and in the muscle cells as a reserve form of carbohydrate food material. It is broken down in the body, yielding glucose. This will be considered further in connection with animal metabolism. 


\section{Inulin}

Inulin is another starch-like carbohydrate found in certain plants, e.g. in potatoes, dandelion roots and dahlia tubers. On hydrolysis inulin is converted into fructose alone and not glucose.

\section{Cellulose}

Cellulose is one of the most important carbohydrates, considering its wide distribution in nature and the useful products made from it. The other two most important carbohydrates considered in this same way are cane sugar and starch. Cellulose is as widely distributed in nature as starch, and is the chief constituent of the fibrous portions of all plants. The fiber of cotton, flax and hemp plants is nearly pure cellulose and yields the materials known as cotton, linen and hemp, from which important products are made in the shape of cotton wool, thread or cloth, linen thread or cloth, and hempen twine and rope. It occurs also as the fibrous constituent of the straw of cereal grains and grasses, and in trees.

In woody fibers of the latter cellulose is not pure, but is present together with (probably in combination with) other substances known as lignin, cutin, etc., the compounds being termed ligno-celluloses in the first case and adipo-celluloses in the latter. In juicy fruits and also in the stems and roots of plants the cellulose or fibrous part contains similarly compounds of cellulose with another group of substances known as pectins, the compounds being termed pecto-celluloses. When fruit juices form jellies, it is due to the decomposition of these pecto-celluloses and the gelatinization of the pectins resulting.

Cellulose, like starch and unlike sugars, is insoluble in water, and unlike starch does not go into solution or colloidal suspension on boiling. When heated with dilute sulphuric acid, cellulose is converted into a starch-like substance called amyloid which gives the starch blue test with iodine. When this is boiled with acid it is hydrolyzed to glucose. Thus cellulose may be converted into glucose which may later be fermented to alco- 
hol. This production of alcohol from cellulose is in the experimental stage, as the process has not yet been perfected so as to be generally profitable on the commercial scale. Starch is still the chief source for the manufacture of alcohol. When unsized paper (filter paper) is treated with concentrated sulphuric acid for a short time and the acid then removed by washing with water, the paper is changed into a tough membrane-like form, which is known as parchment paper.

Cellulose is insoluble in dilute acids or alkalies, and the fibrous part of plant food not dissolved by such treatment is largely cellulose and is termed in analysis of foodstuffs crude fiber. Such crude fiber or cellulose is largely indigestible, possessing a coefficient of digestibility in domestic animals of only about 30 to 60 per cent. The purest form of cellulose readily obtainable is made from cotton fiber or filter paper by washing in alcohol, ether and dilute acids and alkalies. A reagent which dissolves cellulose is the so-called Schweitzer's reagent, which consists of copper hydroxide dissolved in ammonia.

Paper. - Paper in its various forms or grades consists of more or less pure cellulose. The source of the cellulose for the manufacture of paper may be the straw of cereals or grasses, cotton fiber either as such or as worn-out cotton cloth, the fiber of such soft woods as spruce or pine, and linen, which is the cellulose fiber of flax. Such material is first shredded and then treated with solvents such as alcohol, ether and dilute alkalies and acids, in order to remove all oils, gums and other soluble constituents. The fibrous pulp thus obtained is then passed through rolls and dried in the form of thin sheets. The material is bleached to remove all coloring matter, and is sized with rosin, to give it a smooth surface. The purity of the product and the fineness of its texture depend upon the thoroughness of the treatment. The strength and durability depend upon the physical character of the fiber used. Linen papers are stronger and are more durable than those made from cotton or wood. The fine filter paper used in chemical laboratories is practically pure cellulose. 
Mercerized Cotton and Artificial Silk. - When ordinary cotton is treated with moderately strong alkalies, compounds are formed with the cellulose which decompose again with water, yielding hydrates of cellulose. The cotton so treated maintains its general character, but is more or less transparent, resembling silk in appearance and possesses greater strength than the original cotton. It can also be dyed more readily than the original cotton. Such a product is known as mercerized cotton. This is not, however, what is known as artificial silk. The latter is prepared from cellulose by various methods. A solution of cellulose in Schweitzer's reagent or a solution of certain derivatives, e.g. nitrates or acetates, is passed through capillary tubes into a liquid which reprecipitates the cellulose or its derivatives. It is thus obtained in the form of fine threads or fibers consisting of pure cellulose or some derivative of it. As it is thus obtained it possesses many of the characters of silk and is commercially used as artificial silk. It can be readily dyed, possesses considerable silky luster, but though more durable and stronger than cotton or other cellulose fibers is not as strong or as durable as pure silk.

Explosives and Celluloid. - The chemical derivatives of cellulose are chiefly of two classes, viz. nitrates and acetates. These have been referred to as having been used in the preparation of artificial silk. The nitrates of cellulose are, however, a very important class of derivatives in themselves. When treated with nitric acid cellulose forms derivatives containing two to six nitric acid groups. When a mixture of nitric and sulphuric acid is used, six nitric acid groups unite with the cellulose and the compound, cellulose hexanitrate, is formed. This compound is highly explosive and is the chief constituent of gun cotton. Gun cotton explodes violently when struck or when set off by means of a detonator, but will burn quietly when it is ignited. It is used as an explosive by itself or mixed with nitroglycerin. It is also a constituent of some smokeless powders.

When cellulose is treated with nitric acid in a less concentrated form or for a shorter time, the nitrates of cellulose containing 
two, three, four and five nitric acid groups are formed. A mixture of these lower nitrates of cellulose is called pyroxylin or soluble gun cotton. It is soluble in alcohol and ether. Such an alcohol-ether solution of pyroxylin is known as collodion and is used in photography. When pyroxylin is mixed with camphor and heated, a plastic mass is obtained which can be molded into various shapes. This is known as celluloid. It is inflammable, but non-explosive, and is used in manufacturing a great variety of small articles for ornamental and toilet purposes.

\section{EXPERIMENT STUDY XXV}

\section{Cellulose}

(I) Examine some cotton fiber and some filter paper as examples of practically pure cellulose.

(2) Test solubility of cellulose in ordinary reagents and in Schweitzer's reagent prepared as follows: To a solution of copper sulphate add sodium hydroxide until a heavy light blue precipitate is formed. (Excess of the alkali will dissolve the precipitated cupric hydroxide to a deep blue solution.) Filter the cupric hydroxide, and wash out all excess alkali. To Io or I5 c.c. of concentrated ammonium hydroxide add the cupric hydroxide as long as it will dissolve in the ammonia. The deep blue solution resulting is ammoniacal cupric oxide, and is known as Schweitzer's reagent.

(3) Parchment Paper. Dip a piece of filter paper into dilute sulphuric acid I: $\mathrm{I}$. Remove the paper immediately and rinse in running water until well washed. The paper will be found to be tough and transparent and gives a blue test with iodine. It is called parchment paper.

(4) Hydrolysis of Cellulose to Glucose. Shred up a little filter paper and add it to ro c.c. concentrated sulphuric acid. Allow to stand until the paper is all dissolved. When all dissolved, pour the acid solution into 200 c.c. of water. Test a little of the dilute solution with iodine solution. What does the test show? The product is known as amyloid from amylum which is starch. Now boil the dilute solution for a half hour or so, and test a little with iodine, and another portion with Fehling's solution. What does the test show? 


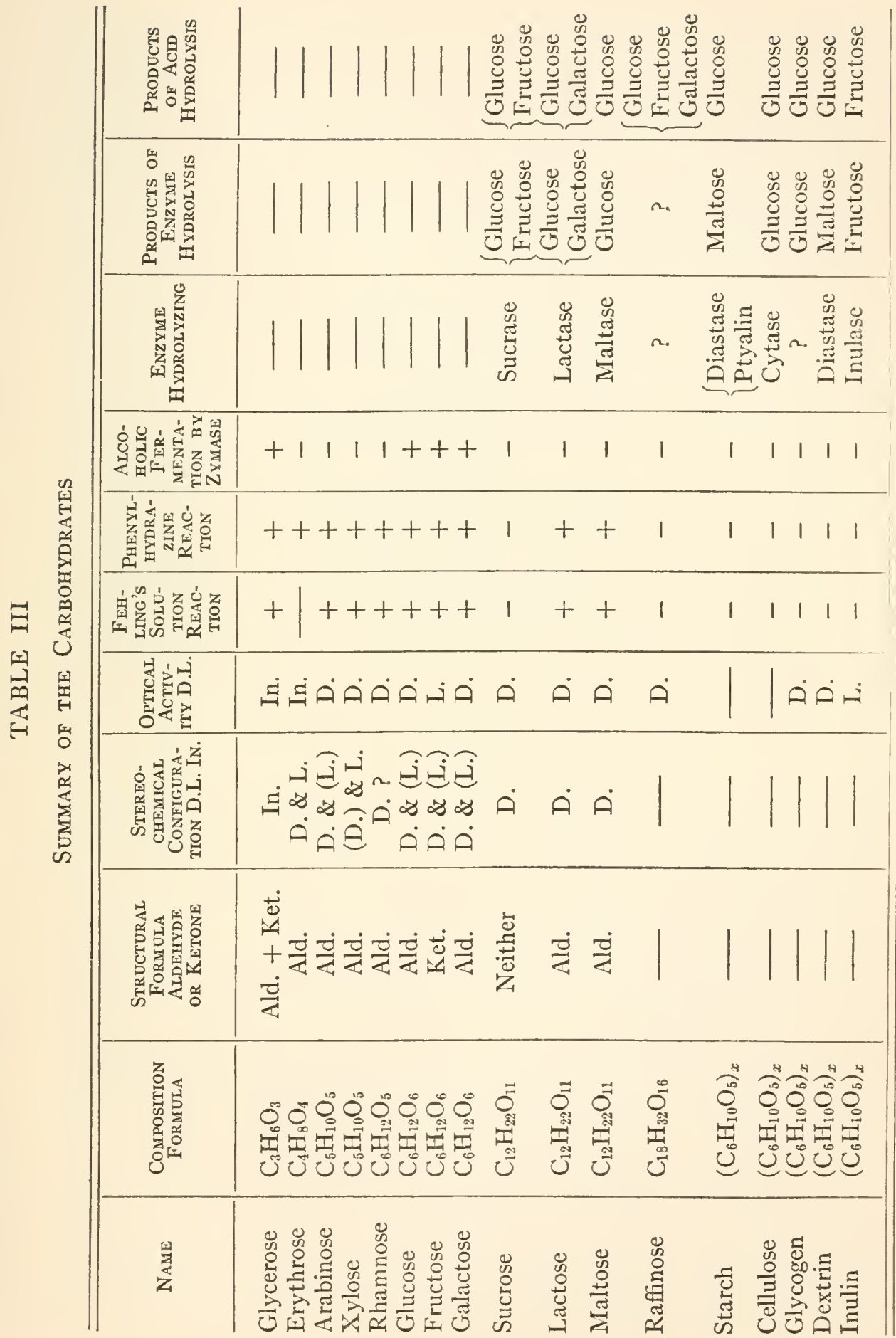


The reaction is the same as that for the hydrolysis of starch, Experiment XXIV, 5 .

Summary of the Carbohydrates. - The importance of the carbohydrates may be emphasized by briefly reviewing them. In this class we have the important food materials, starch, cane sugar, malt sugar, milk sugar, glucose and fructose. Starch is also widely used industrially as a sizing material and in the manufacture of alcohol and glucose. Dextrin is used as an adhesive. Cellulose has the greatest use industrially. It is the constituent of such useful materials as cotton, linen, hemp, jute and paper in all their various forms. Derivatives of cellulose or cellulose that has been modified in form by certain treatment are important as explosives (gun cotton, etc.), collodion, celluloid, mercerized cotton and artificial silk. Also glucose and glycogen are important metabolic products of the animal body. When we add to all this the fact that the carbohydrates are most widely and abundantly distributed in plants, we realize their extreme importance in relation to agriculture.

\section{UNSATURATED COMPOUNDS}

While the carbohydrates are the last group of compounds of any direct importance in our present study there still remains an entirely distinct class of compounds which we shall briefly mention.

In the compounds which we have discussed we have considered representatives of all of the characteristic divisions or groups, as follows :

Hydrocarbons; simple substitution products of the hydrocarbons such as mono- and poly-halogen products, and amino compounds, mono- and poly-hydroxy compounds or alcohols, glycerol, etc.; aldehydes; ketones; mono- and poly-carboxy acids; esters or ethereal salts, including the glycerol esters or fats; amides such as urea ; the related uric acid or purine compounds; hydroxy-acids ; amino-acids and the related proteins; hydroxy-aldehydes and the related carbohydrates. 
In the new class of compounds which we shall consider we shall meet with no new group of derivatives but mention a few which, though of like character, are derived from other hydrocarbons which possess a distinctly new property and constitution.

All of the compounds thus far considered have been derived from members of the methane or saturated series of hydrocarbons. In this series one of the fundamental ideas in connection with them is that of saturation. In methane and all of its derivatives the carbon atoms are always fully satisfied or are saturated, and this is shown by the fact that so far as the carbon atoms are related to each other they are united by only a single linkage and furthermore whenever derivatives are formed it is by a reaction of substitution, never by addition of new elements or groups. Each carbon element has four univalent elements or groups attached to it as in ethane, $\mathrm{H}_{3} \mathrm{C}-\mathrm{CH}_{3}$ or ethyl alcohol $\mathrm{H}_{3} \mathrm{C}-\mathrm{CH}_{2}(\mathrm{OH})$ or one bivalent element and two univalent elements or groups as in aldehydes,

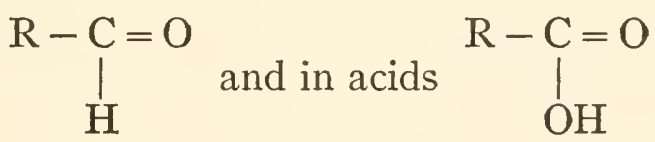

or the carbon has a trivalent element and one univalent element or group as in the cyanides $\mathrm{R}-\mathrm{C} \equiv \mathrm{N}$. In some cases addition does occur due to the conversion of a bivalent oxygen into a univalent hydroxyl, necessitating the addition of a new univalent group as in the addition products of the aldehydes.

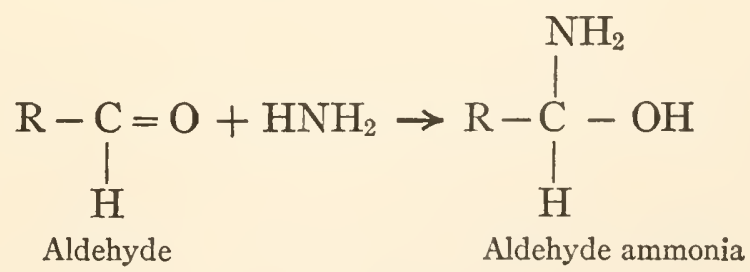

But in none of these cases of addition does the change effect the single linkage by which carbons are united to each other.

Unlike these saturated hydrocarbons we have other hydro- 
carbons which readily take up elements by addition to the molecule in such a manner as to indicate that in them the carbon atoms are not fully saturated. Ethylene or ethene gas, the simplest member of the series, has the composition $\mathrm{C}_{2} \mathrm{H}_{4}$ and when treated with bromine it easily takes up two atoms as follows :

$$
\underset{\text { Ethylene }}{\mathrm{C}_{2} \mathrm{H}_{4}+} \mathrm{Br}_{2} \rightarrow \underset{\text { Ethylene bromide }}{\mathrm{C}_{2} \mathrm{H}_{4} \mathrm{Br}_{2}}
$$

The compound formed is known as ethylene bromide and also as symmetrical di-brom-ethane. It is the same compound as is obtained from ethane gas, $\mathrm{C}_{2} \mathrm{H}_{6}$, by substituting two bromine atoms for two hydrogens. This latter reaction, as discussed previously (p. 20), we represent as follows:<smiles>CCCCCCBr</smiles>

As this same product is obtained by adding two bromine atoms to ethylene we are led to represent the reaction and the constitution of ethylene as follows:

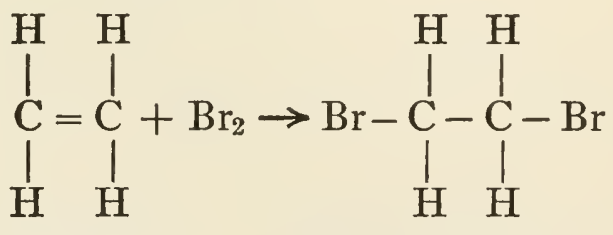

Ethylene Di-brom-ethane, or

Ethylene bromide

In ethylene we believe that the two carbons are only partly saturated, each one having one free valence or bond, but that this bond instead of remaining free is joined to the other carbon, thereby making the two carbon atoms doubly joined, instead of singly, as in the methane hydrocarbons. This double linkage of two carbon atoms is not a point of strength, but rather of weakness due to strain, and thus is easily broken and converted into singly bound carbons while the broken bond of each carbon 
atom becomes satisfied with the added bromine. In exactly a similar way we have compounds in which the carbon is considered as triply linked with another carbon atom while only the remaining bond is held by another element or group. Such a hydrocarbon is the common illuminating gas, acetylene, $\mathrm{C}_{2} \mathrm{H}_{2}$, and is represented as $\mathrm{HC} \equiv \mathrm{CH}$.

Now similar to each of these hydrocarbons we have an homologous series of higher hydrocarbons related to the simplest or mother substance just as ethane and the higher paraffin hydrocarbons are related to methane. These two series are known as the ethylene series and the acetylene series. Their relation to each other and to the methane series is readily seen if they are placed together as represented by their structural formulas.

\begin{tabular}{l|c|c}
\hline Saturated Hydrocarbons & \multicolumn{1}{|c}{ Unsaturated Hydrocarbons } \\
\hline \multicolumn{1}{c|}{ Methane Series } & Ethylene Series & Acetylene Series \\
\hline $\begin{array}{l}\text { Methane, } \mathrm{H}-\mathrm{CH}_{3} \\
\text { Propane, } \mathrm{H}_{3} \mathrm{C}-\mathrm{CH}_{3} \\
\begin{array}{l}\text { Butane, } \\
\mathrm{H}_{3} \mathrm{C}-\mathrm{CH}_{2}-\mathrm{CH}_{3}-\mathrm{CH}_{2}-\mathrm{CH}_{3}\end{array}\end{array}$ & $\begin{array}{l}\text { Ethylene, } \mathrm{H}_{2} \mathrm{C}=\mathrm{CH}_{2} \\
\text { Propylene, } \mathrm{H}_{3} \mathrm{C}-\mathrm{CH}=\mathrm{CH}_{2} \\
\text { Bulylene, } \\
\mathrm{H}_{3} \mathrm{C}-\mathrm{CH}_{2}-\mathrm{CH}=\mathrm{CH}_{2} \\
\text { or } \mathrm{H}_{3} \mathrm{C}-\mathrm{CH}=\mathrm{CH}-\mathrm{CH}_{3}\end{array}$ & $\begin{array}{l}\text { Acetylene, } \mathrm{HC} \equiv \mathrm{CH} \\
\text { Allylene, } \mathrm{H}_{3} \mathrm{C}-\mathrm{C} \equiv \mathrm{CH} \\
\text { Ethyl acetylene, } \\
\mathrm{H}_{3} \mathrm{C}-\mathrm{CH}_{2}-\mathrm{C} \equiv \mathrm{CH}\end{array}$ \\
\hline \hline
\end{tabular}

Each of these unsaturated series, viz. the ethylene hydrocarbons and the acetylene hydrocarbons, form derivatives, such as alcohols, aldehydes and acids. These are exactly analogous to those of the methane series. A few common and important ones will be mentioned.

Allyl alcohol

Allyl aldehyde or Acrylic aldehyde (acrolein)

Acrylic acid

Crotonic aldehyde

Crotonic acid

Oleic acid, $\mathrm{C}_{18} \mathrm{H}_{34} \mathrm{O}_{2}$
$\mathrm{CH}_{2}=\mathrm{CH}-\mathrm{CH}_{2} \mathrm{OH}$

$\mathrm{CH}_{2}=\mathrm{CH}-\mathrm{CHO}$

$\mathrm{CH}_{2}=\mathrm{CH}-\mathrm{COOH}$

$\mathrm{CH}_{3}-\mathrm{CH}=\mathrm{CH}-\mathrm{CHO}$

$\mathrm{CH}_{3}-\mathrm{CH}=\mathrm{CH}-\mathrm{COOH}$

$\mathrm{CH}_{3}-\left(\mathrm{CH}_{2}\right)_{7}-\mathrm{CH}=\mathrm{CH}-\left(\mathrm{CH}_{2}\right)_{7}-\mathrm{COOH}$ 
Derivatives of allyl alcohol which contain sulphur are contained in oil of garlic and some containing the iso-sulphocyanate group are found in oil of mustard. Acrolein or acrylic aldehyde is the sharp smelling substance produced when glycerol or fats are heated.

Oleic acid, a higher acid of the ethylene series containing eighteen carbon atoms and one doubly linked group of two carbon atoms, is found as a glycerol ester in fats and oils, especially in olive oil, maize oil, cotton seed oil and a small amount in butter.

Linolic acid, an eighteen-carbon acid, containing, probably, two groups of doubly linked carbon atoms, is found as a glycerol ester in linseed oil. We may compare here three of the acids found as glycerol esters in fats, each of which contains eighteen carbon atoms, but two of them are poorer in hydrogen than the other and belong to the unsaturated series.

\section{$\mathrm{C}_{18} \mathrm{H}_{36} \mathrm{O}_{2}$}

Stearic acid

Saturated acid

Methane series

Occurs as glyc-

erol ester

in beef fat.
$\mathrm{C}_{18} \mathrm{H}_{34} \mathrm{O}_{2}$

Oleic acid

Unsaturated acid

Ethylene series

Occurs as glycerol ester in butter fat.
$\mathrm{C}_{18} \mathrm{H}_{32} \mathrm{O}_{2}$

Linolic acid

Unsaturated acid

Occurs as glycerol ester in linseed oil.

These unsaturated acids, and the fats which contain their esters, like the hydrocarbons from which they are derived, readily take up bromine or iodine, forming addition compounds, and this reaction enables them to be distinguished and quantitatively separated from the saturated acids occurring with them in fats and in oils. The property of drying oils which makes them useful in paints and injurious in lubricating oils is due also to the presence of these unsaturated acids, especially linolic acid.

\section{Conclusion}

In a continuation of our study beyond the point of these unsaturated compounds, and the compounds we have considered 
previously to them, we would next come to compounds in which carbon groups instead of being joined together in open chains, either straight or branched, are united to each other in the form of a closed chain or ring. Such compounds are known as carbocyclic compounds. Chief among all the carbocyclic hydrocarbons is the well-known substance benzene (not benzine) which is obtained from coal tar. The name benzol, which is German, also applies to this compound. The derivatives of this hydrocarbon benzene $\left(\mathrm{C}_{6} \mathrm{H}_{6}\right)$ are even more numerous than those of methane, and many of them are of the greatest industrial importance in connection with dyeing, medicine and numerous industries and arts. The coal tar dyes, or aniline dyes, are derivatives of this class, and will suffice to give some indication of the importance of the compounds yet to be considered were we to complete our study of the compounds of carbon.

Few of the compounds of this large series are, however, of any direct importance in agriculture, and as in their study we should gain no new general ideas of value to us in connection with agricultural chemistry we shall not do more than mention them in this very brief way. We shall thus bring to a conclusion at this point our study of the organic compounds.

\section{References, Section I}

Abderhalden, Neuere Ergebnisse der Eiweisschemie, I909.

Armstrong, The Carbohydrates and Glucosides (Monographs on Biochemistry), I9I2.

Cohen, Organic Chemistry for Advanced Students, I9I3.

Diels, Organische Chemie, I909.

Holleman-Walker, Text-book of Organic Chemistry, I9I r.

Holleman-Walker, Laboratory Manual of Organic Chemistry, I9r3.

Leathes, The Fats (Monographs on Bio-chemistry), rgro.

Lewkowitsch, Chemical Technology and Analysis of Oils, Fats and Waxes, I9I5.

Mandel, Handbook for Bio-Chemical Laboratory, I896.

Meyer and Jacobson, Lehrbuch der Organischen Chemie, I893.

Molinari-Pope, General and Industrial Organic Chemistry, I9I3. 
Norris, Organic Chemistry, I9I 2.

Norris, Laboratory Manual of Organic Chemistry, I9I 5.

Noyes, Organic Chemistry, rgi2.

Osborne, The Vegetable Proteins (Monographs on Bio-chemistry), Igog.

Perkin and Kipping, Organic Chemistry, IgI I.

Plimmer, Practical Organic and Bio-Chemistry, I9I5.

Plimmer, Constitution of the Proteins (Monographs on Bio-chemistry), I908.

Remsen, Organic Chemistry, I909.

Schryver, General Characters of Proteins (Monographs on Biochemistry), I909.

Sherman, Organic Analysis, Igr 2. 
SECTION II

\section{PHYSIOLOGICAL}





\section{CHAPTER VIII}

\section{ENZYMES AND ENZYMATIC ACTION}

\section{Enzymes and Fermentation}

In the discussion of alcohol and its formation from glucose sugar by the process of fermentation we referred to the substances known as enzymes and to the particular enzyme, zymase, which produces alcoholic fermentation. The action of enzymes or of bacteria, the latter owing their activity to the enzymes produced, have also been mentioned in connection with acetic acid, lactic acid, glucose, fructose, sucrose, starch, fats and proteins. It will thus be seen that enzymes play an important part in the natural formation of many organic substances. In fact, most of the chemical changes occurring in plants and animals are produced by enzymes. This important connection with living things makes it desirable, before we take up the chemistry of plant and animal physiology, to discuss briefly the general facts in regard to enzymes.

The term fermentation applies to those chemical reactions which take place usually in connection with living organisms, in which the organism or substance produced by it takes no real part in the mass changes of the compounds involved. They act by their mere presence, or, as we say, catalytically, the chemical reaction itself being one of the ordinary type, such as oxidation, hydrolysis, etc.

The word enzyme means in yeast, and signifies the fact that the activity of yeast is due to an enzyme or enzymes. The isolation of the enzyme in yeast was not accomplished, however, until the word had been suggested and used for some time. The first enzymes known were those found in the digestive 
fluids of animals such as ptyalin in saliva, pepsin in gastric juice, and diastase in the leaves and seeds of plants, etc. These enzymes were also termed unorganized ferments to distinguish them from yeast and certain bacteria which were called organized ferments and in which the fermentation action was considered to be due to the living organism itself. In I897 Buchner isolated from yeast an enzyme, which he called zymase, which without the presence of the living yeast organism produced the alcoholic fermentation. This proved that in this case what had been considered an organized ferment was, in fact, an unorganized ferment or enzyme similar to the others mentioned.

This was the beginning of the idea that all fermentation, whether connected with an animal or a vegetable organism or not, is due to the activity of substances, not of the organism itself. These substances or enzymes, however, are produced by the organism so that indirectly the organism is essential to the fermentation. Pasteur, the great French chemist and biologist, showed the connection between fermentation and living organisms leading to the vitalistic theory of fermentation, while Buchner, in isolating an enzyme from yeast, showed the relation of a non-living substance, produced by the organism, to the fermentation, thus establishing the enzyme theory of fermentation.

Definition of Enzyme. - These facts which have been given lead to the definition of an enzyme as follows:

An enzyme is a substance which acts catalytically in bringing about a chemical reaction of the ordinary type, the enzyme being a product of a living cell but acting independently of that cell.

General Nature of Enzymes. - The exact nature of enzymes is unknown, though it is supposed that they are of protein character. They are colloidal substances, non-diffusible, soluble in water, dilute alcohol, dilute glycerol and sodium chloride solution, but precipitated by strong alcohol and by a solution of ammonium sulphate. In general they follow the physicochemical laws applying to colloids and catalysers. They act best at a certain optimum temperature which is, in most cases, approximately the temperature of the animal body, $37^{\circ} \mathrm{C}$. 
Their action is inhibited at low temperatures and is destroyed by boiling. Each enzyme also acts best in media of a certain reaction as regards acidity or alkalinity. Some act in acid media, some in alkaline, some in neutral. The concentration of acidity or alkalinity is often quite definite and the action is inhibited or even destroyed by a different concentration or by a change from acid to alkaline or vice versa. It is impossible to say whether the enzymes that have been isolated are pure and individual substances or not.

\section{Reactions Brought About by Enzymes}

The reactions which enzymes bring about are of several kinds, viz. hydrolysis, oxidation, reduction, coagulation and decomposition without extra-molecular oxidation, reduction or hydrolysis. The reaction of hydrolysis takes place with either carbohydrates (di- and poly-saccharoses), fats or proteins. With the carbohydrates hydrolysis results in the resolving of the polysaccharoses into their constituent monosaccharose units, e.g. sucrose into glucose and fructose, starch into maltose and this into glucose. With fats, which are glycerol esters, the hydrolysis splits the molecule into its constituent glycerol and fatty acid or acids. With proteins hydrolytic cleavage yields polypeptides and finally amino-acids. These reactions as such have each been discussed under the study of the different compounds concerned. In their final products the results of enzymatic hydrolysis and of acid hydrolysis are the same.

Hydrolyzing Enzymes. - The hydrolyzing or hydrolytic enzymes are defined further according to the compounds upon which they exert their catalytic effect, e.g.

Starch-hydrolyzing enzymes are amylolytic,

Sugar-hydrolyzing enzymes are sugar-splitting (saccharolytic), Protein-hydrolyzing enzymes are proteolytic,

Fat-hydrolyzing enzymes are lipolytic,

Glucoside-hydrolyzing enzymes are glucoside-splitting. These hydrolytic enzymes are, as we shall find, mainly concerned in the digestion and metabolism of plants and animals. 
Oxidizing Enzymes. - The enzymes causing oxidation reactions involve in most cases the presence of atmospheric oxygen, though in many important cases the oxygen comes from other compounds rich in oxygen, such as nitrates and carbohydrates. They are most important in the final oxidation reactions in plants and animals by which the food is oxidized in the cells of the organism and energy is liberated. The principal substance thus oxidized in the animal body is glucose, but it is possible that both fats and proteins are oxidized in this same way.

Reducing Enzymes. - The reducing enzymes produce the reverse reaction to the above and are probably present in animal and plant organisms, but no common examples can be given.

Coagulating Enzymes. - The chemical reaction involved in the coagulation of proteins, e.g. the coagulation of milk casein, has not been established. The coagulating enzymes are found both in digestive fluids (milk coagulating) and in blood (blood clotting).

Decomposing and Splitting Enzymes. - Those enzymes which cause the decomposition of the molecule without accompanying extra molecular change of the preceding types are of two classes. (I) Sugar (monosaccharose) fermenting enzymes that decompose glucose or fructose and yield alcohol and carbon dioxide. This is the action of the yeast enzyme zymase. (2) Sugar-splitting enzymes that decompose a large molecule into a smaller one with the same percentage composition, e.g. the conversion of glucose into lactic acid, $\mathrm{C}_{6} \mathrm{H}_{12} \mathrm{O}_{6} \rightarrow 2 \mathrm{C}_{3} \mathrm{H}_{6} \mathrm{O}_{3}$.

\section{Character of Enzyme Action}

Specific Action of Enzymes. - It has been found that enzymes act specifically upon certain compounds and not upon others. Emil Fischer believes that this specific action is due to the stereochemical configuration of the molecules of both the substance acted upon and the enzyme, i.e. that the enzyme and compound are related in their configuration as a key is to 
the lock. This is known as the lock-and-key theory. This specific action in the case of the hydrolytic enzymes is distinctly different from the action of acids in producing hydrolysis. While the hydrolysis of the different carbohydrates, fats and proteins may all be produced by boiling with acids or alkalies, an individual enzyme is necessary for each particular compound hydrolyzed.

Reversible Nature of Enzyme Action. - In discussing the reactions of esterification and hydrolysis in connection with fats (p. 58) we referred to the fact that these two reactions represent the two directions of one of the most common reversible reactions. It is a striking fact that the fat-hydrolyzing enzymes especially have been found to possess the property of reversibility, i.e. they are able either to cause the hydrolysis of a fat or to esterify glycerol and a fatty acid, depending upon conditions, e.g. the excess of end products of the first reaction. The first enzyme with which this property was established was the one which hydrolyzes maltose sugar to glucose. Proteolytic enzymes have also been claimed to act reversibly. The importance of this property will be better realized when we study the digestion, absorption and metabolism of food.

\section{Zymogens}

We have referred to enzymes as occurring in plant and animal organisms. In some cases the enzyme does not occur as such and is probably not elaborated as such by the organism but in the form of a mother substance known as a zymogen. The zymogen of an enzyme is itself inactive but when acted upon by another substance called an activator or a kinase it is converted into the active enzyme. The best examples of this are the enzymes, pepsin of the gastric juice and trypsin of the pancreatic juice. In the stomach cells the pepsin is not active, but is in the form of its zymogen known as pepsinogen. This pepsinogen becomes activated by hydrochloric acid, which is a normal constituent of the stomach, and pepsin, the active enzyme, is the result. Trypsin occurs in the pancreatic juice as the zymogen, 
trypsinogen. In this case the activator or kinase is another enzyme present in the intestinal juice known as enterokinase. When these two substances, the trypsinogen and enterokinase, come together, the active enzyme trypsin is the result. The activator may thus be another enzyme or a non-enzyme substance like hydrochloric acid.

Co-enzymes and Anti-enzymes. - It has also been shown that an enzyme may not be a single unit, but may consist of two parts known as the enzyme and the co-enzyme. The activity of the enzyme is dependent upon the presence of its complement the co-enzyme. These two substances have been separated in the case of the enzyme zymase and activity results only when the two are present together. The nature of the co-enzyme is not well established.

Also there have been shown to be substances present in the animal body which prevent the action of certain enzymes. These have been called anti-enzymes. These anti-enzymes are exceedingly important and are connected with the action of toxins and the condition known as immunity.

Without going into detail we have thus presented the main known facts and theories in regard to enzymes and enzymatic action. What has been said will help us to understand what will be presented later on in connection with the digestion, absorption and metabolism of food both in plants and in animals. In all of the chemical reactions connected with the physiological processes of living organisms enzymes are, no doubt, the catalytic agent. In both plants and animals they are abundant, probably much more so than our present knowledge establishes. It may emphasize their importance in animal physiology to state that in the liver alone there are probably fifteen or more distinct enzymes that have been shown to be active.

\section{Names of Enzymes}

The name of an enzyme, where a systematic name has been applied, is made up from the name of the substance upon which the enzyme acts and the termination ase. The enzymes re- 
ferred to already which act upon starch, hydrolyzing it to maltose sugar, are known as amyl-ases, the prefix amyl coming from the word amylum for starch. Similarly, an enzyme hydrolyzing sucrose is known as sucrase, one hydrolyzing maltose as maltase. In the same way fat-splitting or lipolytic enzymes are lipases and protein-hydrolyzing enzymes are proteases.

A brief list of the more important plant and animal enzymes may be given.

\section{TABLE IV}

ENZYMES

\begin{tabular}{|c|c|c|c|c|c|}
\hline ENZYME & Actron & Group Name & $\begin{array}{l}\text { Where } \\
\text { Found }\end{array}$ & $\begin{array}{c}\text { SuBstance } \\
\text { ACTED } \\
\text { UPON }\end{array}$ & Products \\
\hline Ptyalin & Hydrolysis & $\begin{array}{l}\text { Animal } \\
\text { Amylase }\end{array}$ & Saliva ${ }^{\swarrow}$ & Starch & Maltose \\
\hline Diastase & Hydrolysis & $\begin{array}{l}\text { Plant } \\
\text { Amylase }\end{array}$ & $\begin{array}{l}\text { Leaves } \\
\text { Seeds }\end{array}$ & Starch & Maltose \\
\hline Amylopsin & Hydrolysis & $\begin{array}{l}\text { Pancreatic } \\
\text { Amylase }\end{array}$ & $\begin{array}{l}\text { Pancreatic } \\
\text { juice }\end{array}$ & Starch & Maltose \\
\hline $\begin{array}{l}\text { Sucrase or } \\
\text { Invertase } \\
\text {. }\end{array}$ & Hydrolysis & $\begin{array}{l}\text { Saccharase } \\
\text { (Sugar-split- } \\
\text { ting) }\end{array}$ & $\begin{array}{l}\text { Intestinal } \\
\text { juice }\end{array}$ & Sucrose & $\begin{array}{l}\text { Glucose, } \\
\text { Fructose }\end{array}$ \\
\hline Maltase & Hydrolysis & $\begin{array}{l}\text { Saccharase } \\
\text { (Sugar-split- } \\
\text { ting) }\end{array}$ & $\begin{array}{l}\text { Intestinal } \\
\text { juice }\end{array}$ & Maltose & Glucose \\
\hline Lactase & Hydrolysis & $\begin{array}{l}\text { Saccharase } \\
\text { (Sugar-split- } \\
\text { ting) }\end{array}$ & $\begin{array}{l}\text { Intestinal } \\
\text { juice }\end{array}$ & Lactose & $\begin{array}{l}\text { Glucose } \\
\text { Galactose }\end{array}$ \\
\hline Pepsin & Hydrolysis & Protease & Gastric juice & Protein & $\begin{array}{l}\text { Proteoses, Pep- } \\
\text { tones, Pep- } \\
\text { tides }\end{array}$ \\
\hline Trypsin & Hydrolysis & Protease & $\begin{array}{l}\text { Pancreatic } \\
\text { juice } \\
\downarrow\end{array}$ & Protein & $\begin{array}{l}\text { Proteoses, Pep- } \\
\text { toncs, Pep- } \\
\text { tides, Amino- } \\
\text { acids }\end{array}$ \\
\hline Erepsin & Hydrolysis & Protease & $\begin{array}{l}\text { Intestinal } \\
\text { juice }\end{array}$ & $\begin{array}{c}\text { Proteoses } \\
\text { Peptones }\end{array}$ & Amino-acids \\
\hline Steapsin & Hydrolysis & Lipase & $\begin{array}{l}\text { Pancreatic } \\
\text { juice }\end{array}$ & Fats & $\begin{array}{l}\text { Glycerol } \\
\text { Fatty acids }\end{array}$ \\
\hline Rennin & Coagulation & Coagulating & $\begin{array}{l}\text { Gastric juice } \\
\text { Pancreatic } \\
\text { juice }\end{array}$ & $\begin{array}{l}\text { Caseino- } \\
\text { gen }\end{array}$ & Casein \\
\hline Enterokinase & Activates & Kinase & $\begin{array}{c}\text { Intestinal } \\
\text { juice }\end{array}$ & $\begin{array}{l}\text { Trypsino- } \\
\text { gen }\end{array}$ & Trypsin \\
\hline Emulsin & Hydrolysis & $\begin{array}{l}\text { Glucoside- } \\
\text { splitting }\end{array}$ & $\begin{array}{l}\text { Bitter } \\
\quad \text { almonds }\end{array}$ & $\begin{array}{l}\text { Amygda- } \\
\text { lin }\end{array}$ & $\begin{array}{l}\text { Glucose, Benz- } \\
\text { aldehyde, } \\
\text { HCN }\end{array}$ \\
\hline $\begin{array}{l}\text { Oxidases } \\
\text { Reductases } \\
\text { Zymase }\end{array}$ & $\begin{array}{l}\text { Oxidation } \\
\text { Reduction } \\
\text { Decompo- } \\
\text { sition }\end{array}$ & $\begin{array}{l}\text { Glucose-fer- } \\
\text { menting }\end{array}$ & Yeast & Glucose & Alcohol, $\mathrm{CO}_{2}$ \\
\hline
\end{tabular}




\section{CHAPTER IX}

\section{THE COMPOSITION OF PLANTS AND A N I M A L S}

IN our study of the organic compounds which are of importance in connection with plants and animals from the agricultural standpoint we gave especial attention to three groups, viz. carbohydrates, fats and proteins. These three groups comprise all of the essential organic food materials of both plants and animals. Only relatively few compounds outside of these three groups were mentioned, for example, lactic, malic and tartaric acids, some of the esters in addition to the glycerol esters or fats, urea, uric acid and some others. The last two we shall find are physiologically directly connected with the proteins. The others, and some which were not mentioned at all, while they are no doubt essential to the life history and environment of the plant or animal, are nevertheless not essential in the same way as the carbohydrates, fats and proteins, i.e. as food materials. As the relationship of plants and animals to their food supply is the primary one in their agricultural connection we see that in a study of agricultural chemistry these three groups of compounds occupy a predominant position.

Organic and Inorganic Constituents. - In their chemical composition plants and animals may be readily shown to consist of two distinctly different kinds of material, viz. organic and inorganic. Considering the definition of organic compounds which we derived from our study of organic chemistry, we term organic any compound which in its constitution is proven to be derived from the fundamental compounds of carbon and hydrogen, the hydrocarbons. As such, the organic compounds present in plants and animals contain, in most cases, 
the elements carbon, hydrogen and oxygen with nitrogen and sometimes also sulphur and phosphorus in the important group of the proteins. Some few other elements may also occur in strictly organic combination, but these six elements are the constituents of practically all of the organic compounds of both plants and animals.

The inorganic compounds present in plants and animals consist mainly of the metallic elements, potassium $(\mathrm{K})$, sodium $(\mathrm{Na})$, calcium $(\mathrm{Ca})$, magnesium $(\mathrm{Mg})$ and iron $(\mathrm{Fe})$, in combination, mostly as salts, with the nonmetallic elements chlorine $(\mathrm{Cl})$, sulphur $(\mathrm{S})$, phosphorus $(\mathrm{P})$, nitrogen $(\mathrm{N})$ and oxygen $(\mathrm{O})$. Aluminium ( $\mathrm{Al})$, arsenic (As) and some others may also be present. It is not always possible to determine whether these elements that we consider inorganic are present in the living plant or animal in true inorganic combination as salts or whether they really are part of a true organic compound containing also carbon, hydrogen, oxygen, nitrogen, etc. We know, for example, that in the blood, urine and gastric juice of animals we find such compounds as sodium chloride, calcium phosphate and hydrochloric acid, which are evidently present as such in these liquids. On the other hand we believe that in the blond the iron which is present is unquestionably in the form of a true organic compound, a protein known as hamoglobin. Also in chlorophyll, a constituent of green leaves, magnesium is present as part of a true organic compound, and in milk the metallic element calcium is present as part of one of the protein constituents. Thus, if we should consider as organic any substance present as part of the living material of a plant or animal, it is probable that most of the inorganic elements mentioned should be classed as in organic combination.

Volatile and Nonvolatile Constituents. - The separation of the constituents of plants and animals into organic and inorganic may be easily accomplished in an approximate way by simply burning the plant or animal substance in the air. When thus burned in the air the organic constituents consisting in general of the six elements previously mentioned are converted 
by oxidation into gaseous or volatile products which disappear, while the inorganic constituents are converted into nonvolatile compounds which remain. Thus, generally speaking, the organic constituents yield volatile products on burning, and the inorganic constituents yield nonvolatile.

If we were dealing with pure organic constituents by themselves, such as pure carbohydrates, fats or proteins, we should find this to be wholly true. On burning in air the carbon would be converted into carbon dioxide gas, $\mathrm{CO}_{2}$, the hydrogen into water, $\mathrm{H}_{2} \mathrm{O}$, the nitrogen into free nitrogen, $\mathrm{N}$, the sulphur would yield the gas sulphur dioxide, $\mathrm{SO}_{2}$, and the phosphorus would be oxidized to phosphorus pentoxide, $\mathrm{P}_{2} \mathrm{O}_{5}$, a solid. All of these products, whether gases, liquids or solids, would be volatilized at the temperature of the combustion and would thus disappear. In a like manner the pure inorganic constituents by themselves would be left on burning in the form of oxides, carbonates, chlorides, sulphates, nitrates or phosphates, depending largely upon the original form in which they were present.

However, on burning any mixed plant or animal material the two sets of products are present together and a sharp separation does not take place. All of the hydrogen of the organic constituents disappears in the form of water vapor. A large part of the carbon likewise goes off as carbon dioxide gas. Some of the carbon dioxide, however, which is formed from the carbon of organic compounds, in the presence of the metallic elements of the inorganic constituents, unites with the oxides of these metals and remains as nonvolatile carbonates, e.g. potassium carbonate, $\mathrm{K}_{2} \mathrm{CO}_{3}$. The sulphur and nitrogen also, instead of being completely volatilized, combine with the metal oxides as sulphates and nitrates, e.g. sodium sulphate, $\mathrm{Na}_{2} \mathrm{SO}_{4}$, potassium nitrate, $\mathrm{KNO}_{3}$. Likewise, the phosphorus from organic compounds will not volatilize, but will remain nonvolatile as a phosphate of some metal, e.g. calcium phosphate, $\mathrm{Ca}_{3}\left(\mathrm{PO}_{4}\right)_{2}$. Also any iron, calcium or other metallic element, although present as part of a true organic compound, will remain after combustion in the form of some nonvolatile salt. 
Ash. - On burning a plant or animal substance the nonvolatile products as described above will be left in the form of a gray or white $a s h$. This ash represents the nonvolatile products of the combustion and contains all of the inorganic constituents and some part at least of the carbon, nitrogen, sulphur and phosphorus of the organic constituents together with any metallic elements which may have been present in organic combination. Therefore, this simple separation of a plant or animal substance into volatile and nonvolatile products does not correspond exactly to the organic and inorganic constituents present. It does, however, indicate approximately their relative amounts.

On making such a separation of the volatile and nonvolatile products of combustion and determining the amounts present, it is found that the organic constituents yielding volatile products are much in excess of the inorganic constituents which yield the nonvolatile products, or ash. The number of different elements present in the latter are more than those in the former.

The table on pages I $^{\circ-1} 5^{I}$ gives some results of the determination of volatile and nonvolatile or ash constituents in some common plant materials.

We have thus shown that plants and animals consist of both organic and inorganic constituents. The two classes of materials are, therefore, both essential to the life of the organism. In animals, the skeleton portion of vertebrate animals is largely inorganic, being chiefly calcium phosphate, $\mathrm{Ca}_{3}\left(\mathrm{PO}_{4}\right)_{2}$. The other inorganic constituents are found mostly in the liquids or secretions of the animal body such as blood, milk, urine and the digestive fluids. All of these inorganic substances play an important rôle in the life of the animal. Their action is, however, not well understood in most cases and is at least distinctly different from the action of the organic constituents. We shall, therefore, not consider them in detail, simply stating that in the animal body they are formed from the inorganic materials in the food which the animal eats.

In plants the inorganic constituents are related directly to the soil, from which source the plant obtains its food material 


\section{TABLE V}

\section{Volatile and Nonvolatile Constituents}

\begin{tabular}{|c|c|c|c|c|c|}
\hline $\begin{array}{c}\text { Plant or Plant } \\
\text { Product }\end{array}$ & & WATER & AsH & $\begin{array}{c}\text { VOlatile } \\
\text { CONSTITUENTS } \\
\text { OTHER THAN } \\
\text { WATER }\end{array}$ & \\
\hline Maize (Flint) . . & & II.3 & I.4 & 87.3 & J. \& W., pp. I $2-19$ \\
\hline Maize (sweet) (Mass.) & & 8.7 & I. 8 & 89.5 & $\begin{array}{l}\text { J. \& W., pp. I2-т9 } \\
\text { (Bul. I } 20, \text { p. } 33 \text { ) }\end{array}$ \\
\hline Wheat (spring) . . & - & I0.4 (9.94) & I.9 (I.94) & $87.7(88.12)$ & J. \& W., pp. I $2-19$ \\
\hline Wheat (winter) . & . $\cdot$ & I0.5 (10.55) & $I .8(2.0)$ & $87.7(87.45)$ & $\begin{array}{l}\text { J. \& W., pp. I } 2-19 \\
\text { (Bul. I } 20, \text { p. } 33 \text { ) }\end{array}$ \\
\hline Sorghum grain . . & - & I 2.8 (II.7I) & 2.I (I.75) & 85. 工 $(86.54)$ & $\begin{array}{l}\text { J. \& W., pp. 12-199 } \\
\text { (Bul. r20, p. } 42)\end{array}$ \\
\hline Barley . . . & $\cdot$ & I0.9 (9.32) & $2.4(3.04)$ & $86.7(87.64)$ & $\begin{array}{l}\text { J. \& W., pp. I } 2-19 \\
\text { (Bul. r20, p. 36) }\end{array}$ \\
\hline Rye . . . . & - & Ir.6 (9.38) & $1.9(2.18)$ & $86.5(88.44)$ & $\begin{array}{l}\text { J. \& W., pp. I } 2-19 \\
(\text { Bul. I } 20, \text { p. } 35)\end{array}$ \\
\hline Oats $\cdot \cdot \cdot \cdot$ & $\cdot$ & II.O (7.82) & $3.0(3.96)$ & $86.0(88.22)$ & $\begin{array}{l}\text { J. \& W., pp. I } 2-19 \\
\text { (Bul. I } 20, \text { p. } 24)\end{array}$ \\
\hline Rice $\cdot \therefore$. . & $\cdot$ & I 2.4 & 0.4 & 87.2 & J. \& W., pp. I $2-19$ \\
\hline Wheat middlings . & - $\cdot$ & I 2.I & $3 \cdot 3$ & 84.6 & J. \& W., pp. I $2-19$ \\
\hline Wheat bran . . . & . & II.9 & 5.8 & 82.3 & J. \& W., pp. I $2-\mathrm{I} 9$ \\
\hline Maize stalks (green) . & - & 76.1 & 0.7 & 23.2 & J. \& W., pp. I 2-I 9 \\
\hline Maize stalks (cured). & - & 68.4 & 1.2 & 30.4 & J. \& W., pp. I 2-I 9 \\
\hline Maize stover (cured). & & 40.1 & 3.4 & 56.5 & J. \& W., pp. I2-19 \\
\hline Maize fodder (green). & & 79.8 & I.I & I 9.1 & J. \& W., pp. I 2-I9 \\
\hline Maize fodder (cured). & & 42.2 & 2.7 & $55 . \mathrm{I}$ & J. \& W., pp. I2-I 9 \\
\hline Maize silage . . & - & 79.1 & I.4 & I9.5 & J. \& W., pp. I 2-19 \\
\hline Wheat straw & . & 9.6 & 4.2 & 86.2 & J. \& W., pp. I2-I9 \\
\hline Oat straw . . & - & 9.2 & 5.I & 85.7 & J. \& W., pp. I2-I 9 \\
\hline Timothy grass . & - & $6 \mathrm{r} .6$ & $2 . \mathrm{I}$ & 36.3 & J. \& W., pp. I 2-I9 \\
\hline Timothy hay . . & - & I 3.2 & 4.4 & 82.4 & J. \& W., pp. I 2-I9 \\
\hline Red clover, grass . & . & 70.8 & $2 . I$ & 27.1 & J. \& W., pp. I 2-I9 \\
\hline Red clover hay . . & . & I 5.3 & 6.2 & 78.5 & J. \& W., pp. I $2-19$ \\
\hline Alfalfa, grass . . & - & 71.8 & 2.7 & 25.5 & J. \& WV., pp. I2-I9 \\
\hline Alfalfa hay . . & & 8.4 & $7 \cdot 4$ & 84.2 & J. \& W., pp. I2-I9 \\
\hline Cowpea (fresh). & $\cdot$ & 83.6 & I.7 & 14.7 & J. \& W., pp. I2-19 \\
\hline Cowpea (cured) . & . & I0.7 & $7 \cdot 5$ & 8 г. 8 & J. \& W., pp. I2-19 \\
\hline Cowpea (peas only) & . & I 4.8 & 3.2 & 82.0 & J. \& W., pp. I2-I9 \\
\hline Soja beans (fresh) . & & 74.8 & 2.4 & 22.8 & J. \& W., pp. I2-19 \\
\hline Soja beans (bean only) & y) & 10.8 & 4.7 & 84.5 & J. \& W., pp. I 2-19 \\
\hline Potatoes . . . & - & 78.9 & 1.0 & 20.1 & J. \& W., pp. I 2-I9 \\
\hline Sweet potatoes . & $\cdot$ & 71.1 & 1.0 & 27.9 & J. \& W., pp. I2-I9 \\
\hline Red beets $\cdot$. . & $\cdot$ & 88.5 & I.O & 10.5 & J. \& W., pp. I $2-I 9$ \\
\hline Sugar beets . • . & . & 86.5 & 0.9 & I 2.6 & J. \& W., pp. I $2-19$ \\
\hline
\end{tabular}




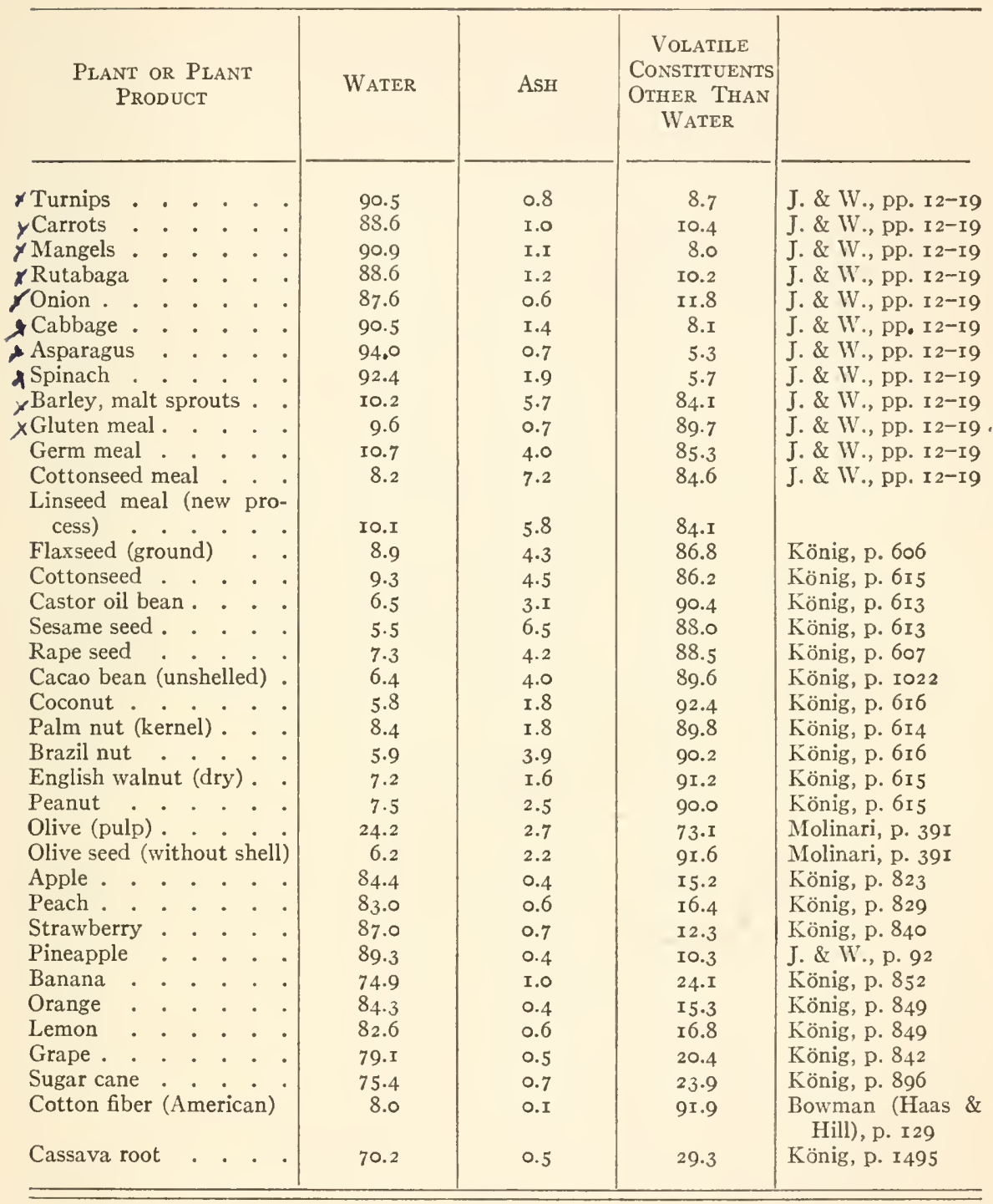

“J. \& W. ”: Jenkins \& Winton, American Feeding Stuffs, U. S. Dept. Agr. O. E. S. Bul. II, 1892. "König": Chemie der Mensch. Nähr. u. Genussmittel, vierte Auf. r903. "Bul. I20" : Chamberlain, Feeding Value of Cereals, U. S. Dept. Agr. Bur. Chem. Bul. I20, rgog. "Molinari" : Molinari, General and Industrial Organic Chemistry, Eng. Ed. I9I3. "Haas \& Hill": Haas \& Hill, Chemistry of Plant Products, r9r4. 
of this character. In the soil this inorganic food is present in the form of salts, principally as nitrates, phosphates, chlorides and sulphates of potassium, sodium, calcium and magnesium. These salts constitute what is termed the soil plant food. They are also the constituents of substances used to supply an abundance of soil plant food in the form of manure or commercial fertilizers, the latter being mostly of three kinds, viz. nitrate, phosphate and potassium salts. All of this relationship of the plant to the soil and to fertilizers is part of the study of Inorganic Agricultural Chemistry. We shall, therefore, not say anything further in regard to the inorganic constituents of plants and give only slight references to the inorganic constituents of animals. The chapters which follow will deal primarily with the organic constituents and will endeavor to show, by general and well-established facts, how these constituents are produced, what their function is and how this function is carried out.

\section{EXPERIMENT STUDY XXVI}

\section{Organic and Inorganic Constituents of Plants and Animals}

(I) Organic or Volatile Constituents. (a) Place r.o g. of pure dry wheat starch or potato starch in a porcelain crucible or evaporating dish. Heat the dish gradually with low flame. Note charring of the starch, indicating free carbon. As fumes are given off hold a test tube, dry on outside but half full of cold water, in the vapor. Note deposit of water vapor. Increase the heating, and hold in the vapor a glass tube that has been dipped in limewater. A cloudy appearance of the limewater on the tube shows presence of carbon dioxide in the vapor. Continue to heat with full flame until all free carbon has disappeared. What is the source of carbon? What has become of it? What other elements are shown to have been present in the starch? Is there any ash left? (b) Repeat the experiment, using pure fat, e.g. lard or cottonseed oil. (c) Repeat again, using pure protein, $e . g$. white of egg or wheat gluten.

(2) Inorganic or Nonvolatile Constituents. (a) Weigh a small porcelain evaporating dish that has been previously cleaned, dried 
by heat and cooled in a desiccator. Weigh into this dish $10.0 \mathrm{~g}$. of dry grass, straw or leaves. Heat the dish slowly, testing the volatile products as in (I). Heat with full flame until all free carbon has been oxidized. When only a light gray ash is left, cool the dish in a desiccator and weigh. Subtract the weight of the dish from the weight of dish and ash to obtain the weight of ash. Calculate the per cent in the original material. The difference between this and roo per cent will give the per cent of volatile or organic constituents in the original substance. In the ash obtained from most mixed plant and animal materials we may show the presence of the following metallic elements and salts: (I) sodium, $\mathrm{Na}$, potassium, $\mathrm{K}$, calcium, Ca, magnesium, $\mathrm{Mg}$, carbonates, $\mathrm{Na}_{2} \mathrm{CO}_{3}$, nitrates, $\mathrm{KNO}_{3}$, phosphates, $\mathrm{Na}_{3} \mathrm{PO}_{4}$, sulphates, $\mathrm{K}_{2} \mathrm{SO}_{4}$, chlorides, $\mathrm{NaCl}$.

(b) Evaporate 25 c.c. of milk, blood, urine or saliva slowly to dryness and repeat $(a)$ with dry residue. 


\section{CHAPTER X}

\section{THE LIVING CELL AND ITS FOOD}

Plant and Animal Cell Alike. - At the very beginning of our study of the chemical processes of plants and animals we must emphasize the important fundamental fact that, as living organisms the plant and the animal are alike. Each individual plant and each individual animal is composed of an aggregation of simple cells, and the fundamental chemical processes of these living cells are alike. The life of the complex individual is but the total of the lives of all the cells of which it is composed. Thus, to understand the chemical processes of the individual we must first understand the rhemical processes of the living cell.

We do not wish to give the impression that the whole question of life is simply one of chemical reaction. We may understand the chemical reactions which take place together with the physical conditions under which they occur without being able to explain the phenomenon of life itself. As a great German biochemist has said, ${ }^{1}$ "Physiology cannot really be identical with the chemistry and physics of living organisms." Furthermore it is only a small part of the reactions involved in living organisms which we as yet do understand or which are so clearly demonstrated that they are proper subjects for discussion in this study.

Composition of the Cell. - Biologically considered the living cell is characterized by containing the substance known as protoplasm. This substance is essential to living matter. Chemically its composition is not definitely known, but it has been defined as a solution of protein containing also carbohydrates, fats and inorganic salts, either in solution or colloidal suspension. Thus all living matter contains these three groups of organic compounds, carbohydrates, fats and proteins.

'Czapek, "Chemical Phenomena in Life," I9II. 
Cell Energy and Cell Food. - The living cell, whether plant or animal, performs its function of life through the agency of energy which is set free by its utilization of food supplied to it from without. When we study later the peculiar processes or functions of plants which differentiate them from the animals we shall find that the ultimate source of this energy is the sun. For the present, however, and so far as the cell itself is concerned, the source of the cell's energy is its food. We have just stated that the cell is composed of carbohydrates, fats and proteins and inorganic salts. It is clear, therefore, that the food of the cell must contain these same substances. So far as we know the inorganic constituents of the cell or of the cell food have nothing to do, at least directly, with the energy of the cell. In its energy relationship, therefore, the food of the cell is wholly organic of the three groups of compounds mentioned. This is borne out by the fact that the seeds of plants which contain the germ of a new plant have stored within them all of these constituents, and these are used by the developing embryo as food. Also all animals require as food, not one only, but all of these groups of compounds.

Food as Energy Material. - How then do these organic substances which we may term energy food yield this energy to the living cell and thus to the whole living organism? If we recall the chemical composition and constitution of these compounds we see that they are alike in being complex compounds of carbon, hydrogen and oxygen, with nitrogen in addition to these in the proteins. The percentage composition of the three groups of compounds is:

\begin{tabular}{|c|c|c|}
\hline CARBOHYDRATES & FATS & Proteins \\
\hline $\mathrm{C}_{6} \mathrm{H}_{12} \mathrm{O}_{6}$ (Glucose) & $\begin{array}{l}\mathrm{C}_{51} \mathrm{H}_{98} \mathrm{O}_{6} \text { (Glyceryl tri- } \\
\text { palmitate) }\end{array}$ & \\
\hline C. 40.00 per cent & 75.93 per cent & $51.00-55.00$ per cent \\
\hline H. 6.66 per cent & I 2. 6 per cent & $6.00-7.00$ per cent \\
\hline O. 53.33 per cent & II.9I per cent & $20.00-25.00$ per cent \\
\hline N. $\quad-$ & & I $5.00-$ I 7.6 per cent \\
\hline S. $\quad \longrightarrow$ & - & $0.3-2.5$ per cent \\
\hline
\end{tabular}


They all contain large amounts of carbon and hydrogen in proportion to the oxygen. This is not so clear from the percentage composition as when we consider the atomic relations of the elements present. The two elements, carbon and hydrogen, unite readily with oxygen, forming carbon dioxide, $\mathrm{CO}_{2}$, water, $\mathrm{H}_{2} \mathrm{O}$. In the carbohydrates only, in which oxygen is in the greatest amount and hydrogen the least, is there enough oxygen to combine with the hydrogen when the compound is decomposed. When therefore these compounds are brought in contact with free oxygen under certain conditions, e.g. at raised temperatures or through the agency of enzymes, then the carbon and the excess hydrogen will become oxidized or, as we say, the substance burns. This reaction is the basis for the characterization of these organic constituents of plants and animals as volatile or combustible. Now when this reaction of oxidation takes place and the complex compounds are thus decomposed into simpler oxygen compounds, energy is set free. We indicate this in the reaction by writing it as follows, using the carbohydrate glucose as our example:

\section{$\mathrm{C}_{6} \mathrm{H}_{12} \mathrm{O}_{6}+6 \mathrm{O}_{2} \rightarrow 6 \mathrm{CO}_{2}+6 \mathrm{H}_{2} \mathrm{O}+$ energy}

Glucose

Each of the other compounds, viz. fats and proteins, undergoes a similar oxidation with the liberation of energy. We shall find later that each of the three compounds yields, per gram or ounce of substance, a different but definite amount of energy.

Oxidation of Food. - Now when the living cell utilizes its food, this reaction of oxidation takés place and energy is set free, and it is this energy that is the energy of the living cell. The reaction is not always as simple as we have written it and it may take place only partially or in several steps, but the result is the liberation of a whole or a part of the energy of such a complete reaction.

Heat and Work. - In the reaction as it takes place in the air or in oxygen, the energy liberated manifests itself in the form of heat, i.e. the substance burns. Such a manifestation of the 
energy is not, however, always the result. When the oxidation occurs in the cell it is probably always due to the influence of enzymes, and the energy set free may be in the form of heat which is not accompanied with burning, as we ordinarily think of it, but in the form of heat that maintains a certain temperature such as the body heat of warm-blooded animals. The energy may not, however, produce heat at all, but may be manifested in the form of muscular work, as in the case of animals or of work not exactly muscular but which may be called cellular, such as is required in the growth of large plants or trees.

The fundamental chemical reaction of living cells, then, is the oxidation of the complex organic compounds of the food to simple compounds with the liberation of energy, which energy is the basis of the living process manifesting itself as heat or work in the various functions and properties of the living organism whether the organism is plant or animal.

Food as Building Material. - Not only must the living cell be furnished with food which by oxidation yields energy, but it must also utilize its food for building up its own substance. This will necessarily be much greater in the cases of young and rapidly growing organisms, but in all organisms cell substance is continually used up in the life process and new building material must be supplied. We cannot state as a positive fact that all food is first converted into cell substance or, as we say, body substance, before it is oxidized, but it is at least probable that this is so. We know that if an animal is deprived of food it utilizes its own body substance, which is torn down and oxidized, thus yielding the energy necessary for life.

Function of Food. - Thus the function of food may be considered as twofold, i.e. to build body or cell substance and to furnish energy.

\section{Plants and Animals Compared}

Each plant or animal of the higher forms, and it is only these higher forms that we shall consider, is a very complex individual. The single cells of which the organism is composed do not per- 
form their functions separately, but are united into different tissues and organs, and the functions of the various tissues and organs are very different. Thus, while as stated above the individual cells are alike in their fundamental chemical processes, the net result of the processes of all the cells, or, as we may say, the predominating reaction, is distinctly different so that the single plant bears little resemblance to the single animal.

In the animal organism, particularly in the mature animal, as we shall find, the two functions of food are practically resolved into one, for food material which is converted into body substance is eventually oxidized for the production of energy. Only a small part of the food is utilized to build body substance which is not later oxidized, and this material is largely the inorganic portion. The net result of the physiological processes of animals or, as we may say, the predominating physiological process of animals, is the utilization of food for the production of energy and this energy is manifested as animal work or animal heat. In the plant organism, however, the two functions remain more distinct. Only a small part of the food is utilized for the production of energy. The greater part is built up by means of this energy into body substance which becomes either reserve food or structural material. The net result of the physiological processes of plants is thus the formation of body substance. These distinctly different net results are correlated with distinctly different physiological processes in plants and animals which differentiate them from each other and which we shall consider later as we study each kind of organism.

With these distinct differences between plants and animals which we shall discuss we must not lose sight of the fact, first stated at the beginning of this chapter, that in their fundamental reaction plant cells and animal cells are alike, and this fundamental reaction is the oxidation of the three organic food constituents, whereby energy is liberated and this energy is the energy of the life process. 


\section{CHAPTER XI}

\section{ANIMAL FOODAND NUTRITION DIGESTIONANDABSORPTION}

\section{ANIMAL FOOD}

WE have now to consider the question as to how and in what form the food reaches the cell and how the fundamental oxidation reaction is brought about. It is impossible to investigate these processes with the single cell, but as the animal organism as a whole utilizes its food for the production of energy just as the single cell does, we are able to understand the chemical reactions by which food is eventually converted into energy by making a study of the way in which it is accomplished in the animal body. Furthermore, it is not possible to study these processes in the plant with the same detail that we can in the animal for the simple reason that they have not yet been worked out in the plant, because in the plant they are masked or overshadowed by the predominating constructive processes. We shall, therefore, turn our attention from the single cell as such, which is alike in its fundamental chemical processes in both plants and animals, to the consideration and study of the animal as a whole and the chemical processes by which it utilizes its food material primarily for the liberation of energy.

Definition of Food. - As we have previously stated in a general way, the chemical composition of the animal body while it is made up of very complex individual compounds is, nevertheless, simple in that they are all comprised in the three groups, carbohydrates, fats and proteins, together with some inorganic salts. These latter are found mostly in the skeleton part of vertebrate animals and in small amounts in the various animal fluids, where they perform important functions, but in 
which functions they bear no direct relation to the energy of the living animal. Different animals and different organs of the same animal contain different individual compounds of the three groups, but, considered as a whole, and in general, the living cellular portions of the animal body are composed of carbohydrates, fats and proteins. It will thus be natural to find that the organic or energy food of animals consists of these three groups of compounds, for out of these food materials the body substance of the animal must be formed and from them the energy of the aqnimal is derived.

Animal food has been defined as " anything, which taken into the animal body is utilized by the animal for the building up of body substance or for the production of energy."

Utilization of Food. - In order that the miscellaneous food may thus be utilized to build cellular material or to furnish energy by oxidation, it is necessary for it to undergo certain changes. In other words, the food material must fit the conditions of the animal body. The changes which the food thus undergoes are included in the various processes known by the general name of digestion.

After the food has been put in the proper condition by the processes of digestion, it must then be taken up by the circulating fluid of the body and conveyed to the cells and organs where later changes occur. This process is known as absorption. The digested and absorbed food then undergoes other changes necessary for conversion into body substance or for oxidation. These changes are included in the processes known as metabolism. The final change in metabolism is always oxidation with the liberation of energy and the formation of certain waste products. These waste products are then eliminated from the body by the processes of excretion.

Thus the food is subjected to the two main processes of digestion and metabolism, with the secondary processes of absorption and excretion. For the purpose of considering the food of animals we may, therefore, divide the animal body into four regions, viz. (a) the region of digestion, where the food is 
converted into conditions necessary for absorption and metabolism, $(b)$ the region of absorption, where the digested food is taken up and conveyed to the cells, $(c)$ the region of metabolism, where the digested and absorbed food is built up into body substance, or is oxidized, (d) the region of excretion, where the products of metabolism are removed from the body. It must be noted that these are not regions defined anatomically by location in certain organs but by the process which takes place.

We shall now consider each one of these processes in the order in which they take place in the animal body. In the following discussion of the physiological processes of animals the facts refer primarily to human beings. In general they apply also to domestic animals, but in cases where they are known to be different some qualifying statement will be made.

Mastication or Chewing. - The mastication of the food in the mouth, or in other regions where this is accomplished in some animals, as the gizzard of fowls, is not, strictly speaking, part of the process of digestion. In most cases it must precede digestion and is part of the physical operation by which the food is obtained and introduced into the animal body in a proper condition for digestion. It results in the finer division of the food substance so that it will be in such a physical condition that digestive juices may act upon it. It will naturally vary as the character of the food substances varies. In the case of liquid foods or foods already in solution no mastication is necessary. We must caution against assuming from what has previously been said that all soluble substances are on that account already digested and do not need digestive action. A soluble substance, as we shall soon explain, may or may not be subject to digestion. For each food constituent there is a final form which it must assume before it can be absorbed and metabolized. The food material in a few cases may be already in this form, but it may also be readily soluble and still require digestion. The solid foods require more or less thorough mastication in order to make them subject, under the best conditions, to digestive action. Plainly, the tougher and 
harder the solid food the more thorough must be the mastication. This is why the food of herbivorous animals like the horse and cow must be subject to the most thorough mastication, and in the latter animal and other ruminants is subject to a second mastication. Mastication in all the common animals, except the fowls, takes place in the mouth by means of the teeth. Thus we find that animals which naturally eat the tougher foods, like raw piants, have the more elaborate and stronger masticating teeth.

Digestion. - The animal body is composed of material more or less saturated with water. All of the body fluids are water solutions or suspensions and the cells contain water solutions. The cell walls are membranes permeable to water and semipermeable to substances in solution. A living cell which is thoroughly dried becomes dead as a consequence. The whole body may thus be considered as a water system. Thus solubility in water and permeability through cellular membranes are necessary conditions for food material that is to be absorbed and built up into body substance. Of the three organic food constituents the carbohydrates are the only ones that are soluble in water to any extent. Even of the carbohydrates the most widely distributed member considered as a food is starch which is insoluble. The fats are wholly insoluble and of the proteins only one group, viz. the albumins, is soluble in water. The conversion of the insoluble forms of food material into soluble is thus essential and is brought about by the process of digestion.

Not only, however, must the food material be soluble, but it must be brought into certain definite forms so that the subsequent changes of metabolism may take place. This may be illustrated by the fact that though cane sugar and milk sugar are soluble compounds they, nevertheless, undergo digestive changes, because in their unchanged character they cannot be built up into body substance or oxidized.

We may, therefore, say that the object of digestion is twofold: first, to convert insoluble food materials into soluble com- 
pounds in order to meet the conditions of a system saturated with water; second, to convert the miscellaneous food material into certain uniform compounds to meet the conditions of further metabolic change.

So far as we know the inorganic compounds which serve as food do not require digestive action, so that the process of digestion has to do entirely with the organic constituents. In the following discussion we shall take up each one of the three organic food constituents by itself and consider first the digestion of carbohydrates, next the digestion of proteins and then the digestion of fats. Of course, with a mixed food such as almost all food substances are, separate digestion does not take place, the entire food mass being digested more or less at the same time. However, as we shall find, each constituent is acted upon by certain digestive enzymes which act upon it alone, so that in order to avoid seeming confusion we shall treat them as separate actions.

Digestive Region. - The digestive region in animals begins with the mouth and continues through the stomach and the small intestine. In man practically no digestive action takes place in the large intestine. The entire digestive tract, or alimentary canal, as it is termed, consists of (a) mouth, (b) esophagus, (c) stomach, (d) small intestine, (e) large intestine, with several contributory organs which connect with it, e.g. pancreas and gall bladder. By the time the food mass reaches the large intestine practically all of the food capable of digestion has been digested and absorbed into the circulation through the cell membranes of the digestive tract.

\section{DIGESTION OF CARBOHYDRATES}

The carbohydrate food materials belong to the three classes of carbohydrates, viz. :

Monosaccharoses, typified by glucose and fructose sugars; Disaccharoses, typified by cane sugar, milk sugar and malt sugar; Polysaccharoses not sugars, typified by starch and cellulose. 
Monosaccharoses the Final Product of the Digestion of Carbohydrates. - The digestive action upon carbohydrates consists in their conversion into the final form of one of the three monosaccharoses, viz. glucose, fructose or galactose, $\mathrm{C}_{6} \mathrm{H}_{12} \mathrm{O}_{6}$. These simple sugars, therefore, are the only carbohydrate foods which do not require digestion, but are directly absorbed as they are. All other forms of carbohydrate food, whether soluble or insoluble, must be digested; and this digestion consists in their conversion into one or more of the three named monosaccharoses. The chemical reactions involved in the conversion of the disaccharoses and polysaccharoses into monosaccharoses have been considered in the first section of our study. In the laboratory this conversion may be brought about by hydrolysis with dilute acids or alkalies. In the animal body it is always accomplished by the action of hydrolytic enzymes. In the chapters on carbohydrates and on enzymes these reactions have all been considered, but it is well to review them here before we take up the digestive action in the animal body.

Hydrolysis of Disaccharoses and Polysaccharoses. - All of the disaccharoses commonly occurring in food, viz. cane sugar, milk sugar and malt sugar, are hydrolyzed by particular enzymes into monosaccharoses as follows:

$\mathrm{C}_{12} \mathrm{H}_{22} \mathrm{O}_{11}+\mathrm{H}_{2} \mathrm{O}$ by sucrase (invertase) $\rightarrow \mathrm{C}_{6} \mathrm{H}_{12} \mathrm{O}_{6}+\mathrm{C}_{6} \mathrm{H}_{12} \mathrm{O}_{6}$

Cane sugar

Glucose Fructose or sucrose

$\mathrm{C}_{12} \mathrm{H}_{22} \mathrm{O}_{11}+\mathrm{H}_{2} \mathrm{O}$ by lactase Milk sugar or lactose

$\mathrm{C}_{12} \mathrm{H}_{22} \mathrm{O}_{11}+\mathrm{H}_{2} \mathrm{O}$ by maltase Malt sugar or maltose

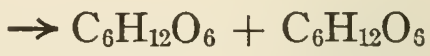
Glucose Galactose

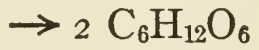

2 Glucose

The polysaccharoses, starch and dextrin, are hydrolyzed by enzymes into maltose. Cellulose yields galactose and mannose.

$2\left(\mathrm{C}_{6} \mathrm{H}_{10} \mathrm{O}_{5}\right)_{x}+\mathrm{H}_{2} \mathrm{O}$ by ptyalin or diastase $\rightarrow x \mathrm{C}_{12} \mathrm{H}_{22} \mathrm{O}_{11}$ Starch, or dextrin (animals)

(plants)

Maltose 
These are the chemical reactions which occur through the agency of enzymes in the conversion of carbohydrate food, not already in the form of monosaccharoses, into this form.

\section{The Mouth}

Saliva, its Properties and Action. - Beginning with the mouth let us follow the course of the digestion of carbohydrates until they have all reached the assimilable form of one of the monosaccharoses. Digestion of carbohydrates in the mouth consists in the conversion of polysaccharoses into maltose by the action of the two enzymes, ptyalin and maltase. These enzymes are present in the digestive juice known as saliva. The saliva is secreted by glands near the mouth known as salivary glands, and in man amounts to about 1000 to I 500 c.c. per twenty-four hours. The mechanical operation of mastication causes the salivary glands to discharge into the mouth the juice saliva. There are several salivary glands each discharging a saliva of somewhat different physical character. The drier and larger the amount of food mass the more watery is the saliva sent to the mouth, while a compact mass of food causes the flow of a juice more mucousy in its character. The stimulation of the salivary glands to discharge saliva may be brought about by a variety of means. The stimulation may be (a) mechanical, as is proven by the flow of saliva caused by putting pebbles or sand into a dog's mouth, (b) chemical, as is produced when a small amount of acid placed in the mouth causes a flow of watery saliva for the purpose of dilution or ejection, (c) psychical, as is produced when the mere sight of food causes the flow of saliva or, as the expression is, "makes the mouth water." In addition to these more common stimuli the flow of saliva may be brought about by either (d) electrical or (e) thermal stimulation. It is not possible to separate sharply these different kinds of stimulation or to determine which is the particular stimulation most active. In most cases where normal food acts, the stimulation will be a combination of several of those given. This stimulation of the flow of saliva 
by these different stimuli typifies in general the flow of all of the digestive juices, which we shall presently consider. Thus the character of the food, the particular nature of the stimuli exerted and the mastication required regulate the operation of salivary mixing. This is because the saliva in addition to containing ptyalin and maltase, which act chemically on the starch, also acts in a mechanical or physical manner and enables the food to be swallowed or passed down the esophagus to the stomach; the esophagus acting merely as a connecting canal between the mouth and stomach. Chemically the action of salivary digestion is that already given of converting, by the action of ptyalin and maltase, all starch into maltose and this into glucose. This is the chief chemical reaction of the saliva due to the enzymes present in it. Other carbohydrate food, viz. the disaccharoses, cane sugar and milk sugar, and the monosaccharoses are not acted upon at all by the saliva.

The ordinary saliva, which is the mixed secretion of the different salivary glands, is a thin, more or less sirupy or mucousy liquid, having a specific gravity only slightly more than that of water, viz. 1.005. The solid matter, therefore, in solution is only about 0.5 per cent. The substances present in solution in saliva are as follows :

Enzymes. - The enzymes present are (a) ptyalin, converting starch into maltose; (b) maltase, converting maltose into glucose. Enzymes, capable of splitting polypeptides, the action of which is of only secondary importance, may also be present.

Ptyalin and Maltase. - The complete series of changes which have been shown to take place when starch is digested by the enzymes of saliva are as follows: the starch is first converted from its insoluble or colloidal state into a truly soluble form known as soluble starch or amidulin. This soluble starch still gives the blue color with iodine. The soluble starch is then converted into dextrin, and several varieties of dextrin are successively produced, viz. (a) erythrodextrin, which gives a red color with iodine; $(b) \alpha$-, $\beta$ - and $\gamma$-achroodextrins which give no color with iodine. Following the dextrins there are produced 
iso-maltose and maltose. The iso-maltose is not formed simply from the $\gamma$-achroodextrin, but also from each of the dextrins directly. The formation of maltose is the end product of the action of the enzyme ptyalin on starch. The action of the enzyme maltase, which is also present in saliva, is small in amount, and, as we shall see, this enzyme acts more completely in another part of the digestive tract.

Conditions of Salivary Action. - The action of ptyalin takes place in alkaline, neutral or combined acid solution. The principal action occurs in alkaline solution and the saliva itself is of slight alkaline reaction. The alkalinity of saliva is equivalent to about o.I per cent sodium carbonate, and is due to the presence in the saliva of di-sodium phosphate, $\mathrm{Na}_{2} \mathrm{HPO}_{4}$. While ptyalin will continue to act in somewhat strong combined hydrochloric acid solution, its activity is destroyed by the presence of 0.003 to 0.006 per cent of free hydrochloric acid.

We should explain at this point the term combined acid. When protein substances react with free hydrochloric acid they unite with it as bases forming salts (protein salts). These salts ionize differently than free hydrochloric acid or such salts as sodium chloride, and thus act in a different way in preventing the action of ptyalin or as a germicide. This property will be referred to again when we consider the action of hydrochloric acid in the stomach.

In stronger alkaline solutions than the saliva the action of ptyalin is inhibited but not destroyed. The action of saliva is better when it is somewhat diluted, to about seven times its volume. This fact is not in accord with the often advanced claim that water-drinking at mealtime is injurious to digestive action.

Salts. - The second chief group of solid substances present in solution in saliva is that of inorganic salts. The principal salt present is di-sodium phosphate, $\mathrm{Na}_{2} \mathrm{HPO}_{4}$, already mentioned as the cause of the alkaline reaction of saliva. The sodium phosphate present in saliva is the cause of the formation of the tartar on the teeth. With the teeth the phosphate forms 
calcium phosphate which remains soluble when in the form of calcium acid phosphate, but is precipitated as insoluble calcium phosphate through the action of ammonia present in the breath. The tartar also contains various other constituents in addition to the calcium phosphate.

Organic Substances. - In addition to the enzymes and inorganic salts saliva also contains several organic substances, viz. mucin, urea, an albumin and a globulin. The mucin is the most important and is the constituent which gives to saliva its mucilaginous character, acting as a lubricant in the passage of the food down the esophagus. It is a glyco-protein (see p. 89).

\section{EXPERIMENT STUDY XXVII}

\section{Saliva and Salivary Digestion}

(I) Properties. (a) Collect $25-50$ c.c. of saliva on a folded filter paper in a funnel, and allow it to filter into a beaker or cylinder. Note general properties. (b) With a urinometer, specific gravity spindle or other form of hydrometer determine the specific gravity of the filtered saliva. (c) Drop a piece of red litmus paper into the saliva and allow to stand for some minutes. Note alkaline reaction to litmus. (d) Make the Biuret and Millon's test for proteins (Experiment XVIII, $4, a$.c) with 5 c.c. of saliva.

(2) Isolation and Test of Mucin. (a) Pour 50 c.c. of saliva into $25^{\circ}$ c.c. of strong alcohol $(95 \%)$ in a tall beaker or cylinder. Allow to stand a day or so. Carefully decant or siphon off all but a few cubic centimeters of the supernatant liquid from the flocculent precipitate of mucin. Slowly pour the remainder of the liquid containing the mucin upon a small $(7 \mathrm{~cm}$.) filter paper in a funnel or filter through a Witt plate with filter paper disk on top. Wash the mucin with two or three small portions of alcohol and then a little ether. Remove paper and scrape off the collected mucin with a knife blade, and place it on the edge of a porous drying plate to dry. (b) After about fifteen minutes take one half of the mucin and divide into three portions. Make Millon's, Biuret and Xantho-proteic tests for proteins (Experiment XVIII, 4, a.b.c). (c) Place the other half of the mucin in beaker with 50 c.c. water. Add 5 c.c. of concentrated hydrochloric 
acid, and boil for ten or fifteen minutes to hydrolyze the mucin. Neutralize the acid with sodium carbonate and then make Fehling's solution test (Experiment XXII, 2), by adding 5 c.c. of mixed Fehling's solution to the solution in the beaker and boiling again. A positive test for reducing sugar should be obtained. The protein and Fehling's solution tests prove mucin to be a conjugated glyco-protein (p. 89).

(3) Action of Saliva on Starch. (a) Make up some fresh starch paste (Experiment XXIV, 3). (b) To Io c.c. of this paste add an equal volume of water and warm to $35^{\circ} \mathrm{C}$., then add I c.c. of saliva and keep mixture at $35^{\circ}-40^{\circ} \mathrm{C}$. Immediately remove a drop of the mixture, and add to a drop of iodine on a porcelain drop plate. (The drop plate should be prepared first by placing a drop of iodine in each cavity.) If no blue color is obtained at the first test, the starch paste is too dilute or too much saliva has been added. At intervals of one minute repeat the test and follow the transformation of starch as given on p. I66. When no starch test is obtained with the iodine, test 5 c.c. of the solution with Fehling's solution. A positive test proves the hydrolysis of starch to maltose or glucose. (c) Repeat (b), adding before the saliva o.x c.c. of concentrated acid. This amount of acid makes the solution approximately 0.3 per cent acid. Note the effect of the acid on the action of the saliva enzymes.

\section{The Stomach}

In the stomach the only carbohydrate digestion which takes place is the continuation of the action of ptyalin which began in the mouth. As we shall find when we consider protein digestion, the stomach juice has an acidity of about 0.2 to 0.3 per cent free hydrochloric acid. This is far above the limits of acidity destructive to ptyalin which we have just given as 0.003 to 0.006 per cent. While the stomach juice has this high acidity the food mass on entering the stomach does not reach this acidity for a considerable length of time. It rests in the front or cardiac end of the stomach for a period of time varying from one half to two hours before its acidity reaches the limit of 0.003 per cent which destroys the action of ptyalin. Within this time salivary digestion of carbohydrates continues in the stomach and ceases when the limit of acidity is reached. 


\section{The Small Intestine}

The digestion of carbohydrate food beginning in the mouth and ceasing in the stomach is taken up again when the food reaches the small intestine. The action of the salivary enzymes has been completely destroyed, and the action which is taken up again in the small intestine is due to new enzymes.

Pancreatic Juice. Amylopsin. - The first enzyme acting on carbohydrate food in the intestine is the starch-hydrolyzing enzyme amylopsin. This enzyme is present in the pancreatic juice which flows into the intestine from the pancreas very near the opening from the stomach into the intestine. The action of amylopsin is exactly like that of ptyalin, i.e. it hydrolyzes starch to maltose through the intermediate stages of dextrin and iso-maltose. It is, however, more active than ptyalin. The pancreatic juice is like the saliva in being alkaline.in reaction and the amylopsin, like ptyalin, acts best in this medium. Any starch or dextrin food which is undigested by the action of ptyalin of the saliva is acted upon in the intestine by the amylopsin and the resulting product is maltose. Thus, when the carbohydrate food materials have been acted upon by both ptyalin and amylopsin, it contains only the following substances: (a) monosaccharoses, originally present in the food, and some glucose formed from maltose by the action of maltase in the saliva, (b) disaccharoses, cane sugar and milk sugar, originally present in the food and malt sugar in the food or formed from polysaccharoses by the action of ptyalin and amylopsin. The monosaccharoses now present in the food mass need no further digestion. The disaccharoses, however, all need to be hydrolyzed to monosaccharoses before digestion is complete. It is interesting to note that amylopsin is not present in the pancreatic juice of infants for the first few weeks after birth, which explains their inability to digest starch.

Intestinal Juice. - The hydrolysis of the three disaccharoses is accomplished by three enzymes which are present in the intestinal juice secreted by the cells of the mucous lining of the 
small intestine and by them discharged upon the food mass at about the same time or very soon after it has been mixed with the pancreatic juice. These two digestive juices act more or less together upon the food mass. The intestinal juice is also termed succus entericus.

The three enzymes of the intestinal juice which hydrolyze disaccharoses are:

Sucrase or invertase, which hydrolyzes cane sugar (sucrose) to glucose and fructose.

Maltase, which hydrolyzes malt sugar (maltose) to glucose. Lactase, which hydrolyzes milk sugar (lactose) to glucose and galactose.

The intestinal juice is alkaline to methyl orange and contains no free hydrochloric or other strong acid. The enzymes present act in media of this reaction.

The digestion of carbohydrate food is now completed and the final products are ghucose, fructose and galactose: the three most common monosaccharoses. These three are all diffusible through the cellular membranes of the digestive tract and as such they pass into the circulatory system ready to take up the metabolic changes by which they form body substance or yield energy.

\section{DIGESTION OF PROTEINS}

The protein food of animals may consist of either animal or vegetable proteins or both. These different proteins are alike in most respects, and any difference in them shows itself mainly in the products of digestion and does not concern the digestive process itself. The digestive enzymes acting upon protein food act alike, so far as we know, on both classes.

The chemical changes occurring in the digestion of protein food are analogous to those that take place with carbohydrates, i.e. they are hydrolytic. In the laboratory proteins may be hydrolyzed by boiling with acids or alkalies and the products obtained are eventually amino-acids such as glycine (aminoacetic acid), etc. This same hydrolysis of proteins may be 
brought about by enzymes, but in such actions several intermediate products have been isolated, known as proteoses, peptones and polypeptides. In the classification of proteins these are termed secondary derived proteins as they still possess certain protein characters. The final products of both acid and enzyme hydrolysis, the amino-acids, are definite nonprotein compounds.

\section{The Stomach}

The digestion of protein food begins in the stomach, practically no digestion of these food constituents taking place in the mouth, by the action of salivary enzymes. The protein digestion in the stomach is brought about by the action of two enzymes, gastric rennin and pepsin, both contained in the stomach juice known as gastric juice.

Gastric Juice. - The gastric juice is secreted by two sets of gastric glands present in two regions of the mucous lining of the stomach, and flows into the stomach when certain stimulation occurs. This stimulation is usually either chemical, due to the character of the food mass, such as presence of water, milk or food juices, or psychical, due to the psychic influence of sight, thought or taste of food. It has been found that water in the stomach stimulates the flow of gastric juice and that water taken at mealtimes is beneficial rather than injurious to the action of gastric digestion. This agrees also with the fact previously referred to in connection with the influence of water upon the action of salivary digestion.

Gastric juice is a thin liquid varying considerably in specific gravity from I.OOI to I,OIO. It contains from 2 to 3 per cent of solid matter. The chief substances present in gastric juice are enzymes, free hydrochloric acid and inorganic salts. The distinctive property of gastric juice is its acidity due to the free hydrochloric acid, and equaling 0.2 to 0.3 per cent.

Enzymes. - The enzymes found in gastric juice are of three classes, two of which act upon proteins and one, gastric lipase, acts upon fats. The protein enzymes are: 
Gastric Rennin. - This enzyme is not a protein-hydrolyzing enzyme, but a protein-coagulating enzyme. It acts upon milk caseinogen, the form of casein present in milk, and converts it into soluble casein and a proteose body. The soluble casein reacts with calcium salts forming calcium casein or true casein, which is insoluble and is precipitated as a curd or coagulum. Gastric rennin acts best in acid media equal to the acidity of gastric juice.

Pepsin. - The most important enzyme of the gastric juice is pepsin, which is a true protein-hydrolyzing or proteolytic enzyme. The enzyme does not occur as such in the cells where it is secreted, but is present there in the form of its mother substance or zymogen, known as pepsinogen. Pepsinogen is activated or converted into pepsin enzyme by the action of the free hydrochloric acid present in the gastric juice. Pepsin acts best in acid media, the amount of acidity varying with the character of the protein to be hydrolyzed. Fibrin protein is digested better by pepsin when the acidity is 0.08 to 0.10 per cent, while coagulated egg albumen requires an acidity of 0.25 per cent. The hydrolysis of protein by means of the enzyme pepsin yields as products not only the derived proteins, proteoses and peptones, but also amino-acids. It is probable that in the stomach, however, the derived proteins, proteoses and peptones are the chief hydrolytic products varying more or less with the character of the protein food. Therefore, when the protein food has passed through the stomach, it is more or less completely converted into proteoses and peptones with some amino-acids and some unhydrolyzed protein.

Hydrochloric Acid. - As has been stated the distinctive character of gastric juice is its relatively strong acidity, 0.2 to 0.3 per cent, due to the presence of free hydrochloric acid. The origin of this hydrochloric acid is not well established, but it is probably derived from the chlorides, principally sodium chloride, present in the blood and may be produced by electrolytic action or by the action of the lactic acid which is also present. 
The function of hydrochloric acid in the gastric juice is also somewhat in doubt. It is probably not, as has been supposed, to assist in the hydrolysis of the protein, though the action of pepsin itself is best in acid solution. Its most important function is probably that of a germicide to prevent the action of putrefying bacteria. It has been found that hydrochloric acid of approximately the same strength as that found in the gastric juice acts best as a germicide. We have stated that free hydrochloric acid of much less strength, viz. 0.003 to 0.006 per cent, destroys the activity of ptyalin. When, however, the free hydrochloric acid reacts with protein it forms protein salts, or, as it is then termed, combined hydrochloric acid. This combined acid is not nearly so effective as a germicide as the free acid. The food mass as it comes from the mouth remains for some time below 0.003 per cent acidity as the acid in the gastric juice first combines with the protein and only gradually exerts an influence as free acid, thus destroying ptyalin action. Eventually the whole food mass becomes saturated with free acid of about 0.2 per cent and is rendered germ-resistant while the action of ptyalin is destroyed.

\section{EXPERIMENT STUDY XXVIII}

\section{Gastric Digestion}

(I) Action of Pepsin (a) Preparation of Egg Albumen. Cut some glass tubing of small diameter $(2-3 \mathrm{~mm}$.), in twelve-inch lengths. Using a tube as a pipette, suck it one half full of fresh egg albumen. Holding the finger over the mouth end, insert the portion containing the albumen into a beaker full of water at $80^{\circ}-90^{\circ} \mathrm{C}$., keeping the finger over the end until the albumen has coagulated. Heat the water to $100^{\circ}$ and allow the tube to remain in the water until the albumen is thoroughly coagulated. Prepare several tubes in this way. When the albumen is all hard remove the tubes from the water and with a sharp file scratch and break the tube containing coagulated albumen into one half or one fourth inch lengths. These sections of tubing containing coagulated albumen are now used as test pieces for studying the action of pepsin.

(b) Prepare 
a Io per cent water solution of commercial pepsin and an approximate 0.5 per cent solution of hydrochloric acid made by adding I.5 c.c. concentrated $\mathrm{HCl}$ to roo c.c. water. (c) Take four test tubes and place in (I) 5 c.c. pepsin solution +5 c.c. water (neutral). In tube (2) 5 c.c. pepsin solution +5 c.c. 0.5 per cent hydrochloric acid solution (approximately 0.25 per cent acid). In tube (3) 5 c.c. pepsin solution +5 c.c. of 0.5 per cent sodium carbonate solution. Into each test tube now place a test section of coagulated egg albumen. Put the tubes in an incubator at $38^{\circ} \mathrm{C}$. or in a beaker of water kept at $38^{\circ}-40^{\circ} \mathrm{C}$, and let them remain for an hour or more, noting any changes in the albumen. Digestion takes place only in tube (2). (d) If desired make similar tests diluting the acid so as to make solutions containing 0.2 per cent acid, O.I per cent acid and another to which I.O c.c. of concentrated hydrochloric acid has been added. Note most favorable acidity. (e) Repeat also with three tubes made as tube $(2)$ in $(b)$, keeping one at room temperature, one at $38^{\circ}-40^{\circ} \mathrm{C}$., one heated to $100^{\circ} \mathrm{C}$. in boiling water, and another immersed in cold water $10^{\circ}-\mathrm{I} 5^{\circ} \mathrm{C}$. Note at which temperature digestion is most active. Warm the first and last of these tubes to $38^{\circ}-40^{\circ} \mathrm{C}$. and note result. Cool the one heated to boiling down to $38^{\circ}-40^{\circ} \mathrm{C}$. and note result. Low temperatures inhibit the action of pepsin but do not destroy the enzyme. Boiling temperature destroys the enzyme completely.

(2) Action of Rennin. Use a commercial rennet obtained from a dairy laboratory or dissolve a rennet tablet in Io-20 c.c. water. Warm Ioo c.c. of whole milk to $38^{\circ}-40^{\circ} \mathrm{C}$. and add 2 or 3 drops of the rennet solution. Mix slightly and then allow to stand. Note coagulation of milk casein. When a good coagulation has formed, break it up with a glass rod; decant off the whey and collect the casein on a folded filter paper. Press as dry as possible and test a portion of the casein for protein by Millon's or Xantho-proteic test (Experiment XVIII, 4, a.b). Compare with Experiment XXIX.

\section{The Small Intestine}

The most important protein digestion takes place in the small intestine by the action of several enzymes present in two digestive juices, viz. pancreatic juice, secreted by the pancreas, and intestinal juice, secreted by the cells of the mucous 
lining of the small intestine. Although we shall consider these two digestive juices and the action of their enzymes separately, they act more or less together.

The chemical reactions taking place when pratein food is hydrolyzed by the enzymes of these two juices are of the same nature as those occurring with pepsin, i.e. the protein is hydrolyzed to amino-acids as the final product.

Pancreatic Juice. - The pancreatic juice is secreted by the pancreas, a contributory organ which is connected with the small intestine by a duct known as the duct of Wirzung. This duct opens into the small intestine near the opening from the stomach to the intestine. This opening is known as the pylorus.

Hormones. - The secretion of the pancreatic juice and its flow into the intestine for the purpose of digesting the protein food, which comes from the stomach, is an exceedingly interesting process involving the action of a new class of substances known as hormones. These hormones are similar to enzymes in some respects, but are not destroyed by boiling. In the case of the relation of hormones to pancreatic juice the series of actions has been very thoroughly established, and it will be worth our while to consider them carefully.

When the food mass has been thoroughly mixed in the stomach by means of the peristaltic action of the stomach muscles, it is finally passed along to the pyloric region of the stomach, where it remains until its acidity reaches a certain point. In this condition the food mass is known as chyme. The opening of the pylorus and the actual passage of the chyme through it is regulated by the acidity of the chyme. When this condition is reached the pylorus opens and the chyme enters the small intestine, which, for the length of about twelve inches, is known as the duodenum (the name signifies twelve). Into this duodenum the duct of Wirzung opens. In the epithelial cells of the lining of the duodenum is a substance or hormone known as prosecretin. The hydrochloric acid of the chyme hydrolyzes this prosecretin and yields a second hormone known as secretin. This hormone secretin is then conveyed by the blood to the 
pancreas where it acts as a stimulus causing the flow of pancreatic juice.

The pancreatic juice then passes from the pancreas through the duct of Wirzung to the duodenum. It is a colorless alkaline solution amounting in twenty-four hours to about 650 c.c. in man. It has a specific gravity of about I.008 and contains about I.3 per cent solid matter.

Enzymes. - The most important constituents of the pancreatic juice are the enzymes. These enzymes are of three classes, (a) amylolytic or starch-hydrolyzing, viz. amylopsin, which we have already considered, $(b)$ protein enzymes, viz. a protein-coagulating enzyme, pancreatic rennin, similar to gastric rennin, and a protein-hydrolyzing enzyme known as trypsin, resembling pepsin, $(c)$ a fat-hydrolyzing enzyme which we shall consider later.

Rennin. - The enzyme pancreaic rennin, present in the pancreatic juice, acts exactly like gastric rennin of the gastric juice, coagulating the caseinogen of milk.

Trypsin. - The most important enzyme of the pancreatic juice is the proteolytic enzyme trypsin. This enzyme, like pepsin, does not exist in the digestive juice as the enzyme itself, but as the mother substance or zymogen known in this case as trypsinogen. When the pancreatic juice reaches the intestine, it is unable to hydrolyze protein as has been shown by drawing off the pancreatic juice from the pancreas by means of a fistular opening. In order that the trypsinogen present in the pancreatic juice may become active by conversion into trypsin it must be activated by another enzyme which is present in the intestinal juice and known as enterokinase. This substance is probably an enzyme though differing from them in a certain particular in that it seems to act quantitatively upon a definite amount of trypsinogen. It is also found to be present in the intestinal juice only when pancreatic juice is present. When, therefore, pancreatic juice containing trypsinogen becomes mixed with intestinal juice, the enterokinase of the latter activates the trypsinogen and the enzyme trypsin is produced. 
This shows why it is always necessary for the pancreatic juice and intestinal juice to act together in the same region and on the same food mass.

The hydrolytic action of trypsin takes place in alkaline solutions and is similar to that of pepsin in its chemical nature. It differs, however, in the end products of the hydrolysis. While pepsin hydrolysis of proteins yields mostly derived proteins, proteoses, peptones and polypeptides with a small amount of amino-acids, the action of trypsin yields mostly amino-acids and only small amounts of the derived proteins. Trypsin may produce the amino-acids from either original protein or from derived protein. The final result then of the action of the enzymes of the pancreatic juice upon protein food is to convert them largely into the final end products, aminoacids.

It should also be mentioned that according to some authorities trypsinogen may be activated by calcium salts, while others claim that trypsin is formed by the action of calcium salts upon another zymogen than trypsinogen.

Intestinal Juice. Erepsin. - The juice secreted by the epithelial cells of the small intestine and known also as succus entericus contains another enzyme connected with the digestion of proteins in addition to the enterokinase just mentioned. This is the proteolytic enzyme erepsin. Erepsin differs from the two proteolytic enzymes thus far considered in that its action is almost wholly upon the derived proteins; proteoses, peptones and polypeptides. These compounds are present after protein food has been acted upon by pepsin and trypsin, and they are hydrolyzed by erepsin to the final end products, amino-acids. Erepsin does possess the power of hydrolyzing a few original proteins, viz. caseinogen of milk and protamines and histones.

This completes, therefore, the digestion of protein food, which by the combined and supplementary action of the three proteolytic enzymes, pepsin of the gastric juice, trypsin of the pancreatic juice and erepsin of the intestinal juice, are hydrolyzed to the final end products, amino-acids. The protein food is 
thus converted into soluble and diffusible forms, and is in a condition ready for absorption through the digestive tract into the circulation. It must not be concluded, however, that no absorption of the products of protein digestion takes place until the intestinal juice has acted upon the food mass. As will be shown later when the absorption of the products of digestion is considered, this process is a gradual and continual one almost from the beginning of the digestive action.

\section{DIGESTION OF FATS}

We now come to the consideration of the digestion of the third of the three essential food constituents, viz. fats.

Fat food consists of both animal and vegetable fats and oils which may be treated as one in connection with the processes of digestion. The difference between the different fats and oils consists in different physical properties, or different forms in which they may be present in the food, e.g. as free globules of fat, or in the form of an emulsion as in milk. The difference in chemical composition of the fats and oils used as food consists in the different fatty acids which are present in combination. It will be recalled that fats and oils are esters or ethereal salts of glycerol and a certain few of the fatty acids, especially butyric, caproic, lauric, myristic, palmitic, stearic of the saturated series, and the unsaturated acid oleic and sometimes linolic. The metabolism of fats is somewhat dependent upon the character of the fatty acid present, but the process of digestion is the same for all.

Hydrolysis of Fats. - The digestion of fats consists, chemically, simply in the hydrolysis of the glycerol ester into glycerol and the fatty acid as represented by the following equation:

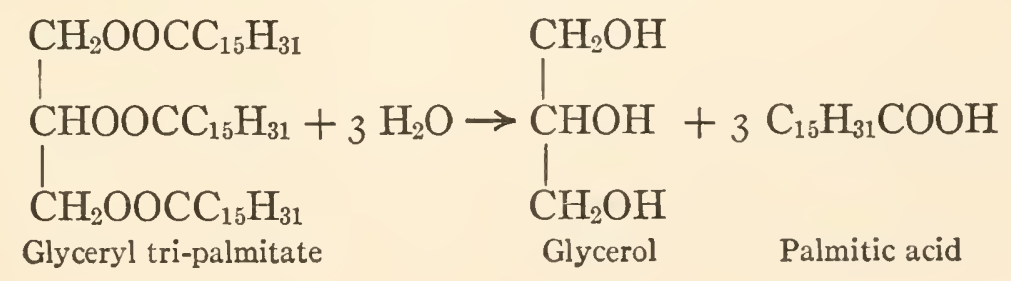


This reaction is brought about in the digestive tract by means of fat-hydrolyzing enzymes known by the general name of lipolytic enzymes or lipases. It is well to consider the striking fact that all of the digestive reactions of either carbohydrates, proteins or fats are reactions of hydrolysis. The actions are all brought about by means of enzymes, and digestive enzymes are all hydrolytic. This statement has one exception if the enzymes gastric rennin and pancreatic rennin are classed as digestive. These two enzymes are coagulating enzymes, and, as they may be considered as simply preparing the proteins for the real action of digestion, they may be classed in a different group than the true digestive enzymes.

\section{The Stomach}

Gastric Lipase. - Digestion of fats like that of proteins begins in the stomach. In the gastric juice, in addition to the enzymes already mentioned which produce protein hydrolysis, there is present a lipolytic or fat-hydrolyzing enzyme known as gastric lipase. This enzyme acts best in neutral solutions, so that under normal conditions of stomach acidity its action is not great, and the larger part of fat digestion is deferred till later. The gastric lipase also acts best on emulsified fat, and fat not so emulsified is very little, if at all, digested in the stomach. In milk the fat is in the form of an emulsion and this is also true in the yolk of eggs. In both of these cases in man a large part of the fat digestion ( 78 per cent in egg yolk) occurs in the stomach. On this account infants, before the pancreatic juice is developed, are able to digest milk and egg yolk.

\section{The Small Intestine}

Pancreatic Lipase. - The chief fat digestion takes place in the small intestine due to the action of a fat-hydrolyzing enzyme present in the pancreatic juice. This enzyme is known as pancreatic lipase or as steapsin. The enzyme acts in alkaline 
solution and is, therefore, in a favorable medium in the small intestine.

As a result then of the digestion of fat by the gastric and pancreatic lipases (mostly the latter) the fat of the food is hydrolyzed into glycerol and fatty acids. The glycerol is soluble in water and is diffusible through the cell membranes. The free fatty acids are, however, practically insoluble in water and are nondiffusible through the cell walls. They become soluble and diffusible by reacting with the alkalies of the pancreatic juice with the formation of alkali salts of the fatty acids. These alkali salts of the fatty acids are, it will be recalled, soaps. Soaps have the property of forming emulsions with fats, and in the form of such an emulsion fats are diffusible through the cell membranes. Fats are thus rendered diffusible in two ways. (I) By a true process of digestion consisting of hydrolysis into glycerol and fatty acids and the subsequent formation of soluble salts of the acids by means of alkalies present in the digestive juices. (2) By the formation of an emulsion of unchanged fat with the soaps formed as a result of the first process. In both of these resulting forms, i.e. alkali salts of fatty acids or soaps and emulsions of free fats, the fat food is absorbed through the cell walls of the digestive tract and enters the circulation.

\section{The Bile}

There still remains one more digestive liquid to consider, which, while it contains no digestive enzymes, assists in the digestion of food constituents, especially the fats. The bile is a secretion of the liver, from which it passes to the gall bladder, which acts as a reservoir, and thence through the bile duct to the small intestine joining with the duct of Wirzung, which brings the pancreatic juice. The bile, therefore, mixes with the pancreatic juice and it is here that it assists in the digestion of the fats.

Its first action is probably one in which it acts as a stimulator of the steapsin of the pancreatic juice. This stimulation re- 
action appears to rest in constituents of the bile known as bile salts. These salts are usually sodium salts of two acids, glycocholic and taurocholic acids, which are so-called conjugated acids of glycocoll or glycine and cholic acid in the case of glycocholic acid, and taurine and cholic acid in taurocholic acid. Cholic acid itself is a complex acid probably monobasic, but of undetermined constitution.

The second way in which the bile assists in the digestion of fats is in the formation of soaps and emulsions. Bile is alkaline in reaction and the alkalies present unite with the free fatty acids formed by the hydrolysis of the fats, and the result is soap. These soaps or alkali salts of the fatty acids are probably directly absorbed through the cell membranes. The emulsifying power of bile may be due in part to the formation of these soaps, but it is also a function of the bile itself. When bile alone is mixed with pure fat, the fat is emulsified and can then diffuse through cell membranes. In these two ways, then, by a stimulation of the lipolytic enzyme of pancreatic juice, and by the formation of soaps and emulsions, the bile assists in the pancreatic digestion and absorption of fats.

The secretion of bile and its flow into the intestine is dependent upon the presence in the intestine of undigested fat food and probably also of protein food, and it seems to be regulated by the same or similar hormones as were described in connection with the flow of pancreatic juice.

Bile is a viscous alkaline liquid of specific gravity, I.OI to I.04. It is of various colors, mostly yellow, green or brown, and has a bitter taste. The amount secreted daily varies between 500 and I I00 c.c. per day for man.

\section{The Large Intestine}

It was previously stated that, in man, no digestion occurs in the large intestine. This is true so far as new digestive processes or the secretion of juices containing digestive enzymes are concerned. No digestive juices containing enzymes are secreted in the large intestine. A continuation of digestive 
processes begun in the small intestine may take place for some time in the upper portion of the large intestine. The greater part of the digestion of food material is, however, completed by the time the food mass enters the large intestine.

\section{ABSORPTION OF FOOD}

The absorption of food, or more exactly of the end products of food digestion, takes place more or less continually from the time the food mass reaches the stomach until it has passed through the small intestine and into the large intestine. This absorption process is one of diffusion through the cell membranes lining the digestive tract. It has been found, however, that the process is not one of simple diffusion through membranes in accordance with physico-chemical laws, but that it takes place much more rapidly than can be explained by such laws. On this account the process has been termed resorption rather than absorption. We shall, however, use the more common term, viz. absorption.

Carbohydrates. - The carbohydrate food converted by the process of digestion into the three monosacharoses, glucose, fructose and galactose, is not absorbed through the cell membranes of the digestive tract until it reaches the small intestine. At this point, when the digestion is practically complete, absorption occurs and the monosaccharoses pass through the cell walls of the intestine and enter the capillary blood vessels in the wall of the intestine and then pass into the portal vein leading to the liver. The blood present in the portal vein always contains a large amount of these monosaccharoses, principally glucose, though both fructose and galactose may be present. After the food mass leaves the small intestine, any digested carbohydrate material remaining is absorbed through the walls of the large intestine and reaches the same destination. It has been found, however, that less than ro per cent of digested carbohydrate food remains unabsorbed when the food leaves the small intestine. Carbohydrate food, therefore, after digestion reaches the circulation in the portal vein leading to 
the liver in the form of the three common monosaccharoses, though mostly in that of glucose. It is claimed by some authorities that absorption of carbohydrates does take place in the stomach, but if so it is probably only in a limited amount or under special conditions. When such absorption does occur, the products reach the portal vein as just described.

Proteins. - While some absorption of protein digestion products may occur in the stomach, yet with these food materials, as with carbohydrates, the chief absorption of the products takes place in the small intestine and is completed in the upper part of the large intestine. More than 90 per cent of the digested protein is, however, absorbed before the food mass reaches the large intestine.

We have shown that the final products of protein digestion are amino-acids, and that the hydrolysis of proteins yielding these products takes place in the small intestine due to the combined action of the pancreatic enzyme trypsin and the intestinal enzyme erepsin. While gastric digestion in the stomach begins with original proteins and ends almost wholly with derived proteins; peptones, and proteoses, the tryptic digestion beginning at the same point, i.e. with original protein, carries the hydrolysis through to amino-acids. Erepsin cannot begin with original proteins, but takes the derived proteins from uncompleted gastric and tryptic digestion and completes the hydrolysis to the final stage of amino-acids.

It has been difficult to determine whether absorption of digested protein food takes place with the final end products only or with the derived proteins as well. The presence of erepsin, which has without doubt an essential action in protein digestion, as supplementing the action of both pepsin and trypsin, would seem to indicate that it is necessary for absorption that protein food be completely hydrolyzed to amino-acids. It has long been considered as a fact, however, that aminoacids alone when fed to animals or when injected into the blood are unable to be used by the animal to synthesize body protein. If, however, a polypeptide nucleus is present, the amino-acids 
may be utilized. It is possible that this polypeptide nucleus may be present in the blood as a result of the tearing down of body protein, and that it may not be necessary for it to have been absorbed from the protein digestion products of the digestive tract. If polypeptide material is absorbed for the later synthesis of body protein, it would seem to be probable that the stomach as a digestive organ is of primary importance, and that considerable absorption of digestion products would occur before the food mass was further digested. The evidence has lately gone to show, however, that the digestive function of the stomach is of secondary importance and of almost no essential character; the essential digestion and absorption taking place later after the small intestine is reached. It has been shown, too, that almost immediately, even in the cell wall of the small intestine, resynthesis of protein material takes place. We can only say then that while it may be true that absorption of protein digestion products is all in the form of amino-acids, yet it is not fully established, and polypeptide groups may also be absorbed.

In the end the digestion products are found immediately after absorption in the intestinal wall, and are thence conducted to the portal vein, where both amino-acids and derived protein groups are present.

Fats. - The absorption of fats takes place in two forms as has been indicated, viz. as salts (soaps) of the fatty acid formed through the reaction of the bile and intestinal alkalies with the free acid resulting from the fat hydrolysis, and in the form of emulsions produced directly by the bile or by the soaps previously formed. The fat thus absorbed is collected first in the lymphatic circulatory system, and from that reaches the blood. Like the proteins, the fats if absorbed wholly as hydrolyzed products and not as free fat (in emulsion), are immediately in the intestinal wall resynthesized to fat. The question of whether free unchanged fat is directly absorbed is still open, but the experiments with hogs fed with cottonseed oil, in which the lard shows positive proof of the presence of cottonseed oil, 
goes to show that the absorption may be direct. If not, the resynthesis of the fat from the hydrolytic products must be immediate and must yield the same original fat as is fed in the food. The fact should be mentioned that lipolytic enzymes which bring about the hydrolysis of fats may also assist in their resynthesis, as it has been shown that these enzymes primarily possess the power of reversibility, i.e. of producing the reverse reaction.

\section{RÉSUMÉ OF DIGESTION AND ABSORPTION}

Before taking up the study of metabolism let us review in outline the course of food through the digestive tract and its absorption into the circulatory system, i.e. the blood.

Mouth. - In the mouth ptyalin present in the saliva hydrolyzes starch and dextrin to maltose and some maltose may be further hydrolyzed to glucose by maltase also present. The food then passes down the esophagus to the

Stomach, where it remains for a short period (one half to two hours) still alkaline from the action of saliva and where ptyalin still continues to work. Eventually the peristaltic movements of the muscular lining of the stomach mix the food mass with the acid gastric juice and the food mass passes slowly from the cardiac or front end of the stomach through to the rear or pyloric end. As the food mass becomes acid through the action of the free hydrochloric acid of the gastric juice the action of ptyalin and maltase is completely stopped, the enzymes being killed. The free acid of the gastric juice acts as a germicide preventing bacterial putrefaction, and produces an acid medium in which the pepsin of the gastric juice can best act. In the gastric juice gastric rennin coagulates the milk caseinogen preparing it for digestion. Pepsin hydrolyzes protein food to peptones, proteoses, polypeptides and a small amount of amino-acids. Gastric lipase hydrolyzes fats, almost wholly those in the form of emulsions, to glycerol and fatty acids. In the stomach some absorption may take place, though probably small in amount. 
Intestines. - The acid condition of the food mass (chyme) regulates the passage of the mass through the pylorus, the opening from the stomach to the small intestine, the first twelve inches of which is known as the duodenum. In the duodenum, a few inches from the pylorus, the duct of Wirzung, leading from the pancreas, together with the common bile duct from the gall bladder, unite in a common opening. Due to the action of the free hydrochloric acid of the chyme food mass a hormone, prosecretin, produced by the ceil walls of the small intestine, yields another hormone, secretin, which is then conveyed by the blood to the pancreas. In the pancreas the secretin stimulates the flow of pancreatic juice, which then flows down the duct of Wirzung, unites with the bile from the gall bladder and together they enter the small intestine. The intestinal juice, succus entericus, secreted by the cells of the small intestine, also mixes with the pancreatic juice and the bile, and the three act together in the complete intestinal digestion. These juices are all alkaline and neutralize the acid reaction of the chyme. The amylolytic enzyme, amylopsin, of the pancreatic juice hydrolyzes any undigested starch or dextrin to maltose, and then by the combined action of the three disaccharose-hydrolyzing enzymes, sucrase, maltase and lactase, present in the intestinal juice, all carbohydrate food is hydrolyzed to the final end products viz. glucose, fructose and galactose. In this form the carbohydrate food is absorbed through the intestinal wall into the blood capillaries, and enters the portal vein where they may all three be found. Glucose is, however, the chief one of the three. The pancreatic juice contains the zymogen, trypsinogen, which is activated by an enzyme, enterokinase, of the intestinal juice, yielding the active enzyme, trypsin. Trypsin is a proteolytic enzyme and hydrolyzes unchanged protein mostly to aminoacids but yielding also polypeptides, peptones and proteoses. Following this in its action on protein food the enzyme, erepsin, of the intestinal juice acts upon the derived proteins (peptones, proteoses and polypeptides) converting them all by hydrolysis into amino-acids. While some absorption of digestion products 
may take place in the stomach, it is mostly accomplished in the small intestine and approximately 90 per cent of the digested food is absorbed here before the food mass passes on to the large intestine. The protein digestion products are absorbed into the blood capillaries and, like the carbohydrate products, enter the portal vein.

The fats are hydrolyzed by pancreatic lipase, steapsin, into glycerol and fatty acids. The fatty acids are converted into soluble, diffusible soaps by the alkalies of the bile and intestinal juice. These soaps are diffusible and are absorbed through the cell walls, entering the lymphatic circulation and thence passing into the blood. Fats are also emulsified by the direct action of the bile and also of the soaps just mentioned. The bile also acts as a stimulator of the steapsin. In the large intestine there are no enzymes secreted, and, in man, the only digestion occurring takes place in the upper end, and is the simple gradual completion of the digestive processes already mentioned. Absorption of digestion products takes place in the large intestine to some extent, but amounts to less than ro per cent of the digested food material. The absorbed material here follows the same course as that previously absorbed from the small intestine.

\section{TIME FOR FOOD PASSAGE}

The length of time required for food to be completely digested varies considerably, as would be expected. Small test meals have been known to pass through the stomach in one to four hours, while large meals of meat have required twelve hours. In man the average time is about seven hours for small meals. For the food mass to pass the ileocacal valve, between the small intestine and the large, requires about nine to twentythree hours from the time of eating. The three food constituents when fed separately pass through the digestive tract with different speeds. Carbohydrates are the most rapid, requiring about four hours, fat about five hours, and protein 
about six hours from the time of feeding until the first food passes into the large intestine. These data refer to experiments with cats. When mixed, as in ordinary food, each constituent has the effect of either retarding or hastening the passage of the other constituents. In the large intestine the residual food mass remains for a considerable time, usually for one to two days or even longer. 


\section{CHAPTER XII}

\section{A N I M A F O O D A D N U T R I T I N (Continued) M E T A B O L I S M}

WE have emphasized the fact that the distinctive character of animals as compared with plants is that they are predominantly energy-liberating organisms. The energy is stored up in complex compounds and the tearing down of these compounds by oxidation sets free the energy contained in them. We have also given as a definition that any substance which is used by the animal to build up body substance or to yield energy is a food. Body substance in this connection means not only cell substance and muscular tissue, essentially protein in composition, and body fat, but also any substance more complex than the absorbed food material. Such substances may be reserve or stored, or they may be transition material on the way to still more complex forms.

The food substances which we have been considering and which we have followed through their absorption into the animal circulation are, therefore, to undergo further change, and this change probably always occurs within the living cell. They are to be built up into body materials, and they or the body materials formed from them are to be torn down by oxidation that the energy resulting therefrom may be set free. This energy in its various forms is the manifestation of the life of the cell and the animal.

Metabolism, Anabolism, Katabolism. - The two processes, viz. the one building $u p$, the other tearing down, are most intimately connected. The building-up process, by which the body substance is formed from absorbed food material is known 
as anabolism, and the tearing-down and oxidation process as katabolism. The double process is termed metabolism.

Metabolism then means the double process by which the digested and absorbed animal food is first built up by anabolism and then torn down by katabolism, in which latter process energy is liberated, thus fulfilling the complete function of food. The entire double process includes all the changes which the original food material undergoes subsequent to digestion and absorption. These latter processes simply prepare the food and convey it to the animal cells where the metabolic changes take place.

As will be readily understood, this process of metabolism is not simple, but becomes often very complicated both because of partial changes and because of transformations from one form of substance into another. Many of the intricate changes occurring in metabolism have not yet been made clear by means of physiological and physiological-chemical investigations, but are still subjects of discussion and experimentation. It will not be profitable, therefore, in this study to enter into the discussion of many of these questions. We shall consider, therefore, only the fundamental facts and certain details which have been well established by experimental evidence.

\section{METABOLISM OF CARBOHYDRATES}

\section{Direct Metabolism}

The metabolic changes which carbohydrate food undergoes in the animal body are more thoroughly understood than are those of either fats or proteins. We shall discuss these changes more fully than those of the other two food constituents, not because they are more important, but because they can be made clearer in an elementary treatment.

As previously explained, the carbohydrate food which is eaten by an animal is changed by the combined digestive actions into the form of the three common hexose monosaccharoses, viz. glucose, fructose and galactose. In the normal diet of a mature animal, in which starch is the predominating carbo- 
hydrate food, glucose is very much in excess of the other two digestive products. In the case of infants, galactose is also present in equal amounts with the glucose. By the process of absorption or assimilation, these three monosaccharoses are taken up by the blood capillaries of the small intestine and they are all found in that part of the blood circulatory system which leads to the portal vein. After a meal rich in carbohydrate food the amount of glucose, or of the three hexoses together, may be as much as 0.2 per cent, which is double the normal amount. The portal vein leads to the liver, and the three products of carbohydrate digestion are thus carried to this organ.

Glycogen. - In the liver, due probably to enzymatic action, the first metabolic change occurs. This change is anabolic in character, and the result is the conversion of the three hexoses found in the portal vein into the polysaccharose glycogen. This glycogen is stored in the liver cells and in some cases may amount to as much as Io per cent of the liver itself.

The blood which is brought to the liver by the portal vein leaves the liver by the hepatic vein and passes thus into the general venous blood stream which reaches by means of fine capillaries the muscle cells of the whole body. It is a striking fact that while the glucose content of the portal vein varies in its amount with the supply of assimilated carbohydrate food the glucose content of the hepatic vein and general venous system remains constant at $0 . I$ per cent.

Conversion of Glycogen into Glucose. - Furthermore, while the portal vein, which receives its supply of sugar from the absorbed food, may contain all three of the hexoses mentioned, the hepatic vein contains only glucose. This constant supply of glucose is maintained by the katabolic conversion of the liver glycogen into glucose. This change, also occurring in the liver, is like the preceding anabolic change of glucose, fructose and galactose to glycogen, without question brought about by enzymes.

Amount of Glycogen in the Liver. - The amount of glycogen stored in the liver, like the amount of hexose sugars present in the blood of the portal vein, increases with the increase of ab- 
sorbed carbohydrate food. With an abundance of such food the amount of glycogen reaches its maximum of ro per cent of the weight of the liver, in man. A gradual conversion of the liver glycogen into glucose is constantly going on in order to maintain the constant supply of o.I per cent of glucose in the general venous circulation. If the supply of carbohydrate food is diminished or cut off, this constant conversion of glycogen into glucose gradually exhausts the supply in the liver and it may fall to practically nothing. So far as is known, however, there is no passage of absorbed carbohydrate food into the general circulation except through the form of liver glycogen. The liver is thus not only a storehouse of carbohydrate food material, but is a kind of regulating reservoir by which a varying supply of absorbed carbohydrate food is passed on to the general circulation in a constant supply of o.I per cent of the blood. Without going into detail, which would involve the discussion of yet unsettled questions, it may be stated that carbohydrate food of a pentose nature derived from pentosans in vegetable foods probably passes through the form of liver glycogen and reaches the general circulation as glucose.

Oxidation of Glucose. - What now is the fate of the constant supply of glucose furnished by the liver to the general circulation? The hepatic vein leads to venous capillaries which terminate in the muscle cells. In this way the glucose product of carbohydrate food reaches the ultimate cells of the animal and in these cells the oxidation takes place by which the energy of the carbohydrate food is liberated. By means of the arterial blood system leading from the lungs the muscle cells receive also a supply of oxygen in the form of oxyhamoglobin of the arterial blood. Within the cell the oxyhæmoglobin gives up its oxygen to the glucose brought by the venous blood and oxidation of the glucose takes place in accordance with the reaction,

$$
\mathrm{C}_{6} \mathrm{H}_{12} \mathrm{O}_{6}+6 \mathrm{O}_{2} \rightarrow 6 \mathrm{CO}_{2}+6 \mathrm{H}_{2} \mathrm{O}+\text { energy }
$$

Oxidizing enzymes are probably the agents which produce this reaction. The reaction does not take place as simply as in- 
dicated, for lactic acid, which is a normal constituent of muscles, is probably an intermediate product.

The rate at which this oxidation takes place is dependent upon the activity of the muscle cells. Certain muscular activities, such as the involuntary actions of the body connected with the maintenance of body heat, body tone or tension, and the processes of circulation, respiration and digestion, are constantly going on and a large part of the energy of the food of animals is so expended. Another part of energy of animal food is used for producing muscular work which is voluntary, and varies with the physical or muscular activity of the animal. The total energy demands of the body regulate the demands upon the supply of glucose in the blood, and thus upon the reserve supply of glycogen in the liver. In general it may be said that under normal conditions of feeding and activity the supply of glycogen in the liver is used up between two succeeding meals.

Muscle Glycogen. - The liver is not, however, the only place where carbohydrate food is stored in reserve in the form of glycogen. In case the maximum amount of glycogen has been stored in the liver and the supply of carbohydrate food is still in excess of the energy demands of the body, then the glucose of the general circulation on reaching the muscle cells is not all oxidized but, here likewise, is partly converted into glycogen and stored in the muscles as muscle glycogen. The amount possible of storage in this form may attain a maximum of 2.0 per cent of the muscles which, though less in percentage amount than in the liver, may amount in total to much more, owing to the far greater mass of the muscle tissue over that of the liver. With an increase in the energy demands of the body or a decrease in the food supply, this muscle glycogen is first drawn upon, being converted back into the form of glucose.' In all of these metabolic changes enzymes play a most important part. Probably each metabolic reaction is brought about through their agency. 


\section{Conversion of Carbohydrates into Fats}

The carbohydrate metabolism thus far discussed may be considered as the most direct metabolic change which carbohydrates undergo, in order to yield their energy to the animal body. In these changes the carbohydrate remains always as carbohydrate, simply passing from mono- to poly-saccharoses, and vice versa, until it is finally oxidized. Another metabolism of carbohydrates occurs, however, in which they become converted into compounds that are not carbohydrates. This is the metabolic conversion of carbohydrates into fats.

The fact that the feeding of carbohydrate food increases the fat of animals has long been known and is the basis of practical animal feeding. The farmer feeds, not fat food, but largely carbohydrate food, e.g. grain, in order to increase body fat or to maintain a large production of milk fat. We cannot follow in detail the reactions by which carbohydrate food is converted into fat, but we can simply state the fact that such conversion does take place in the animal body. It is probably true that fat is not formed from carbohydrates until both liver glycogen and muscle glycogen have been stored to their maximum amounts; that is, until all temporary reserve supplies for energy demands are filled. When such a condition occurs and the supply of carbohydrate food is still in excess, then this excess carbohydrate becomes converted into fat.

Feeding Experiments. - While this conversion is a fact, as shown by common feeding practice, it has likewise been established by direct experiment. By feeding pigs and milch cows with rations carefully analyzed and calculated for the exact amounts of carbohydrate, fat and protein eaten and digested; and then, similarly, accurately determining the gain in fat, in the case of the pigs, and the amount of milk fat produced in the case of the milch cows, it has been proven in both cases that the fat produced was very largely in excess of that possible of formation from the fat and protein of the food and must, therefore, have been formed from the carbohydrate. 
Respiratory Quotient. - Another proof of the metabolic conversion of carbohydrates into fat is furnished by a study of what is termed the respiratory quotient. The two classes of compounds concerned, viz. carbohydrates and fats, are alike in containing the elements carbon, hydrogen and oxygen. They differ, however, in the relative proportions of these elements. On oxidizing, the products of oxidation are alike in both cases, being simply carbon dioxide and water. As the relative amount of oxygen in each compound is different, the amount of added oxygen necessary for complete oxidation is different also. This will be made clear if we write the reactions for the oxidation of the two substances. Glucose, as we have just discussed, is the final form in which carbohydrate food is oxidized. Taking this as our example, we have the reaction of oxidation as follows:

$$
\begin{array}{ccc}
\mathrm{C}_{6} \mathrm{H}_{12} \mathrm{O}_{6} & +6 \mathrm{O}_{2} \rightarrow 6 \mathrm{CO}_{2}+6 \mathrm{H}_{2} \mathrm{O} \\
\text { I mol. } & 6 \text { mol. } & 6 \text { mol. } 6 \text { mol. } \\
& 6 \text { vol. } 6 \text { vol. }
\end{array}
$$

This means that to oxidize one molecule of glucose 6 molecules of oxygen are required and 6 molecules of carbon dioxide are produced. Now, by a fundamental hypothesis of chemistry (Avogadro's Hypothesis) equal molecules of gases represent equal volumes. Therefore, in the oxidation of glucose the volume of oxygen gas used is exactly equal to the volume of carbon dioxide gas produced.

If now we write the corresponding reaction for the oxidation of a fat, we have, taking glyceryl tri-stearate as an example:

$$
\begin{aligned}
2 \mathrm{C}_{57} \mathrm{H}_{110} \mathrm{O}_{6}+ & \text { I63 } \mathrm{O}_{2} \rightarrow \\
& \text { I I } 43 \text { mol. } \mathrm{CO}_{2}+\text { I I } 4 \text { mol. } \mathrm{H}_{2} \mathrm{O} \\
& \text { I63 vol. I } 4 \text { vol. }
\end{aligned}
$$

This means that in the oxidation of fats, which contain less oxygen relatively than do carbohydrates, the volume of oxygen used is greater than that of the carbon dioxide produced. 
If we express these results in the form of a ratio between the carbon dioxide produced and the oxygen used, we have:

$$
\begin{array}{rlrl}
\frac{\text { Vol. } \mathrm{CO}_{2}}{\text { Vol. } \mathrm{O}_{2}} & =\text { for carbohydrates } \frac{6 \text { vol. }}{6 \text { vol. }}=\frac{\text { I.0 }}{\text { I.0 }}=\text { I.0 } \\
& =\text { for fats } & \frac{\text { II } 4 \text { vol. }}{\mathrm{I} 63 \text { vol. }}=\frac{0.7}{\text { I.0 }}=0.7
\end{array}
$$

Now in the animal body the oxidation of the food products or body substance is brought about in the muscle cell by the oxygen of the inhaled air and the carbon dioxide gas produced by the reaction is then exhaled by the lungs. The two gases then are involved in the process of respiration and this quotient, between the carbon dioxide and oxygen, in the oxidation of carbohydrates or fats, may be determined by accurately measuring the oxygen inhaled and used and comparing it with the carbon dioxide produced and exhaled. This quotient is therefore known as the respiratory quotient.

When now an animal that is fasting and in which all reserve carbohydrate food has been used up is examined, by a determination of this quotient it is found that the quotient approximates 0.7 , the value for the oxidation of fats. This must mean that the animal is using up body fat as fuel for the energy production of the body.

In a similar way if the animal body is supplied with a sufficient supply of carbohydrate food, but not an excess, the respiratory quotient approximates I.O, the value for the oxidation of carbohydrates. This means that under these conditions the animal is using, as fuel for its energy production, only carbohydrate food. When the carbohydrate food supply is less than sufficient to furnish the necessary energy of the body, it is found that the respiratory quotient lies between 0.7 and I.0, which means that the body is oxidizing both carbohydrates and fat.

If, however, the animal is fed a large excess of carbohydrate food, so that both liver glycogen and muscle glycogen are stored to their maxima, it is found that a determination of the respiratory quotient gives a value greater than I.o. This can 
mean only one thing, that is, that, as the carbon dioxide exhaled is greater in volume than the oxygen used, some oxygen must have been supplied from some other source than the inhaled air. If now we try to convert carbohydrates into fats, we find that in doing so some of the oxygen of the carbohydrate must be given off as free oxygen.

$$
\underset{\text { Glucose }}{\text { I9 } \mathrm{C}_{6} \mathrm{H}_{12} \mathrm{O}_{6}} \rightarrow \underset{\text { Glyceryl tri-stearate }}{{ }_{2} \mathrm{C}_{57} \mathrm{H}_{110} \mathrm{O}_{6}+{ }_{4} \mathrm{H}_{2} \mathrm{O}+49 \mathrm{O}_{2}}
$$

This free oxygen obtained from the conversion of carbohydrates into fats would then be used to oxidize other carbohydrate and thus diminish the oxygen required by inhalation, so that the ratio of carbon dioxide exhaled to oxygen inhaled would be greater than I.o.

Thus the experimental fact that with excess of carbohydrate food the respiratory quotient becomes greater than 1.0 can mean only one thing, viz. carbohydrate is being converted into fat.

We have then not only results of feeding experiments but also results of the respiratory quotient proving that in the animal body carbohydrate food is metabolized into body fat or into milk fat. The body fat so formed is, in part at least, simply a more lasting reserve form of storing the excess of carbohydrate food. On fasting, this body fat is drawn upon for producing energy as is shown by loss in body fat in fasting, or in the case of hibernating animals.

\section{METABOLISM OF FATS}

The digestive action upon the fat constituents of food results in the hydrolysis of the fats into fatty acids and glycerol. The products of digestion are absorbed through the intestinal wall and enter the capillaries, not of the blood circulatory system, as do the products of carbohydrate digestion, but of the lymphatic system, from which they pass to the thoracic duct and thence to the general venous system, where they are present in the blood plasma or liquid constituent of the blood. The fatty acids are rendered soluble and diffusible by means 
of the bile. In the lymph and later in the blood plasma, the products of fat digestion appear not as fatty acids and glycerol, but as recombined fat in a soluble form, giving to the blood plasma a turbid character, in case large amounts of fat have been eaten. In this form in the blood plasma, the absorbed and recombined hydrolytic products of fat food may become oxidized on reaching the muscle cells in a similar way to that by which the glucose is oxidized. In case the fat carried in the blood plasma is not required to be burned to furnish the energy supply of the body, the soluble fat in the blood plasma becomes reconverted again into the ordinary insoluble form and is deposited as fat globules which eventually form the fatty or adipose tissue of the body.

Body Fat and Milk Fat. - The occurrence in body fat and also in milk fat of certain characteristic fats eaten as food has led to the belief held by some that fat food is absorbed in the form of an emulsion of unhydrolyzed fat. The fat of hogs which have been fed on cottonseed meal has been shown to give the tests for cottonseed oil. Also the milk fat of cows which have been fed on sesame oil cake responds to the tests for sesame oil. It is generally accepted, however, that the presence of such fats in the body and milk is not incompatible with the idea that all fat food is hydrolyzed into fatty acids and glycerol. The reversible nature of the enzymatic reaction, especially of lipolytic enzymes, is well established; and this reversible reaction may take place even during the passage of the hydrolytic products through the wall of the digestive tract, so that, when the assimilated products of digested fat food first appear in the lymphatic capillaries, they are in the form of recombined fat, and not of the separate hydrolytic products. This recombined fat synthesized from the hydrolytic products so immediately would thus appear in the lymph and blood plasma and then in the muscle cells or in the milk in the same form in which it was eaten.

When the absorbed products of fat food are thus metabolized into the fat of blood plasma, and this fat is not used as fuel to 
supply energy, it is deposited as body fat. This body fat may later be drawn upon to supply energy, in which case it is reconverted into the soluble form and again enters the blood of the muscle cells and is oxidized. This is proved by experiment upon fasting or hibernating animals in which body fat is lost in proportion to the energy set free.

Conversion of Fats into Carbohydrates. - There is still a question as to whether body fat, or even the first formed fat in blood plasma, is burned directly as fat or is first converted into glucose. Experimental evidence seems to indicate, however, that while body fat may be first converted into glucose and then oxidized, yet directly absorbed food fat is undoubtedly burned in the body, that is, in the muscle cells, without being first converted into glucose. Such a conversion of food fat into glucose preceding oxidation would result in the loss of a considerable proportion of the fuel value of the fat, whereas experiments have shown that almost the full amount of the fuel value of fat food is utilized as energy in the animal body.

We have, nevertheless, almost as conclusive evidence that body fat is at least possible of conversion into glucose. In fasting or hibernating animals the blood maintains its constant amount of glucose, viz. O.I per cent. This constant supply of glucose in the blood could only be maintained under these conditions by the conversion of body fat into glucose. Also in these cases the respiratory quotient has been found to be below 0.7 , the value of the quotient when fat alone is oxidized. Such a value for the respiratory quotient must mean that fat is being converted into glucose, just as the value greater than I.o means that carbohydrate is converted into fat, as previously discussed. It has also been shown that the glycogen content of the body has increased, in the case of hibernating animals, at the expense of body fat. This conversion of fats into carbohydrates is thought to take place in the liver, and as this organ contains a very large number of different enzymes such a transformation is not improbable. It is possible that the formation of carbohydrate from fat takes place only from the glycerol 
part of the molecule, as such a conversion of glycerol into glucose would be much simpler than of the entire fat molecule. This view is not, however, in accord with the results indicating the transformation of fat into carbohydrate by the production of a respiratory quotient below 0.7. Taken all together, therefore, while the evidence of the conversion of fat into carbohydrate is not as conclusive as that indicating the reverse formation of fat from carbohydrate, it is, nevertheless, pretty well established, at least so far as body fat is concerned.

While the greater part of the fat of the body and of milk is formed from carbohydrate food, yet food fat itself also yields body fat. The proportion of the food fat that is utilized directly for the production of energy varies with the diet and with the energy requirements of the animal body. Probably in most cases, except when body fat is increasing or milk fat is continually produced, the greater part of the fat food is almost directly converted into heat energy, for, as we shall find, fat is the highest energy food constituent of the three.

\section{METABOLISM OF PROTEINS}

The metabolism of the protein food is much more complicated than that of either of the other constituents and there are many points not yet made clear and concerning which there is more or less discussion and difference of opinion. We shall therefore not pretend to take up the subject in its entirety or to consider any point of it in very great detail.

The difference between proteins and carbohydrates or fats, as has been repeatedly stated, is that they only, of the three organic food constituents, contain the element nitrogen. The complicated reactions connected with the metabolic changes of this element nitrogen present exceedingly difficult problems which have not yet been fully explained and proved by investigation.

Amino-acids. - The results of the combined processes of digestion upon protein food constituents is their cleavage into the ultimate products of protein hydrolysis, viz. the amino- 
acids. It was formerly believed that all absorption of digested protein was in the form of amino-acids. The presence of the enzyme erepsin in the intestinal juice seemed to uphold this view for, as this enzyme completes all partially digested protein, carrying the hydrolysis through to the amino-acids, its presence would indicate that the complete hydrolysis is necessary for absorption. It is now pretty generally accepted, however, that all protein food is not converted into amino-acids. The experimental evidence for this is that amino-acids themselves, at least singly, are not used as nutritive material when fed to animals. It seems possible, however, that certain combinations of amino-acids, including some of the more complex ones like tryptophane, can be utilized directly as food.

Polypeptide Nucleus. - On the other hand, it has been found that tryptic digestion is inactive toward certain polypeptides, and it is believed that this indicates a sparing or protective action toward the further hydrolysis of these compounds in order that they may be absorbed as such. Being absorbed through the intestinal wall together with the amino-acids, these polypeptides act as a mucleus with which the amino-acids combine to form new protein. It has been established that neither polypeptides nor amino-acids are present in the blood except perhaps small amounts of the latter. This would indicate that, as in the case of fats, the resynthesis of the protein from the polypeptide and amino-acid products of digestion occurs during the absorption of these materials through the intestinal wall.

Serum Albumin. - As stated, the absorbed products of protein digestion are found in the blood capillaries leading to the portal vein. In the blood of this part of the circulatory system there is always present in the serum a protein known as serum albumin. It is interesting that while absorbed and resynthesized fat is found in the animal body of exactly the same nature as the food fat, even though this is different in character from the normal body fat, yet, in the case of proteins, no matter how different the protein food may be from the serum albumin of the animal, the serum albumin synthe- 
sized from the food protein is always the same. The selective action of the digestive enzymes in not hydrolyzing certain polypeptides would be in accord with such results. The animal body in its digestive action upon proteins would retain certain polypeptides in an unhydrolyzed form, while all others would be completely hydrolyzed to amino-acids. These unhydrolyzed polypeptides would then act as a nucleus with which the various amino-acids could combine to synthesize a protein of uniform character, viz. the serum albumin.

Body Protein. - What now is the fate of the synthesized serum albumin of the blood? We know that the blood protein synthesized from the absorbed products of food protein is built up in the muscle cells into body protein, but we do not know the different steps in this metabolic change. It is important here to emphasize the fact that under normal conditions body protein can be formed, either directly or indirectly, only from food protein. Unlike plants, animals are unable to use other nitrogen compounds together with carbohydrates to synthesize body protein. It is true that for a short time the animal body can live with a protein free diet, but this is always at the expense of body protein, and any formation of body protein from carbohydrates can only take place when protein residues, probably polypeptides and amino-acids obtained from the katabolism of body protein, are present to combine with carbohydrate to form new body protein. Under such conditions body protein is gradually lost and protein katabolism grows gradually less and less until life ceases. Food proteins in some form, or compounds analogous to them, such as certain combinations of amino-acids or polypeptides or both, and these only under limited conditions, are absolutely essential to the formation of body protein and the existence of animal life.

Oxidation of Protein. - We do not know certainly whether all food protein first converted into blood protein is built up into body protein and then this body protein torn down and oxidized, or whether only part of it forms body protein while another part is oxidized without ever having been converted 
into body protein. It seems probable that part of the protein is oxidized immediately and never forms body protein. This may take place with the entire blood protein molecule, or it is possible that in being synthesized into the various forms of body protein certain groups of the blood protein are unadapted for the synthesis of the body protein and these portions then become oxidized.

While we cannot therefore follow with any definiteness the conversion of food protein into body protein or state definitely whether katabolized protein is body protein or blood protein (food protein), we can follow in certain detail the results of the katabolism of protein in the body.

Katabolism of Proteins. - We have thus far discussed, though without a much to be desired definiteness in detail, the conversion of food protein into body protein. It remains to consider the reactions and results of the katabolism or degradation of protein and the oxidation by which it, like carbohydrates and fat, yields energy to the animal body. For a long time it was held that protein alone was the material of the body from which muscular energy was derived. This is not now considered as true, for it has been shown that both carbohydrates and fats contribute to the supply of muscular energy.

Katabolic Products. - In considering the katabolic or tearing down changes of protein it is necessary to remember that proteins, because of their containing nitrogen as well as carbon, hydrogen and oxygen, may be looked upon as consisting of two parts, viz. (I) a carbon, hydrogen and oxygen part, which acts like the carbohydrates and fats and on oxidation yields carbon dioxide and water as the products, (2) a nitrogen-containing part, also containing carbon, hydrogen and oxygen, which on oxidation yields distinctly different products. It is not meant that in the protein molecule there are two separate portions united together, but simply that by their oxidation two classes of products are formed. It is through a study of these end products of protein katabolism that we gain an insight into the process itself. When protein is oxidized in an excess of oxygen, as in a calo- 
rimeter, the products are carbon dioxide, water and nitrogen; and the theoretical fuel value or calorific value of proteins is in -accordance with such a reaction. In the animal body, however, the reaction does not take place in just this way. The products formed here are carbon dioxide, water and complex nitrogen compounds such as urea, uric acid and the purine bases. The carbon dioxide and water are eliminated in the respiration as in the case of carbohydrates and fat.

Nitrogen Excretion in Urine. - The nitrogen-containing compounds are all eliminated through the kindeys in the urine. It is important to emphasize the fact that the urine is thus a true excretion substance, carrying out from the body the end products of metabolism, exactly analogous to the exhaled breath and not like the feces, which are almost entirely a waste product of undigested food material. The urine contains all of the nitrogen of the katabolized protein and about go per cent of this nitrogen is in the form of urea, only the other ro per cent being in the form of uric acid and the other nitrogen compounds of urine. Thus a study of the urine nitrogen is the means we have of studying the nitrogen portion of katabolized protein. Also the total nitrogen of the urine is a measure of the total katabolism of protein and approximately every 16 grams of urine nitrogen represents Ioo grams of protein that have been katabolized. This explains the importance of nitrogen analysis of urine.

Formation of Urea, etc. - Let us now examine in more detail the way in which the protein nitrogen is converted into urea. When protein is oxidized under the conditions present in the muscle cells, or perhaps by a preceding hydrolysis of the protein molecule, the nitrogen splits off in the form of ammonia. This is readily understood when we remember that proteins are polypeptide compounds of amino-acids. Illustrating by a simple amino-acid the hydrolysis occurring we have:

$$
\begin{array}{c:cc}
\mathrm{H}_{2} \mathrm{~N}_{2} & -\mathrm{CH}_{2}-\mathrm{COOH} \\
\hdashline & -\mathrm{OH}
\end{array} \rightarrow \mathrm{NH}_{3}+\mathrm{CH}_{2} \mathrm{OH}-\mathrm{COOH}
$$


By the further oxidation of these products we would obtain carbon dioxide and water from the carbon-hydrogen-oxygen portion, the ammonia remaining as ammonia. From our study of the chemistry of urea in Section I (p. 97) we know that urea may be synthesized from ammonia and carbon dioxide. Thus part of the carbon dioxide of the complete oxidation would remain combined with the ammonia as urea. This explains what we shall later consider again, that the theoretical calorific value or energy value of protein is not obtained in the animal body, because a part of this energy is lost in urea and the other nitrogen compounds of urine. In practice, therefore, we subtract from the theoretical calorific value of protein the calorific value of the urine to obtain the physiological or body calorific value of protein.

This would seem to indicate that in the katabolism of protein a hydrolytic cleavage of the molecule into a nitrogenous unoxidizable portion and a non-nitrogenous oxidizable portion must precede the oxidation, for if the oxidation occurred with the protein molecule before splitting, we should expect all of the carbon and hydrogen to be oxidized, and the body calorific value of proteins would be more nearly equal to the value obtained in a combustion calorimeter.

\section{Conversion of Proteins into Carbohydrates}

What now happens to this non-nitrogenous portion of the protein molecule? We know that such a portion would be capable of immediate oxidation and we know also that eventually it is completely oxidized, though not all of its energy of oxidation is liberated, some of the carbon dioxide combining with the ammonia, the other hydrolytic product of the protein, yielding urea. Whether the oxidation of the non-nitrogenous portion takes place immediately or whether other metabolic changes occur before oxidation is not clear.

It has been claimed that all of the oxidation in the body by which energy is liberated is the oxidation of glucose and that 
all food materials are finally converted into this sugar before they are oxidized to yield energy. This has not borne the test of experiment in the case of fats, though we know that in the body fats may be converted into carbohydrates. With the proteins also we are not able to claim that such a transformation of the products of protein cleavage into carbohydrates, before oxidation, always takes place, though we can show that such a conversion is possible.

In the cleavage of proteins alanine or $\alpha$-amino-propionic acid is one of the normal products, and this by hydrolysis, as already mentioned on page 85 , would yield ammonia and lactic acid ( $\alpha$-hydroxy-propionic acid). We know that lactic acid is formed in the body from glucose, such a conversion being simply a splitting of the molecule without hydrolysis.

\section{$\mathrm{C}_{6} \mathrm{H}_{12} \mathrm{O}_{6} \rightarrow{ }_{2} \mathrm{C}_{3} \mathrm{H}_{6} \mathrm{O}_{3},\left(\mathrm{CH}_{3}-\mathrm{CH}(\mathrm{OH})-\mathrm{COOH}\right)$} Glucose Lactic acid

It would not, therefore, be impossible for the reverse action to occur and glucose to be formed from the lactic acid resulting from the non-nitrogenous portion of protein. That a formation of carbohydrates from protein actually does take place in the animal body has been proved by experiment. It has not been proved, however, that all non-nitrogenous protein cleavage products are first converted into carbohydrates before oxidation.

The actual conversion of proteins into carbohydrates does take place in the body in case there is a lack of carbohydrate and fat food. In such cases the normal supply of glucose in the blood is maintained wholly by protein, and also the glycogen supply in the liver may be similarly kept up.

\section{Conversion of Proteins into Fats}

That both body fats and milk fats may be formed from proteins has been well established by experiment. Whether such a conversion is direct from proteins to fats, or indirect from proteins through carbohydrates to fats, is not so well proved. 
We have just demonstrated that proteins can be converted into carbohydrates, and the conversion of carbohydrates into fats is likewise proved.

Thus protein food may yield both carbohydrates and fats from the non-nitrogenous portion of the molecule, and this portion, whether it is thus transformed or not, is eventually oxidized with the liberation of energy. This energy, however, is not equal to the entire energy of the original protein molecule, as a portion of it remains locked up, with the nitrogen portion of the protein, in the form of urea and other nitrogen excretion products of protein katabolism. 


\section{CHAPTER XIII}

\section{I L K, B L O O D A N D URINE}

BEFORE dismissing the general subject of animal food and nutrition, and taking up the study of plant physiology, it is best to consider the three animal fluids mentioned at the head of this chapter. Milk is a normal secretion of all mammalian animals, serving as food for the offspring during the first period of its life. Blood is the main circulatory liquid of the animal body by means of which the absorbed food nutrients are carried to the different parts of the body and in the muscle cells brought in contact with oxygen, also carried by the blood, and finally oxidized. Urine is an excretion liquid which serves as the medium by which the nitrogen end products of protein katabolism are removed from the body.

\section{MILK}

Milk is the normal secretion of the mammary glands of mammalian animals. It is provided by the animal as the sole food of the young for the first period of its life. In harmony with this use it is natural to find that it contains all of the substances essential as animal food. These substances, as we have previously stated, embrace carbohydrates, fats, proteins and certain inorganic salts. As an agricultural product milk means almost exclusively cows' milk and, unless otherwise stated, what we shall say refers to this particular milk, though in general the statements will apply also to all milk.

\section{Constituents}

Carbohydrates. - There is only one carbohydrate found in milk, viz. milk sugar, or lactose. This sugar is a disaccharose of the same composition as cane sugar, i.e. $\mathrm{C}_{12} \mathrm{H}_{22} \mathrm{O}_{11}$. It is 
easily soluble in water and crystallizes in large crystals. It does not taste quite as sweet as cane sugar, but is more easily digested; at least human beings, and probably all mammals, are able to digest it before any other carbohydrate. It is the sole carbohydrate food so long as the animal lives upon milk alone. It reduces Fehling's solution and may be tested for or determined quantitatively by means of this reagent.

An important property of milk sugar is that certain bacteria, viz. lactic acid bacteria, ferment it with the production of lactic acid. The lactic acid so produced is the cause of what is termed the souring of milk and is also connected with the separation of the protein casein. Milk sugar is obtained from milk in considerable quantities for use as an infant food and the sugar left in whey is used without separation for the commercial preparation of lactic acid.

Fats. - The fat constituents of milk are contained largely in the cream, which may be separated from it, and in butter the most important milk product. As has been previously explained, fats are esters of glycerol and organic acids. With two exceptions, the acids present as esters in milk fat belong to the monobasic saturated acids of the acetic acid series. The exceptions are oleic acid, the eighteen-carbon acid of the ethylene unsaturated series, and a dihydroxy derivative of stearic acid, the eighteen-carbon saturated acid.

The acids found in milk fat, as glycerol esters, are the following in the order of their amounts present as given by Browne:

Palmitic acid

Oleic acid

Myristic acid

Butyric acid

Lauric acid

Caproic acid

Stearic acid

Dioxystearic acid

Caprylic acid

Capric acid
$\mathrm{C}_{15} \mathrm{H}_{31} \mathrm{COOH}$

$\mathrm{C}_{17} \mathrm{H}_{33} \mathrm{COOH}$

$\mathrm{C}_{13} \mathrm{H}_{27} \mathrm{COOH}$

$\mathrm{C}_{3} \mathrm{H}_{7} \mathrm{COOH}$

$\mathrm{C}_{11} \mathrm{H}_{23} \mathrm{COOH}$

$\mathrm{C}_{5} \mathrm{H}_{11} \mathrm{COOH}$

$\mathrm{C}_{17} \mathrm{H}_{35} \mathrm{COOH}$

$\mathrm{C}_{17} \mathrm{H}_{33}(\mathrm{OH})_{2} \mathrm{COOH}$

$\mathrm{C}_{7} \mathrm{H}_{15} \mathrm{COOH}$

$\mathrm{C}_{9} \mathrm{H}_{19} \mathrm{COOH}$ 
The fat of milk is held in suspension in the form of an emulsion, and is one of the constituents to which the characteristic opaque white color is due. Owing to the fact that its specific gravity is less than that of water it rises to the surface on standing in the form of cream, or it may be separated by subjecting the milk to a strong centrifugal action as in the ordinary milk separator. The size of the fat globules present in the emulsion varies with the particular breed of cow and with the period at which the milk is obtained. Barthel gives the size as $0.000 \mathrm{I}$ to $0.022 \mathrm{~mm}$. in diameter with an average of $0.003 \mathrm{~mm}$.

The particular physical and chemical properties of milk fat which serve as a basis of analysis will be referred to under butter. The simple determination of the amount of fat present in milk is carried out in the laboratory by absorbing the milk into a porous block of filter paper and then subjecting this, after drying, to extraction with ether or light petroleum oils (benzine). After evaporation of the solvent the fat is left practically pure. In the dairy the determination is made by means of the wellknown Babcock method. The principle upon which this method is based is that, by the addition of a certain amount of sulphuric acid, the specific gravity of the milk liquid is raised considerably so that the fat separates very completely from its emulsion state. The separation is assisted by whirling the mixture in a centrifugal machine after first placing it in a specially constructed bottle with a narrow graduated neck. After centrifuging, the fat stands completely separated as a clear layer in the graduated neck and is read directly in per cent of fat in the milk.

Proteins. - The protein constituents of milk are three, viz. caseinogen, a phosphoprotein; an albumin, lactalbumin; and a globulin, lactoglobulin. Caseinogen is in much greater amount than either of the other two, 85 per cent of the total protein being in this form. The lactalbumin constitutes most of the remaining 15 per cent, while the lactoglobulin is present only in traces. 
Caseinogen is not soluble but is held in colloidal suspension, and it is this colloidal suspended protein together with the emulsified fat already mentioned which give milk its white opaque color.

Casein or Curd. - When milk sours, due to the lactic acid fermentation of the milk sugar, or when sweet milk is acidified carefully with dilute acetic acid, the caseinogen is converted into wholly insoluble casein. The casein separates as a flocculent mass, or curd, which is the basis for the manufacture of cheese.

This conversion of colloidal caseinogen into insoluble casein is also effected by a milk-coagulating enzyme or enzymes known as rennin. In the animal body gastric rennin in the gastric juice and pancreatic rennin in the pancreatic juice produce this change. Commercially, the enzymes obtained from animals are used under the name of rennet.

The exact nature of the chemical changes that occur in this coagulation is not fully established, nor is it determined whether the enzyme coagulation is exactly the same as that produced by acids. The generally accepted view is as follows: The enzyme splits the caseinogen into a truly soluble form of protein and perhaps also yields a peptone. The soluble protein then unites with calcium, from calcium salts present in the milk, yielding a calcium salt of the protein which is the casein or curd.

Lactalbumin. - After the separation of the casein from milk the filtrate is known as whey. This contains in solution the other two proteins lactalbumin and lactoglobulin. On heating the whey the albumin coagulates just as egg albumin does, and may then be filtered off. The lactoglobulin does not coagulate with heat and remains in the final filtrate. Its amount, however, is very small and we need not consider it further. The albumin obtained as above agrees in properties with other albumins, e.g. egg albumin and blood serum albumin, giving the characteristic protein reactions.

Inorganic Constituents, Salts. - The salt constituents consist almost entirely of salts of inorganic acids. Only one organic 
acid is present, viz. citric acid, which amounts to about 0.2 per cent. The principal salts are chlorides and phosphates of the metals, sodium, potassium, calcium, magnesium and iron. Barthel gives the following for the composition of milk ash according to Fleischmann $:^{1}$

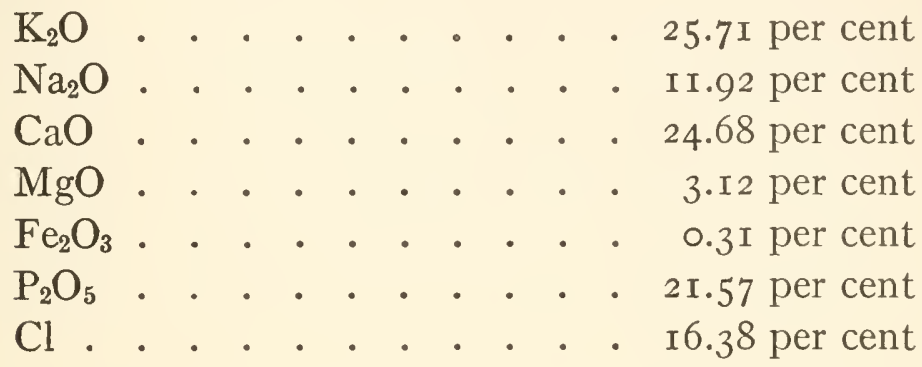

Also according to Söldner, ${ }^{2}$ the same author gives the following as the salts present in milk.

Sodium chloride . . . . . 10.62 per cent

Potassium chloride . . . . 9.16 per cent

Monopotassium phosphate . . 12.77 per cent

Dipotassium phosphate • . 9.22 per cent

Potassium citrate . . . . 5.47 per cent

Dimagnesium phosphate . . 3.7 I per cent

Magnesium citrate . . . . 4.05 per cent

Dicalcium phosphate . . $\quad 7.42$ per cent

Tricalcium phosphate . . . 8.90 per cent

Calcium citrate . . . . 23.55 per cent

Calcium oxide (in casein) . . 5.I3 per cent

The salts of milk are in solution, and on evaporation of the milk to dryness and burning the dry residue they remain as an ash. The amount of ash is about 0.7 per cent. The total solids of milk, which include not only salts but also the organic constituents, amount to about 13.0 per cent, leaving about 87.0 per cent of water.

1 Fleischmann, "Lehrbuch der Milchwirtschaft," p. 56 (1907).

2 Söldner, Landw. Vers-Stat., I 888, p. 370. 


\section{General Properties}

Milk has an opaque white color with a more or less yellow tint depending upon the amount of fat present. The opaque appearance, as previously stated, is due to the combined effect of the emulsified fat and the colloidal caseinogen. The physical properties and percentage composition of milk are fairly constant so that it is possible to establish standards of quality. According to the U. S. Department of Agriculture, standard milk has the following composition in fat and total solids:

\section{Standard Milk}

Fat, not less than 3.25 per cent

Total solids (not fat), not less than 8.5 per cent

An average milk may be given as follows :

Specific gravity . . . . . . . . I.029-1.034 Fats . . . . . . . . . . 4.0 per cent Proteins . . . . . . . . 3.3 per cent Milk sugar . . . . . . . . 5.0 per cent Ash . . . . . . . . . . . 0.7 per cent Total solids . . . . . . . . I3.0 per cent

A fat rich milk will contain approximately:

Fats

Proteins

Milk sugar

Ash .

Total solids
$5 \cdot 39-7.76$ per cent 3.66-4.68 per cent $4.76-4.82$ per cent

$0.75-0.83$ per cent I4.62-I8.03 per cent

Extreme variations in composition may be:

\begin{tabular}{|c|c|c|c|c|c|c|c|c|c|}
\hline Fats & & & & & & - & & & I.04-I4.67 per ce \\
\hline Proteins & & & & & & 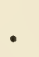 & & & $2.86-9.98$ per cent \\
\hline $\begin{array}{l}\text { Milk sugar } \\
\text { Ash . }\end{array}$ & & & & & & • & & & $2.33-5.28$ per cel \\
\hline
\end{tabular}

Of the three organic constituents the fat varies most and the sugar least. 
Analysis of American milk by the Vermont Experiment Station in 1890 gave the following results:

\begin{tabular}{|c|c|c|c|c|c|c|c|c|c|c|}
\hline Total solids, p. c. & II.35 & II.77 & I $2.2 \mathrm{I}$ & I 2.75 & I3.I 7 & $13.7 \mathrm{I}$ & 14.25 & I4.77 & I5.1 7 & I5.83 \\
\hline Fat, p. c. & 3.20 & 3.36 & 3.60 & 3.82 & 4.09 & 4.46 & 4.87 & 5.20 & 5.47 & 5.88 \\
\hline Protein, p. c. & 2.99 & 3.03 & 3.10 & 3.29 & 3.40 & $3 \cdot 48$ & 3.65 & 3.87 & 4.07 & 4.26 \\
\hline Sugar and ash, p. c. & 5.16 & 5.38 & $5.5 \mathrm{I}$ & 5.64 & 5.68 & 5.77 & 5.73 & 5.70 & 5.63 & 5.60 \\
\hline
\end{tabular}

\section{Analysis}

The determination of the specific gravity and the composition of milk is usually carried out by different methods in the chemical laboratory and in the dairy or creamery. The specific gravity is the weight of a volume of milk compared with the weight of an equal volume of water both at the same temperature or at definitely stated temperatures for each. In the laboratory this is determined by direct weighing. In the dairy, and also in the laboratory, it is usually made by the use of an hydrometer spindle graduated especially for use with milk. Such a hydrometer is called a lactometer. It may also be determined by means of a Westphal balance.

The total solids in milk are determined by evaporation and then weighing the dry residue. As the specific gravity varies with the total solids it is possible to calculate the latter from the former if the fat content is also known. A formula that has been worked out for use with direct Quevenne lactometer readings is as follows:

$$
\text { Total solids }=\frac{\text { lactometer reading }}{4}+(\mathrm{I} .2 \times \text { fat per cent })
$$

The ash is determined by incinerating the dry residue or total solids at a low red heat and weighing the remaining ash. The proteins are determined by means of the Kjeldahl method for nitrogen as given under proteins (p. 93). A creamery method by means of the centrifuge has also been devised by Hart for determining milk casein. Fats are determined by extraction or by the Babcock method, as stated under milk fats. The determination of milk sugar may be made in the 
whey by means of Fehling's solution. It is often, however, calculated from the total solids by subtracting fats, proteins and ash.

\section{Preservatives}

The preservatives used with milk include formaldehyde (formalin), hydrogen peroxide, boric acid and sodium carbonate. The testing and determination of these belong to the special field of food analysis and will not be discussed in detail. By means of the hydrochloric acid test formaldehyde may be detected in I part to 250,000. Hydrogen peroxide by the para phenylene diamine test may be detected in I part to 40,000 . Boric acid by the turmeric paper test may be detected in I part to 8000 , and sodium carbonate by hydrochloric acid on the ash may be detected in I part to 2000 . Methods of procedure for these tests may be found in books on food analysis such as Leach, Sherman and Hawk.

\section{Butter}

The questions concerning the two important milk products, butter and cheese, belong more to a special study of dairy chemistry or food analysis than to a general discussion of agricultural chemistry. In addition, therefore, to what has already been said in regard to the particular milk constituents characterizing these products, only a few facts will be given in regard to their general composition.

Butter consists principally of the milk fat with a part of the other constituents of milk that are separated with the fat. The separated fat is subjected to churning and working operations by which the fat is pressed together and mostly freed from the liquid known as buttermilk, when it takes on the appearance of ordinary butter, salt being added as flavoring and as a preservative. The average composition of butter may be given as follows, according to McKay and Larsen (Iowa) : 


\section{Composition of Butter}

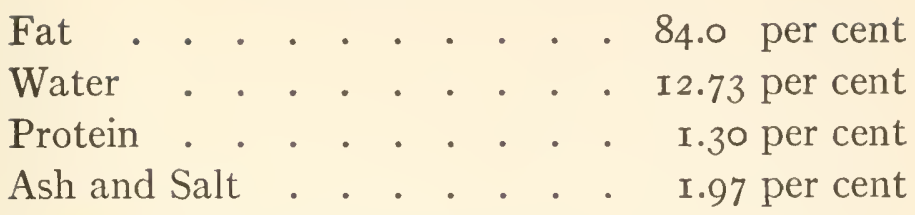

The different substitutes for butter are of two types. Renovated or Process Butter consists of old rancid butter worked over to remove objectionable substances and to incorporate a small amount of fresh milk or cream. Oleomargarine, Butterine and similar products consist of mixtures of animal fats, other than milk fat, such as beef fat and lard, to which also some fresh milk or cream is usually added.

\section{Cheese}

Cheese consists principally of the coagulated casein of milk separated by natural souring of the milk or by the use of commercial enzyme preparations known as rennet (rennin). The curd carries down with it most of the fat and some of the other constituents of the milk. After separation the curd is worked into various forms of cheese, and most varieties, except the soft fresh cream cheeses, are subjected to a fermentation or ripening. The fermentation produces various substances which give to the cheese a particular character and flavor. The average composition of Cheddar cheese made in New York State may be given as follows, according to Van Slyke:

\section{Composition of New York Cheddar Cheese}

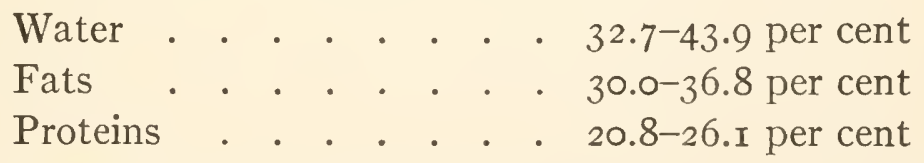

(Milk sugar, lactic acid, ash and salt about 5.0 per cent.)

Whey. - The filtrate obtained when the coagulated casein is separated is known as whey. It contains the soluble proteins, practically all of the milk sugar, and some of the inorganic 
constituents. It has food value for domestic animals, being used especially for swine. Commercially the whey is used as a source of milk sugar and, after fermentation, of lactic acid.

\section{Food Value}

The definite consideration of food values will be given in another chapter. As stated at the beginning of our study of milk it is a normal balanced food in itself, containing all of the essential food constituents. While primarily a normal food for young animals, including babies, it is also used to a very large extent as a food for adult human beings. The food value of butter is largely in its fat content and of cheese in both fat and protein.

\section{EXPERIMENT STUDY XXIX}

\section{Separation of Milk Constituents}

(I) Casein. Dilute a pint of whole milk with an equal volume of water. Add slowly with slight stirring a dilute (Io per cent) solution of acetic acid. When flocculation begins, proceed very slowly and stop the addition of acid as soon as the coagulum becomes nearly solid. Allow to stand a few minutes until the coagulated protein separates slightly, leaving a whey that is only slightly opaque. Filter through a double cheesecloth and press the curd as dry as possible. This curd is casein with included fat. After extracting the fat as in (2) the casein should be white and quite easily pulverized. Test the dry casein by the tests for protein (Experiment XVIII, 4).

(2) Fat. Place the pressed casein in a flask or bottle and cover with 95 per cent alcohol. Shake a little to aid the extraction of the water. Pour off the alcohol extract. Repeat the extraction with ether instead of alcohol and collect the ether extract by itself. Extract again and a third time if necessary with ether, combining the ether extracts. Distill off the ether from the extracts and a residue of milk fat will be obtained.

(3) Lactalbumin. If the whey from the separated casein in ( 1 ) requires it, filter through a filter paper. Place the clear whey in an evaporating dish or beaker and heat to boiling for a few minutes. Notice the coagulation of the milk albumin. Filter off the albumin through filter paper and repeat the heating. If more albumin sepa- 
rates, filter again. Dry the albumin and make the protein tests. Test Io c.c. of the filtrate from the albumin by the Biuret Test (Experiment XVIII, 4, c) to prove the presence of a non-coagulable protein (lactoglobulin).

(4) Phosphates. Without separating the traces of lactoglobulin boil the albumin filtrate in an evaporating dish carefully until bumping occurs. Filter through paper. The separated solid is largely calcium phosphate, $\mathrm{Ca}_{3}\left(\mathrm{PO}_{4}\right)_{2}$. Repeat the boiling with the filtrate from the calcium phosphate and obtain a second crystallization of phosphate. Repeat as many times as necessary until no more phosphate separates. Test the collected phosphate by dissolving in dilute nitric acid and adding an equal volume of ammonium molybdate solution. A yellow precipitate proves the presence of phosphates.

(5) Milk Sugar. When no more separation of calcium phosphate occurs, continue to evaporate the filtrate with a low flame so as to prevent charring. When quite small in volume (about roo c.c.) transfer to a steam bath and continue the evaporation until the liquid is of a sirupy consistency. Cool, and see if any crystals separate. If not, evaporate further until crystallization does take place. Filter or decant off the liquid, wash the crystals with a little water, dry them on filter paper and examine by taste, etc. They are milk sugar (lactose). Dissolve a few crystals in water and test with Fehling's solution (Experiment XXII, 2).

\section{THE BLOOD}

While the blood is the chief circulatory fluid of the animal body, there is associated with it another known as lymph. In discussing the metabolism of food we have stated that the absorbed food nutrients are carried to the cells by means of the blood, where they come into intimate contact with the oxygen brought from the lungs by means of the blood also. In bringing about this contact between oxygen and food nutrients within the cell, and thus effecting their final katabolism, the lymph plays a very important part and also in removing from the cells the waste products of katabolism. We shall not attempt to discuss in detail the exact part which each of these fluids takes in this utilization of food but present the general 
facts in regard to the nature and properties of the more prominent of the two, viz. the blood.

Properties. - The blood of mature animals is an opaque, dark red fluid with a neutral reaction according to the concentration of hydrogen and hydroxyl ions, but an alkaline reaction as ordinarily tested with litmus paper, due to the presence of sodium carbonate and phosphate. In man it has a specific gravity of 1.06 and the amount in the body equals about 7.5 per cent of the body weight.

\section{Constituents}

The constituents of the blood are of two kinds, viz. organic and inorganic. These are present in two conditions, viz. either in true solution or in suspension in the liquid substratum, water. The liquid portion of the blood, including both the solvent and those substances in true solution, is known as blood plasma. In this plasma the suspended substances are held.

The material held in suspension in blood plasma amounts to about 60 per cent of the blood and consists of cellular bodies known as blood corpuscles, blood plates and blood dust. The most important of these bodies are the two forms of corpuscles known as red corpuscles or erythrocytes and white corpuscles or leucocytes.

Red Blood Corpuscles or Erythrocytes. - The erythrocytes are cells which have lost their nucleus. In mammals they have the microscopical appearance of biconcave disks. They are of a yellowish color but in masses appear red. Their color is due to a protein known as hamoglobin which permeates the real cell material known as the stroma. The stroma constitutes only 5 to Io per cent of the dry matter of the corpuscles, while 90 to 95 per cent consists of hæmoglobin. Two important constituents of the stroma are lecithin and cholesterol, which will be considered later (p. 280).

Hæmolysis and Hæmagglutination. - Two properties of erythrocytes are of especial importance in connection with the action of toxins and the condition of immunity. When the 
blood plasma which holds the erythrocytes in suspension is made more dilute by the addition of water, an osmotic pressure is produced within the erythrocytes due to the rapid inward diffusion into the corpuscle of water from the plasma. This pressure may become strong enough to rupture the cell wall of the corpuscle, when the colored hæmoglobin is discharged into the plasma, leaving the corpuscles colorless. This general action is termed hamolysis or laking, and may be produced also by certain substances, e.g. ether, chloroform, bile, the toxins of snake venom and of certain bacteria, and products produced in the body by immunization. The osmotic pressure of blood plasma is approximately equivalent to a 0.9 per cent solution of sodium chloride and in such a solution no hæmolysis takes place. A salt solution of this strength is known as a physiological salt solution or normal saline solution.

The second special property of erythrocytes is that of agghutination, or precipitation, when acted upon by certain substances. The action is called hamagglutination.

Hæmoglobin and Oxyhæmoglobin.-Hæmoglobin, it will be recalled, was mentioned, in the discussion of proteins, as one of the conjugated proteins, consisting of a protein part (a histon called globin), together with an iron-containing colored part known as hamochromogen. The erythrocytes are oxygen carriers, and it is this hæmoglobin which is the essential constituent of red blood corpuscles in the performance of this function. Hæmoglobin occurs in the venous blood, and when it comes in contact with inhaled air in the lungs it absorbs oxygen and is thereby converted into oxyhamoglobin in the arterial blood. In the blood capillaries of the cellular tissue the oxyhæmoglobin gives up its oxygen to the food nutrients, which are thereby oxidized and energy liberated, the oxyhæmoglobin in turn being reduced to hæmoglobin. In this way the hæmoglobin, a constituent of red blood corpuscles, acts as a carrier in conveying oxygen from the lungs to the muscle cells. This action probably rests in the iron component of the protein and is analogous to the bromine carrier property of 
ferrous bromide. The amount of hæmoglobin in fresh blood is about I4 per cent. As previously stated, the amount of blood is about 7.5 per cent of the body weight. A man of 68 kilograms ( $150 \mathrm{lbs}$.) would, therefore, have approximately 5100 grams of blood containing 7I4 grams of hæmoglobin. The oxygen-absorbing power of hæmoglobin has been determined as I.34 c.c. oxygen per gram of hæmoglobin. The total oxygencarrying power of the blood of an adult man would, therefore, be about 950 c.c. Oxyhæmoglobin may be crystallized, and it has been found that the crystal form varies with different species of animals.

The shape and size of erythrocytes vary with different animals. In man the size is about $\frac{1}{3200}$ of an inch, in the elephant $\frac{1}{2700}$ of an inch, in the ox $\frac{1}{4200}$ of an inch, and in the musk deer $\frac{1}{12300}$ of an inch.

The number of erythrocytes is very large and has been shown to vary with marked changes in condition. In the adult human male the number is about 5,500,000 per cubic millimeter, in the female about 4,500,000. Under abnormal conditions affecting the rate of oxidation in the tissues, as after physical exertion, or at high altitudes, the number has been found to increase to $7,000,000$, and in pathological cases as high as I I , $, 00, \infty 00$. Under conditions of decreased oxidation, as in the disease known as ancemia, the number has been found to fall to 500,000 .

White Blood Corpuscles or Leucocytes. - The other corpuscles of the blood, known as white corpuscles, or leucocytes, because they do not contain a color pigment, are larger than the red corpuscles and are characterized further by possessing a nucleus. They are not as numerous as the erythrocytes, varying from 5000 to 10,000 per cubic millimeter. This number varies still more widely under certain pathological conditions. The functions of the leucocytes is not fully established. They have been termed blood scavengers, as it is claimed that they destroy pathogenic organisms such as bacteria, either by devouring them, or by producing other substances 
which prevent their activity. It is also thought that they take part in the production of immune substances in the blood. Other theories are that they aid in the absorption of fats and peptones, that they take part in the process of blood coagulation, and that they maintain the protein content of the blood plasma.

Blood Plasma. - The blood plasma, as we have stated, is the liquid portion which holds the corpuscles, plates and dust in suspension. In this blood plasma there are held in true solution both organic and inorganic substances. The amount of solid matter contained in the plasma is about 8.0 per cent. The organic constituents amount to about 7.0 per cent and the inorganic to about r.o per cent.

The two most important organic constituents are glucose sugar and proteins. The former is in very small amounts, only about o.I per cent, but is very important, as it is the form in which carbohydrate food, and perhaps all food, is finally oxidized in the cells. The protein constituents are in larger amounts and are four in number, viz. (I) fibrinogen, (2) a mucleoprotein, (3) a globulin, and (4) serum albumin. Other organic constituents present in small amounts are enzymes, fats, lecithin, cholesterol, sarco-lactic acid, urea, uric acid and some others.

The inorganic constituents of blood plasma include chlorides, carbonates, sulphates and phosphates of the metals sodium, calcium, magnesium, potassium and iron.

Blood Serum. - When fresh-drawn blood is exposed to the air, the striking phenomenon termed clotting takes place. In this clotting of the blood one of the soluble protein constituents of the blood plasma, the fibrinogen, is converted into an insoluble protein termed fibrin. This insoluble fibrin in separating carries down with it the blood corpuscles and other suspended matter in the form of a thick clot. As this clot separates there is left a light yellow liquid known as blood serum. The serum differs from plasma in containing no fibrinogen. In it there are present, however, all of the other soluble constituents of the plasma. 
Serum Albumin. - The most important protein constituent of serum is the albumin, which is like egg albumin in being soluble in water. In considering the absorption and metabolism of protein food we stated that the absorbed products of protein digestion enter the blood and are metabolized into blood protein, which is then carried to the tissue cells, where oxidation takes place. Although it is not fully established, it is probable that the serum albumin is the form in which food protein is carried to the cells. If this is true, the relation between serum albumin and food protein is of direct importance. The amount of serum albumin varies in different animals, and in man amounts to about 4.5 per cent.

Fibrinogen and Fibrin. - The second protein constituent of blood plasma is the fibrinogen, which is a globulin soluble in dilute salt solutions such as the blood plasma. It is present in small amount, probably not over 0.4 per cent, in man. It is also a normal constituent of lymph.

Clotting. - The special interest in connection with fibrinogen is its relation to the characteristic clotting property of blood. This action takes place whenever fresh blood comes in contact with the air, and is the natural process by which the flow of blood from a wound is stopped, thus preventing too great loss of this important body fluid. The process of clotting is a complicated one, involving the action of several enzymes. It is not fully established, but the most generally accepted view in regard to the various steps may be given as follows.

The leucocytes, or white blood corpuscles, together with the blood plates produce, probably with the aid of a kinase, or activator, a ferment known as prothrombin. This prothrombin is the zymogen of another enzyme, and when activated by calcium salts; present in the plasma, produces the enzyme called thrombin, or fibrin enzyme. Thrombin then acts directly upon the soluble protein fibrinogen, and the product is an insoluble protein called fibrin. The separation or coagulation of this insoluble protein forms the network or foundation of the blood clot, which contains also the solid suspended constituents of 
the blood, i.e. corpuscles, etc., which are held mechanically and carried down with the fibrin.

If fresh-drawn blood is beaten rapidly with a bundle of fine twigs or of strings, the coagulating fibrin will be caught on the twigs, while most of the corpuscles remain in the serum. Blood so treated is called de-fibrinated. The fibrin so separated may be used for testing the color reactions of proteins or the digestible action of proteolytic enzymes. It is a white fibrous material and responds to all protein tests.

Under normal conditions, freshly drawn blood will clot in from two to ten minutes, though the rapidity of clotting varies a good deal in different animals and is especially slow under certain pathological conditions as in fever. The separation of the clot from the serum takes place very slowly, requiring from ten to forty-eight hours. The time taken for clotting may be shortened very greatly by certain treatment and is often done in controlling hemorrhages. A solution of ferric chloride or alum applied to a fresh cut produces an almost instantaneous clotting. The natural clotting may be hastened or retarded by the injection of certain substances, e.g. calcium salts. In general an increase of carbon dioxide and decrease of oxygen causes blood to clot more slowly and vice versa. Snake venom and toxic albumin cause marked retardation in clotting; and if blood is drawn into a solution of ammonium oxalate, it will not clot.

The reason why blood does not clot until exposed to the air is not wholly explained, but is considered to be due to the presence in the normal blood of an anti-enzyme called antithrombin which prevents the action of thrombin upon fibrinogen. It is also probably true that very little if any thrombin is present in the blood within the blood vessels, as the leucocytes do not yield prothrombin until the action of air causes them to disintegrate. 


\section{EXPERIMENT STUDY XXX}

\section{Blood}

(I) Oxalated Blood. Secure some blood from a horse or cow and let it flow directly into a Io per cent solution of ammonium oxalate. The blood will remain unclotted and may be examined under high power microscope for blood corpuscles. (See Hawk, "Practical Physiological Chemistry" (I9I3), p. I97, for plates showing corpuscles.)

(2) Fibrin. Draw off another quantity of blood, I00-200 c.c., and immediately whip or stir it vigorously with some fine glass rods or a small bundle of twigs or a bunch of stout cord tied on to a stick and with loose ends like a mop. When clotting has been effected and the fibrin has adhered to the rods or string, remove the beater and wash the fibrin as clean as possible from all other material. Examine the fibrin as to general character and make the protein tests with it as in Experiment XVIII, 4.

(3) Defibrinated Blood. The blood from which the fibrin has been removed may now be examined for blood corpuscles and for other constituents such as sugar, chlorides, etc.

\section{URINE}

Urine differs from milk in being considered as an excretion, not as a secretion. It is the medium by means of which the nitrogenous products of protein metabolism are removed from the body. When the food nutrients are oxidized in the cells, the carbon dioxide and water, resulting from the carbon and hydrogen of the fats and carbohydrates and also from a portion of the carbon and hydrogen of proteins, is excreted in the exhaled breath. All of the nitrogen and some of the carbon and hydrogen of the protein oxidation yield products which find their way into the urine and are excreted in this way. The nitrogen content of urine becomes, therefore, a measure of the protein metabolism in the animal body. The nitrogen compounds in urine are more or less complex compounds, containing carbon and hydrogen together with the nitrogen, and they consequently possess the possibility of being oxidized. This means that all of the energy of oxidizing proteins is not yielded in the cell 
where this oxidation takes place, but that some of it is still retained and locked up, as it were, in the urine excretion products and thus lost to the body. This will be explained in detail when we study food values (Chapter XVII).

\section{Constituents}

Nitrogen Compounds. - The most important constituents of urine in connection with normal metabolism are the nitrogen compounds. The most abundant compounds of this class are urea, uric acid, creatinine and the purine bases; xanthine, etc. The chemical constitution and relationship of these compounds has been already considered, so far as is necessary, in Section I.

Urea. - The chief constituent of urine and the principal nitrogen product of protein katabolism is urea. Under normal conditions of diet and health the urea represents about 88 per cent of the total nitrogen in urine. This relative amount may, however, be changed very decidedly by changes in the total amount of protein metabolized. Urea is more abundant in the urine of man and flesh-eating animals than in herbivorous animals. It is also present in most of the fluids of the animal body, as in blood, as already mentioned. In man the total amount per day is about 30 grams. As this represents about 88 per cent of the total nitrogen in urine which, in turn, is the whole of the nitrogen of metabolized protein, it means that the total nitrogen metabolism per day is about I6.0 grams, equivalent to roo grams of protein. As we shall find under food requirements this is the normal amount of protein required by man per day.

Isolation and Determination. - The isolation of urea from urine is easily accomplished by converting it first into a nitric acid salt, crystallizing this, and then setting the urea free by the action of a weak base (barium carbonate). This will be described in the experiment following. The approximate determination of urea in urine is also easily made, and as the 
accurate determination of total nitrogen in urine is a complicated chemical process, the former is used very largely as a clinical method for judging the protein metabolism of the body. This also will be considered in the experiment study.

Uric Acid. - This compound, closely related to urea in its constitution (see p. I02), is an important constituent in man and other flesh-eating animals, though present in quite small amounts. The daily excretion is about 0.6 grams under normal conditions, and represents about 1.0 per cent of the total urine nitrogen. The amount varies greatly however under certain pathological conditions. The source of uric acid is the metabolism of a special group of proteins, viz. the nucleo-proteins, and in mammals is one of the minor products of metabolism. In birds, however, it is the chief nitrogenous metabolic product, being formed similarly to urea in mammals.

Creatinine. - This nitrogen compound is present in urine to the amount of about I.5 grams per day, equivalent to about 3.6 per cent of the total urine nitrogen. It is an anhydride of creatine which is a normal constituent of muscular tissue. Creatine is related to urea through guanidine which is imino urea or

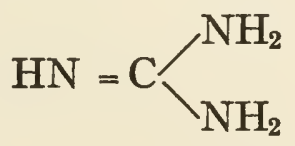

Ammonia. - About 3.0 per cent of the total nitrogen in urine is present as ammonia. The amount is, however, subject to considerable variation, depending upon the relative amounts of acid and basic constituents of the food. If not held by acids in a stable form, it is converted into urea. The relative amounts of these two constituents are thus interdependent and in pathological cases have been known to be almost reversed. According to Sherman the amounts of the different nitrogen compounds in urine per day following a high protein diet are as follows : 


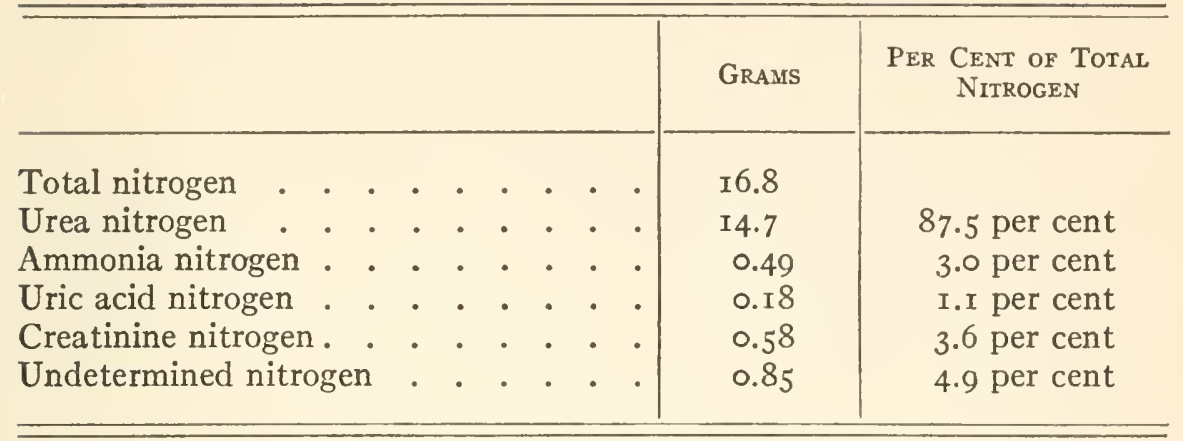

Hippuric Acid. - This compound, it will be recalled (p. 92), is benzoyl amino-acetic acid. It is present in the urine of man in about the same amount as uric acid, 0.7 grams per day. It is much more abundant in herbivorous than in carnivorous animals.

Pathological Constituents, Glucose. - Two important pathological constituents of urine should be mentioned. These are glucose and albumin. Under deranged metabolic conditions, the cause of which is not fully understood, the body loses its power of utilizing carbohydrate food by the oxidation of glucose. Under such conditions the glucose is excreted in the urine. The pathological condition in such cases is known as glycosuria, and the particular disease when the condition is persistent is called diabetes mellitus. Glucose is never a constituent of normal urine, at least in amounts detected by ordinary chemical tests. Any positive test for glucose in urine is, therefore, indicative of an abnormal condition. The qualitative and quantitative determination of glucose in urine is made by means of Fehling's solution, or some modification of it. The original Fehling's solution will not detect glucose in amounts less than about o.I per cent, and the action is also interfered with by creatinine, a normal constituent of urine. On this account, Benedict has suggested a modification of the solution, which is not interfered with by creatinine and that will detect as little as 0.015 per cent. The solution is made as follows: 


\section{Benedict's Modified Fehling's Solution}

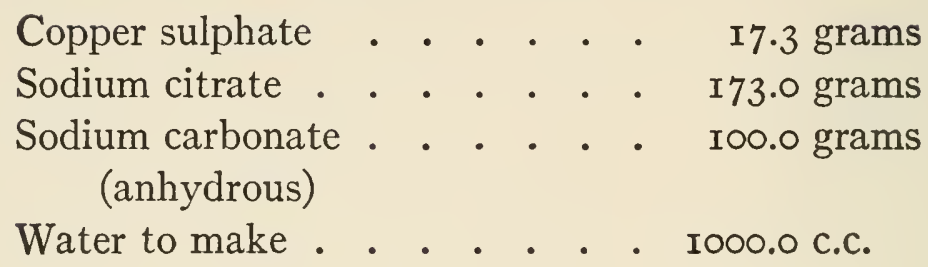

Glucose is also sometimes tested for clinically by subjecting the urine to the action of yeast and measuring the carbon dioxide evolved.

Albumin. - The presence of albumin in urine indicates a pathological condition termed albuminuria or nephritis. Bright's disease is a particular form of the condition. The testing of urine for albumin, as for glucose, is therefore an important clinical operation. The test usually made depends upon the property of albumins to form insoluble compounds with mineral acids. It is known as Heller's ring test and is described in the experiment study.

\section{General Properties}

Human urine is a clear straw-colored liquid, becoming often considerably darker if of high specific gravity. The amount varies greatly with the amount of water that is drunk, but averages from 1000 to 1500 c.c. in twenty-four hours. It frequently becomes cloudy on standing, due to the precipitation of phosphates, especially if the urine is alkaline in reaction, which often occurs after a hearty meal. Normally urine is slightly acid in reaction. The specific gravity of normal urine is 1.015 to 1.025 . This may be greatly changed by large variations in drinking water. Excessive drinking of water may so dilute the urine as to lower its specific gravity to 1.003 and cutting down the supply of water may raise it to 1.04. Diabetic urine has a high specific gravity, but this alone does not indicate the disease unless the amount of water is considered. 


\section{EXPERIMENT STUDY XXXI}

\section{Urine}

(I) Determine the amount of urea in normal urine by means of the ureometer as in Experiment XIX, I.

(2) Isolation of Urea from Urine. Evaporate 2-3 liters of urine in a large evaporating dish in a hood until it is the consistency of sirup. Cool and add concentrated nitric acid as long as crystals form. Filter, with suction on a Buchner funnel. The crystalline product is urea nitrate. Recrystallize and decolorize to light straw color with potassium permanganate solution. Dissolve the urea nitrate in water and add barium carbonate as long as effervescence occurs. Filter off any excess of barium carbonate and evaporate the filtrate to dryness. Extract the dry residue with hot alcohol, filter, evaporate the alcoholic extract to a small volume, cool, and allow the urea to crystallize out. Filter off the crystals of pure urea and examine them as in (I).

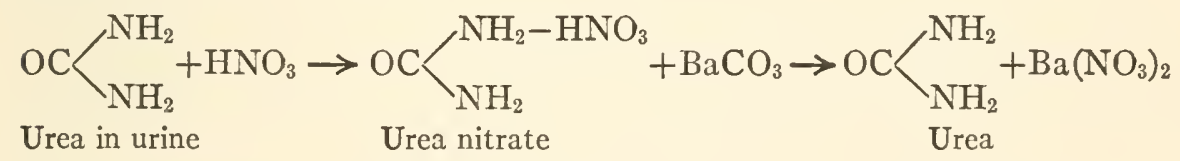

(3) Albumin, Heller's Ring Test. Place 5 c.c. of dilute egg albumin solution in a test tube or, better, a conical test glass. By means of a pipette lowered to the bottom of the test tube let an equal volume of pure concentrated nitric acid flow underneath the albumin solution so as to keep the two layers. Note the cloudy precipitate form at the junction of the two liquids. Repeat several times, diluting the egg albumin solution ten times at each successive trial. Note the delicacy of the test. This is used as a clinical test for albumin when present in small amounts in urine in cases of the disease known as Nephritis or Bright's Disease.

(4) Glucose. To a sample of urine add about 0.5 per cent of glucose. (a) Test the urine for glucose with Fehling's solution as described under glucose (p. II4). (b) Test similarly, using Benedict's modified Fehling's solution. (See Hawk, "Practical Physiological Chemistry," p. 329, for details in regard to this test.) (c) Dilute the urine with an equal volume of fresh urine five times and repeat with each solution. 


\section{CHAPTER XIV}

\section{P L A N P H Y I O L G Y}

\section{PLANTS AND ANIMALS COMPARED}

IN the discussion just concluded we have endeavored to show how the living cell, and thus the organism as a whole, utilizes food materials for the production of the energy necessary for its living processes, and by a study of the animal body to explain the chemical changes that take place in the transformations of this food until it is finally oxidized and the energy liberated.

We shall now study the plant organism to find out how, by means of its distinctive physiological processes, the three essential organic food constituents, carbohydrates, fats and proteins, are formed and the plant structure built up.

Similarity of Plants and Animals. - In our study of animals and the physiological processes by which they utilize their food we grouped the chemical reactions taking place under two heads, viz. digestion and metabolism. Digestion may be considered as a preliminary change taking place in the food material outside of the real body proper, that is, in the digestive tract. By means of this change the mixed food substance is brought into the particular condition necessary for absorption and metabolism. After the digested food material is absorbed into the body proper it undergoes more or less complicated changes embraced in the term metabolism. During the period of metabolism the food performs its two functions, viz. it is built up into body substance or it is oxidized and yields energy. These two functions eventually become one, for the body substance, in most part, is, sooner or later, metabolized further and finally oxidized with the liberation of energy. 
In the animal this liberation of energy is the predominating function of the organism or, as we may say, energy is the net result of the animal physiological reactions. Animals may be characterized therefore as energy-liberating organisms.

The energy food of animals consists of three classes of compounds, viz. carbohydrates, fats and proteins. These three complex compounds, containing carbon, hydrogen, oxygen and nitrogen, on oxidation, are broken down into simpler compounds, viz. carbon dioxide and water, which are excreted mostly in the breath, and nitrogen compounds derived from the proteins only, which are excreted in the urine. In this breaking down by oxidation the potential energy stored or conserved in these complex compounds is liberated as kinetic energy of the living animal. The reaction illustrating such changes is that of the oxidation of glucose as it takes place in the animal cell, viz. :

\section{$\mathrm{C}_{6} \mathrm{H}_{12} \mathrm{O}_{6}+6 \mathrm{O}_{2} \rightarrow 6 \mathrm{CO}_{2}+6 \mathrm{H}_{2} \mathrm{O}+$ energy Glucose}

The energy thus liberated as kinetic is manifested in two forms, (I) as animal heat, (2) as muscular work. As the animals with which we have to do are warm-blooded organisms, a considerable amount of energy is required to supply the recessary heat. The expenditure of energy as muscular work is also large because such work is continual, either as voluntary or involuntary, so long as life exists. In man it has been found that the energy so expended for body heat and simply the involuntary muscular work of the body at rest amounts to about I600 to 2000 Calories per day.

Now all that we have thus reviewed as to the relation between food and energy is true of the plant organism as well as the animal, except as to amount. In animals the expenditure or liberation of energy is the chief or predominating reaction, while in plants it is not the predominating reaction.

The plant cell or the complex plant organism of many such cells is of exactly the same nature in its living processes as the animal. For the maintenance of life energy must be set free, 
and in both plants and animals this energy is supplied by the same food materials, carbohydrates, fats and proteins, which undergo analogous metabolic reactions. As has been stated, however, the entire function of food is the formation of body substance and the liberation of the energy necessary for life. We have given an example as to how much this energy amounts to in man. In plants, while we cannot express the results in definite figures, we can readily conceive of the magnitude, in both body substance and energy, if we think of one of our large trees. The mass of body material that has been built up and the amount of energy expended to lift such a mass to the height attained and to maintain it in position must both be of very great magnitude. This material and this energy are both supplied by the food of the plant.

In the animal body we can easily measure and control the food supply and we can also determine, to a large extent, the energy expended. In plants, on the contrary, it is impossible to do this and on this account the study of food metabolism and the relation between food and energy has been almost entirely studied in connection with animals. For this reason, and because it is necessary first to understand this food and energy relation of living organisms, we began our physiological study with animals rather than with plants.

Too much emphasis cannot be placed upon the fact that the animal and the plant, as living organisms, are essentially the same. Both build their body substance and obtain the energy of their living processes by the metabolism of food consisting of carbohydrates, fats and proteins.

In connection with animals we have spoken of the inorganic food materials consisting of certain inorganic salts. Some of these are essential to the building of certain parts of the body substance, while others act physiologically in the fluids of the body. They are undoubtedly just as essential as the organic foods, but they are not directly related to the energy supply of the body. They are also used in much smaller amounts and, being present in sufficient quantity in most foods, they do 
not appear to be so important. In plants the inorganic food materials obtained from the soil are essential as building material, and as physiological activators, but here also they do not contribute directly to the energy of the plant. Because, however, the supply of these materials in the soil is liable to exhaustion and, because the supply of organic food materials as manufactured by the plant itself is practically limitless, these inorganic foods have a much greater relative importance in plants than in animals, and are usually referred to when the term plant food is used.

Differences between Plants and Animals. - If then animals and plants are alike, as living organisms in the relation of food and energy, wherein lies the essential difference that characterizes them as plants and as animals?

In the discussion which follows we must emphasize the point that we shall speak of general facts and conditions as pertain especially to the higher green plants with which our study is related. In considering all of the varying forms of plant life, from the lowest to the highest, many different conditions exist, and plant physiology as a whole must consider them all and correlate the facts into a system, but for our purpose only the main general facts are essential and these we shall obtain from a study of the higher plants.

Exothermic and Endothermic Reactions. - All chemical reactions are of two kinds in their relation to energy. One kind of reaction liberates or expends energy or is, as we term it, exo-thermic (gives out heat). The other kind absorbs or conserves energy and is termed endo-thermic (takes in heat). The exothermic reaction converts potential energy into kinetic, while the endothermic reaction converts kinetic energy into potential. The exothermic reaction is in general true in cases in which a complex compound is broken down into simpler ones, especially if the reaction involves additional oxygen, that is, if the compound is oxidized. Such a reaction is typified by the oxidation of glucose, as given above, yielding carbon dioxide and water as the products, with the liberation of energy. Re- 
actions of this kind are those by which the living organism obtains the energy necessary for its life and, as we have shown, take place in both plants and animals.

Endothermic reactions are in general those in which simpler compounds are synthesized or built up into complex compounds. These may be typified by the reverse of the reaction just mentioned, viz.

$$
6 \mathrm{CO}_{2}+6 \mathrm{H}_{2} \mathrm{O}+\text { energy } \rightarrow \mathrm{C}_{6} \mathrm{H}_{12} \mathrm{O}_{6}+6 \mathrm{O}_{2}
$$

Such a reaction involves the absorption of kinetic energy and the conversion of it into potential energy which is stored or conserved as such in the complex compound formed. At the same time oxygen is set free. These endothermic reactions also occur in living organisms, and in animals may be illustrated by the known conversion of carbohydrates into fats with the storage of energy and the evolution of oxygen. In plants we shall find that the endothermic reaction above given takes place in a wonderful way in the synthesis of glucose from carbon dioxide and water.

Animals Liberate Energy. - We have mentioned the fact that in animals the reactions which liberate energy, the exothermic reactions, are predominant.

Plants Store Energy. - In plants, on the contrary, the predominating reactions are not the exothermic or energy liberating, but are endothermic or energy storing. In other words, the net result of plant physiological reactions is the storage of energy.

This, then, is the characteristic difference between animals and plants. Both, as living organisms, require complex compounds as food material, which by oxidation break down into simpler compounds with the liberation of energy. Both also build up simpler compounds into more complex with the storage of energy and the evolution of oxygen. In animals, however, the liberation of energy is predominant, that is, animals are energy liberators; while in plants the storage or conservation of energy is predominant, that is, plants are energy storers. This 
characteristic difference may be stated in another way. Animals utilize food that is brought to them from the outside, they cannot synthesize their own food. Plants, on the other hand, manufacture or synthesize their own food.

\section{PHOTOSYNTHESIS}

We shall now study the way in which plants store energy in building up complex compounds out of simple ones, these complex compounds so produced being the food of the plant itself. The compounds concerned in this energy-storing process are, as we have repeatedly said, the three classes, carbohydrates, fats and proteins, and the material out of which they are constructed consists of the two common substances, carbon dioxide and water, together with nitrogen obtained mostly from the soil. How, then, is the plant enabled to carry out this wonderful synthesis?

Source of Energy. - As we have previously explained, the endothermic reaction involved in the synthesis of carbohydrates from carbon dioxide and water requires the addition of energy. Where does the plant get this energy? The energy by means of which plants are able to carry out this reaction comes directly from the sun. Through this endothermic reaction the kinetic energy of the sun is converted into the potential energy of complex organic compounds and stored in the plant. This kinetic energy reaches the plant through the action of the sunlight and acts, therefore, only during daylight and only upon those parts of the plant which are above ground and exposed to the light. Furthermore, generally speaking, only those plants known as green plants, or phanerogams, are able to thus utilize the energy of the sun. It has been shown experimentally that other forms of energy can produce this synthesis in plants, but it is not necessary to discuss them. In normal living green plants it is certain that much the greater part, if not all, of the energy connected with this synthesis is the radiant energy of the sun. 
Chlorophyll Bodies and Chlorophyll. - This power of plants to utilize the energy of the sunlight is dependent upon the action of certain bodies known as chloroplasts or chlorophyll bodies. These chlorophyll bodies have associated with them a green pigment known as chlorophyll. It is this chlorophyll which gives to the aërial parts of plants their green color and which characterizes them as green plants. Much has been learned of late years in regard to the chemical character of chlorophyll, but its exact nature is still a question, and it will not be desirable to enter into any discussion of it here.

These two agencies always act together, the chlorophyll as the assimilatory pigment, and the chloroplasts as the mechanism of assimilation. Thus through the action of the chlorophyll in its relation to sunlight some of the energy of the sun is used by the chlorophyll bodies in bringing about a chemical reaction of endothermic character which results in the synthesis in the plant of complex organic compounds which have stored up in them as potential the kinetic energy derived from the sun. These compounds then become the energy food of the plant itself. Because light is necessary for this synthesis it is known as photosynthesis. The simple compounds involved in this photosynthesis are carbon dioxide and water. The former is present in the atmosphere and the latter in both atmosphere and soil.

Products of Photosynthesis. - We have stated that the final products of this synthetic reaction are carbohydrates, fats and proteins. We can ask, however, what is the first or direct product? This question we are unable to answer definitely. We do not know positively what individual compound is first formed by this synthesis, nor can we even state absolutely whether it is carbohydrate or fat or protein.

We have written the endothermic reaction for the production of glucose from carbon dioxide and water as:

$$
6 \mathrm{CO}_{2}+6 \mathrm{H}_{2} \mathrm{O}+\text { energy } \rightarrow \mathrm{C}_{6} \mathrm{H}_{12} \mathrm{O}_{6}+6 \mathrm{O}_{2}
$$

This is the reverse of the exothermic reaction whereby glucose is oxidized to carbon dioxide and water with the liberation of 
energy. In this reaction we can measure exactly the amount of the energy liberated. Results of such measurement show that one gram of glucose, when completely oxidized, yields 4. I Calories of energy. We write this reaction, then,

$$
\underset{\text { I. }}{\mathrm{C}_{6} \mathrm{H}_{12} \mathrm{O}_{6}}+6 \mathrm{O}_{2} \rightarrow 6 \mathrm{CO}_{2}+6 \mathrm{H}_{2} \mathrm{O}+\underset{\text { 4.I Cal. }}{\text { energy }}
$$

We know, also, that by the laws of chemical equilibrium the energy required in the synthesis of glucose from carbon dioxide and water is exactly equivalent to the energy liberated when glucose is completely oxidized. Furthermore, the synthesis of glucose from carbon dioxide and water has actually been accomplished in the laboratory, though the reaction involves several steps and is not so simple and direct as we have written it.

We stated in our discussion of glucose and fructose sugars (p. II3) that they have both been synthesized in the laboratory from formaldehyde. Also, in speaking of formaldehyde (p. 43), we said that it had been synthesized from carbon dioxide and water. If we write the chemical reaction expressing these facts, we have :

$$
\begin{aligned}
& \mathrm{CO}_{2}+\mathrm{H}_{2} \mathrm{O} \rightarrow \underset{\text { Formaldehyde }}{\mathrm{H}-\mathrm{CHO}}+\mathrm{O}_{2} \\
& \underset{\text { Formaldehyde }}{6 \mathrm{H}-\mathrm{CHO}} \rightarrow \underset{6}{\mathrm{C}_{6} \mathrm{H}_{12} \mathrm{O}_{6}} \\
& \text { Glucose }
\end{aligned}
$$

The above formation of formaldehyde from carbon dioxide and water has been claimed by several investigators in plant physiology to take place when the two substances are acted upon by sunlight in the presence of a catalyzer. This catalyzer may be either an inorganic substance like a uranium salt, or it may be an extract of green leaves. It has also been claimed that in green plants formaldehyde is present, though it is so rapidly removed, probably by polymerization, that it does not collect. It is possible, too, that the synthesis is not in one direct step but that intermediate products, such as formic acid, hydrogen peroxide or carbon monoxide, may be produced. At any rate it 
seems probable, and is pretty generally accepted, that formaldehyde is first produced and is immediately further transformed into carbohydrate. Fincke, ${ }^{1}$ however, claims that the formation of glycolic aldehyde, $\mathrm{CH}_{2} \mathrm{OH}-\mathrm{CHO}$, as an intermediate product is in closer agreement with known facts.

One further point in connection with this step in the photosynthetic process is that the other product of this laboratory synthesis, viz. oxygen, is also the other product of the reaction as it takes place in plants. When carbon dioxide is assimilated by plants, oxygen is given off, and this evolution of oxygen is directly proportional to the photosynthetic activity. The absorption of carbon dioxide and evolution of oxygen by plants was originally taken to indicate that the life process in them was directly the opposite of that in animals. This we now know to be wrong, for, as we have shown, the living process of the cell and the utilization of its food for the liberation of energy, with the excretion of carbon dioxide as one of the products of the oxidation reaction, is alike in both plants and animals.

The other part of the double reaction representing the synthesis of glucose from carbon dioxide and water, viz. the polymerization of formaldehyde to glucose, is one of which there is no doubt as a laboratory reaction and also one that is perfectly possible in the living plant.

We must emphasize the fact, however, that because we have a right to express by these reactions a known laboratory synthesis, this does not establish the fact that the same synthesis takes place in plants. Other reactions have been established in the laboratory which make it also possible that from the same original substances fats may be synthesized and even proteins, provided nitrogen compounds are supplied from the soil. All plant physiologists and chemists have not yet accepted it as proved that formaldehyde is present in plants nor that it is the actual intermediate product in carbohydrate synthesis. We know beyond question this much only: (I) The end products of the reaction of photosynthesis are on the one hand

1 Fincke, Z. Nähr. Genuss., xxvii, 8 (Igr4). 
carbon dioxide and water and on the other not only carbohydrates, but also fats and proteins; (2) the kinetic energy of sunlight is necessary to produce the synthesis; (3) oxygen is evolved. Still, taking everything into consideration, it seems probable, as supported by laboratory syntheses and by the well-supported claim of the presence of formaldehyde in plants, that in plants the process of photosynthesis results first in the synthesis of a non-carbohydrate compound, formaldehyde, from carbon dioxide and water at the same time setting free oxygen which is given off by the plants, the formaldehyde then polymerizing to the formation of glucose sugar which is thus the first of the essential organic constituents to be formed as the direct product of photosynthesis. This view, it may be said, is more generally accepted than any other.

\section{FUNCTION OF THE PRODUCTS OF PHOTOSYNTHESIS}

Accepting, then, this view that the carbohydrate glucose is the first essential compound formed, we still have the fact that the final result of photosynthesis as a whole is the formation of the three energy-storing substances, carbohydrates, fats and proteins. All of these compounds are formed in the leaves and other green parts of plants and serve as food material for the plant itself, being in a condition analogous to that of digested and absorbed food in animals. Let us now take up separately these three groups of compounds which, either directly or indirectly, are the products of photosynthesis, and follow them in the fulfillment of their function as plant food.

\section{Carbohydrates}

This group of compounds is more abundant in plants than are fats or proteins. As an energy food for the plant itself we can hardly say that the carbohydrates are more important than the others, but they are used more abundantly as building material for the plant body. This is in accord with their presence in greater amounts in most parts of the plant. 
Carbohydrates Present in Plants. - The more common members of the carbohydrate group found in plants may be given as follows:

Hexose monosaccharoses,

Glucose - Grape sugar

Fructose - Fruit sugar

Disaccharoses,

Sucrose - Cane sugar

Maltose - Malt sugar

Polysaccharoses (not sugars), yielding hexoses,

Starch

Cellulose

Dextrin

Inulin

Polysaccharoses, yielding pentoses,

Pentosans

We find thus in plants all three of the main classes of this group, viz. simple sugars or monosaccharoses, double sugars or disaccharoses and compound sugars (non-sugar in character) or polysaccharoses. All of these which are not hexoses themselves are related to them and yield them on hydrolysis. In addition to these we have also the polysaccharoses yielding pentose sugars, i.e. the pentosans. In fact only three carbohydrates, viz. glycogen, lactose and galactose, are found either exclusively in animals or to a larger extent in animals than in plants. This characterizes plants as the main and, with the exceptions cited, the only source of the carbohydrates.

Where, then, in the plant, do we find these different compounds and how do they act as food? In the leaves and other green parts we find two of these carbohydrates in such conditions that we are inclined to believe they are directly produced by photosynthesis. These two are glucose and starch.

Metabolic Transformations. - From our chemical study of the carbohydrates we see that the relationship of the entire group is such that in the living plant there is possible a con- 
tinual transformation from one to the other. The chemical reactions involved require in most cases simply the loss or addition of the elements of water. These reactions are peculiar, also, in being brought about through the agency of enzymes which in many instances are known to be capable of producing a reversible reaction. In plants, water and enzymes are both abundant, so that there is nothing strange or improbable in the belief that here the various members of the carbohydrate group are constantly undergoing transformations back and forth into each other. For example, glucose and fructose may yield sucrose, glucose may yield maltose and then starch or cellulose, and vice versa in each case. Not only are such transformations possible theoretically, but direct experiment has proved that in many instances they actually do occur. If then glucose is the first essential constituent that is formed as a product of photosynthesis, all of the other carbohydrates may be derived from it by metabolic changes.

Sugars. - In all plant sap and juices, sugars are present and oftentimes several of them, not only monosaccharoses but also disaccharoses. Thus in fruit juices glucose, fructose and sucrose are found, while in plant sap sucrose is the sugar usually present.

Translocation Material. - As sugars are the soluble carbohydrates, all of the insoluble carbohydrates, starch in particular, must be converted into one of the sugars in order to be possible of translocation from one part of the plant to another. Also, as all carbohydrates, used as building material or as cell food, must be translocated throughout the plant organism to all the various cells, the sugars are the particular form of carbohydrates thus used.

Cell Food. - In plants, as in animals, glucose is the form in which all carbohydrate food, and perhaps all food, is finally oxidized to yield energy. In plants, however, the production of energy is of much less relative magnitude than in animals, and not all of the glucose and other soluble sugars are required to be used as energy food. The greater part of these compounds is used in the plant as intermediate translocation material for 
the building up of body substance or for storage as reserve food. The sugars are carried by the sap to all of the plant cells, and in the cells they undergo metabolic changes whereby they yield energy, form body substance or are converted into reserve food.

Starch. - In two localities, in particular, do we find the sugar glucose thus metabolized into the polysaccharose starch.

Reserve Food. - In both of these places the starch is reserve food. In the leaves of plants starch is always present. In fact it is so universally present here and follows so closely the photosynthetic activity that it was long believed to be the direct product of photosynthesis. It is probable, however, that glucose is first formed and the starch then produced by enzymatic action, involving loss of water and condensation or union of the unit glucose molecules into larger starch molecules. Though starch is constantly being thus formed in the leaves, it does not accumulate but is continually reconverted into maltose or glucose and carried away by the plant sap. This is clearly shown by the disappearance of the starch in leaves during darkness, when photosynthesis is not going on. In the morning, following the darkness of night, practically all starch has left the leaves. This conversion and translocation of starch in the form of glucose is being carried on during the day as well as during the night, but as new starch is being continually formed at the same time, the translocation does not show as well as at night. The conversion of glucose, the product of photosynthesis, into starch which is immediately reconverted into glucose for translocation is quite closely analogous to the process in animals whereby absorbed carbohydrate food in the form of glucose, fructose or galactose is converted into glycogen in the liver and the glycogen then continually reconverted into glucose and sent out in the blood to all parts of the animal.

Diastase and Maltase. - The conversion of starch in the leaves into glucose is brought about by enzymes known as diastase and maltase. These two enzymes convert starch first into maltose sugar and then into glucose. The starch in the leaves thus acts as a temporary reserve material very like the 
glycogen in animals. The glucose and maltose formed from the starch which in turn was formed from photosynthesized glucose, is carried by the sap throughout the plant, where it undergoes further metabolism, as previously stated.

Part of this glucose is carried to other organs of the plant, viz. the seeds, tubers, roots, etc., which are reserve organs for the storage of starch food. In these reserve organs the sugars are again converted into starch and here the starch acts as reserve food for renewed growth in the germ, buds, twigs, etc.

Germination. - Roughly speaking, the seed of a plant consists of a germ which is surrounded by a reserve supply of food on which the new plant lives for the first period of its life. This reserve food consists of all three of the essential organic constituents, carbohydrates, fats and proteins, and also inorganic constituents or salts. The carbohydrate food in the seed consists usually of starch, though this may be replaced by sugars, reserve cellulose or inulin. When the germ begins to grow these food materials are gradually assimilated.

In order to be used as food by the developing germ the starch is again hydrolyzed into maltose and glucose. This hydrolysis is brought about by the same enzymes as are active in the leaves, viz. diastase and maltase. This diastase of the seed, while considered to be the same enzyme as is present in the leaves, acts somewhat differently physically; and to distinguish between the two the one in the seed is called diastase of secretion and the one in the leaves diastase of translocation.

The isolation of diastase and maltase from germinating seeds and their hydrolytic action upon the starch of the seed, yielding glucose, has been fully established experimentally. In fact both the enzyme maltase and the sugar maltose, or malt sugar, upon which it acts, derive their names from the fact that they are present in, and can be easily isolated from, malt, which is germinated grain, usually barley.

Thus we see that one of the results of carbohydrate synthesis in green plants is to produce food material either for the plant itself or for the germ of its offspring. 


\section{EXPERIMENT STUDY XXXI}

\section{Action of Diastase on Starch}

(a) Extract 50 grams of finely ground malt (germinated barley) with warm $\left(25^{\circ}-30^{\circ} \mathrm{C}\right.$.) water. Filter and test filtrate for reducing sugars (maltose or glucose). Ferment this filtrate with yeast until all fermentable sugars (maltose and glucose) have been converted into alcohol. Filter again if necessary and retest for reducing sugars. No test should be obtained. Make a little starch paste, add the filtrate to this paste, and keep at $35^{\circ} \mathrm{C}$. After a day test for starch and reducing sugar.

(b) Prepared diastase may be used instead of the extract of malt if desired.

Building Material. - We have discussed thus far two of the functions fulfilled by the photosynthesized carbohydrates, viz. (I) in the form of soluble sugars, probably always as glucose, to furnish the plant cells with food material for oxidation and the liberation of the energy of the living processes. (2) To be converted into starch as a temporary reserve material in leaves or as a reserve food for the germ of the plant's offspring in the seed, tuber, root, etc.

One more function fulfilled by photosynthesized carbohydrates is to be mentioned in more detail, viz. the conversion of it into material out of which the body substance of the plant is built. This building of body material is the second distinct function of food.

In our study of animal food and nutrition we defined food, more especially the organic food, as any substance which taken into the body is used to build body material or to yield energy. Nutrition embraces all of the processes by which these functions are performed. The changes involved constitute metabolism, which is either constructive (anabolism) or destructive (katabolism). The result of anabolism is the building of body material which may be either temporary or more or less permanent. The result of katabolism is the yielding of energy. The metabolic changes which we have been considering in 
plants, following the photosynthesis of carbohydrates, have been mainly katabolic in their final results. We shall now consider those metabolic changes in carbohydrate material that are anabolic.

Cell Wall. - We have spoken of the fact that the plant cell contains all three of the essential organic compounds, carbohydrates, fats and proteins, as constituent parts of the cell protoplasm. In addition to the cell protoplasmic contents we have the cell wall, and this consists largely, if not wholly, of carbohydrates in the form of cellulose. In all cases it is produced by the conversion of the translocated sugars into cellulose, by reactions undoubtedly similar to those by which starch is formed in leaves and seeds.

Cellulose. - In the young living cells of plants the cell wall is probably pure cellulose and it is somewhat different in character from the cellulose of mature and old cells found in the stems, branches and trunks of the plant. Oftentimes the cellular structure takes on peculiar forms and produces the fiber which is contained in the boll of the cotton plant and in the stems of grasses, flax, hemp, etc. As the plant grows, especially in the case of large trees, the pure cellulose of the young cell walls becomes thicker and harder, due to the impregnation with gums, resins, lignins, pectins, pentosans, etc. Cell walls thus hardened give to the cellular structure the character of wood, which is much tougher and stronger than young cellular structures. In all these cases, whether in young living cells or in old woody cells, the cellulose of the cell wall is truly the building material of the plant and is not reserve food material. It is into such building material that a great part of the photosynthesized carbohydrates is eventually metabolized. When we consider the immense amount of cellulose thus formed in the case of large trees, and realize that while the plant is forming all of this body substance, it is, at the same time, using photosynthesized carbohydrates as direct energy food for the cells and also forming large amounts of reserve starch food, we get some idea of the magnitude of the process of photo- 
synthesis. All of this food, representing both the energy and the body substance, is synthesized from the two simple compounds carbon dioxide and water by means of the energy of the sun through the agency of the chlorophyll bodies and chlorophyll.

\section{Fats and Proteins}

In the preceding discussion we have considered in detail simply the carbohydrates. 'The cell substance, however, contains all three of the essential organic compounds, and all three of them serve together as energy food.

Synthesis of Fats and Proteins in Plants. - Though it is not absolutely proved, it is generally accepted that neither fat nor protein is a direct product of photosynthesis. The fact that, while the most important protein formation takes place in the leaves of plants, this formation is not connected with the activity of either chlorophyll or light, is evidence that protein is not thus formed. The synthesis of protein in leaves takes place in the absence of both of these agencies if there is present in the soil an abundant supply of soluble carbohydrate food together with nitrate nitrogen.

If then, as we believe, the first product of photosynthesis is carbohydrate, both fat and protein are produced from this carbohydrate by metabolic change. We know that in animals the metabolic conversion of carbohydrates into fat is a fact. A similar metabolism in plants is entirely probable and is, in fact, definitely established by experimental study of the relation between these two constituents.

As fats are non-miscible with water they are unable to be translocated as such in the plant sap, but it has been shown that when they are in the form of fine emulsions they may be carried in the sap to the reserve organs. It is probable, however, that the greater part of the fat present in seeds has not been brought there by translocation, but has been formed in the seed directly by the metabolism of carbohydrates. In this metabolism different carbohydrates may take part, for it has been shown 
that an increase in fat may be accompanied by a decrease of either glucose or starch and in some cases of the hexahydroxy alcohol, mannitol. In the protoplasmic cell contents fats are present in the form of small globules.

Location of Fats. - Fats, including in this term both fats and oils, occur in plants mostly as reserve food in the seeds. Waxes, on the other hand, occur principally in the vegetative organs, where they serve as protective material against drouth and cold. Fats are also found in smaller amounts in the vegetative organs and may likewise be protective. In most plants fats are not so abundant as carbohydrates. A few exceptions to this are oil-bearing seeds such as castor-oil bean, cottonseed, flaxseed and most nuts except chestnuts.

Location of Proteins. - Protein, like fat, while occurring as an essential constituent of cell protoplasm and serving as energy food, is found mostly as a reserve food in seeds. It is synthesized originally in the leaves, as just stated. As it is found stored in seeds it is generally somewhat localized in the layer just beneath the outside, as in the aleurone layer in wheat grain. In the seed the protein together with the other constituents is used as food for the developing germ.

Source of Nitrogen. - In the metabolism of photosynthesized glucose or other carbohydrate compounds into protein it is, of course, only the carbon-hydrogen-oxygen portion of the protein that can be supplied by the carbohydrates. The nitrogen of plant protein is derived from another source. In most plants the source of nitrogen is the soil, where it occurs principally in the form of nitric acid salts or nitrates. In this form the nitrogen is taken up by the plant roots and translocated to the cells. Here it meets with the carbohydrate cell food, and the two materials become metabolized into protein. In the case of other forms of nitrogen which are present in the soil, e.g. ammonium salts and organic nitrogen compounds (humus, etc.), these are converted by bacterial action into nitric acid nitrogen. The organic nitrogen compounds, consisting mostly of dead protein or protein residues, such as amino compounds, urea and 
other urine constituents, are first decomposed into ammonia. This ammonia and other ammonium salts of whatever origin are probably in greater part then oxidized to nitric acid. This oxidation of ammonia to nitric acid takes place in the presence of atmospheric oxygen in the soil through the action of aërobic bacteria. The reaction may be represented in its simple form as follows:

\section{$\mathrm{NH}_{3}+{ }_{2} \mathrm{O}_{2}+$ bacteria $\rightarrow \mathrm{HNO}_{3}+\mathrm{H}_{2} \mathrm{O}$}

The nitric acid thus formed unites with bases in the soil, forming nitrates, e.g. potassium, sodium, ammonium, calcium, magnesium nitrates. In the form of these compounds, the nitrate nitrogen is taken up by the plant and metabolized into protein as above explained. It has been definitely proved, however, that plants can utilize ammonia nitrogen directly and also nitrogen in the form of urea or other amino compounds. To just what extent such nitrogen is utilized has not been established.

One other source of nitrogen is of especial importance, but it applies only to certain plants, so far as is known only legumes such as clover, pea, bean, etc. In these plants there are present on the roots nodules containing bacteria which possess the characteristic property of assimilating free nitrogen from the air and converting it into protein nitrogen.

Nitrogen Cycle. - The cycle of changes through which the element nitrogen passes in its existence in the atmosphere, soil, plants and animals is exceedingly interesting. Nitrogen, phosphorus and sulphur are the only ones of the essential constituents of the soil food of plants which are converted into organic or energy food of the plant. The other more important plant food constituents, obtained from the soil and present also in fertilizers, are potassium and some others such as calcium, magnesium and iron. While compounds of these elements must be considered as true plant food, they are not energy food and should always be termed the soil food of plants as distinguished from their cell food or energy food. Their action is not fully 
understood, but they probably either contribute material for the formation of protein or act physiologically in connection with some of the metabolic changes which we have been discussing. The general discussion of the questions connected with the plant's soil food constituents belongs properly to the study of soils and fertilizers in inorganic agricultural chemistry. As the nitrogen of the soil food of plants is, however, directly connected with the organic or energy food materials of plants, a further consideration of it is not out of place in our present study.

Fixation of Atmospheric Nitrogen. - The ultimate source of all nitrogen is the atmosphere, where it is present in large amount, about 80 per cent.

In just what way this atmospheric nitrogen first entered the cycle connected with living organisms is not certain, nor is it desirable for us to discuss the question at length. Three possible ways have been suggested by which nitrogen from the air could have entered the soil.

(I) By the decomposition of metallic nitrogen compounds, e.g. the nitride of boron $(\mathrm{BN})$. Such compounds were doubtless formed when the surface of the earth cooled. On later decomposition with water, ammonia would be formed, and this could then have been oxidized to nitrate compounds by bacteria which at first used the ammonia directly as nitrogen food. Such a process, though it may have taken place originally, is probably not going on at present.

(2) By Electrical Discharges in the Air. - During the electrical discharges of thunderstorms there is a continual conversion of appreciable amounts of the free nitrogen of the air into oxides of nitrogen, which with water yield nitrous or nitric acid.

$$
\begin{aligned}
& \mathrm{N}+\mathrm{O}+\text { electric discharge } \rightarrow \mathrm{NO} \\
& \text { Nitric oxide } \\
& 2 \mathrm{NO}+\mathrm{O}_{2} \overleftrightarrow{\leftrightarrows} 2 \mathrm{NO}_{2} \\
& 3 \mathrm{NO}_{2}+\mathrm{H}_{2} \mathrm{O} \rightleftarrows 2 \mathrm{HNO}_{3}+\mathrm{NO} \\
& \text { Nitric acid }
\end{aligned}
$$


These reactions are the basis of new and important commercial processes for the conversion of atmospheric nitrogen into compounds useful as soil food for plants. In the Birkelund-Eyde process, as carried out in Norway, calcium nitrate is thus made and used as a fertilizer. Such fixation of atmospheric nitrogen is not only a commercial process, but it is probably a means by which soil nitrogen is continually supplied.

(3) By the Action of Nodule Bacteria. - As just recently discusser, bacterial nodules occurring on leguminous plants fix atmospheric nitrogen in the plant and indirectly in the soil, probably in the form of protein compounds. In the total this method is possible of fixing large amounts of free nitrogen and is continually going on at present.

It is possible that in one or perhaps all of these three ways atmospheric nitrogen originally entered the soil and became food for plants. The last two methods are constantly going on in nature under present conditions, tending to preserve nitrogen equilibrium. Whatever the original process was, it is true that in the soil there is present a large amount of nitrogen in the form of nitrate salts, ammonium salts or amino compounds, and this nitrogen is the source of all protein nitrogen in plants, except as stated in connection with the nodule bacteria. By means of this nitrogen, together with the products of photosynthesis, the plant is able to metabolize protein compounds which serve as its own food supply or as reserve food. This reserve protein food, intended for the plant's offspring, becomes, however, animal food and in herbivorous animals is the sole source of the nitrogen for animal protein. In the metabolic processes of animals this plant protein nitrogen, built up into animal protein, is again torn down to furnish energy to the animal. The nitrogen products of protein katabolism in animals are urea and the other nitrogen compounds of the urine. In the form of these compounds in animal manure the original nitrogen again reaches the soil. Here they are decomposed by bacterial action, yielding ammonia, and this by similar action is converted into nitric acid and the cycle of the nitrogen is completed. 
If the animal dies, the unchanged protein of the body decomposes bacterially in the soil, yielding simpler compounds, amino-acids, etc., and eventually ammonia. This is then further changed as above described and the cycle is again completed. Thus the nitrogen of animal protein, either as dead animal protein or as excretion products of living animals, is eventually converted into soil nitrate compounds and assimilated by plants as their soil food for the synthesis of new plant protein.

During the decomposition of organic nitrogen compounds of manure or dead animal bodies and the transformation of the nitrogen into nitrate compounds, another class of bacteria known as denitrifying bacteria cause the loss of some of the nitrogen into the atmosphere as free nitrogen. Also some ammonia fails to become oxidized and is volatilized as a gas. This ammonia gas is absorbed by water and returned to the soil in rain. The whole cycle of changes is controlled by conditions of equilibrium, both biological and chemical, so that it cannot be represented as a clean-cut series of reactions always going in one direction. The final results are, however, those which have been indicated.

For the purpose of a review and to condense what has been said into a short presentation, we may write the following reactions as representing the general course of the cycle of changes. 


\section{Nitrogen Cycle}

$$
\mathrm{N} \stackrel{\text { by nodule bacteria }}{\longrightarrow} \text { Plant protein }
$$

In the atmosphere

$$
\mathrm{N}+\mathrm{O} \stackrel{\text { electrically }}{\longrightarrow} \mathrm{HNO}_{3} \rightarrow \mathrm{KNO}_{3}
$$

In the atmosphere Nitric acid Nitrates in the soil

$$
\mathrm{KNO}_{3} \underset{\text { by plants, as soil food }}{\longrightarrow} \text { Plant protein }
$$

Nitrates of soil carbohydrates

Plant protein $\stackrel{\text { By animals, as food }}{\longrightarrow}$ Animal protein

$$
\text { Animal protein } \underset{\text { Btilized by some plants }}{\longrightarrow} \text { Urea, etc. }
$$

Urea, etc. and Dead protein $\stackrel{\text { In soil, by bacteria }}{\longrightarrow} \underset{\text { In soil }}{\mathrm{NH}_{3}}$

Utilized by some plants

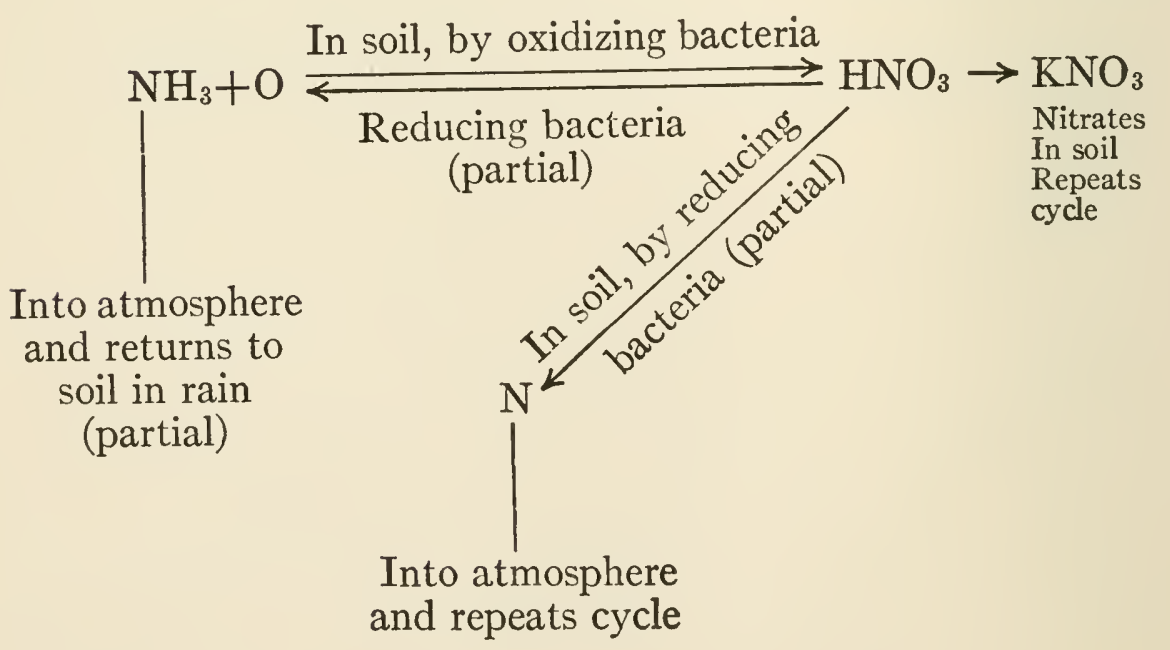


The following diagram also represents the series of changes:

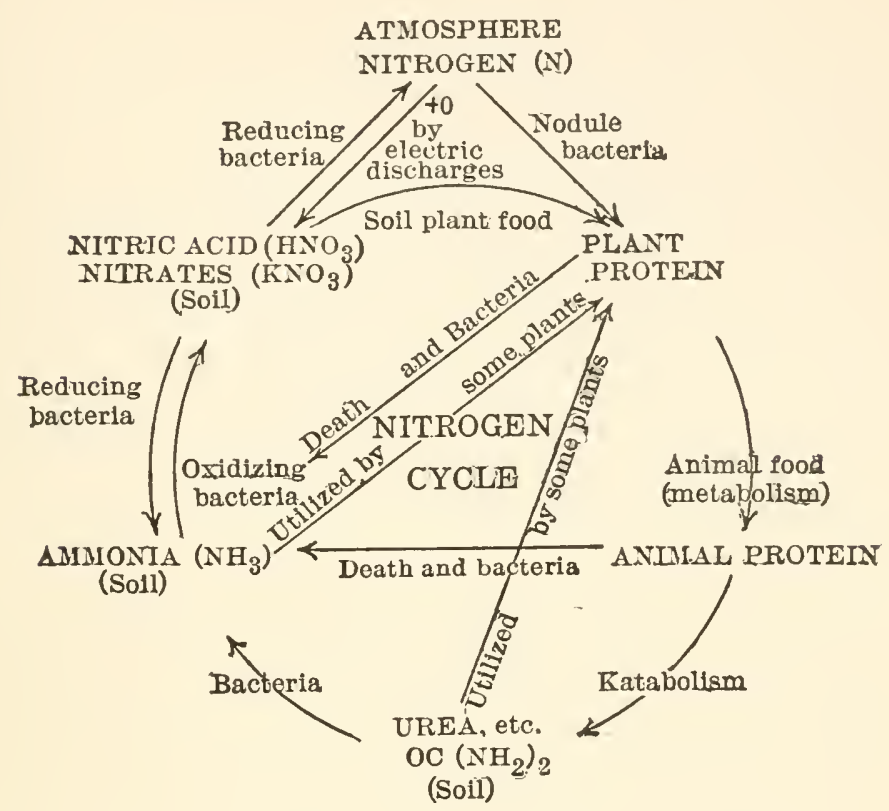

\section{RÉSUMÉ}

Plants, like animals, as living organisms, utilize organic food consisting of carbohydrates, fats and proteins, for the liberation of energy necessary for the life process. In plants, however, the net result, or the predominating reaction, is not to expend energy but to conserve or store it. The process that produces this result is photosynthesis. By the photosynthetic action of green plants chlorophyll bodies or chloroplasts, together with the green pigment chlorophyll, utilize the kinetic energy of sunlight for the synthesis of complex organic compounds from the carbon dioxide of the air and water of the air and soil, at the same time setting free oxygen which is given off into the air. In these complex compounds the used kinetic energy of the sun is stored as potential energy.

The probable direct result of photosynthesis is the carbohydrate glucose. This photosynthesized glucose is converted by metabolic changes into more complex carbohydrates, e.g. cane 
sugar, malt sugar, starch, inulin. Carbohydrate material is also further metabolized into fat and, with the assistance of nitrogen, mostly in the form of nitrates, in the plant's soil food, into protein.

All three of these organic products of photosynthesis and metabolism, the carbohydrates, fats and proteins, serve as plant cell food for the liberation of energy. They are also stored as reserve food supply for the young plant or offspring. In addition to this they are converted into building material for the plant body, the most abundant substance of this kind being cellulose, which forms the cell wall structure and which impregnated with resinous compounds results in the woody fiber of trees.

As a net result of all of these reactions, in which chlorophyll bodies, chlorophyll and enzymes play an essential part, the plant builds up from simple compounds the complex organic food constituents which possess the energy of the sun's rays stored in potential form. Thus the plant manufactures its own energy food which is used either to yield energy or to build body substance. Not only, however, does it manufacture its own energy food, but in excess of this it stores up a reserve supply for its offspring. This reserve supply is often not allowed to be used by the young plant, but the plant or some part of it is used by animals as food. As animal food both the reserve food in seeds, etc., and all of the other constituents of the plant body are utilized to a greater or less extent. From this food herbivorous animals wholly, and all animals in part, obtain the energy necessary for their life process and the material out of which their bodies are built, in this last the inorganic foods also taking part.

\section{References, Section II}

Abderhalden, Lehrbuch der Physiologischen Chemie, I909.

Atwater, Principles of Nutrition (U.S. Dept. Agr. Bul. I42), I902. Barthel-Goodwin, Milk and Dairy Chemistry, ı 9 Iо.

Bayliss, Nature of Enzymes (Monographs on Bio-Chemistry), I9II. 
Czapek, Biochemie der Pflanzen, I9I3.

Czapek, Chemical Phenomena in Life, I9II.

Euler-Pope, General Chemistry of Enzymes, I9I 2.

Haas \& Hill, Chemistry of Plant Products, rgr3.

Hammersten-Mandel, Text-book of Physiological Chemistry, I90I.

Hawk, Practical Physiological Chemistry, I9I4.

Howell, Text-book of Physiology, I9ıо.

Jordan, Principles of Human Nutrition, I913.

Lusk, Elements of the Science of Nutrition, I909.

Mathews, Physiological Chemistry, I9 I5.

Pfeffer-Ewart, Physiology of Plants, Igoo.

Salkowski, Practicum der Physiol. and Pathologischen Chemie, I 906. Sherman, Chemistry of Food and Nutrition, I9I4.

Stiles, Nutritional Physiology, I9I 2. 

SECTION III

CROPS. FOODS AND FEEDING 



\section{CHAPTER X V}

\section{OCCURRENCE AND USES OF IMPOR- TANT CONSTITUENTS IN AGRICUL- TURAL PLANTS}

Having now considered the physiological processes by which plants utilize the energy of the sun in synthesizing their own food material which is used both to yield energy and to construct the body substance, let us now examine different plants as to the particular compounds which they contain and the general uses to which the plants are adapted. We shall study the different constituents according to their occurrence in plants which have agricultural importance as crops and the uses to which each crop is thus adapted. Generally speaking, plants have two main uses economically: (I) as animal food, (2) as the basis of important manufactured products. The study in detail of their food value to man and animals will be taken up in the next chapter. In this chapter we shall consider the general distribution and uses of the plant constituents.

\section{CARBOHYDRATES}

The carbohydrates are the most widely and most abundantly distributed of the three groups of organic constituents. There is no green plant in which they are not present and in most cases they are the predominating constituent. The different members of this group that are found in plants may be considered in the following order: Polysaccharoses not sugars cellulose, starch, dextrin, imulin; anhydrides of pentose sugars - pentosans; disaccharose sugars - cane sugar, malt sugar; hexose monosaccharose sugars - glucose and fructose. 


\section{Cellulose}

Considering all forms of plants and all parts of them, the most abundant carbohydrate is cellulose. It is the material which is used by the plant for the construction of the cell wall and is elaborated as a metabolic product by the cell protoplasm.

Forms of Cellulose. - In the walls of young cells the cellulose is probably pure and is considered simpler in its nature than cellulose as usually obtained from fiber plants.

Three different types or varieties of cellulose are known: (a) Normal cellulose as found in the fibers of such plants as cotton, flax and hemp; (b) Hemicellulose as found in the stems and leaves of green grasses, cereals, etc., and in the cell walls of certain seeds, e.g. peas and beans. This is considered as simpler than normal cellulose and more like the newly metabolized cellulose of young cells. (c) Compound cellulose as found in the woody cells of ripened grasses and cereals and in trees. Also in jute, probably in flax and hemp, and in the cellulose fiber of juicy fruits. Each of these different forms of cellulose is usually spoken of in the plural, as it is probable that there are different individuals or varieties of each.

Normal Celluloses. - The purest form of cellulose generally obtained is the fibrous variety (normal celluloses) as it occurs in cotton, flax and hemp. Such cellulose is the most valuable of all forms for industrial purposes, and from these sources are manufactured all of the various kinds of cloth, thread, string, and rope, with the exception of those made of wool and silk. From the cotton fiber, as found in the cotton boll, the different varieties of cotion cloth, thread and string are made. From flax fiber, obtained from the straw of the flax plant, all of the like forms of linen are prepared. Hemp fiber, obtained from the stalks of the hemp plant, is used in making a stronger kind of cloth known as canvas and also string and rope. Jute fiber, largely compound celluloses, likewise obtained from the stalks of the jute plant, is made into canvas, sacking and carpets. Cellulose, mostly as cotton, is also used in making exceedingly 
important chemical derivatives such as cellulose explosives, collodion, celluloid, mercerized cotton and artificial silk. The chemical nature of these derivatives has been discussed in Section I (p. I 27).

Cellulose in the form of flax fiber or old linen cloth is also used to make the best grades of paper. Cotton fiber or cotton cloth are used for poorer grades of paper, and a large amount of paper used, especially for newspapers, is made from wood cellulose.

As an agricultural crop cotton is grown most abundantly in the United States, but also to a greater or less extent in South America, India, Egypt and Australia. The chief production of flax and hemp is in Russia. Jute comes mostly from India, where its cultivation is replacing that of indigo, which is now made largely by synthetic processes. Considerable flax and some jute come from the United States.

Analysis of cotton fiber by Bowman, as cited by Haas and Hill, shows it to have the following composition:

\begin{tabular}{|c|c|c|c|c|c|c|}
\hline Cellulose & - & - & - & & & 91.00 \\
\hline Wax, Oil, Fat & & & & & & \\
\hline Protoplasm & & . & • & & & \\
\hline & & . & . & 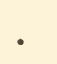 & & \\
\hline Vater & & & . & & & \\
\hline
\end{tabular}

König's investigations ${ }^{1}$ give the following amounts of pure cellulose in some plants:

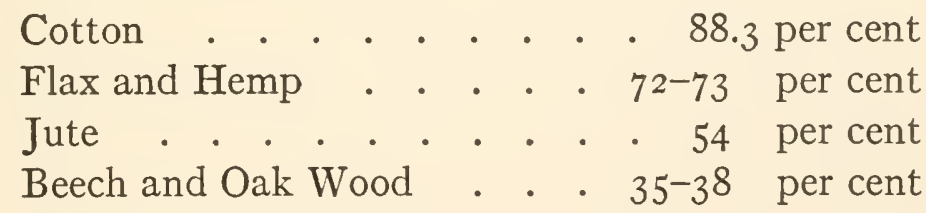

Hemicelluloses. - In the young plant cell, as previously stated, the wall is probably pure cellulose. Such cellulose would be more easily soluble than the normal cellulose, and

${ }^{1}$ Huhn, "Chemie der Zellmembran"; Z. Nähr. Genuss., XXVII, 2I (I9I4). 
would also hydrolyze with comparative ease, yielding monosaccharose products. The cellulose which is present in peas, beans, etc., and in green grasses seems to be a simpler and purer cellulose than the normal fibrous variety, and does in fact dissolve more easily and hydrolyze more easily than the normal. This form has been termed hemicellulose. Other substances known as mannans, galactans and pentosans (pp. 270, 272) are either identical with hemicelluloses themselves or are contained in them.

Lignocelluloses. - As the cell walls, especially of the stems, stalks and trunks of plants, become older they take on a special character which is known as woody. They then possess much greater hardness and strength and form the supporting structure of plants. The change in character is due to a change in chemical composition resulting from the infiltration into the original cell wall of noncellulose substances possessing a gummy or resinous nature. These substances are known in general as lignins, and the celluloses formed are called ligno-celluloses. It is probable that these lignins are in actual chemical combination with the cellulose, though it may be that they are simply mixed with it. The exact chemical nature of the lignins is also unknown, but they are undoubtedly of pentosan character. They yield pentose sugars on hydrolysis. While the normal celluloses are the chief source for the manufacture of the best grades of paper, the lignocelluloses of the softer woods, such as spruce, fir, etc., are being used almost exclusively in the manufacture of paper for newspapers and similar uses. In making the paper from wood more or less of the lignins are removed. Cellulose so obtained amounts to about 55 per cent of the weight of the wood itself. (See also Paper, p. I26.)

Pectocelluloses. Pectins. - Two other kinds of compound celluloses should be mentioned. The first of these is the pectocelluloses, in which cellulose has associated with it noncellulose substances termed pectins analogous to the lignins of the lignocelluloses. These pectins, like the lignins, are probably not simple substances, but are of carbohydrate character, perhaps 
polysaccharoses like pentosans. They are soluble in water and on boiling the solution, or by the addition of alcohol, they gelatinize. It is these pectins which are present in the juices of succulent fruits, and which on the concentration of the juice by boiling produce a jelly. The other variety of compound celluloses is that found in the corky tissue of plants, and is termed adipo-cellulose. The noncellulose constituent is probably of fatty nature, and is known as cutin. In all plants containing largely hemicelluloses or compound celluloses, the normal cellulose is also present to a greater or less extent.

Cellulose as Food. - As a constituent of human foods cellulose does not play an important part and is very slightly digested. In the case of herbivorous animals, like the cow, sheep and horse, however, they constitute a large part of their normal food, and are thus of far greater importance than with man. The most easily digested form of cellulose is that of the hemicelluloses, which, however, are not as abundant as the normal celluloses, which probably rank next in order of digestibility. The least digestible form is that of the lignocelluloses and of these those found in hay and straw are the most valuable. In the digestion of cellulose by herbivorous animals an amount varying from 30 to 60 per cent is considered as digestible. Of this amount, however, a considerable portion is fermented by bacteria in the intestines, and is converted into products, such as methane gas, which are unabsorbed. This necessitates a correction for the digestibility of cellulose constituents in order to determine the amount actually utilized by the animal. This will be considered again (p. 297). The cellulose actually utilized by animals is considered to have the same food value as the other carbohydrates, such as starch and sugar.

Crude Fiber. - In the analysis of cellulose-containing foods the substance is usually determined in the form of what is commonly termed crude fiber. If such a food is boiled with a I.25 per cent acid solution and then filtered, and the undissolved residue again boiled with a 1.25 per cent alkali solution, the undissolved residue finally obtained is largely cellulose, and is 
TABLE VI

Cellulose Content of Crops

Crude Fiber

\begin{tabular}{|c|c|c|c|c|c|c|}
\hline \multicolumn{4}{|l|}{ Crop } & \multirow{3}{*}{$\begin{array}{r}\text { (FRESH } \\
\text { BASIS) } \\
\begin{array}{r}91.0 \\
50-60\end{array}\end{array}$} & \multirow{2}{*}{$\frac{(\text { DRY BASIS })}{99.0}$} & \multirow{2}{*}{$\overline{\text { Bowman (Haas \& Hill, p. 129) }}{ }^{1}$} \\
\hline Cotton fiber . & & & & & & \\
\hline Pine wood . . & - & & - & & & \\
\hline Wheat straw . & - & - & • & 38.1 & 42.1 & J. \& W., pp. I2-I $9^{2}$ \\
\hline Oat straw . & & & - & 37.0 & 40.7 & J. \& W., pp. г $2-19$ \\
\hline Corn stalks (cur & ed) & & - & Ir.o & 34.8 & J. \& W., pp. г2-19 \\
\hline Corn stover (cur & red) & & - & I9.7 & 33.0 & J. \& W., pp. I2-19 \\
\hline Corn fodder (cur & red) & & . & $\mathbf{I} 4.3$ & 24.7 & J. \& W., pp. r2-r9 \\
\hline Timothy grass & & - & - & II. 8 & 30.7 & J. \& W., pp. r2-rg \\
\hline Timothy hay . & . & . & . & 29.0 & 33.5 & J. \& W., pp. I 2-r \\
\hline Red clover grass & & - & - & 8.I & 27.8 & J. \& W., pp. r2-r9 \\
\hline Red clover hay & . & . & - & 24.8 & 29.1 & J. \& W., pp. 12-r9 \\
\hline Alfalfa grass & . & - & . & $7 \cdot 4$ & 26.2 & J. \& W., pp. r2-r9 \\
\hline Alfalfa hay . & & . & . & 25.0 & 27.3 & J. \& W., pp. I $2-19$ \\
\hline Cowpea (hay). & & & - & 20.1 & 22.5 & J. \& W., pp. I2-r9 \\
\hline Cowpea (peas on & aly) & & & $4 \cdot I$ & 4.8 & J. \& W., pp. I 2-I9 \\
\hline Soja bean (bean & onl & & & 4.8 & $5 \cdot 4$ & J. \& W., pp. I 2-r9 \\
\hline Sugar cane. . & · & $\cdot$ & & 7.0 & 28.0 & König, p. $896^{3}$ \\
\hline Oats . : : & . & - & - & $9.5($ II.24) & 10.8 (1 2.20$)$ & J. \& W., pp. I2-r9 (Bul. I 20, p. 34) \\
\hline Wheat (spring) & - & - & - & I.8 (2.39) & $2.0(2.66)$ & J. \& W., pp. r2-r9 (Bul. r 20, p. 33) \\
\hline Wheat (winter) & - & & - & $1.8(2.23)$ & $2.0(2.49)$ & J. \& W., pp. 12-I9 (Bul. I 20, p. 33) \\
\hline Barley • • . & - & - & & $2.7(5 . \mathrm{II})$ & $3.0(5.64)$ & J. \& W., pp. r2-xg (Bul. r2o, p. 36) \\
\hline Rye $\cdot \cdot \cdot$ & & - & . & I.7 $(2.08)$ & x.9 (2.30) & J. \& W., pp. I2-r9 (Bul. I20, p. 35) \\
\hline Sorghum grain & & - & - & $2.6(\mathrm{r} .58)$ & $3.0(\mathrm{r} .80)$ & J. \& W., pp. I2-r9 (Bul. I 20, p. $4 \mathrm{I}$ ) \\
\hline Maize (flint) . & . & - & - & I.7 & r.9 & J. \& W., pp. r2-r9 \\
\hline Rice . . · . & & . & . & 0.2 & 0.2 & J. \& W., pp. I 2-I9 \\
\hline Wheat middling: & & - & & $4.6(6.3)$ & 5.2 & $\begin{array}{l}\text { J. \& W., pp. r2-r9 (Mass. Exp. } \\
\text { Sta., p. } 5^{5} \text { ) }\end{array}$ \\
\hline Wheat bran & - & - & - & $9.0(9.5)$ & 10.2 & $\begin{array}{l}\text { J. \& W., pp. I2-I9 (Mass. Exp. } \\
\text { Sta., p. 5r) }\end{array}$ \\
\hline Malt sprouts . & • & - & - & $10.7(12.5)$ & Ir.8 & $\begin{array}{l}\text { J. \& W., pp. I2-I9 (Mass. Exp. } \\
\text { Sta., p. 49) }\end{array}$ \\
\hline Linseed meal ( $\mathrm{n}$ & ew & proc & cess) & $9.5(8.6)$ & 10.5 & $\begin{array}{l}\text { J. \& W., pp. r2-rg (Mass. Exp. } \\
\text { Sta., p. 47) }\end{array}$ \\
\hline Linseed meal (ol & ld $\mathrm{p}$ & roc & ess) & $8.9(8.9)$ & 9.7 & $\begin{array}{l}\text { J. \& W., pp. I2-Ig (Mass. Exp. } \\
\text { Sta., p. 46) }\end{array}$ \\
\hline Cottonseed meal & & - & - & $5.6(9.4)$ & 6.1 & $\begin{array}{l}\text { J. \& W., pp. I2-r9 (Mass. Exp. } \\
\text { Sta., p. 46) }\end{array}$ \\
\hline Germ meal (mai & ize) & . & - & 4.I & 4.6 & J. \& W., pp. I 2-I9 \\
\hline Gluten meal . & $\cdot$ & & & $1.6(2.3)$ & I. 8 & $\begin{array}{l}\text { J. \& W., pp. I2-I9 (Mass. Exp. } \\
\text { Sta., p. 47) }\end{array}$ \\
\hline Cassava root . & . & - & - & I.I & 3.7 & König, p. I 495 \\
\hline Turnips . · · & - & . & - & $\mathbf{1 . 2}$ & $\mathrm{I} 2.2$ & J. \& W., pp. 12-r 9 \\
\hline Mangels . & · & - & $\cdot$ & 0.9 & 9.5 & J. \& W., pp. ז2-rg \\
\hline Rutabaga . & . & - & - & $\mathrm{r} .3$ & Ir.o & J. \& W.,pp. I2-19 \\
\hline Cabbage . & - & - & - & 1.5 & I 5.5 & J. \& W., pp. I2-19 \\
\hline Red beets & $\cdot$ & - & ${ }^{\circ}$ & 0.9 & 7.8 & J. \& W.,pp. I2-I9 \\
\hline Sugar beets & . & - & . & 0.9 & 6.5 & J. \& W., pp. I2-I9 \\
\hline Potatoes. . . & - & - & - & 0.6 & 2.7 & J. \& W., pp. I 2-r9 \\
\hline Sweet potatoes & . & $\cdot$ & & I.3 & 3.6 & J. \& W., pp. I2-r9 \\
\hline
\end{tabular}

${ }^{1}$ Haas \& Hill, l.c. (Table V).

${ }^{3}$ König, l.c. (Table V).

2 J. \& W., l.c. (Table V).

5 "Mass. Exp. Sta."; Smith \& Beals, Com'l. Feeding Stuffs, Mass. Agr. Exp. Sta. Bul. No. I, I914. 
called crude fiber. As there is always some mineral matter present the actual determination is made by drying the cellulose as above obtained and igniting it. The loss of dry material on ignition is calculated as the actual crude fiber. (See below.) As the method is wholly an empirical one, the crude fiber does not represent pure cellulose, but is an approximation to it. Probably the greater part of the crude fiber represents normal celluloses, but with more or less unhydrolyzed hemi- and lignocelluloses. Part of these latter are, however, dissolved by the treatment with acid and alkali.

Cellulose Content of Crops. - The preceding table gives the amounts of cellulose determined as crude fiber which are present in the more important crops.

\section{EXPERIMENT STUDY XXXIII}

\section{Cellulose in Plants}

Cotton. Examine cotton fiber and recall the study in Experiment $\mathrm{XXV}$. This is practically pure cellulose. (See analysis of cotton, p. 263.$)$

Crude Cellulose. Crude Fiber. Use $2.0 \mathrm{~g}$. of ground hay or grass. Place in a 500 c.c. flask and add 200 c.c. of 1.25 per cent hydrochloric acid, and boil with return condenser for one half hour. Filter through a linen filter. Wash with hot water. Return the residue to the flask and add 200 c.c. I. 25 per cent sodium hydroxide and boil again with return condenser for one half hour. Filter through asbestos and wash as before. The residue consists of the ash constituents plus the crude cellulose. After drying, the loss of weight on ignition represents the crude cellulose, or, as it is termed, crude fiber.

\section{Starch}

The next carbohydrate to be considered is starch, with which we may also group dextrin and inulin. While starch does not occur as abundantly in plants as a whole as does cellulose, yet it far outranks it in importance and value as a food. In fact, starch is the most important carbohydrate food for both man and animals. 
Starch as Food. - Physiologically starch is a reserve food material for the plant itself, as has already been discussed. It occurs in the leaves and other green parts of all green plants, where, as we have shown, it is a temporary reserve material, being immediately converted into sugars and translocated. In these parts of the plant it possesses food value for animals, but as it never collects in any amount, its actual value is slight, the chief carbohydrate constituent here being cellulose.

Those portions of the plant in which starch is most abundant are the strictly reserve organs, e.g. seeds, tubers, roots, etc. In these organs the plant has stored large amounts of starch, for the use of its offspring or for renewed growth, and it is these storage houses of the plant which form the most valuable animal foods. The three most important groups of plants in this respect are: (I) cereal plants, in which the starch is stored in the seed, i.e. the cereal grains, e.g. wheat, maize, oats, barley, rye, sorghum grain, millet, etc.; (2) tuber-forming plants, e.g. potato; (3) roots of certain plants, e.g. arrowroot, cassava, etc. ; (4) unripe fruits, e.g. apples, pears, etc., which are not, however, important as a source of starch because the fruit is never used in this state, and on ripening the starch is converted into sugars.

As was stated in the chapter on the chemistry of carbohydrates, the grains of starch found in different plants have in each case a distinctive microscopical structure. As a food material there is no difference in these various forms, so that in this respect starch is a single substance. Both human beings and animals digest starch; in the former case it is easily digested only when first cooked, but in the latter raw starch is the common form in which the food is eaten. Its common and abundant occurrence in so many foods makes it in many instances the particular constituent upon which the food value of the material largely depends. Several forms of pure starch are used as human food, e.g. ordinary cooking starch, usually obtained from corn, and tapioca, which is a specially prepared form of starch obtained from the cassava plant.

Industrial Uses. - For industrial purposes, such as the manu- 


\section{TABLE VII}

\section{Starch Content of Crops}

Nitrogen-free Extract

(starch, sugars, pentosans)

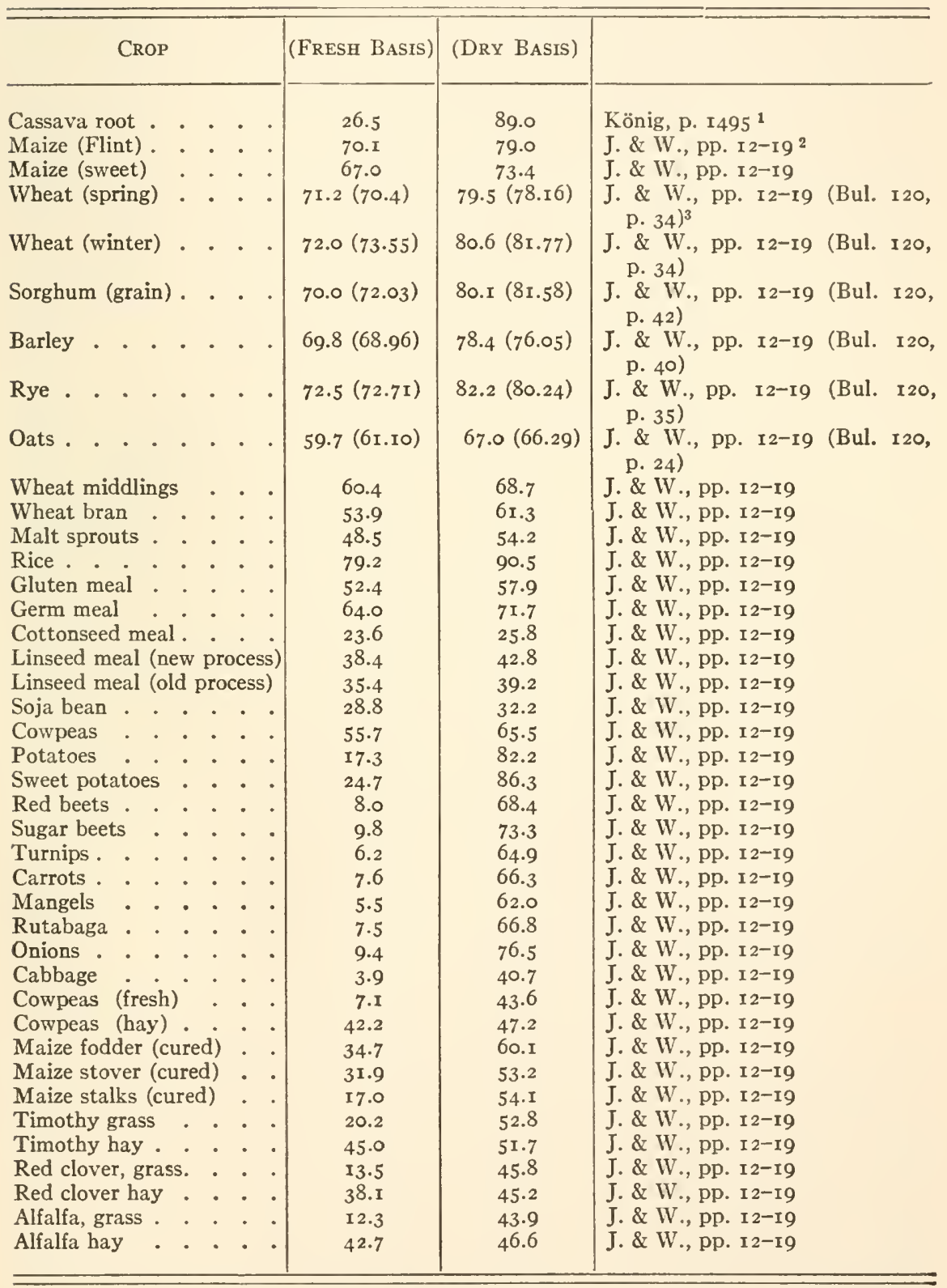

${ }^{1}$ König, l.c. (Table V). $\quad{ }^{2}$ J. \& W., l.c. (Table V). $\quad{ }^{3}$ Bul. I20, l.c. (Table V). 
facture of glucose, which is really a food use, and as laundry starch, or as sizing for cloth or paper, it is generally obtained from either corn or potatoes, which are the two most common and abundant sources.

Starch Content of Crops. - The preceding table gives the percentage amounts of starch (in some cases including small amounts of sugars) in some of the more important crops. The figures are those for " nitrogen free extract," which ordinarily includes with the starch the small amounts of sugars and pentosans if these have not been separately determined.

\section{EXPERIMENT STUDY XXXIV}

\section{Starch}

(I) Cut a wheat grain and moisten the cut surface with iodine solution. Note test for starch. Repeat with other cereal grains.

(2) Cut a slice of potato and moisten similarly with iodine solution.

(3) Cut a slice of a green apple and similarly test for starch by moistening the entire surface. Repeat the test with a slice of a ripe apple. Note difference in amount and location of starch.

(4) Wash out the starch from some wheat flour made into a dough and kneaded in the hand under a small stream of running water. Keep the dough in a compact ball and continue to knead until practically all starch is washed out and an elastic gummy ball is left. This is gluten. Test for protein (Experiment XVIII). Collect the starchy washings and allow to settle. Examine the starch residue.

(5) Peel a potato and grate it into a large dish of water. Allow the starch to settle and examine it. This is the principle of the preparation of commercial potato starch.

\section{Dextrin, Inulin, Mannan, Galactan}

While there is only one form of starch chemically considered, there are several other substances occurring in plants which are isomeric with it and which are often included with it in a general group sometimes termed the starches. They all have the same composition formula, viz. $\left(\mathrm{C}_{6} \mathrm{H}_{10} \mathrm{O}_{5}\right) x$. They differ probably in complexity of the molecule, but their chief differ- 
ence is in the hexose monosaccharoses which they yield on hydrolysis. Starch and dextrin each yield glucose or dextrose and are, therefore, both termed dextrosans or glucosans. Inulin, on the other hand, yields levulose and is termed a levulosan. Similarly, the mannans or mannosans are starchlike polysaccharoses which yield mannose and the galactosans or galactans yield galactose.

Dextrin. - The most important member of the group is dextrin. It occurs in quantity only in a few plants, for it is a transitory substance in the enzymatic hydrolysis of starch by diastase. In the chapter on salivary digestion (Chapter XI), the formation of dextrin in its several forms as an intermediate substance in the hydrolysis of starch to maltose sugar by ptyalin has been fully discussed. It differs from starch in being soluble in cold water. As a food substance it has the same value as starch.

It may be prepared by the action of enzymes on starch or by heating starch to $230^{\circ}-260^{\circ} \mathrm{C}$. In this latter way it is made for industrial use. We spoke of the use of starch as a sizing material for cloth and paper. Strictly speaking, except in laundering, it is not starch, but dextrin, made as above, which is generally used in this way. It is also used as an adhesive gum or mucilage.

Glycogen. - This compound may be referred to in this connection, for it is also a glucosan. It does not occur in green plants, but is found in some fungi, especially yeast, and in some other cryptogamous plants. It is known as animal starch and has been discussed in connection with the metabolism of carbohydrates in animals (Chapter XII).

Inulin. - This isomer of starch differs from it and from dextrin in yielding only levulose on hydrolysis. Like starch it is a reserve food in certain plants, especially the dahlia, where it occurs in the tubers. It is also present in the artichoke and in cherry roots. It is not hydrolyzed by diastase or ptyalin and is, therefore, undigested by animals. The enzyme which hydrolyzes it is known as inulase. 
Mannan and Galactan. - These two starch-like polysaccharoses are similar substances and are associated with cellulose in the form of hemicelluloses already discussed. They are found in wheat and in numerous other seeds, especially legumes, but not in amounts sufficient to deserve more attention. A particular source of mannan is the substance known as vegetable ivory. Agar-agar is a galactan. On hydrolysis mannan yields mannose, and galactan, galactose.

\section{Pentosans}

The polysaccharoses which we have just considered are all hexosans, i.e. they yield hexose sugars on hydrolysis. Analogous to these we have polysaccharoses which on hydrolysis yield pentose sugars (arabinose, xylose, etc.). They are termed pentosans. They have already been referred to as constituting the noncellulose part of lignocelluloses and probably also pectocelluloses. They constitute the gummy or resinous material which on hardening within the cell wall produces the lignocelluloses of woody fibers in trees and the stems of cereals and grasses.

They are found in purer form in what are known as natural gums, such as gum Arabic, gum tragacanth, wood gum, etc. These natural gums are not simple pentosan polysaccharoses, but are of a complex glucoside nature which readily yield first the pentosan and then the pentose sugar on hydrolysis. Some gums also yield galactans and galactose. They are also considered as acid compounds which are present in the gums as salts of potassium, calcium or magnesium.

Whether, however, they are present as constituents of lignocelluloses, pectocelluloses or natural gums, the pentosans yield pentose sugars on hydrolysis and probably possess a food value close to that of other polysaccharoses. Their wide distribution in plants gives them an importance as food constituents, and their determination is a usual part of food analysis, especially in connection with ordinary farm crops used as food for domestic animals. The principle of the analysis is that 
on hydrolysis with boiling acid the pentose sugar is obtained and the pentose sugar on boiling with acid (hydrochloric) is converted into furfural. The furfural forms an insoluble compound with phloroglucinol, which is weighed and the pentose and pentosan calculated from this.

\section{EXPERIMENT STUDY XXXV}

\section{Determination of Pentosans ${ }^{1}$}

Place $5.0 \mathrm{~g}$. of finely ground wheat or oat straw in a flask, together with I00 c.c. of I 2 per cent hydrochloric acid (specific gravity, I.06), and several pieces of recently heated pumice stone. Place the flask on a wire gauze, connect with a condenser, and heat, rather gently at first, and so regulate as to distill over 30 c.c. in about ten minutes, the distillate passing through a small filter paper. Replace the 30 c.c. driven over by a like quantity of the dilute acid added by means of a separatory funnel in such a manner as to wash down the particles adhering to the sides of the flask, and continue the process until the distillate amounts to 360 c.c. To the completed distillate gradually add a quantity of phloroglucinol (purified if necessary) dissolved in I 2 per cent hydrochloric acid and thoroughly stir the resulting mixture. The amount of phloroglucinol used should be about double that of the furfural expected. The solution first turns yellow, then green, and very soon an amorphous greenish precipitate appears, which grows rapidly darker, till it finally becomes almost black. Make the solution up to 400 c.c. with I 2 per cent hydrochloric acid, and allow to stand overnight.

Filter the amorphous black precipitate through an asbestos felt in a tared Gooch crucible, wash carefully with 150 c.c. of water in such a way that the water is not entirely removed from the crucible until the very last, then dry for four hours at the temperature of boiling water, cool and weigh, in a weighing bottle, the increase in weight being reckoned as phloroglucid. To calculate the furfural, pentose, or pentosan from the phloroglucid, use the following formulas given by Kröber :

${ }^{1}$ Official Methods of Analysis, A. O. A. C., U. S. Dept. Agr. Bur. Chem. Bul. ro7, p. 54 (I9 2). 
(a) For weight of phloroglucid " a" under 0.03 gram.

$$
\begin{aligned}
& \text { Furfural }=\left(a+0.005^{2}\right) \times 0.5170 \\
& \text { Pentoses }=\left(a+0.005^{2}\right) \times 1.0170 \\
& \text { Pentosans }=\left(a+0.005^{2}\right) \times 0.8949
\end{aligned}
$$

(b) For weight of phloroglucid " a " over 0.300 gram.

$$
\begin{aligned}
& \text { Furfural }=\left(a+0.005^{2}\right) \times 0.5180 \\
& \text { Pentoses }=\left(a+0.005^{2}\right) \times 1.0026 \\
& \text { Pentosans }=\left(a+0.005^{2}\right) \times 0.8824
\end{aligned}
$$

For weight of phloroglucid " a" from 0.03 to 0.300 grams use Kröber's table ${ }^{1}$ or the following formulas: ${ }^{2}$

$$
\begin{aligned}
& \text { Furfural }=\left(a+0.005^{2}\right) \times 0.5185 \\
& \text { Pentoses }=\left(a+0.005^{2}\right) \times 1.0075 \\
& \text { Pentosans }=\left(a+0.005^{2}\right) \times 0.8866
\end{aligned}
$$

\section{Sugars}

Both monosaccharoses and disaccharoses are found very widely distributed in the vegetable kingdom. They are all soluble compounds and are, therefore, found in the plant juices, especially in fruits.

Sucrose. - Of the three common disaccharose sugars, viz. sucrose or cane sugar, maltose or malt sugar and lactose or milk sugar, the first two are present in plants, while the last is found only in animals.

The most abundant disaccharose in plants is common cane sugar, or sucrose. Its most important sources are the juice of the sugar cane and of the sugar beet. From these two agricultural crops almost all of the sugar used as human food is obtained. This has all been fully discussed in the chapter on the chemistry of the carbohydrates (Chapter VII). Numerous other plants contain cane sugar in considerable quantity, but, with the exception of the sorghum cane and the sap of the hard or sugar maple, none of them serve as commercial sources of sugar.

${ }^{1}$ J. Landw. 48, 379, I900. See p. 226 of the above bulletin.

2 These factors were calculated from Kröber's tables by C. A. Browne. 
Whether cane sugar is originally formed in the plant from the monosaccharoses, glucose and fructose, is uncertain. From its wide distribution in plant juices it seems probable that it is a translocation form of carbohydrate from which the glucose and fructose in fruits are formed.

In all plants where cane sugar is present it is an important food material possessing approximately the same value as starch. Because of its abundance in sugar cane and sugar beet it is one of the most valuable of the carbohydrates found in agricultural crops. The amount present in some of the common crops will be seen from the table given later.

Maltose. - This disaccharose is a transition substance in the conversion, by diastase, of reserve starch into glucose and is found chiefly in sprouting grain or malt. It has also been found in the sap of green leaves. As it is simply transition material in plants it plays no large part in crops as a food substance. In malted grain produced artificially for the manufacture of alcohol by fermentation it is present in large amount. The waste mash from distilleries contains some unchanged maltose and glucose and is valuable as an animal food. In preparing some human cereal foods the grain is sometimes malted and in these maltose sugar is present.

Monosaccharoses. - The only two monosaccharoses that are present as such in plants are the two hexoses glucose and fructose. These two sugars occur in the leaf sap and, as has been stated, glucose is probably the first photosynthesized carbohydrate. Except in their physiological relations, the most important occurrence of glucose and fructose is not in the leaves but in the juice of fruits. In most fruit juices the two sugars occur together, from which fact we derive their common names of grape sugar and fruit sugar. In these juices they have probably been produced by the hydrolysis of cane sugar, which is undoubtedly their precursor. In almost all plant juices and in seeds some glucose and fructose are usually found. When present in plants, their food value is practically that of starch and the other sugars. 
The monosaccharoses mannose and galactose do not occur free in plants, but are derived by hydrolysis from the starchlike polysaccharoses mannan and galactan just considered. The same is true of the pentose monosaccharoses arabinose and xylose obtained from the pentosans.

Sugar Content of Crops. - The sugar content of crops is given in the following table:

\section{TABLE VIII}

Sugar Content of Crops

(Fresh Basis)

\begin{tabular}{|c|c|c|c|c|c|}
\hline Crop & SuCrose & INVERT SUGAR & Pectins & $\begin{array}{c}\text { ORGANIC } \\
\text { ACIDS }\end{array}$ & \\
\hline Sugar cane. & I $4.3($ I $5-20)$ & $\begin{array}{c}8.6 \\
\text { other carbo- } \\
\text { hydrates }\end{array}$ & & & König,pp. 896, 1507 1 \\
\hline Sugar beet . & I $2.3-17.4$ & $\begin{array}{c}2.9 \\
\text { other carbo- } \\
\text { hydrates }\end{array}$ & & & König, p. 76 I \\
\hline Sorghum cane & $7.0-12.0$ & & & & \\
\hline Maple sap. & $2.0-3.0$ & & & & \\
\hline Red beet . & 0.5 & & & & König, p. 777 \\
\hline Carrot . . & 6.4 & & & & König, p. 765 \\
\hline Sweet potato . & 2.3 & & & & König, p. I 495 \\
\hline Onion $\cdot$ & 5.8 & & & & König, p. 780 \\
\hline Cabbage . & 1.9 & & & & König, p. 790 \\
\hline Wheat. & 0.3 & .03 & .I6 Dextrin & & Bul. I3, p. $1_{207^{2}}$ \\
\hline Barley . & 0.2 & .02 & .I4 Dextrin & & Bul. I3, p. I 207 \\
\hline Rye • • . & 0.4 & .07 & .22 Dextrin & & Bul. I3, p. I 207 \\
\hline Oats. . & 0.2 & .03 & .26 Dextrin & & Bul. I3, p. 1 207 \\
\hline Apple & $0.9-6.0$ & $5.0-\mathrm{I} 4 . \mathrm{I}$ & 3.2 & $0.7-1.5$ & König, pp. 820, 854 \\
\hline Grape . . & & $\begin{array}{c}(\mathrm{I} 4.4) \\
\text { (total sugar) }\end{array}$ & I.I & 0.7 & König, p. 842 \\
\hline Peach . . & 5.6 & 3.6 & 0.5 & 0.7 & König, p. 829 \\
\hline Strawberry & I.I & 5.1 & & I.I & König, p. 840 \\
\hline Orange . . & 2.9 & 2.8 & & I.4 & König, p. 849 \\
\hline Lemon . . & & $\begin{array}{c}\text { (o.4) } \\
\text { (total sugar) }\end{array}$ & & 5.4 & König, p. 849 \\
\hline
\end{tabular}

1 König, l.c. (Table V).

2 “Bul. I3," U. S. Dept. Agr. Bur. Chem. Bul. I3, part ix (I898). 


\section{CHAPTER XVI}

\section{OCCURRENCE AND USES OF IMPORTANT CONSTITUENTS IN AGRICULTURAL P L A N T S (Continued)}

\section{FATS AND WAXES}

Plant Fats as Food. - In those crops used as food for domestic animals fats do not play so important a part as do either carbohydrates or proteins. They are present in much smaller amounts, in general, and in the case of herbivorous animals they contribute only a small amount to the total energy value of the food. It will be recalled also that body fat in animals is formed largely from carbohydrate and not from fat food. While this is true of most domestic animals, it is not true of human beings. Some of the plants or plant parts used by man as food contain large amounts of fat or oil, and from such sources a considerable part of the total energy of the body is derived.

Occurrence. - Fats, mostly as oils, occur usually as a reserve food in seeds, often largely replacing carbohydrates. They are also found, to some extent, but never in large amounts, in the vegetative organs, as in grasses, etc.

In seeds, which contain mostly starch, as the cereal grains, the fat is stored immediately around the germ so that when the germ is removed most of the fat goes with it. This is the reason for the high fat content of so-called germ meal. In seeds which are very rich in fat, as in the castor oil bean, cottonseed, flaxseed, olive, brazil mit, etc., the fat is variously distributed throughout the seed.

In the case of common crops, whether these are seeds, as the 
cereal grains, or vegetative parts, as the grasses, etc., there is usually no distinction made between fats and waxes, as both are in small amount, the value of the plant depending upon its food value as a whole. In other cases plants are valuable because of a certain fat- or wax-bearing part, as in the castor oil bean, or they may have a double value, one part serving as food or for industrial uses, while another part yields an oil which may also be used either as food or industrially, as in the case of the flaxseed and cottonseed.

Oil-yielding Plants. - The most important oil-producing plants are as follows :

Olive. - This is grown largely for the oil, which is expressed from the flesh of the fruit, the oil being then used as a food or for making soap. Some oil is also obtained from the kernel. The fruit itself is used directly as a food.

Cottonseed. - The cottonseed is a by-product from the cotton boll after the removal of the fiber. The oil is expressed from the seed and is used as food either directly as a substitute for olive oil or indirectly as a culinary article. After the oil is extracted from the seed the ground residue is known as cottonseed meal. It still contains considerable oil and also protein, and is largely used as a stock food.

Peanut. - The oil is obtained from the seed and is used as food. The seed itself is used as food either directly or in the form of peanut butter.

Sesame. - The seed of this plant and the oil obtained from it are both used as food, mostly in India. The extracted residue is used as a stock food similar to cottonseed meal.

Castor Bean. - This plant is grown wholly for the oil which is obtained from the seed. The oil is used both medicinally and as a lubricant. The extracted residue cannot be used as a stock food, but is used as a fertilizer and is called castor pomace.

Palm. - Both the fleshy part of the palm fruit and also the kernel are used for securing an oil used largely in making soap. The oils are called palm oil and palm mut oil and are solid at ordinary temperatures. 
TABLE IX

Fat Content of Crops

Ether Extract

\begin{tabular}{|c|c|c|c|c|c|}
\hline \multicolumn{3}{|l|}{ CROP } & $\begin{array}{l}\text { (FRESH } \\
\text { BASIS) }\end{array}$ & (DRY BASIS) & \\
\hline Olive, pulp . . & & & 56.4 & $74 \cdot 4$ & Molinari, p. 391 1 \\
\hline Olive seed (without & she & & I 2.3 & 13.1 & Molinari, p. 39r \\
\hline Castor oil bean . & . . & . . & $5 \mathrm{I} .4$ & $55 \cdot 3$ & König, p. $6 \mathrm{I}_{3}{ }^{2}$ \\
\hline Cacao bean . . & . . & . . & $44 \cdot 4$ & $47 \cdot 4$ & König, p. 1022 \\
\hline Palm nut. . . & . & . & 48.7 & 53.2 & König, p. 614 \\
\hline Cocoanut. . . & . . & . & 67.0 & $7 I . I$ & König, p. 6I6 \\
\hline Brazil nut . . . & . & . & 67.7 & 71.8 & König, p. 6I6 \\
\hline Peanut. . . . & . & . & 44.5 & 48.1 & König, p. 6I5 \\
\hline English walnut (dry) & & . & 58.5 & 63.0 & König, p. 6r I \\
\hline Sesame seed . . & . & . & 45.6 & 48.3 & König, p. 613 \\
\hline Sesame seed (cake). & . & & $10-15$ & & Molinari, p. 59r \\
\hline Cottonseed . . . & . & & I9.I & 22.0 & König, p. 6I 5 \\
\hline Cottonseed meal. & • & & $13.1(7.6)$ & I 4.2 & $\begin{array}{l}\text { J. \& W., pp. I } 2-19^{3} \text { (Mass. Exp. } \\
\text { Sta. p. }{ }_{46} \text { ) }\end{array}$ \\
\hline Flaxseed . . . . & & & 34.4 & 37.8 & König, p. 606 \\
\hline Linseed meal (new p & proc & cess) & $3.0(3.8)$ & 3.3 & $\begin{array}{l}\text { J. \& W., pp. 12-I9 (Mass. Exp. } \\
\text { Sta., p. 47) }\end{array}$ \\
\hline Linseed meal (old pr & roce & ess) & $7.9(7.0)$ & 8.6 & $\begin{array}{l}\text { J. \& W., pp. I } 2-\text { I } 9 \text { (Mass. Exp. } \\
\text { Sta., p. 47) }\end{array}$ \\
\hline Germ meal (maize) . & & . & 7.4 & 8.3 & J. \& W., pp. 12-19 \\
\hline Maize (flint) . . & & & 5.0 & 5.6 & J. \& W., pp. I2-19 \\
\hline Maize (sweet) & . & & 7.6 & 8.3 & J. \& W., pp. I 2-I9 \\
\hline Wheat (spring) & . & . & $2.2(2.23)$ & $2.5(2.48)$ & J. \& W., pp. I $2-19(\text { Bul. I } 20, \text { p. } 33)^{5}$ \\
\hline Wheat (winter) . & . & . & $2.1(\mathrm{I} .7 \mathrm{I})$ & $2.3(\mathrm{I} .9 \mathrm{I})$ & J. \& IV., pp. I 2-19 (Bul. I 20, p. 33) \\
\hline Sorghum grain . & . & . & $3.6(2.86)$ & $4 . I(3.25)$ & J. \& W., pp. I2-19 (Bul. I 20, p. 42) \\
\hline Barley . . . & . & . & I. 8 (1.69) & $2.0(\mathrm{I} .87)$ & J. \& W., pp. I 2-I9 (Bul. I 20, p. 36$)$ \\
\hline Rye . . . . & . & . & I.7 (I.66) & I.9 (I.83) & J. \& IV., pp. I2-I9 (Bul. I 20, p. 35) \\
\hline Oats... & . & • & $5.0(3.99)$ & $5.6(4.33)$ & J. \& W., pp. I2-I9 (Bul. I 20, p. 24) \\
\hline Rice . . . . . & . & . & 0.4 & 0.4 & J. \& W., pp. I2-Ig \\
\hline Wheat middlings & • & • & $4.0(5.3)$ & 4.5 & $\begin{array}{l}\text { J. \& W., pp. I } 2-19 \text { (Mass. Exp. } \\
\text { Sta., p. 50) }\end{array}$ \\
\hline Wheat bran . & - & • & $4.0(4.9)$ & $4 \cdot 5$ & $\begin{array}{l}\text { J. \& W., pp. I2-I9 (Mass. Exp. } \\
\text { Sta., p. 5I) }\end{array}$ \\
\hline Malt sprouts . & • & . & I.7 (I.3) & 1.9 & $\begin{array}{l}\text { J. \& W., pp. I 2-I9 (Mass. Exp. } \\
\text { Sta., p. 49) }\end{array}$ \\
\hline Wheat straw . & . & . & 1.3 & 1.4 & J. \& W., pp. I $2-19$ \\
\hline Oat straw. . & . & . & 2.3 & 2.5 & J. \& W., pp. I2-I9 \\
\hline Timothy grass . & . & . & 1.2 & 3.1 & J. \& W., pp. I2-I9 \\
\hline Timothy hay . . & . & . & 2.5 & 2.9 & J. \& W., pp. I2-I9 \\
\hline Red clover, grass. & . & . & I.I & 3.9 & J. \& IV., pp. I2-I9 \\
\hline Red clover hay . & . & . & 3.3 & 3.9 & J. \& V., pp. 12-19 \\
\hline Alfalfa, grass. . & . & . & I.O & 3.4 & J. \& W., pp. 12-19 \\
\hline Alfalfa hay . & & . & 2.2 & 2.4 & J. \& IV., pp. 12-I9 \\
\hline Cowpeas (cured) & - & . & 2.9 & 3.2 & J. \& W., pp. I2-I9 \\
\hline Cowpeas (peas) & . & . & I. 4 & I.7 & J. \& IV., pp. I2-19 \\
\hline Soja bean. . . & & . & I6.9 & I 8.9 & J. \& IV., pp. I 2-I9 \\
\hline Maize fodder (cured) & & . & 1.6 & 2.8 & J. \& IV., pp. I 2-I9 \\
\hline Maize stover (cured) & & . & I.I & 1.7 & J. \& IV., pp. I $2-19$ \\
\hline Maize stalks (cured) & & . & 0.5 & I. 6 & J. \& IV., pp. I 2-I9 \\
\hline
\end{tabular}

${ }^{1}$ Molinari, l.c. (Table V). ${ }^{2}$ König, l.c. (Table V). ${ }^{3}$ J. \& W., l.c. (Table V). ${ }^{4}$ Mass. Exp. Sta., l.c. (Table VI). $\quad{ }^{5}$ Bul. I 20, l.c. (Table V). 
Cocoanut. - The fruit of the cocoanut palm yields a solid oil used mostly in making soaps but also somewhat as a food, the entire fleshy part of the nut being used also as food.

Cacao. - The solid oil or fat obtained from the cacao bean is known as cacao butter. It is a by-product in the manufacture of chocolate, etc. It is used mostly as a toilet article and in soap making.

Flaxseed. - This seed is a by-product from flax grown for the fiber for the manufacture of linen. The oil obtained from the seed is known as linseed oil. It is a drying oil and is used in varnishes and paints. It is not a food.

Maize. - The oil extracted from the germ of corn, separated in the milling of the grain, is used as an edible oil to some extent and also as a semi-drying oil and in making soaps. The extracted germ meal is used as stock food.

Fat Content of Crops. - The fat content of crops is given in the above table. The figures are those for the ordinarily determined "ether extract" and thus do not represent pure fat. They include other minor constituents such as waxes, chlorophyll and some of the organic acids.

\section{Lecithin and Phytosterol}

Closely associated with the fats, though not strictly classed with them, are two substances of considerable importance in both plants and animals. They are phytosterol and lecithin.

Phytosterol and Cholesterol. - Phytosterol is a monatomic alcohol of high carbon content which is present in plants. The formula assigned to it is $\mathrm{C}_{27} \mathrm{H}_{45} \mathrm{OH}$, though a phytosterol obtained from Calabar beans has been given the formula $\mathrm{C}_{30} \mathrm{H}_{47} \mathrm{OH}$, on account of which it is distinguished as stigmasterol. Phytosterol occurs in practically all vegetable fats. It is most abundant in pea fat and the fat of the Calabar bean. In most vegetable fats it amounts to o.I-0.3 per cent. A substance isomeric with phytosterol but found in animals, especially in wool fat, is known as cholesterol. It occurs normally in all cells, in blood and in lymph. It is present in largest amounts in brain and 
nerve tissue. Its occurrence here is thought to be connected with the other substance which we have referred to, viz. lecithin. It is also thought to be connected with the action of certain toxins. It is found in the bile, where it causes the formation of a certain kind of gall stone. The constitutional formula for these two compounds has not been fully established, but they are probably secondary alcohols containing both an unsaturated group and a hexahydrobenzene ring, and related to the terpenes. Therefore, without going into details, we may simply say that monatomic alcohols of high carbon content known as phytosterol and stigmasterol in plants and cholesterol in animals are found associated with vegetable and animal fats.

These alcohols are non-saponifiable, so that when fats containing them are saponified they remain as unsaponifiable matter. In analytical determinations of fats the unsaponifiable matter, as usually determined, consists largely of these compounds. They are soluble in ether and in alcohol and may be removed from a saponified fat by extraction with ether.

Phytosterol and cholesterol are very similar in all their properties and have melting points very close together. They cannot, therefore, be separated or identified by determining their melting points. They each yield an ester with acetic acid, however, and these esters have distinctly different melting points which thus makes it possible to identify them.

Cholesterol acetate . . . . . m. p. II $4.3^{\circ}-$ II $4.8^{\circ}$
Phytosterol acetate . . . . . m. p. I $25^{\circ}-\mathrm{I} 37^{\circ}$

It is possible that this difference in melting point is due to the fact that phytosterol is not an individual compound but a mixture of several similar ones such as stigmasterol.

The importance of these two compounds is mainly in the fact that the presence of phytosterol in a fat establishes the fat as of vegetable origin, while cholesterol is present only in animal fats. As to their food value nothing is known. It is probable that the cholesterol in animals is derived from the phytosterol in the plants which the animal uses as food. If 
this is so the importance of phytosterol in plants as a source of cholesterol in animals is connected with the antitoxic action of cholesterol of which we shall soon speak.

Lecithin. - This substance is definitely related to fats in its constitution, as it is an ester of glycerol. Fats, it will be recalled, are neutral or tri-acid esters of glycerol, i.e. all three of the glycerol hydroxyl hydrogens are replaced by fatty acid radicals Lecithin is like the fats in being a neutral or tri-acid ester but, while in fats all of the hydroxyl hydrogens are replaced by fatty acid radicals, in lecithin only two of the three are thus replaced by fatty acid radicals. The third is replaced by the phosphoric acid radical. In addition to this the phosphoric acid radical has one of its remaining acid hydrogens replaced by a basic radical of a compound known as choline. This choline is not a simple alcohol but is a tri-methyl-hydroxy-ethyl ammonium hydroxide compound. Thus in lecithin there are four distinct parts, viz. (a) glycerol; (b) fatty acid, usually stearic, palmitic or oleic; (c) phosphoric acid; (d) choline, a nitrogen (amine) base. On hydrolysis lecithin yields all four of these parts and this hydrolysis is produced enzymatically by the fat-splitting enzyme lipase. Lecithin belongs to a group of compounds known as phospho-lipines, which signifies fat-like bodies containing phosphorus and also nitrogen (amine).

The chief source of lecithin is the yolk of eggs, from which fact the name lecithin is derived. It is also, like cholesterol, a normal constituent of the living cell and is found in blood, lymph and muscle tissue. It is also often associated with fats, especially in brain, nerve tissue and eggs. In plants it is found in the seeds especially of legumes and cereals.

The amounts of lecithin in some of these substances are as follows :

Egg yolk . . . . . 9.4 per cent

Liver

Blood

Legume seeds .

Cereal grains .
2.I per cent

r.8 per cent

0.8-r.6 per cent

$0.25^{-0.53}$ per cent 
Physiological Function. - Physiologically lecithin is very important. We have spoken of the fact that it is hydrolyzed by the enzyme lipase and in the animal body the lecithin of plant food is probably digested and absorbed in much the same way as fats. If the lecithin of animals, essential to the living cell and nerve tissue, is derived in the case of herbivorous animals entirely from plant lecithin, it thus becomes an essential food constituent. The generally accepted connection between organic phosphorus (lecithin compounds) in food and the building of brain and nerve tissue is based upon these facts.

We know nothing in regard to the metabolism of lecithin and only very little in regard to its probable function in the living cell. Recent work upon certain toxic substances, e.g. the toxins of cobra poison and of tetanus, leads to the view that lecithin acts as an accelerator to these toxins. Its general physiological action is perhaps of a like nature, that is, it acts as an accelerator to the activity of enzymes. We spoke of the fact that cholesterol acts as an antitoxin. Toward lecithin it acts in such a way that it prevents the accelerating action of lecithin upon these toxins. We thus see how intimately these two compounds are connected with each other, and though we know relatively little as yet in regard to them, their importance is at least indicated.

\section{PROTEINS}

Proteins differ from carbohydrates in not being an abundant constituent of plants, though they are, nevertheless, a universal and essential constituent. In animals, on the contrary, proteins are the abundant constituent. All protoplasmic cell contents of plants contain protein, and as proteins differ in composition from carbohydrates and fats in containing the element nitrogen this element becomes an essential plant food constituent.

Forms of Proteins. - We have previously stated that proteins are synthesized in the leaves of plants, but they are found 
in the cell contents, in cell sap, in plant juices and as reserve food in seeds, roots, etc. In these different localities we find proteins existing in three different states or forms: (I) in solution in the cell sap or plant juices; (2) in crystalline form in the cell contents or in reserve organs; (3) in amorphous solid bodies as reserve food in seeds. The two solid forms, crystalline and amorphous, in which they occur as reserve food in seeds, roots, etc., may be either pure or mixed, i.e. partly crystalline and partly amorphous. The solid protein bodies resulting are known as aleuron grains. They are found in a certain layer in the seed known as the aleuron layer, as in castor oil bean, wheat grain, etc. The structure of these aleuron grains is often complex, but they consist usually of solid protein inclosed in a less soluble protein membrane and the whole body has a distinctly granular appearance. Several different proteins may be present in one aleuron grain, but the most common one is a globulin. In most seeds the aleuron layer is directly beneath the outer seed coat.

Occurrence. - Proteins occur principally in the seeds of plants and are most abundant in the seeds of legumes and cereals. Crops yielding these seeds are thus of especial importance as food for domestic animals, for while carbohydrates and fats furnish the greater part of the energy value of foods it is from plant protein alone that herbivorous animals must build their own body protein.

In discussing the chemical nature of proteins we stated that they yield amino-acids on hydrolysis. The principal aminoacids obtained from vegetable proteins differ from those that are obtained from proteins of animal origin. Thus, glutaminic acid, proline and arginine are obtained in larger amounts from vegetable proteins. Also alcohol soluble proteins, e.g. gliadin of wheat, are found only in plants. On the other hand, some amino-acids are obtained only from animal proteins. These differences in the two classes of proteins evidently affect their food value, but at present we do not know enough in this regard to warrant further discussion. 
TABLE $\mathrm{X}$

\section{Protein Content of Crops}

\begin{tabular}{|c|c|c|c|c|c|c|}
\hline \multirow{2}{*}{\multicolumn{4}{|c|}{ CROP }} & \multicolumn{2}{|c|}{ PROTEIN $(\mathrm{N} \times 6.25)$} & \\
\hline & & & & \multirow{2}{*}{$\frac{\text { (Fresh Basis) }}{42.3(40.2)}$} & \multirow{2}{*}{$\frac{\text { (Dry Basis) }}{4^{6.1}}$} & \\
\hline Cottonseed meal. & & - & - $\cdot$ & & & $\begin{array}{l}\text { J. \& W., pp. I } 2-19^{1} \text { (Mass. Exp. } \\
\text { Sta., p. 46) }\end{array}$ \\
\hline Linseed meal (nev & w p & roc & cess) & $33.2(36.5)$ & 36.9 & $\begin{array}{l}\text { J. \& W., pp. I2-I9 (Mass. Exp. } \\
\text { Sta., p. 47) }\end{array}$ \\
\hline Linseed meal (old & $1 \mathrm{pr}$ & roce & ess) & $32.9(33.6)$ & 35.2 & $\begin{array}{l}\text { J. \& W., pp. I 2-I } 9 \text { (Mass. Exp. } \\
\text { Sta., p. 47) }\end{array}$ \\
\hline Gluten meal . & - & . & $\cdot \cdot$ & $41.3(24.9)$ & 32.5 & $\begin{array}{l}\text { J. \& W., pp. I2-I9 (Mass. Exp. } \\
\text { Sta., p. 47) }\end{array}$ \\
\hline Malt sprouts . & • & • & • & $23.2(26.6)$ & 25.8 & $\begin{array}{l}\text { J. \& W., pp. I 2-I9 (Mass. Exp. } \\
\text { Sta., p. 49) }\end{array}$ \\
\hline Wheat bran . & - & • & - $\cdot$ & I $5.4($ I6.5) & I $7 \cdot 4$ & $\begin{array}{l}\text { J. \& W., pp. I2-I9 (Mass. Exp. } \\
\text { Sta., p. 5r) }\end{array}$ \\
\hline Wheat middlings & & • & . $\cdot$ & $15.6(17.8)$ & I 7.8 & $\begin{array}{l}\text { J. \& W., pp. I } 2-19 \text { (Mass. Exp. } \\
\text { Sta., p. 50) }\end{array}$ \\
\hline Germ meal $\cdot$ - & & & $\cdot \cdot$ & 9.8 & II.O & J. \& W., pp. 1 $2-19$ \\
\hline Sesame seed (cake & & & - & $35-40$ & & Molinari, p. $59 \mathrm{r}^{3}$ \\
\hline $\begin{array}{l}\text { Brazil nut. . } \\
\text { Peanut. }\end{array}$ & • & & • & I 5.5 & 16.5 & König, p. 616 $6^{4}$ \\
\hline $\begin{array}{l}\text { Peanut } \cdot \text { English walnut } \\
\text { E }\end{array}$ & $\cdot$ & . & . & $\begin{array}{l}27.5 \\
16.7\end{array}$ & $\begin{array}{l}29.7 \\
18.0\end{array}$ & $\begin{array}{l}\text { König, p. 6I5 } \\
\text { König, p. 6II }\end{array}$ \\
\hline & & & $\cdot$ & 20.8 & $\begin{array}{l}18.0 \\
24.4\end{array}$ & J. \& W., pp. 12-19 \\
\hline Soja bean . . & • & & . & 34.0 & 38.1 & J. \& W., pp. I2-19 \\
\hline Oats . $\cdot \cdot$ & & & - & II.8( ( 2.7$)$ & I3.2 (I3.8) & J. \& W., pp. I2-I9 (Bull. I20, \\
\hline Wheat (spring) & & & - & I $2.5(13.3)$ & I 3.9 ( ( 4.8$)$ & J. \& W., pp. I 2-19 (Bul. I 20, p. 33) \\
\hline Wheat (winter) & • & & - . & II. $8($ (10.7) & I3.I（I I.9） & J. \& W., pp. I 2-I9 (Bul. I 20. p. 33) \\
\hline Rye · • · · & & & - & $10.6($ I 2.2$)$ & I2.0 (I 3.4$)$ & J. \& W., pp. I 2-I 9 (Bul. I 20. p.35) \\
\hline Barley · · & & & - & I $2.4($ I $2 . \mathrm{I})$ & I3.9 (I 3.4$)$ & J. \& W., pp. I 2-I9 (Bul. I 20, p. 36) \\
\hline Sorghum : · & • & & . & 9.1 (10.3) & I0.4 (II.7) & J. \& W.,pp. I 2-I9 (Bul. I 20, p. 42) \\
\hline Maize (flint) . & . & & . & 10.5 & I I. 8 & J. \& W., pp. I 2-19 \\
\hline Maize (sweet) & • & & - & I 2.8 & I 4.0 & J. \& W., pp. I2-I9 \\
\hline Rice · · · · & • & & $\dot{*}$ & $\begin{array}{l}7.4 \\
4.8\end{array}$ & 8.5 & J. \& W., pp. I $2-19$ \\
\hline $\begin{array}{l}\text { Alfalfa, grass . } \\
\text { Alfalfa hay : }\end{array}$ & . & & $\cdot$ & $\begin{array}{r}4.8 \\
\mathbf{1} 4 \cdot 3\end{array}$ & $\begin{array}{l}\text { I } 7.1 \\
\text { I } 5.6\end{array}$ & $\begin{array}{l}\text { J. \& W., pp. I } 2-19 \\
\text { J. \& WW., pp. I } 2-19\end{array}$ \\
\hline $\begin{array}{l}\text { Alfalfa hay } \\
\text { Red clover, grass }\end{array}$ & & & : & $\begin{array}{r}\mathbf{1} 4 \cdot 3 \\
4 \cdot 4\end{array}$ & $\begin{array}{l}15.6 \\
15.3\end{array}$ & $\begin{array}{l}\text { J. \& W., pp. I } 2-19 \\
\text { J. \& W., pp. I } 2-I 9\end{array}$ \\
\hline Red clover hay . & . & & . $\cdot$ & 12.3 & 14.5 & J. \& W., pp. I $2-19$ \\
\hline Timothy grass & & & - & 3.I & 8.0 & J. \& W., pp. I 2-I9 \\
\hline Timothy hay . . & . . & & - . & 5.9 & 6.8 & J. \& W., pp. I2-I9 \\
\hline Maize fodder (cur & red) & & - $\cdot$ & $4 \cdot 5$ & 7.8 & J. \& W., pp. 12-I9 \\
\hline Maize stover (cure & red) & & · & 3.8 & 6.5 & J. \& W., pp. I2-r9 \\
\hline Maize stalks (cure & ed) & & - & I.9 & 5.9 & J. \& W., pp. I 2-I9 \\
\hline Potatoes . . & - . & & · & 2.1 & IO.I & J. \& W., pp. I2-r9 \\
\hline Sweet potatoes & · & & - & I. 5 & 5.2 & $\begin{array}{l}\text { J. \& W., pp. I 2-I9 } \\
\text { J. \& W.,PD. I2-19 }\end{array}$ \\
\hline $\begin{array}{l}\text { Turnips . : } \\
\text { Mangels : }\end{array}$ & • & & . & $\begin{array}{l}\text { I.I } \\
\text { I.4 }\end{array}$ & $\begin{array}{l}12.4 \\
15.2\end{array}$ & $\begin{array}{l}\text { J. \& W., pp. 12-I9 } \\
\text { J. \& WW., pp. 12-I9 }\end{array}$ \\
\hline Rutabaga . . & • & & . & $\begin{array}{l}1.4 \\
\mathrm{I} .2\end{array}$ & $\begin{array}{l}15.2 \\
10.4\end{array}$ & J. \& W., pp. 12-19 \\
\hline Red beets . . & $\cdot$ & • & - & 1.5 & I 3.4 & J. \& W., pp. I2-r9 \\
\hline Sugar beets & . & · & $\cdot \cdot$ & I. 8 & I 3.0 & J. \& W., pp. I $2-19$ \\
\hline
\end{tabular}

1 J. \& W., l.c. (Table V). 3 Molinari, l.c. (Table V).

${ }^{5}$ Bul. I 20, l.c. (Table V). protein.
2 Mass. Exp. Sta., l.c. (Table VI).

${ }^{4} \mathrm{König}$, l.c. (Table V).

In this bulletin the factor $\mathrm{N} \times 5.7$ is used for wheat 
Protein Content of Crops. - The protein content of some of the different crops is given in the preceding table. The figures represent crude protein as determined by multiplying the nitrogen per cent by the factor 6.25. This includes, with the proteins, the amino-acids, but these are not of any large amount except in the cases of green crops and root crops and in malt sprouts.

\section{AMINO-ACIDS, ALKALOIDS, ESSENTIAL OILS, TER- PENES, TANNINS, ETC.}

We have thus far discussed the occurrence in plants of the three essential organic food constituents together with a few related compounds of industrial or physiological importance. These are by far the most important plant constituents, especially from an agricultural viewpoint, for plants considered agriculturally are chiefly used as food. When not used as food they are generally used for the manufacture of valuable products. All of these uses have been as fully considered as is desirable.

There remain, however, several groups of substances found in plants which are of considerable importance.

End Products of Metabolism. - In animal metabolism proteins are broken down by the katabolic process into simpler compounds with the liberation of energy. The nitrogen-containing compounds which are thus formed are carried off in the urine, as true excretion products, in the form of urea and related compounds. In plants protein cell food is probably katabolized in a similar way, but the nitrogen-containing products are not cast off from the plant as true excretion substances. It is possible that amino-acids are excreted as such, but in many cases these amino-acids or other complexes derived from the protein molecule are not excreted, but are further metabolized into end products which remain in the plant. Such characteristic compounds as caffeine, theobromine, strychnine, morphine. 
skatol, indigo, and certain essential oils like vanillin, are without doubt formed in this way.

Amino-acids. - In regard to the occurrence of amino-acids themselves in plants it may be stated that about eight have been isolated. A recent view in regard to the occurrence of these acids and other probable products of protein metabolism in plants and soil is, that these excretion products, when present in the soil, act as toxins to the plant itself. As previously stated also (p. 250) amino-acids in the soil may, in some cases, be used by plants as a direct source of nitrogen for the synthesis of plant protein. The amino-acids present in the plant itself also function in the resynthesis of plant protein.

Alkaloids, Essential Oils, Terpenes, Tannins, etc. - Of these different groups of compounds some are of importance medicinally, some have a very great value as perfumes, etc., and others in various ways. They include substances known as alkaloids, e.g. quinine, morphine (from opium), nicotine, strychnine, brucine, etc. These are all valuable medicines. Also substances known as essential oils, e.g. oil of peppermint, oil of cloves, oil of rose, heliotrope, vanillin (vanilla), etc. These are used as constituents of perfumes or flavors and some of them also medicinally. Then we have the group known as terpenes, including lemon oil, turpentine and camphor, and finally the tannins, used in leather manufacture and obtained from the bark of hemlock, oak and other trees.

These various compounds belong mostly to the more complex groups of organic compounds and in most cases are physiologically related to the plant as end products of metabolism, as just discussed. They are of great economic value, and the plants producing them are grown as agricultural crops in certain more or less restricted localities. In general, however, they are not important agriculturally. 


\section{CHAPTER XVII}

\section{A NIMA FOODSAND FEEDING}

\section{FOOD VALUE}

IN the study of the physiological processes of plants and animals we have brought out the following general facts. By utilizing the energy of the sunlight, living plants manufacture carbohydrates out of the simple substances carbon dioxide and water, which are present in the atmosphere and the soil. These photosynthesized carbohydrates by further metabolic changes in the plant are transformed, in part, into the vegetable fats and, with the assistance of nitrogen compounds obtained in most cases from the soil in the form of nitrates, are in part transformed into proteins. In this way the plant builds up its own food supply and stores up a reserve supply of food for its offspring. This reserve food may also become a source of food for animals. These essential organic food constituents all possess potential energy which, through the processes of animal metabolism, becomes converted into the kinetic energy of animal heat or muscular work. This intimate relation between plants and animals is the important one of food and nutrition.

In our study of animal physiology we discussed the processes by which these food constituents - carbohydrates, fats and proteins - were digested and then metabolized in order to yield the energy of animal life. The chemical reaction involved in the liberation of this energy is that of oxidation brought about by the process of respiration, by which the oxygen of the air is brought into contact with the digested, assimilated and partially metabolized food materials.

Quantitative Relation of Food to Energy. - We have now to consider the quantitative relation of this food to the energy of the 
living animal, that is, the relation between the food eaten and the result produced in the form of energy. In the case of domestic animals, however, with the exception of the horse and other draft animals, the ultimate production of energy is not the only result to be obtained by feeding. In all young growing animals a part of the food is used for the building of body substance, and this is also true of sheep, cows and poultry or other animals producing wool, milk, eggs, etc. In the case of fattening animals, also, part of the food is used for the production of stored body fat. Whether the food, however, is used entirely for the production of energy or partly for building body protein or storing body fat, the value of the food is always measured in terms of energy.

\section{Digestibility of Food Constituents}

In considering the relation of food to the energy produced, i.e. the value of the food, the first factor to be taken account of is the digestibility, or the amount of the different food materials actually digested in the animal body. If we consider pure food constituents, that is, pure carbohydrates, pure fats or pure proteins, it might seem natural to suppose that the animal body would completely digest and absorb each constituent. Yet, it will not be surprising to know that, even under the most favorable conditions, the animal body is not thus able to digest all of any pure food constituent. In all cases the amount digested is something less than roo per cent.

Coefficient of Digestibility. - Thus we have for each food constituent what is termed the coefficient of digestibility, which expresses the percentage amount of the food constituent which the animal does actually digest and absorb. For example, the human body, when fed carbohydrate food in the form of starch in cooked cereal grains or as bread, is able to digest approximately 98 per cent of it. This figure, then, is the coefficient of digestibility for carbohydrate food in this form for man.

This coefficient of digestibility is determined directly, by 


\begin{tabular}{|c|c|c|c|c|}
\hline & & ${ }_{9}{ }_{\mathrm{SP}} \mathrm{d}$ & 넷ㅇㅇㅇ & \\
\hline & 䍠 & g әZ!E & 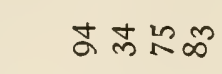 & \\
\hline & & І РЕәЧМ & 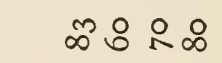 & \\
\hline & 苗 & 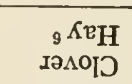 & J tin in in & \\
\hline & 思 & $\begin{aligned}{ }_{9}^{K \varepsilon H} \\
\text { Кqроu!! }\end{aligned}$ & 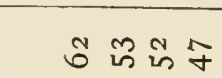 & \\
\hline & & 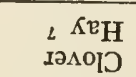 & 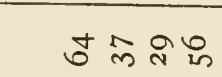 & \\
\hline & & 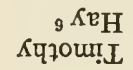 & 字午字出 & \\
\hline & 萨 & 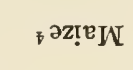 & 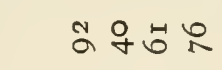 & 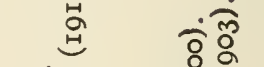 \\
\hline 曷 & & ${ }^{5} \mathrm{St} P \mathrm{O}$ & ำㄴำ용 & ô: \\
\hline 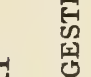 & & 87 РЕч $M$ & 놋요숑 & 峁客 \\
\hline A & & 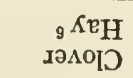 & J & 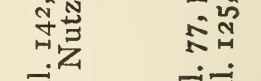 \\
\hline$\stackrel{\mathscr{H}}{\mathrm{H}}$ & & 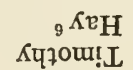 & ช้ in in F & 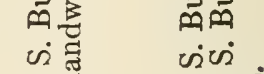 \\
\hline$\sum_{\substack{|=1\\
|=1}}$ & 崽 & $\varepsilon$ əZI़४ & 2n & 0.0000 \\
\hline v & & $\& \mathrm{~s}^{\mathrm{s}} \mathrm{e}$ & $\stackrel{\sim}{\infty} \infty \stackrel{\sim}{\infty}$ & 五蛋 \\
\hline & & $87.2 \% 4 M$ & ๙ูチの゙ & $<.020<<\frac{0}{0}$ \\
\hline & 宓 & г ә8вгәлу & ณ นู สู & 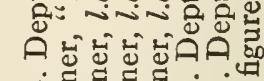 \\
\hline & 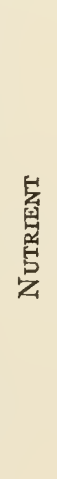 & & 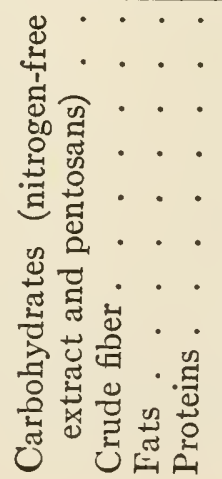 & 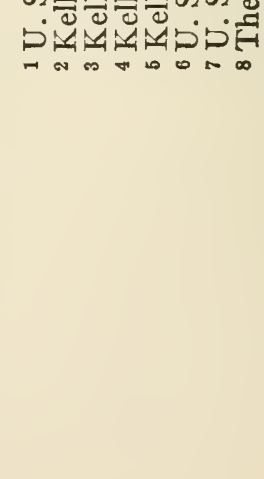 \\
\hline
\end{tabular}


experiment, by subtracting from the amount of food eaten the amount present in the fæcal excrement, as it is in this excrement that the undigested food material remains.

The digestibility of a food constituent will vary also according to the condition in which it is fed, as, for example, whether it is mixed with a large amount of other material, or, in the case of human foods, whether it is raw or cooked. While this is important, it does not alter the actual amount digested so much as it does the rapidity or ease of digestion. In general, the coefficients of digestibility refer to a food constituent in the usual form in which it is eaten. For man therefore the coefficient of digestibility of starch refers to cooked starch, while for domestic animals it refers to raw starch as present in cereal grains, etc. For cattle the average digestibility of starch in corn or wheat is almost as high as for man, viz. 92-95 per cent, while in other animal foods, such as oats and hay, the digestibility of nitrogen-free extract falls as low as 62 per cent and with horses and sheep from 47 to 62 per cent.

We see, therefore, that the particular species of animal and even the particular individual animal may possess a different coefficient of digestibility. To obtain absolute figures therefore for the coefficients of digestibility a great deal of experimentation is required. We can, however, take certain average results and use them in calculating the digestibility of foods and their food value.

Without going more into detail the data in the preceding table represents the average results of experimental evidence on the subject.

Application of Coefficients of Digestibility. - From these coefficients of digestibility we can readily calculate, from the percentage composition of a food, the exact amount of each of the food constituents which an animal actually digests. The following examples will illustrate: 


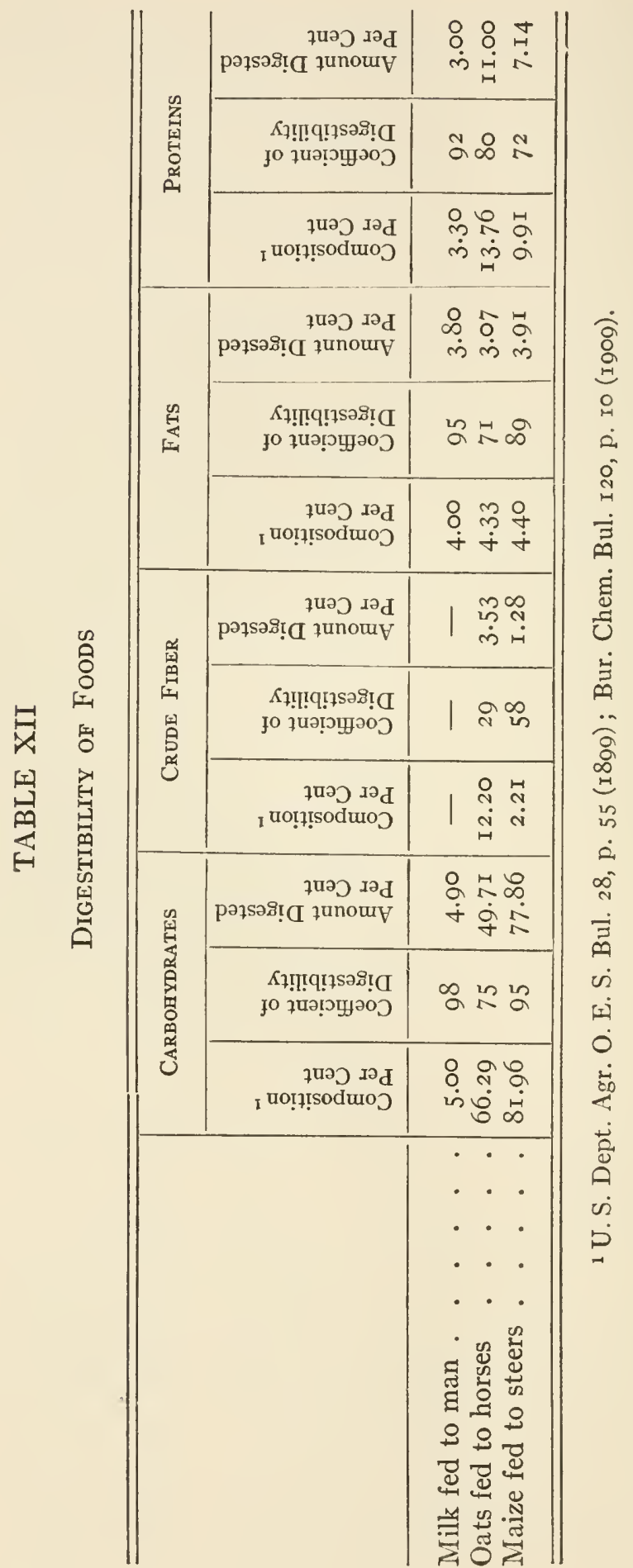


Thus, with any food of which an analysis has been made, we can determine the amount digested, provided we have coefficients of digestibility which apply. In some cases where the identical food or animal has not been subject to experiment it is necessary to use the data most nearly corresponding; e.g. wheat for horses, in the table of coefficients, is given as "figures obtained with oats."

\section{Energy Value of Food Constituents}

Having then determined the amount of food constituents which an animal digests, the next step is to find out how much energy this digested food will yield. We have previously said that whether animal food yields energy directly or is used to build body substance, eventually, in most cases, the final result is energy, as the body substance is later torn down and energy is set free. Also that whether this energy is manifested as heat or as muscular work, the units for expressing the energy are always in terms of heat. The liberation of energy in the animal body is by the reaction of oxidation and this reaction is easily carried out in accurate physical apparatus which allows the exact determination of the energy liberated. In such reactions the substance burns and the heat produced by this burning is the measurement of the energy of the substance.

Fuel Value. - This we term the combustion value or fuel value of the substance, and this fuel value, which we express in heat units, represents the energy value which, in a food substance, means the food value. Therefore the fuel value of a food constituent or any substance used as food is equivalent to its possible food value.

Bomb Calorimeter. - This determination of the fuel value or food value of food substances is made in a piece of apparatus known as a bomb calorimeter. Speaking very generally, this consists of a heavy thick-walled metallic cylinder or bomb. This is so constructed that a substance placed within it may be ignited and burned, usually in pure oxygen gas under pressure, and the heat generated by this combustion is determined 
by measuring the rise in temperature accurately to $.00 \mathrm{I}^{\circ} \mathrm{C}$. which takes place in a large volume of water in which the bomb is immersed. ${ }^{1}$

Calorie. - The rise in temperature produced by the combustion is calculated in units of heat energy known as calories. A calorie is the amount of heat necessary to raise the temperature of $I .0$ gram of water $I^{\circ} C$. In the absolute calorie unit this rise of temperature is from $15^{\circ} \mathrm{C}$. to $16^{\circ} \mathrm{C}$., but the unit may be defined in slightly more general terms, as first given. This unit is small and in practice is multiplied by rooo; i.e. it is the heat necessary to raise $1000 \mathrm{~g}$. of water $\mathrm{I}^{\circ} \mathrm{C}$. To distinguish these two units they are termed respectively the small calorie or gram calorie, written without capitals, and the large calorie written capitalized or Calorie. Still a third unit has been suggested by Armsby known as the Therm (T.), which is equivalent to 1000 Calories or $1,000,000$ gram calories. This is used mostly in calculating large feeding rations of domestic animals. In calculating human foods the unit usually employed is the Calorie (large calorie). In English standards the Calorie is approximately equivalent to the amount of heat necessary to raise I pound of water $4^{\circ} \mathrm{F}$.

Thus the Calorie is the unit in which the energy value or food value of a food is expressed. It will often be found referred to in other terms, as we have mentioned, viz. fuel value, calorific value or heat of combustion. All of these terms are, therefore, synonymous as applied to foods, with the corrections which we shall now consider.

Fuel Values in Calories. - What then are the fuel values in Calories of the three food constituents? While all figures determined do not agree exactly, the ones usually accepted at present are as follows:

I gram Carbohydrates yields 4.I Cal.

I gram Fats yields 9.45 Cal.

I gram Proteins yields 5.65 Cal.

1 A detailed description of this apparatus may be found in U. S. Dept. Agr. O. E. S. Bul. 2I (I895), or in J. Am. Chem. Soc., XXV, 659 (I903). 
These are the results which have been obtained in the bomb calorimeter. If, therefore, these food constituents are burned in the animal body in a similar manner as in the calorimeter, then these figures apply directly to that portion of the food that is actually digested.

Corrected Fuel Values. - In discussing the metabolism of these constituents we showed that in the case of carbohydrates and fats the processes in the body and in the calorimeter are similar; i.e. the constituents are in both cases completely oxidized to carbon dioxide and water. The figures for these two constituents hold therefore for the digestible portion. In the case of proteins, however, katabolism does not yield the simple products of oxidation which are obtained by burning in the calorimeter. Part of the products of the katabolism of proteins are the complex nitrogen compounds excreted in the urine, and these compounds still contain some of the potential energy of the original proteins. It has been found that the amount of energy contained in these excretion products, and thus not liberated when proteins are burned in the body, is equivalent to approximately I.3 Cal. per gram of protein. The fuel value of proteins, as obtained in the calorimeter, must be reduced therefore by this amount, so that,

Fuel value (in bomb) of proteins 5.65 Cal. - r.3 Cal. $=4.35 \mathrm{Cal} .=$ fuel value (in body) or food value

The corrected values then become,

I gram digested Carbohydrates yields in body 4.I Cal.

I gram digested Fats yields in body 9.45 Cal.

I gram digested Proteins yields in body $\quad 4.35 \mathrm{Cal}$.

Metabolizable or Available Energy. - In man the coefficients of digestibility have been determined on the average mixed diet, and as human beings probably differ less in these coefficients than do different species of animals, it is possible to apply these coefficients not to each food and each individual but once for all to the food values in calories. Doing this, we obtain the following : 
I gram Carbohydrates, as eaten, yields 98 per cent of $4 . \mathrm{I}=$

I gram Fats, as eaten, yields 95 per cent of $9.45=9.0 \mathrm{Cal}$. I gram Proteins, as eaten, yields 92 per cent of $4.35=4.0 \mathrm{Cal}$.

These figures represent the energy in Calories which the human body actually uses, i.e. which is available for metabolization from each gram of the constituent as eaten. These results have been designated by different names, viz. physiological fuel value, metabolizable energy or available energy. The figures given are for man and are in Calories per gram. Similar data have been obtained for domestic animals, and it is also often desirable to express them in English standards, viz. Calories per pound. In all calculations for the conversion of grams into pounds, 453.6 grams $=$ I pound. ${ }^{1}$

The following table gives all of these data together:

\section{TABLE XIII}

Fuel Values of Food Constituents

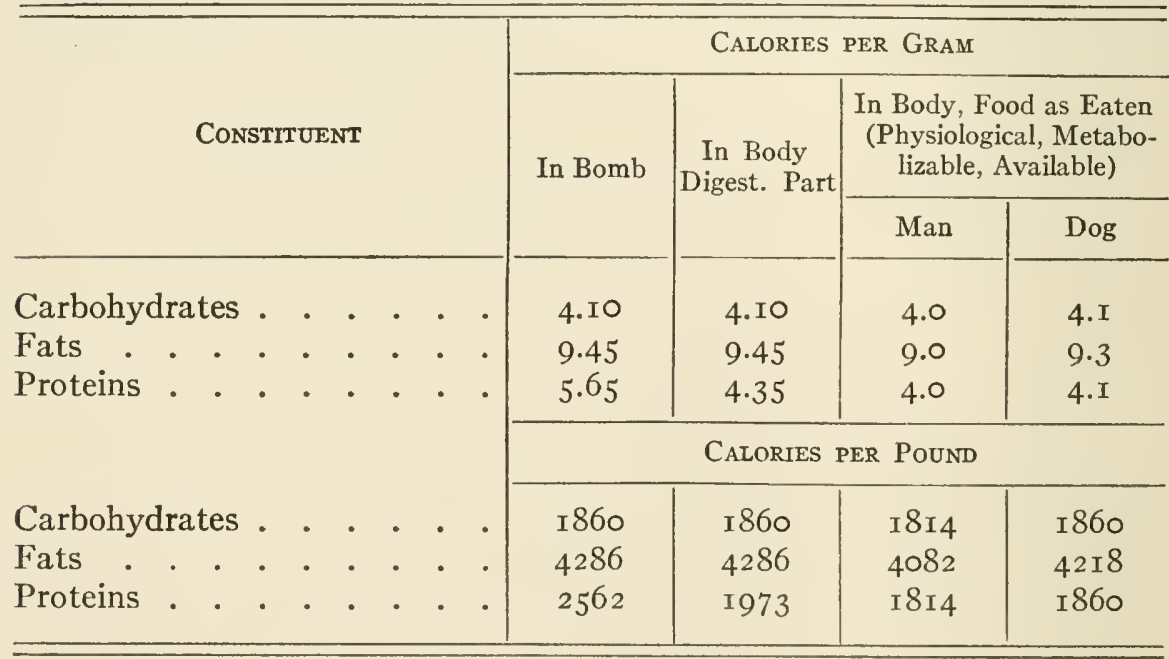

Fuel Values for Cattle. - In working with cattle and other ruminants, Kellner ${ }^{2}$ found that the values obtained with dogs

1 U. S. Bureau of Standards, Tables of Equivalents (I906).

2 "Die Ernährung der landw. Nutztiere," I9r 2. 
were too high. His conclusions and average results are as follows :

Carbohydrates, ${ }^{1}$ chiefly starch and crude fiber, are subject to losses in metabolizable energy due to bacterial fermentation with the formation of methane which is excreted with the fæces. With crude fiber this loss approximates I 3.7 per cent of the fuel value of the digested nutrient, even amounting to as much as 20 per cent in the case of wheat straw. With 4.I84 Cal. per gram as the total fuel value of starch and crude fiber, the above loss reduces this to about $3.6 \mathrm{Cal}$. per gram. The presence of other carbohydrates (pentosans and some sugars) gives a result from experimental data of 3.76r Cal. per gram as the metabolizable or available fuel value for the digestible carbohydrates (embracing nitrogen-free extract, crude fiber and pentosans) in ordinary cattle foods.

Fats ${ }^{2}$ do not suffer loss by bacterial fermentation and their metabolizable energy is the same as their fuel value. In analysis, however, the fats are determined as ether extract and this ether extract contains other substances than pure fats, e.g. waxes, chlorophyll, etc., which have a different fuel value and are not metabolized as fats. This results in the metabolizable value of the ether extract being considerably less than the fuel value. The ether extract of meadow hay and cereals has a fuel value of 9.I94 Cal. per gram, while the metabolizable energy of the digestible nutrient equals only 8.322 Cal. per gram.

Proteins ${ }^{3}$ with a fuel value of $5.778 \mathrm{Cal}$. per gram corrected for loss of energy in the urine constituents, as previously explained, have a metabolizable value of digestible nutrient equal to $4.697 \mathrm{Cal}$. per gram.

Putting these results together in a table with the equivalents in Calories per pound we have as the best data for the metabolizable or available energy of the digestible nutrients in ordinary cattle foods the following:

1 “Die Ernährung der landw. Nutztiere," т 1 I 2, pp. $88-95$.
2 l.c., pp. $87-88$.
${ }^{8}$ l.c., pp. $80-85$. 


\section{TABLE XIV}

Fuel Values of Food Constituents for Catrle (Kellner)

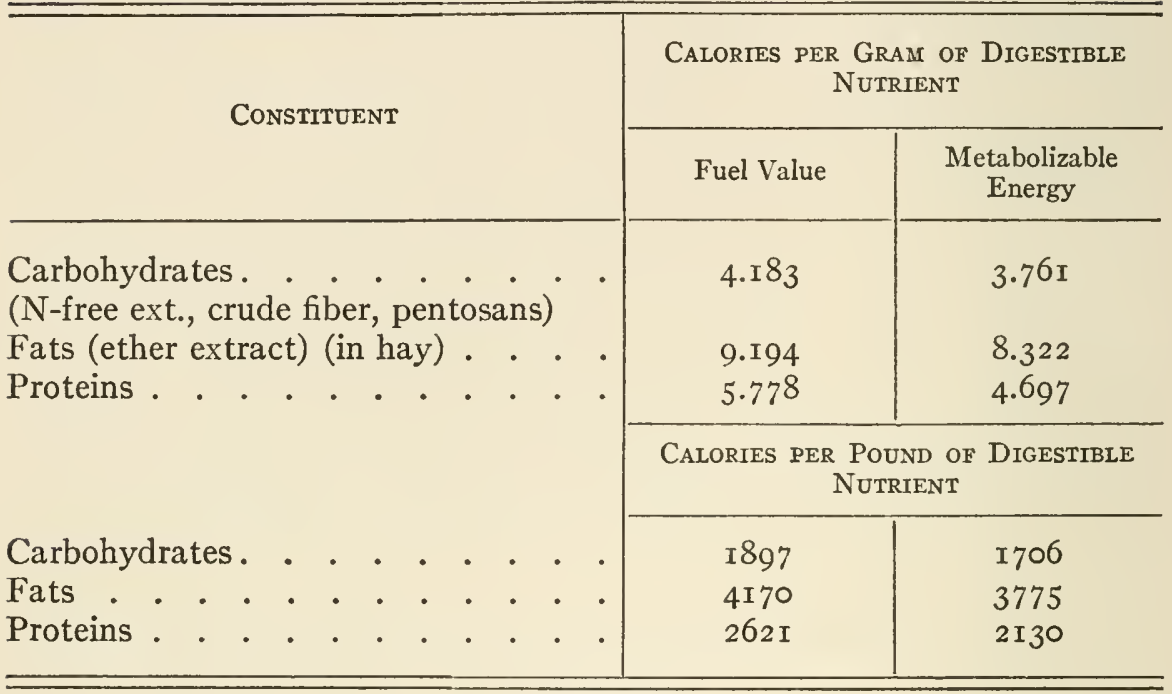

\section{FOOD REQUIREMENT}

\section{Energy Requirement}

Maintenance Requirement. - The energy represented by these figures is the amount per gram or pound of actually digested nutrient which cattle are able to utilize in metabolism. This energy is either liberated in the form of body heat or muscular work, the latter being both the involuntary work of the body and the voluntary work of labor; or, the equivalent nutrient is stored as body substance (mostly fat), in case it is in excess of the energy demands of the body.

The energy which it is necessary to supply in food for the purpose of maintaining the life of the animal (body heat + involuntary muscular work) is known as the maintenance requirement and a ration which supplies this only is termed a maintenance ration.

The energy of this maintenance requirement is expended in performing the essential operations of the body and keeping 
it in a certain condition. It may be divided somewhat as follows, in the case of man:

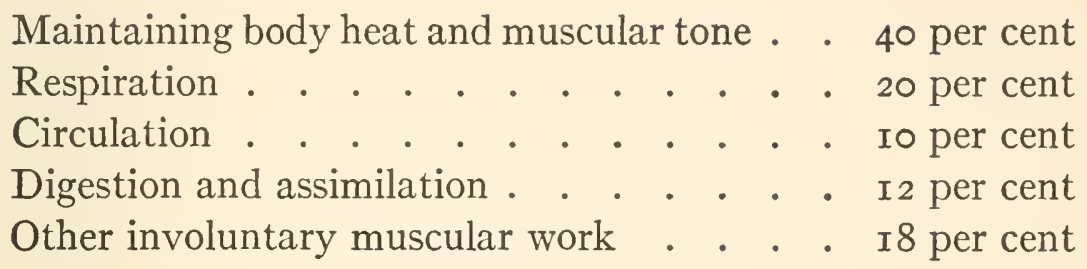

The total amount of energy thus required has been determined in the case of both man and domestic animals. The following may be taken as average results.

$\mathrm{A}$ man of $\mathrm{I} 50 \mathrm{lbs}$. at rest requires approximately $2000 \mathrm{Cal}$. per day.

A steer of $\mathrm{x}$ Ioo $\mathrm{lbs}$. (500 $\mathrm{Kg}$.) requires for maintenance approximately i 2,000 Cal. per day.

All of the energy of the food in excess of this maintenance requirement is utilized by the body in (I) voluntary muscular work, (2) production of body substance (increase in weight).

Respiration Calorimeter. - Experiments to carefully determine the relation between the energy of the food and the energy utilized by the body in maintenance and in doing work or increasing weight have been carried out in what is known as the respiration calorimeter. This consists of a large box in which a man or animal may live under very accurately controlled conditions such that all food and air used and all excretion products, heat produced and muscular work performed are determined. As a result of these experiments, performed on man in this country by Atwater and Benedict, and on animals by Armsby, and in Europe by Rubner, Zuntz, Kellner and others, it has been fully established that the law of the conservation of energy applies to the utilization of food in the animal body, i.e. all of the energy of the food actually metabolized is utilized in one of the ways mentioned.

Production Value. - The energy that is in excess of the maintenance requirement is thus productive in that it produces 
either additional muscular work or body material, and the value of the food for this purpose is termed the production value.

In the normal mature man the production of increased body weight is not desired, and all of the productive energy of food is available for increased muscular work. In horses this same fact is true. In fattening cattle, however, and in swine, milch cows, sheep and poultry, the production value of foods is utilized for increase in body weight or for the building of material which is being constantly withdrawn by man, the voluntary work requirement being practically nothing.

Energy Requirement for Man. - Taking results that have been obtained by Atwater, Benedict and others for the production energy necessary for various degrees of work in man, we have:

Energy Requirement of Normal Adult Man I5o Lbs. Wt.

At rest (maintenance), about 2000 Cal. per day.

Moving about but no active work, about 2300 Cal. per day. Moving about and light work, about $2500 \mathrm{Cal}$. per day.

Moving about and moderate work (carpenter), about 3000 Cal. per day.

Moving about and active work (farmer), about $3500 \mathrm{Cal}$. per day.

Moving about and very active work (excavator), about 4500 Cal. per day.

Moving about and extreme work (lumberman), about 5000 or over Cal. per day.

These results are obtained by figuring a man's day as composed of various activities incident to it, e.g. 8 hours' sleep, at $65 \mathrm{Cal}$. per hour; 2 hours for meals, going to and fro, at I $70 \mathrm{Cal}$. per hour; 6 hours' sitting, at Ioo Cal. per hour; 8 hours of labor, I70 to 600 Cal. per hour, depending upon degree of activity.

We thus see that the production requirement for man ranges from 300 to 3000 Cal. per day.

It may be mentioned that all efforts to determine the energy expended in even the most severe mental and nervous work have failed. 
Production Values for Cattle. - In fattening cattle the productive energy results in increase in body weight, and this factor as well as the Calorie unit has been used as the measure of such energy. The term used is pounds of flesh gained, which is not exactly equivalent to increase in live weight, as the latter includes water.

When fed in addition to a basal maintenance ration each of the food nutrients has been found to possess a certain production value. This value is not, however, in proportion to the relative metabolizable energy values of the same nutrients. Expressed in Calories Kellner ${ }^{1}$ has found that the following are the results :

\section{TABLE XV}

Metabolizable Energy and Production Energy of Nutrients

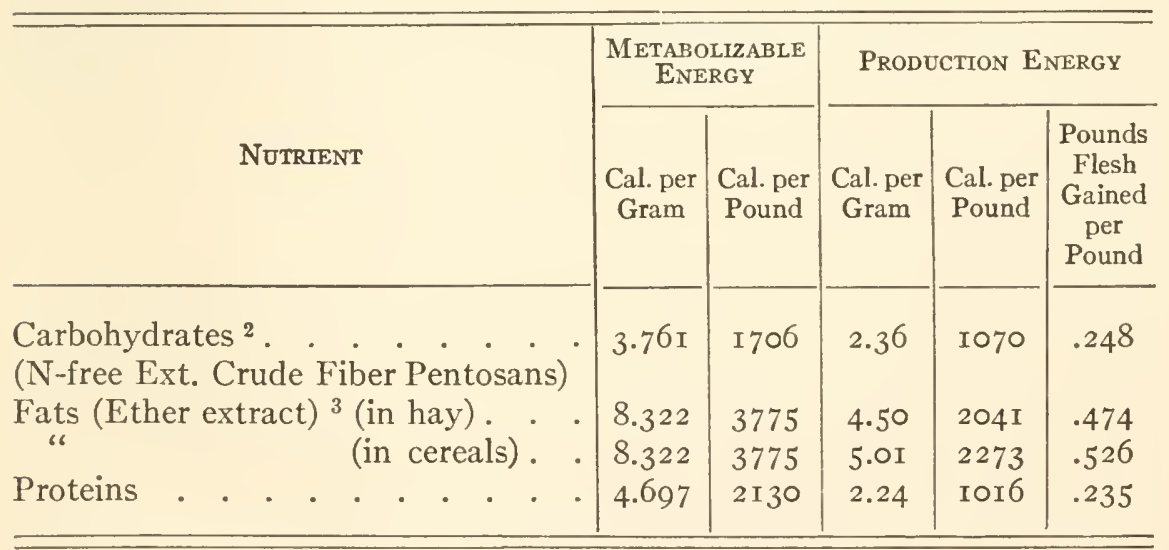

Summary. - Let us summarize what has been said in regard to digestibility and energy values by means of a table giving the results for three of our common animal foods as fed to fattening cattle.

1 “Die Ernährung der landw. Nutztiere,” p. I 59.

${ }^{2}$ The values for sugar are less than for starch and crude fiber, viz. .I 88 pounds flesh gained.

3 The values for fats (ether extract) in concentrates like cottonseed meal and in cereal grains is greater than for hay. Production value for oil foods equals .598 pounds flesh gained, for grains .526 pounds flesh gained. The latter value applies to the total ether extract of ordinary mixed foods. 


\section{TABLE XVI}

Digestibility and Energy Values of Three Animal Foods per ioo Pounds of FOOD

(Based upon Kellner's figures for cattle as already quoted)

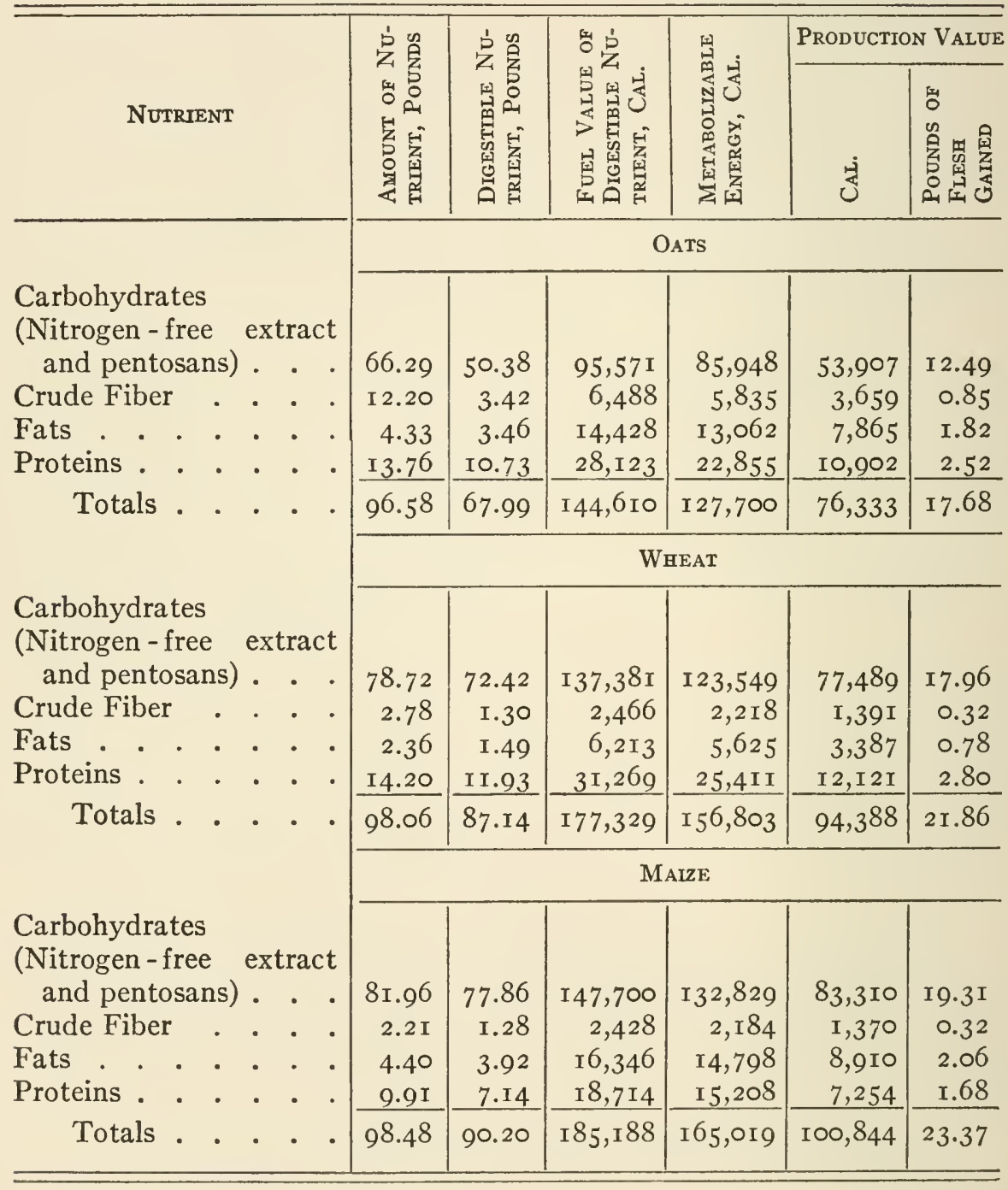

Nutritive Ratio. - The results for the fuel value of the three food constituents have led to the use of a factor, especially in connection with feeding rations of domestic animals, which 
though perhaps not as valuable as originally thought, or at least in the sense first given to it, is yet often used. This is known as the mutritive ratio and expresses the ratio, calculated directly from the amounts present, between the proteins and the other two constituents. It will be observed that, approximately, the protein and carbohydrates are equal in food value while fats are 2.25 times as large. If the amount of fat food is multiplied by 2.25 , it is then in equivalent terms to the other two. If we make the following proportion:

Amount protein : (Amount carbohydrates + amount fats $\times 2.25$ )

then $\mathrm{I}: x$ will represent the ratio of the protein constituents to the other two. This is termed the mutritive ratio. In a general way the results of feeding depend upon this ratio, for when $x$ is large, e.g. 8 to $\mathrm{I} 2$, the ratio is usually a fattening one and is termed broad, whereas when it is small, e.g. 4 to 7 , the ratio is not fattening but still supplies the energy requirements of animals, especially for work, and is termed narrow. In the broad nutritive ratio it will be observed the carbohydrates and fats which produce body fat are in large proportion, while in the narrow ratio they are small.

\section{Protein Requirement}

In discussing the maintenance requirement we have spoken only of the energy factor. Not only does the animal body require a certain amount of energy to be supplied in its food, but there must also be in it a certain minimum amount of protein. As food protein is absolutely essential to the formation of body protein, the torn-down muscle tissue must be replaced by protein supplied in the food. The energy represented in this protein metabolism is part of the total energy requirement, but aside from this there must be in the food a certain amount of protein considered solely as building material. This may be illustrated by the fact that while the necessary maintenance requirement of $2000 \mathrm{Cal}$. per day for man, or I $2,000 \mathrm{Cal}$. per day for steers, 
might be easily supplied by carbohydrates and fats alone, yet, except for a brief period, such non-protein food is unable to supply the needs of the body because torn-down body protein is impossible of reconstruction. In adult man or in non-fattening or non-producing mature animals the amount of protein in the body does not increase. All of the protein food is thus indirectly converted into energy, but in the process it first serves as a constructing substance and cannot be wholly replaced by either of the other food constituents.

The amount of the protein requirement in man is a question over which there has been considerable controversy. The standard usually accepted from studies of normal diets and of the nitrogen income and outgo of normal men has been 100 grams of protein per day for a man of 150 pounds. Some investigators, however, especially Chittenden, reduce this amount to as low as 70 grams or even less.

We have given figures showing the effect of increased muscular activity upon the energy requirement of the body, raising the amount from $2000 \mathrm{Cal}$. per day for maintenance to $5000 \mathrm{Cal}$. per day under severe muscular exertion. In contrast to this is the fact that increased muscular açtivity has only a slight effect upon the amount of protein metabolism. On the other hand, while increased food supply raises the energy metabolism of the body only slightly, it has the direct and marked effect of increasing the protein metabolism. That is, an increase in protein food increases the amount of protein metabolized, there being no appreciable increase in the amount of body protein. An increase in carbohydrate and fat food increases the general metabolic action, which in turn increases the amount of body protein torn down in the muscular activity of the accompanying physiological processes.

In the foregoing discussion we have considered only the main facts in regard to the value of foods and the food requirements of the body. The actual value and economic use of foods, the effect of varying conditions upon the food requirements and the fixing of standard or feeding rations have all been omitted as 
pertaining more to a study of the practice of feeding than to a general presentation such as has been the purpose of this book.

Enough has been considered both in regard to plant and animal physiology and foods to give to the student a general but definite and scientific knowledge of the topics discussed.

\section{Refcrences, Section III}

Atwater, Chemistry and Economy of Food (U. S. D. A.; O. E. S. Bul. 21), I895.

Atwater, Foods, Nutritive Value and Cost (U. S. D. A. Bul. 23), I894. Atwater and Bryant, Composition of American Food Materials (U. S. D. A.; O. E. S. Bul. 28), r899.

Armsby; Principles of Animal Nutrition, I9IO.

Armsby, Available Energy of Timothy Hay (U. S. D. A.; O. E. S. Bul. 5I), 1903.

Allen, Feeding of Farm Animals (U. S. D. A. Bul. 22), Igor.

Chamberlain, Feeding Value of Cereals (U. S. D. A.; Bur. Chem.

Bul. I 20), I 909.

Haywood et al., Commercial Feeding Stuffs (U. S. D. A. ; Bur. Chem. Bul. I08), igo8.

Jenkins \& Winton, Compilation of Analyses of American Feeding Stuffs (U. S. D. A.; O. E. S. Bul. II), I 892.

Jordan \& Hall, Digestibility of American Feeding Stuffs (U. S. D. A. ; O. E. S. Bul. 77), I900.

Kellner, Die Ernährung der landw. Nutztiere, IgI2.

Kellner, Grundzüge der Fütterungslehre, 1908.

Langworthy, Function and Uses of Food (U. S. D. A. ; O. E. S. Bul. 46).

Sherman, Food Products, I9I4.

Wiley, Cereal and Cereal Products (U. S. D. A. ; Bur. Chem. Bul. I3, IX), 1898 .

Wiley, Analysis of Cereals (U. S. D. A.; Bur. Chem. Bul. 45), I895. Wiley, Composition of Maize (U. S. D. A.; Bur. Chem. Bul. 50), I8g8. 



\section{INDEX}

ABSORPTION, of food, I60, I83, I88.

Acetaldehyde, I 44 . experiments, 46 .

Acetamide, 82.

Acetic acid, 46, 47, 49 .

experiments, $5 \mathrm{I}$.

glacial, 49 .

properties of, 49 .

salts of, 49 .

Acetic acid series, table, 47.

Acetic fermentation, 50.

Acetylene, 24, I33.

Acetylene series, I33.

Achroödextrin, I 24, I 66.

Acid-amides, 55, 82.

Acid-chlorides, 55.

Acid-nitriles, $2 \mathrm{I}$.

Acids, 46-53, 67-8I.

derivatives of, $54-65$.

of milk, 2 Io.

polycarboxy, $5 \mathrm{I}$.

saturated and unsaturated, 134 .

Acrolein, I33.

Acrylic acid, I33.

Acrylic aldehyde, I33.

Activators, I43.

Adipocellulose, 125, 265.

Aërobic bacteria, 250 .

Agar-agar, 272.

Alanine, 85 .

Albumin, 89.

egg, 88, 91.

preparation of, for experiments, I 74 .

Heller's ring test for, 230, $23 \mathrm{I}$.

in urine, 230.

serum, 202.

toxic, 205 .

Albuminoids, 89 .

Albuminuria, 230.

Alcohol, 26, 3I.

absolute, 36 .

denatured, 38 .

from carbohydrates, 34, 39, I 2 I , I 26.

industrial uses of, 37 .

per cent, table, 28 .

source of, I 2 I.

taxation of, 37 .
Alcoholic beverages, 36 .

Alcoholic fermentation, 32 .

experiments, 34 .

Alcohols, 25-4I.

derivates of, $54-65$.

dihydroxy, $4 \mathrm{I}$.

experiments, $26,27,3 \mathrm{I}, 34,40$.

higher, 39, 4I.

oxidation products of, 42-53.

polyhydroxy, 40.

table, 26.

trihydroxy, 4I.

Aldehyde, 44 .

Aldehydes, 42, 45 .

addition compounds, 44 .

experiments, 45 .

reactions of, 44 .

Ale, 36 .

Aleurone grains, 284 .

Aleurone layer, 284 .

Alimentary canal, I63.

Alkaloids, 286.

Alkyl halides, I8.

Allyl alcohol, I 33 .

Allyl aldehyde, I33.

Aluminium, in plants and animals, I47.

Amidulin, I66.

Amines, $2 \mathrm{I}$.

Amino-acetic acid, 83, 84 . ammonium salt of, 84 .

hydrochloride, 84 .

Amino-acids, 82, 85, 9 I, 286.

from protein digestion, $20 \mathrm{r}$.

in plants, $284,286,287$.

in soil, 249,287 .

Amino-butyric acid, beta methyl, 85 .

Amino-caproic acid, 86.

Amino-glutaric acid, 86.

Amino-propionic acid, 85 .

beta hydroxy, 86.

beta hydroxy-phenyl, 87 .

beta indol, 87 .

beta phenyl, 86 .

Amino-succinic acid, 86. amide, 86.

Amino-valeric acid, beta methyl, 86 . delta guanidine, 87 . 
Amino-valeric acid, (Continued) gamma methyl, 86.

Amino compounds in soil, 249, 287 .

Amino-formamide, 97.

Amino-formic acid, 97.

Amino-group, I I.

Amino-methane, 22.

Ammonia, derivatives, 22. in urine, 228.

Ammonium amino-formate, 98 .

Ammonium carbamate, 98 .

Ammonium carbonate, 98 .

Ammonium citrate, 80 .

Ammonium cyanate, 99.

Amygdalin, I I I.

Amyl alcohols, 39 .

Amyl valerate, 56 .

Amylases, 145 .

Amyloid, I25.

Amylopsin, I 22, I45, I70.

Anæsthetics, I8.

Aniline dyes, I35.

Animal food, I59, I90, 288.

Animal heat, 233.

Animal nutrition, I59, I90.

Animals, liberation of energy by, 236 . physiological processes of, 158 .

Anti-enzymes, I44, 225.

Antithrombin, 225.

Apple juice, II3.

Arabinose, II 0 .

Arabitol, 4I.

Arachidic acid, 47, 58 .

Arginine, 87, 284.

Argol, 76.

Armsby, 294, 299.

Arterial blood, I93.

Arsenic, in plants and animals, I47.Y

Ash, I49.

Asparagine, 86.

Aspartic acid, 86.

Assimilation, in plants, 238.

Assimilatory pigment, 238.

Asymmetric carbon, 7 I. theory of, 7 I.

Atwater, 299.

Available energy, of foods, 295.

BABCOCK TEST, 2 II, 2 I5.

Bacteria, aërobic, 250. denitrifying, 253 .

nitrate, 250.

nitrogen-assimilating, 250.

nodule, 250.
Baking powder, 77.

Barley sugar, I 6 .

Beer, 36.

Beeswax, 57.

Benedict, 299.

Fehling's solution modified by, 230.

Benzaldehyde, II I.

Benzene, I35.

Benzine, I35.

Benzol, I35.

Benzoyl amino-acetic acid, 84, 92.

Benzoyl glycine, 92.

Bile, I8r, I82.

Bioses, 108.

Biuret, Ior. preparation of, Io2.

Biuret reaction, 96 .

Blood, 209, 219-226.

action of snake venom on, 225 .

arterial, I93, 22 I.

carbohydrates in, 192.

clotting of, 223, 224 .

constituents of, 220 .

corpuscles, 220, 222.

defibrinated, 225 .

dust, 220.

experiments, 226 .

glucose in, I92, I93, 223.

hæmagglutination in, 220 .

hæmogloblin, 89, 220.

hæmolysis in, 220 .

inorganic constituents, 223.

laking of, $22 \mathrm{I}$.

organic constituents of, 223.

oxygen-carrying power of, 222.

oxyhæmoglobin, 9I, 22 I.

plasma, I99, 220, 223.

properties of, 220.

serum, 91, 223.

stroma, 220.

Brandy, 37.

Brazil nut, 277.

Bright's disease, 230.

Buchner, 33, I40.

Building material in plants, 246.

Butane, I3, I 5 .

isomerism of, 16 .

Butter, 2 I6.

composition of, 217 .

Butterine, 2 I 7 .

Butyric acid, 47, 58, 74, 2 ro.

Caffeine, io3, 286.

Cagniard de la Tour, 32. 
Calcium, as plant food, 152. in plants and animals, 147.

Calcium carbide, 24.

Calcium cyanamide, 23. experiments, 25 .

Calorie, 294. large, 294. small, 294.

Calories, fuel value in, 294.

Calorific value, 293.

Calorimeter, bomb, 293. respiration, 299.

Camphor, 287.

Cane sugar, I08, I I5-I 8 . action of yeast on, I 16 . action on Fehling's solution, i 6 . experiments, I 20. hydrolysis of, I 7 . in vegetables, etc., I I6. occurrence of, II 5 . optical activity of, II6. properties of, I 6 .

Capric acid, 47, 58, 2 Iо.

Caproic acid, 47, 2 Iо.

Caprylic acid, 47, 2 Iо.

Caramel, iा6.

Carbocyclic compounds, I35.

Carbohydrates, 87, I04-130. absorption of, I83. classification of, 107, I09. composition of, 104,155 . compound, 107 . constitution of, I05. conversion into fats, 195 . digestibility of, 290.

digestion of, $\mathrm{I}_{3}-\mathrm{I} 7 \mathrm{I}$. by pancreatic juice, I 70.

in mouth, I65.

in small intestine, $\mathrm{I} 7 \mathrm{O}$.

in stomach, 160 .

final digestion products of, I 7 I.

fuel value of, $294-296$.

function of, in plants, $24 \mathrm{I}$.

in blood, 192, 193, 223.

in milk, 209.

in plants, $238-248$.

in portal vein, 183 .

metabolism of, in animals, 19I-198.

in plants, 242 .

metabolizable energy of, 295-298.

respiratory quotient of, 197.

simple, I07.

summary, I 30.

table, I 29.
Carbon, in plants and animals, 147 .

Carbon dioxide, assimilation of, 238 .

Carbon monoxide, in photosynthesis, 239.

Carbon tetrachloride, I9. experiments, I9.

Carboxyl, 46.

Casein, 74, 88, 173, 210, 212.

Caseinogen, 173, $21 \mathrm{I}$.

Castor oil bean, 277 .

Catalytic, 32, 33, I39.

Cattle, food values for, 296. production values for, $30 \mathrm{I}$.

Cattle foods, digestibility of, table, 302 .

Cell, animal, I 54 . composition of, I 54 .

fundamental chemical reactions of, I57.

living, 154 .

plant, I 54 .

Cell energy, I55, I 56 .

Cell food, I $54-I_{5} 8,243,25 \mathrm{r}$

Cell wall, 247 .

Celluloid, 127,263 .

Cellulose, I08, I 20, I 25-I 28.

adipo, 265 .

alcohol from, 39 .

as food, 265.

compound, 262.

digestibility of, 265 .

experiments, 128 .

forms of, 262 .

hemi, 262,263 .

hexanitrate of, 127 .

hydrolysis of, $125,128$.

in plants, $247,252,262$.

experiments, 267 .

ligno, 264.

normal, 262 .

pecto, 264 .

Cellulose content of crops, table, 266.

Cellulose explosives, I27, 263 .

Cereal plants, 269.

Cerebron, I I4.

Cheese, 2I 2, 2 I 7 .

Cherry gum, iso.

Chewing, I6r.

Chloracetic acid, 67.

Chloral, 67,

Chloral hydrate, 67 .

Chlorides, as plant food, I 52 .

Chlorine, in plants and animals, 147 .

Chlormethane, II.

Chloroform, i8.

experiments, I9. 
Chlorophyll, 147, 238.

Chlorophyll bodies, 238 .

Chloroplasts, 238.

Cholesterol, 220, 223, 280.

Cholesterol acetate, $28 \mathrm{r}$.

Choline, 282.

Chyme, 176.

Cider, 49.

Citric acid, 80. experiments, 80 .

Clotting of blood, 224.

Coagulating enzymes, I42, I73.

Coal, 6.

Coal tar, 135 .

Coal tar dyes, 135 .

Coefficients of digestibility, 289, 290, 291.

table, 290.

Coenzymes, I44.

Cognac, 37 .

Collodion, I 28, 263.

Cologne spirits, 36 .

Columbian spirits, 29.

Combined acid, 167, I74.

Combustion value, 293.

Constitutional formula, 8.

Corn sirup, 34, 123.

Cotton, I25, 262. analysis of, 263 .

mercerized, I27, 263.

Cottonseed, 277.

Cream of tartar, 76 .

Creatinine, 97, 288.

Crops, 259.

cellulose content of, table, 266.

fat content of, table, 279 .

protein content of, table, 285 .

starch content of, table, 269.

sugar content of, table, 276 .

Crotonic acid, I33.

Crotonic aldehyde, I33.

Crude fiber, I $26,265$. determination of, 267 .

Crude tartar, 76 .

Curd, 2 I 2.

Cutin, I 25, 265.

Cyanamide, 23.

Cyanides, 21. experiments, 25 .

Cyanogen group, II.

Decane, 13.

Decapeptides, 92.

Denitrifying bacteria, 253 .
Dextrin, I 20, I24, 27 I.

Dextro-rotatory, 70.

Dextrose, III, II 2 .

Diabetes, II I, 229.

Diastase, 33, 34, I20, I22, I40, I45, 244 . experiments, 246 .

of secretion, 245 .

of translocation, 245 .

Di-brom-ethane, symmetrical, 20. unsymmetrical, 20.

Diethyl carbonate, 99.

Dihalogen ethanes, 20. isomerism of, 20.

Digestibility of food, 289-293. table, 302. coefficients of, 289 .

Digestion of food, I59-I83.

Digestion and absorption, résumé of, I86.

Digestive region, I63.

Digestive tract, 163 .

Dioxystearic acid, 2 Io.

Dipeptides, 92.

Disaccharoses, 108, II 5-IIg. experiments, $\mathbf{I} 20$.

hydrolysis of, II5, I64.

Distillation, destructive, 29. fractional, 27.

Distilled liquors, 37 .

Duct of Wirzung, I 76 .

Dulcitol, 4 I.

Duodenum, I76.

Edestin, 9I.

Egg albumin, 9r.

Eicosane, I3.

Electrical fixation of atmospheric nitrogen, $25 \mathrm{I}$.

Emulsion, I45.

Enantiomorphic crystals, 79.

Endothermic reactions, 235.

Energy, kinetic, 233. organisms liberating, 233, 236.

potential, 233.

source of, in plants, 237 .

storage of, by plants, 236 .

Energy food, of plants, 251.

Energy requirement, 298, 300.

Energy value, of foods, 293, 295. table, 302.

Enterokinase, 144, 145, I77.

Enzyme, definition of, I40.

meaning of, 139 . 
Enzyme action, catalytic nature of, 139 . character of, 142 . reversibility of, $\mathrm{r} 43$. specificity of, 142.

Enzymes, 33, I39-I45. amylolytic, I4I. coagulating, 142,173 . decomposing, $\mathrm{r}_{4} 2$. fat-hydrolyzing, r4 r. glucoside-hydrolyzing, I4I. hydrolyzing, I4I. lipolytic, I4I, I80. names of, $\mathrm{I} 44$. nature of, I 40. oxidizing, I42. protein-hydrolyzing, I4I. proteolytic, I4I, I73. reactions brought about by, I4I. reducing, $\mathrm{I}_{4} 2$. saccharolytic, I4I. salivary, $\mathrm{I} 66$. splitting, I42. starch-hydrolyzing, I4T. sugar-hydrolyzing, I4I. table, I45.

Erepsin, I45, $x_{7} 8$.

Erythritol, 4I.

Erythrocytes, 220, 223. number of, 222 . size of, 222.

Erythrodextrin, I24, I66.

Esophagus, I63.

Essential oils, 286.

Esterification, 58. experiments, 62 .

Esters, 56. experiments, $\mathbf{5 5}, \mathbf{6 2}$. properties of, 54 .

Ethane, I3, I5. synthesis of, I3.

Ethereal salts, 56 .

Ethers, 54 .

Ethyl acetate, 56 .

Ethyl alcohol, 26, 31-39. experiments, $3 \mathbf{I}$. properties, $3 \mathbf{I}$. test for, 32 . test for water in, 32 .

Ethyl amino-formate, 98.

Ethyl ether, 34. experiments, 55 .

Ethyl halides, I9.

Ethylene, I32.

Ethylene bromide, 20, I32.
Ethylene series, I33.

Ethylidene bromide, 20.

Excretion, I60.

Exothermic reactions, 235.

Experiment studies, I, Hydrocarbons from wood and coal, 7 .

II. Methane, 9 .

III. Halogen substitution products, 19.

IV. Cyanides, 25.

V. Alcohols, distillation, 26.

VI. Methyl alcohol, 30.

VII. Ethyl alcohol, 3I.

VIII. Alcoholic fermentation, 34 .

IX. Amyl alcohol, 40.

$\mathrm{X}$. Aldehydes, 45 .

XI. Formic acid, 48.

XII. Acetic acid and vinegar, 5 $\mathrm{I}$.

XIII. Oxalic acid, 53.

XIV. Ether, 55.

XV. Esters, 62.

XVI. Fats and soaps, 63 .

XVII. Lactic, malic, tartaric and citric acids, 80 .

XVIII. Proteins, 93.

XIX. Urea, тот.

XX. Carbohydrates, general properties, I05.

XXI. Pentosans and pentoses, IIo.

XXII. Hexoses, II4.

XXIII. Disaccharoses, I20.

XXIV. Starch, I23.

XXV. Cellulose, I 28.

XXVI. Organic and inorganic con. stituents, 152.

XXVII. Salivary digestion, I68.

XXVIII. Gastric digestion, 174 .

XXIX. Milk, 2 r8.

XXX. Blood, 226.

XXXI. Urine, 23I.

XXXII. Diastase and starch, 246.

XXXIII. Cellulose and crude fiber, 267.

XXXIV. Starch, 270.

XXXV. Pentosans, 273.

Explosives, I27.

FATS, 57-65.

absorption of, 185 .

as food, 277 .

body, I99.

chemical constants of, $6 \mathrm{r}$.

composition of, I 55 .

conversion into carbohydrates, 200. 
Fats, (Continued)

digestibility of, 290 .

digestion of, $179-183$.

experiments, 64 .

final digestion products of, $18 \mathrm{I}$.

fuel value, 294 .

hydrolysis of, I79.

important, 60 .

in blood plasma, 199 .

in crops, $277-280$.

in plants, 248, 249, 277 .

metabolism of, I98.

metabolizable energy of, 298 .

milk, I99, 2 Io.

physical constants of, $6 \mathrm{I}$.

properties of, 64 .

respiratory quotient of, 197 .

saponification of, 60 .

experiments, 63 .

synthesis of, in plants, 248 .

table, 62.

Fatty acids, 57 .

of milk fat, 2 ro.

Fehling's solution, 77, I 2.

Benedict's, 230.

Fermentation, I39. alcoholic, 32-35.

Ferments, 33, r40. organized, $33, \mathrm{r} 40$. unorganized, 33 , I40.

Ferric ammonium citrate, 80.

Fertilizers, commercial, I 52.

Fibrin, 223, 224.

Fibrin enzyme, 224 .

Fibrinogen, 223, 224.

Fire damp, 8.

Fire-extinguishing liquids, I9.

Flax, I25.

Flaxseed, 277.

Food, absorption of, I83-188. and energy, 288, 293-303.

animal, 159-208, 288-305.

as building material, 157 .

definition of, I59.

digestibility of, 289-293.

table, 292, 302.

digestion and absorption of, I59-183.

energy, I 55 .

energy value of, 293-303.

fuel value of, 293 .

function of, 157,234 .

oxidation of, 156 .

plant, 234, 24I-257.

production value of, 299 .
Food, (Continued)

reserve in plants, 244.

utilization of, $\mathrm{x} 60$.

Food materials, essential organic, 146 .

Food passage, time for, I88.

Food requirements, 298.

Food value, 288.

Foods and feeding, 288-305.

Formaldehyde, 42 .

as disinfectant, 43, 46 .

as food preservative, 43,216 .

experiments, 45 .

from carbon dioxide and water, 43 .

in photosynthesis, 239.

uses of, 43 .

Formalin, 43 .

Formic acid, 46-48.

experiments, 48 .

in photosynthesis, 239 .

Fractional distillation, 27.

Fructose, I06, I I I, I I3, 275.

optical activity of, II3.

synthesis of, I I4.

Fruit flavors, 56.

Fruit sugar, III, II3, 275.

Fuel value of foods, 293-298.

corrected, 295.

for cattle, 296, 298.

table, 296, 298.

Furfural, I Io.

GaLACTANS, II4, 264, 27 I, 272.

Galactose, I rr.

Gall bladder, 163 .

Gastric lipase, I80.

Gastric juice, 33, I72.

as germicide, I74.

enzymes in, I72.

experiments, 174 .

hydrochloric acid in, I72, I73, 174 .

Germ, 245.

Germination, in plants, 245 .

Germ meal, 277.

Gin, 37 .

Gliadin, 284 .

Globulins, 89.

Glucosans, 27 I.

Glucose, 35, Io6, III, 223, 275.

action on Fehling's solution, I I 2, I I4. determination, II I.

fermentation of, II3.

from other carbohydrates, II 3 .

in blood, I92.

in plants, 275 . 
Glucose, (Continued)

in urine, III, 229, 23 I.

occurrence and properties of, III.

optical activity of, II3.

oxidation of, in body, 193.

photosynthesis of, II 1239.

reduction of silver solution by, II4.

source of, I23.

synthesis of, II4.

Glucose sirup, I I2.

Glucosides, I I I.

Glutaminic acid, 86, 284.

Gluten, wheat, 88.

Glycerin, $4 \mathrm{I}$.

Glycerol, 4I, Iog.

Glycerol esters, 58.

Glycerose, I09, I I4.

Glyceryl tripalmitate, 60.

Glycine, 84 .

Glycocholic acid, 182.

Glycogen, I 20, I2 I, I 24, I92, $27 \mathrm{I}$. amount in liver, 192.

conversion into glucose, 192.

muscle, 194 .

Glycol, 40.

ethylene, 4I.

Glycolic aldehyde, in photosynthesis, 240.

Glyco-proteins, 89, I68.

Glycosuria, 229.

Glycyl-glycine, 92.

Grape juice, I I 3 .

Grape sugar, II I, 275.

Green plants, 238.

Gum arabic, IIO, 272.

Gums, $247,272$.

.Gum tragacanth, 272

Guncotton, 127. soluble, I28.

Heisagglutination, 220.

Hæmoglobin, 89, I 47.

blood, 89, 220 .

Hæmolysis, 220 .

Halogen-acids, 67 .

Halogen-aldehydes, 66.

Halogen-ethanes, I9.

Halogen-methanes, 18.

Hard water, experiments, 64 .

Heat, and work, 156.

body, 157 .

Heliotrope, 287.

Heller's ring test, 230, 23 I.

Hemp, I25, 262.

Hepatic vein, 192.
Heptane, I3.

Heptoses, 108.

Hexacontane, I3, 15.

Hexane, I3, I5.

Hexoses, I08, IIO-II5.

experiments, II 4 .

Hippuric acid, 84, 92. in urine, 229.

Honey, III.

Hormones, I 76 .

Humus, 249.

Hydracrylic acid, 68.

Hydrazones, 107.

Hydrocarbons, 5.

from wood and coal, experiments, 7 .

saturated and unsaturated, table, I33.

synthesis of higher, 13.

table, I3.

Hydrochloric acid, in gastric juice, 174 . combined, $\mathbf{I} 74$.

Hydrogen, in plants and animals, I47.

Hydrogen peroxide, in photosynthesis, 239.

Hydrolysis, 59.

experiments, 63 .

Hydroxy-acids, 67 .

Hydroxy-propionic acids, 68.

Hydroxy substitution products, 65 .

Hydroxyl, 25.

IMMUNITY, I44.

Indigo, 287.

Insecticides, 49.

Intestinal juice, carbohydrate, digestion by, 170 .

protein digestion by, 175,178 .

Intestine, large, digestion in, 182 . small, I63, 175 .

fat digestion in, 180 .

protein digestion in, 175 .

Intestines, digestion in, 187 .

Inulin, I25, $27 \mathrm{I}$.

Inversion, II 7 .

Invertase, II6.

Invert sugar, I I 7 .

Iodoform, I8. experiments, 19.

Iron, in plants and animals, $\mathbf{1 4 7}$.

Isoleucine, 86.

Isomaltose, 167 .

Isomerism, I 5.

space, 17 .

stereo, I7.

structural, I6. 
Isopropyl iodide, I6.

JUTE, 262.

KARO CORN SIRUP, 34, I23.

Katabolism, 190.

Kellner, 299.

Kinase, I43.

Kjeldahl method, 90, 215. calculations of, 95 .

Gunning modification of, 94. reactions of, 94 .

LACTAIBUMIN, 2 II, 2 I 2.

Lactase, I45, I7 I.

Lactic acid, 68, 2 1о. dextro, 69, 74 . experiments, 80 . from milk sugar, I I9. from sour milk, 79, Irg. inactive, 73 .

levo, 74 .

sarco, 74, 223. space formula of, 72 .

Lactic acid bacteria, 73, 74, 210.

Lactic acid fermentation, 69.

Lactide, 74 .

Lactoglobulin, 2 I I.

Lactometer, 2I 5 .

Lactose, II 5, I I9, 209. action on Fehling's solution, I I9. fermentation of, II9. optical activity of, II9.

Lauric acid, 74, 2 ro.

Le Bel, 7 I, 78 .

Lecithin, 220, 223, 280, 282 . amount in plants and animals, 282. physiological function of, 283 .

Lemons, 80.

Leucine, 86.

Leucocytes, 220, 222. number of, 222.

Levo rotatory, 70.

Levulosans, $27 \mathrm{I}$.

Levulose, I I I, II3.

Liebig, 32.

Lignin, I 25, 247.

Lignocellulose, 1 25, 264.

Limes, 8o.

Lime-nitrogen, 24.

Linen, I 25, 262.

Linolenic acid, 6r.

Linolic acid, 6I, I34.

Lipases, I45, I80.
Liver, I $21,192$.

Lock and key theory, I43.

Lymph, 2 I9.

Lymphatic system, I98.

Lysine, 82.

MAGNESIUM, AS PLANT FOOD, I 52.

citric acid salt of, 55 .

in plants and animals, 147.

Maintenance ration, 298.

Maintenance requirement, 298, 299.

Malic acid, 75 . experiment, 80 .

Malt, II 8, I 20.

Maltase, 35, I20, I 23, I45, I65, I7 I , 244.

Maltose, 35, II 5, II8, I67, 275.

action on Fehling's solution, I18.

fermentati on of, Ir8.

in plants, 275 .

optical activity of, II8.

Malt sugar, II5, II8.

action on Fehling's solution, II8.

fermentation of, I 18 .

optical activity of, Ir8.

Man, energy requirement for, 300 .

Mannans, 264, 271, 272.

Mannitol, 4I.

Manure, 152.

Marsh gas, 7 .

Mastication, I6r.

Mercerized cotton, I27.

Metabolism, I60, 190-208.

direct, I9I.

end products of, in plants, 286.

Metabolizable energy, of foods, 295. table, 30r. of carbohydrates, 298.

of fats, 298. of proteins, 298.

Methane, 7, I3, I5. constitution of, 6,8 . experiments, 9 . occurrence of, 7 . properties of, 8 .

Methane series, table, I3.

Methyl alcohol, 26, 27, 29. experiments, 30 . from beet sugar residues, 29 . from wood, 29. properties of, 30 . source of, 29. use of, 30 .

Methyl amine, I2, 22.

Methyl ammonium chloride, 23. 
Methyl bromide, $x 2$.

Methyl chloride, I 2.

Methyl cyanide, I 2.

Methyl halides, I3.

Methyl hydroxide, I2.

Methyl iodide, I2.

Milk, II9, 209-2I6.

American, 215.

analysis, 215 .

average, 2I4.

ash of, 2I4.

constituents of, 209.

experiments, 218 .

extreme variations in, 214 .

fat of, 2 IO.

fat-rich, 2 I 4 .

food value of, 218 .

general properties of, 2I4.

inorganic constituents of, 212.

proteins of, 215.

preservatives of, 216 .

salts of, 212 .

souring of, II 210.

standard, 2 I 4 .

sugar in, II9, 209.

total solids of, 213,214 .

Milk sugar, II 5 , I 19 .

action on Fehling's solution, II 9 .

fermentation of, I I 9 .

optical activity of, Irg.

Millon's reaction, 95 .

Millon's reagent, 95 .

Mixed compounds, 66 .

Mono-chlor methane, I 2.

Mono-halogen ethanes, r.

Monosaccharoses, 107, 109-1 I5. final products of digestion, 164 .

Moore's test, I05.

Morphine, 286.

Mouth, I63, I 86.

Mucin, 89, 168.

Muscular work, 233.

Myristic acid, 47, 2 Io.

Natural gas, 6.

Nephritis, 230.

Nicotine, 287 .

Nitrate bacteria, 250.

Nitrates, as plant food, I 52, 249. in soil, 249.

Nitrides, $25 \mathrm{I}$.

Nitrogen, atmospheric, in fertilizers, 24.

electrical fixation of, $25 \mathrm{I}$.
Nitrogen, (Continued)

excretion of, 205 .

fixation of atmospheric, $25 \mathrm{r}$.

in plants and animals, 147 .

Kjeldahl method for, 90 .

of katabolized protein, 205.

organic, in soil, 249 .

source of, in plants, 249, 252.

Nitrogen-assimilating bacteria, 250.

Nitrogen cycle, 250.

diagram of, 255.

reactions of, 254 .

Nitro group, I I.

Nodule bacteria, 250, 252.

Nonoses, I08.

Normal salt solution, 221 .

Nucleo proteins, 89.

Nutrition, animal food and, $\mathbf{r}_{59-208}$.

OCTADECAPEPTIDES, 92.

Octoses, 108.

Oil, cacao, 280.

castor, 278.

coconut, 280.

cottonseed, 278.

flaxseed, 280 .

linseed, 280 .

maize, 280 .

olive, 278 .

palm, 278 .

peanut, 278 .

sesame, 278 .

Oil of bitter almonds, III.

cloves, 287 .

garlic, 134 .

lemon, 287 .

mustard, 134 .

peppermint, 287 .

rose, 287.

turpentine, 287 .

Oils, plant and animal, 57-65, 277-280. table, 62 .

Oleic acid, 6r, r33, I34, 2 ro.

Oleomargarine, 217.

Olive oil, 277.

Optical activity, 69.

Oranges, So.

Organic chemistry, definition of, 5 .

Oxalic acid, 52.

experiments, 53 .

Oxidases, 145 .

Oximes, 44, 107.

Oxygen, in plants and animals, 147 . evolution, in plants, 240. 
Oxyhæmoglobin, I93, 22 I.

Palmitic ACID, 47, 58, 2 Io.

Pancreas, I63. $_{3}$.

Pancreatic juice, digestion of carbohydrates by, 170 .

digestion of fats by, 180 .

digestion of proteins by, I75-176.

enzymes in, 177 .

properties of, 177 .

Paper, I26, 263, 264.

parchment, I 26, I 28.

Paraffins, Io.

Pasteur, 32, I40.

Pectins, I25, 247.

Pectocellulose, I 25, 264.

Pentane, I3, 55 .

Pentosans, I10, 247, 264, 272. determination of, 273 .

Pentoses, 108, I 10.

Pepsin, 33, I40, I43, I 45, I73. action of, 174 .

Pepsinogen, I43, I73.

Peptones, I72, I73.

Peristaltic action, 176 .

Petroleum, 6.

Phenylalanine, 86.

Phenylhydrazones, 45.

Phosphates, as plant food, I52.

Phospholipines, 282.

Phosphoproteins, 89.

Phosphorus, in plants and animals, 147.

Photosynthesis, 237-24I.

products of, $238,24 \mathrm{I}$.

Physiological salt solution, 221.

Phytosterol, 280.

Phy tosterol acetate, 28I.

Plant physiology, 232-256.

Plants, agricultural, $26 \mathrm{r}$.

building material in, 246.

cell food of, 243, 25I.

end products of metabolism in, 286 .

energy food of, $25 \mathrm{I}$.

inorganic food of, 152 .

physiological processes of, I 58 .

reserve food in, 244 .

soil food of, 250.

source of energy of, 237.

storage of energy by, 236 .

Plants and animals, compared, I57, 232. composition of, I46.

differences between, 235 .

organic and inorganic constituents, 146.
Plants and animals, (Continued) similarity of, 232.

volatile and nonvolatile constituents, I 47.

Polariscope, 70.

Polarized light, 70.

Polypeptide nucleus, I84, 202.

Polypeptides, 92, I72.

Polysaccharoses, I08, I 20-I 28. hydrolysis of, 120,164 .

Portal vein, I83, 192. carbohydrates in, I92.

Potassium, as plant food, I 52. in plants and animals, I47.

Potassium acid tartrate, 76 .

Potassium antimonyl tartrate, 77.

Potassium palmitate, 60.

Potassium tartrate, 76 .

Process butter, 2 I 7.

Production value, 299.

for cattle, 301 .

tables, 301, 302.

Prolamines, 89 .

Proline, 284.

Proof spirit, 38, 82.

Propane, 13, I 5. synthesis of, I4.

Propionic acid, 47.

Propyliodide, I5, I6.

Prosecretin, I76.

Proteases, I45.

Protein food, 203.

Protein requirement, 303.

Proteins, 23, 82, 87-97.

absorption of, I 84 .

analysis of, 90 .

blood, 203.

body, 203.

color reactions of, 95 .

composition of, 90, I55.

conversion of, into carbohydrates, 206. into fat, 207.

chemical properties of, 90 .

determination of, 93 .

digestibility of, 290.

digestion of, I 71-179.

in intestine, 175 .

products of, $\mathbf{I} 78$.

experiments, 93 .

forms of, in plants, 283 .

fuel value of, 294 .

hydrolysis of, 9I.

in crops, 283,285 .

in plants, $248,249,252,283,284$. 


\section{Proteins, (Continued)}

katabolic products of, 204 .

katabolism of, 204.

metabolism of, $20 \mathrm{I}-208$.

metabolizable energy of, 298.

milk, 2 I I.

molecular weight of, 90 .

nitrogen of katabolized, 205.

non-nitrogenous portion of, 206.

occurrence in plants, 284 .

oxidation of, in body, 203.

physical properties of, 88 . precipitation tests for, 96 .

solubility of, 93.

synthesis of, in body, 203.

test for nitrogen in, 93 .

Proteoses, I72, I73.

Prothrombin, 224.

Protoplasm, 88, I 54.

Ptyalin, 33, I2I, I40, I45, I65, I66.

Purine, Io2.

dihydroxy, I03.

trihydroxy, I03.

Purine bases, 97, 102.

Pyroligneous acid, 29, 50.

Pyroxylin, I28.

\section{RACEMIC ACID, 79.}

Racemic compounds, 79 .

Radicals, I 2.

Raffinose, ro8.

Red corpuscles, 220.

Reductases, I45.

References, Section I, I35.

Section II, 257.

Section III, 305.

Rennet, 2 I 2.

Rennin, I45, I 73, I 77, 2 I 2. action of, $I 75$.

Renovated butter, 2 I 7 .

Reserve food in plants, 244 .

Resins, 247.

Resorption, I83.

Respiratory quotient, 196, 197.

Rhamnose, I Io.

Rochelle salts, 77, II 2.

Rubner, 299.

Rum, 37 .

\section{SALIVA, 33, I2I, I22.}

action of, 165,167 .

alkalinity of, 167 .

amount of, 165 .

digestion of carbohydrates by, 165 .
Saliva, (Continued)

enzymes of, 166.

experiments, 168 .

organic substances in, I68.

properties of, 165 .

salts in, 167 .

stimulation of flow of, 165 .

Salivary glands, 165 .

Saponification, 60.

Sarcolactic acid, 223.

Schweitzer's reagent, I 26.

Secretin, 176.

Seidlitz powder, 77 .

Serine, 86.

Serum albumin, 202, 223, 224

Silage, 74 .

Silk, artificial, I27, 263.

Skatol, 287.

Smokeless powder, 127.

Snake venom, 225, 283 .

Soap, 60.

experiments, 63 .

properties of, 64 .

Sodium, as plant food, 152.

in plants and animals, I 47 .

Sodium bicarbonate, 77 .

Sodium hypobromite solution, IOI.

Soil food, of plants, 250 .

Sorbitol, 4I, I06.

Sorghum cane, i 6,274 .

Space isomerism, 69 .

Spermaceti, 57 .

Starch, 35, I08, I 20, I 2 I-I 24, 267-270.

acid hydrolysis of, I 23.

action on Fehling's solution, I2I.

action of saliva on, 169 .

as food, 268.

determination of, 123 .

enzymatic hydrolysis of, I22.

experiments, I $23,270$.

fermentation of, I 20.

hydrolysis of, I 22.

hydrolysis of, in germination, I 20.

industrial uses of, 268.

in crops, 268.

in plants, 244 .

iodine test for, I 22.

occurrence, I $2 \mathrm{I}$.

properties of, I $2 \mathrm{I}$.

salivary digestion of, I66.

soluble, r66.

Starch grains, I 22.

Starch paste, I 22.

Steapsin, I45, I80. 
Stearic acid, 47, 2 I0.

Stereo-chemical formula, 9 .

Stereo-isomerism, 69 .

Stigmasterol, 280.

Still, rectifying, 36 .

Stomach, I63.

acidity of, I69.

digestion in, I86.

digestion of proteins in, I72.

digestion of fats in, I80.

Stout, 36 .

Stroma, blood, 220.

Structural formula, 8.

Strychnine, 286.

Substitution, Io.

Substitution products, II.

Succinic acid, 53.

dihydroxy, 76 .

monobrom, 75 .

monohydroxy, 75 .

Sucrase, II6, I45, I7I.

Sucrose, II5-II8.

action on Fehling's solution, $1 \mathbf{r} 6$.

action of yeast on, II6.

experiments, I 20.

hydrolysis of, II 7 .

in crops, $274,276$.

occurrence, II 5 .

optical activity of, I I6.

Succus entericus, I78.

Sugar, II5-II8, 274-276.

analysis, I 8 .

beet, II 5,274 .

cane, II $5,274$.

in crops, $274^{-276}$.

in plants, 243.

maple, I $6,274$.

Sulphates, as plant food, $\mathrm{r}_{52}$.

Sulphur, in plants and animals, r47.

Sun, as source of energy, 237.

Tables, I. Alcohol per cent and specific gravity, 28.

II. Fats and oils, 62 .

III. Summary of carbohydrates, I 29.

IV. Enzymes, I45.

V. Volatile and nonvolatile constituents of plants, I 50-I 5 I.

VI. Cellulose content of crops, 266.

VII. Starch content of crops, 269.

VIII. Sugar content of crops, 276.

IX. Fat content of crops, 280.

X. Protein content of crops, 285 .
TABLes XI. Coefficients of digestibility, 290.

XII. Digestibility of foods, 292.

XIII. Fuel values of food constituents, 296.

XIV. Fuel values and metabolizable energy for cattle, 298.

XV. Production values for cattle, 301.

XVI. Digestibility and energy values for cattle, 302 .

Tannins, 286.

Tartar, 76.

Tartar emetic, 77 .

Tartaric acid, $76-78$.

dextro, 78 .

experiments, 80 .

levo, 78 .

meso, 78 .

racemic, 78 .

stereo-isomerism of, 78 .

Taurocholic acid, I 82 .

Terpenes, 286.

Tetanus toxin, 283 .

Tetra-chlor-methane, I8.

Tetrahedral theory, 72 .

Tetrapeptides, 92.

Tetroses, I08.

Theobromine, I03, 286.

Therm, 294.

Thrombin, 224 .

Toxic albumin, 225 .

Translocation material, in plants, 243.

Tri-chlor-aldehyde, 66.

Tri-chlor-methane, 18.

Tri-iodo-methane, 18.

Trioses, I08, Iog.

Tripeptides, 92.

Trisaccharoses, ro8.

Trypsin, I43, I45, I77.

hydrolytic action of, $\mathrm{x} 78$.

Trypsinogen, $\mathrm{r} 44, \mathrm{I} 77$.

Tryptophane, 87 .

Turpentine, 287 .

Tyrosine, 87 .

UNSAPONIFIABLE MATTER, 28r.

Unsaturated compounds, $\mathrm{I} 30-\mathrm{r} 34$.

Urea, 82, 97-IOI.

determination of, ror.

experiments, ror.

formation of, roo.

in blood, 223.

in body, 205 . 
Urea, (Continued)

in saliva, $\mathbf{r} 68$.

in soil, 249 .

in urine, 100, 227.

isolation of, from urine, 227, $23 \mathrm{I}$. synthesis of, 99 .

Ureometer, roI.

Uric acid, 82, 97, 102, 103, 223, 228. in blood, 223. in urine, 228.

Urine, 209, 226-23I. albumin in, 230. ammonia in, 228. constituents of, 227 . creatinine in, 228 . distribution of nitrogen in, 229 . experiments, $23 \mathrm{I}$. general properties of, 230. glucose in, III, 229. hippuric acid in, 229. isolation of urea from, 227. nitrogen compounds in, 227 . nitrogen excretion in, 205. pathological constituents of, 229. total nitrogen of, 205. urea in, 227 . uric acid in, 228.

VALERIC ACD, 47.

Valine, 85 .

Vanilla, 287.

Vanillin, 287 .

van't Hoff, $7 \mathrm{I}, 79$.

Vegetable ivory, 272.

Vinegar, 50.

experiments, 5 I.
Volatile and nonvolatile constituents, 147.

experiments, 152 .

in plants, table, 150.

von Schwann, 32.

WATER, ASSiMILATION OF, IN PLANTS, 238.

Waxes, 57.

in plants, 277 .

table, 62.

Westphal balance, 2 I5.

Wheat bran, rro.

Whey, 212, 217 .

Whisky, 37.

White corpuscles, 220, 222.

Wine, 36 .

Wirzung, duct of, I76.

Wöhler, 99.

Wood alcohol, 26, 29.

Wood gum, I ro.

Wood vinegar, 50.

Work, and heat, I57. muscular, I 57, 233.

Xanthine, 97, I03. dimethyl, ro3. trimethyl, I03.

Xanthoproteic reaction, 96 .

Xylose, Iro.

YEAST, 32, II3.

ZUNTZ, 299.

Zymase, 32, II3, 145 .

Zymogens, I43. 


THIS BOOK IS DUE ON THE LAST DATE STAMPED BELOW

AN INITIAL FINE OF 25 CENTS WILL BE ASSESSED FOR FAILURE TO RETURN THIS BOOK ON THE DATE DUE. THE PENALTY WILL INCREASE TO 50 CENTS ON THE FOURTH DAY AND TO \$1.0O ON THE SEVENTH DAY OVERDUE.

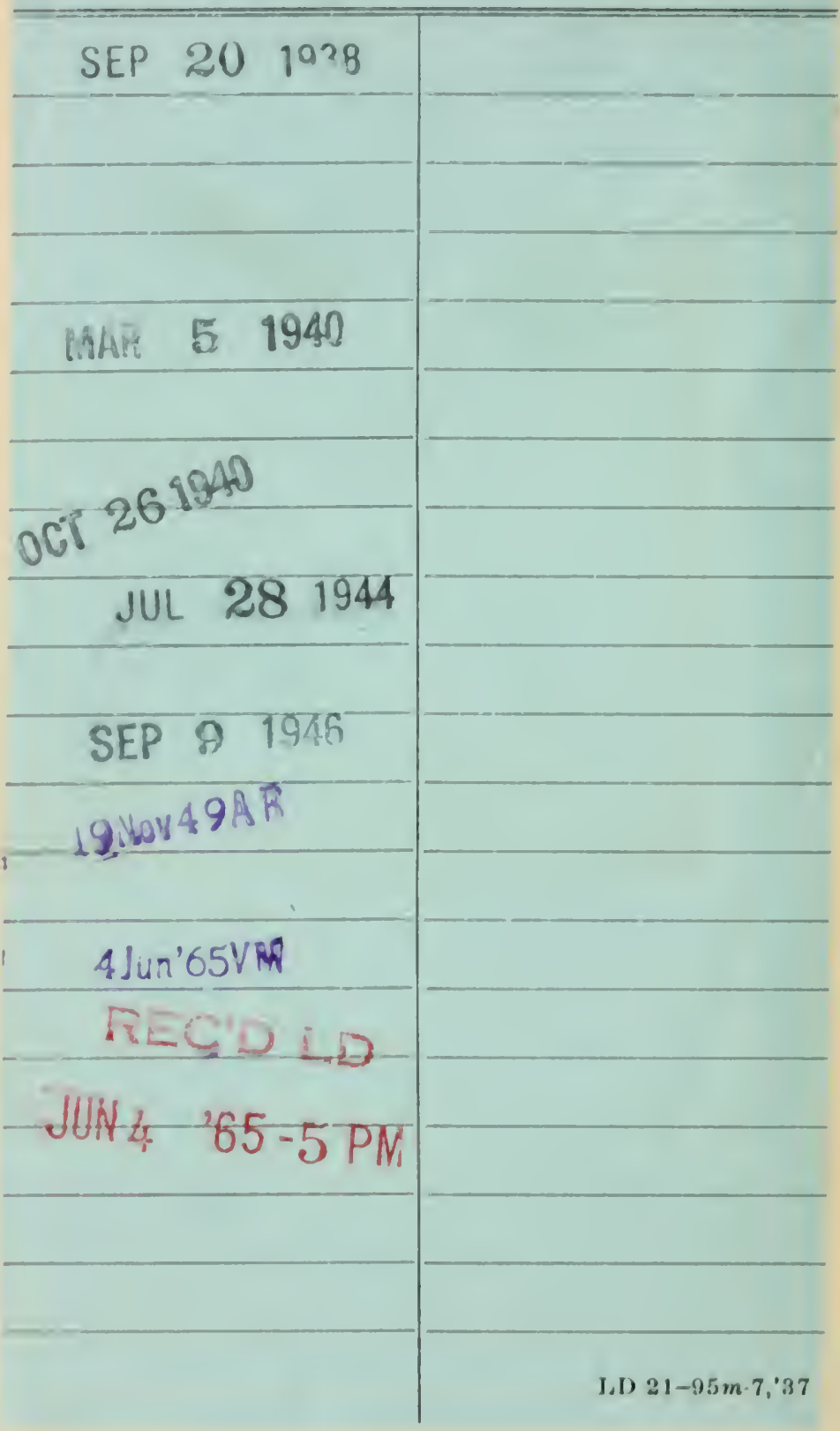




\section{LIBRARY USE}

RETURN TO DESK FROM WHICH BORROWED

\section{LOAN DEPT.}

THIS BOOK IS DUE BEFORE CLOSING TIME ON LAST DATE STAMPED BELOW

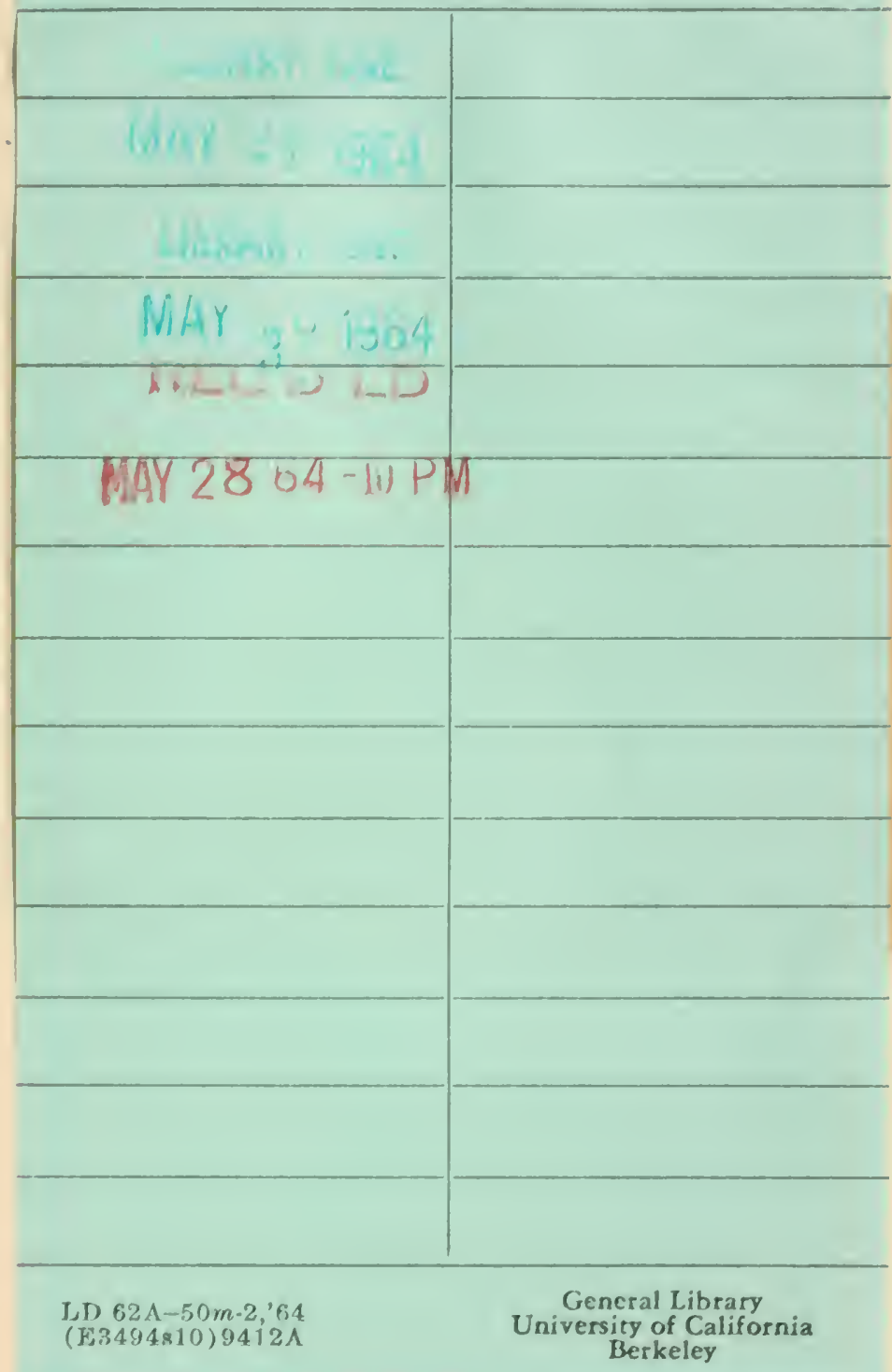


THIS BOOK IS DUE ON THE LAST DATE STAMPED BELOW

\section{AN INITIAL FINE OF 25 CENTS}

WILL BE ASSESSED FOR FAILURE TO RETURN THIS BOOK ON THE DATE DUE. THE PENALTY WILL INCREASE TO 50 CENTS ON THE FOURTH DAY AND TO $\$ 1.00$ ON THE SEVENTH DAY OVERDUE.

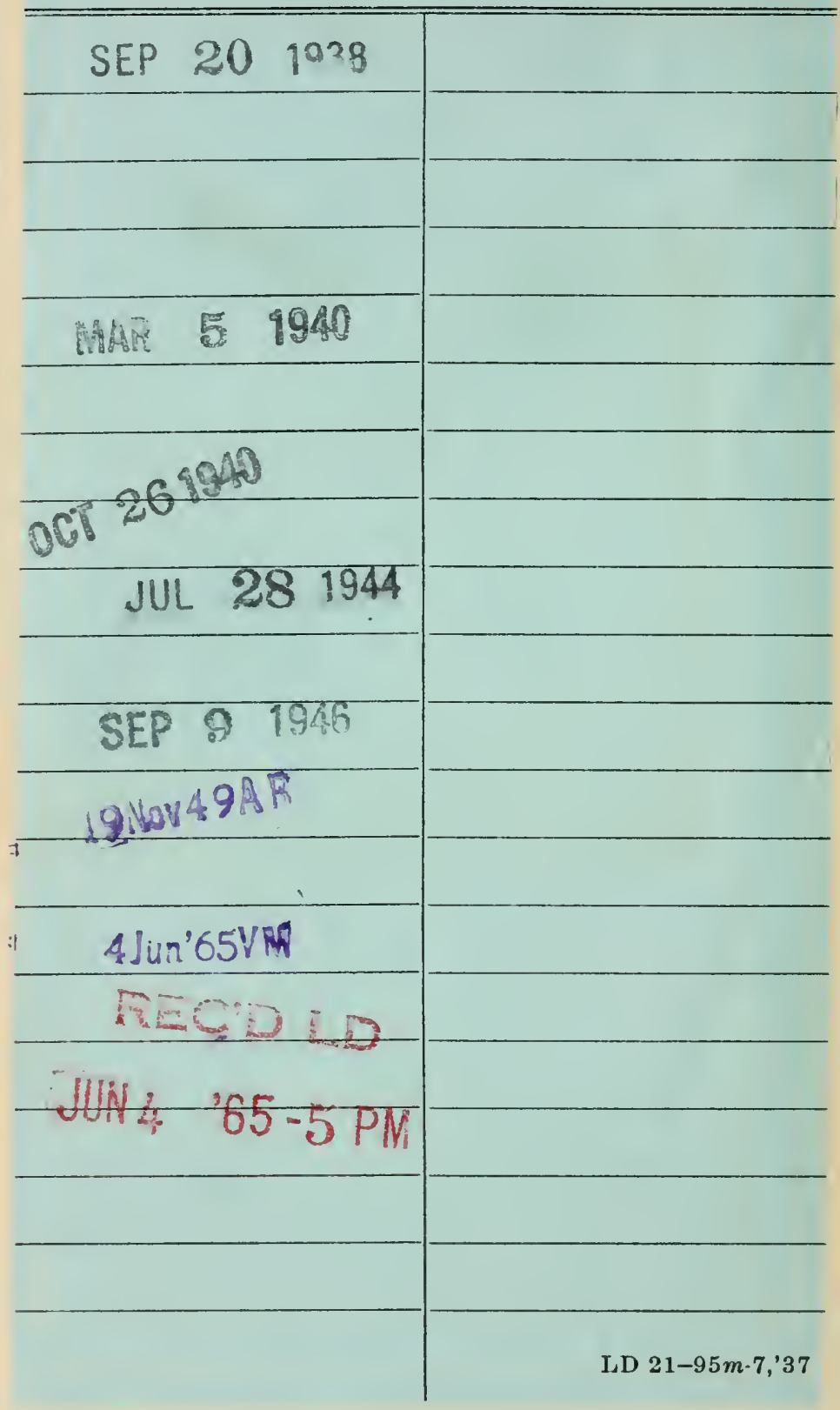




\section{LIBRARY USE}

RETURN TO DESK FROM WHICH BORROWED

\section{LOAN DEPT.}

THIS BOOK IS DUE BEFORE CLOSING TIME ON LAST DATE STAMPED BELOW

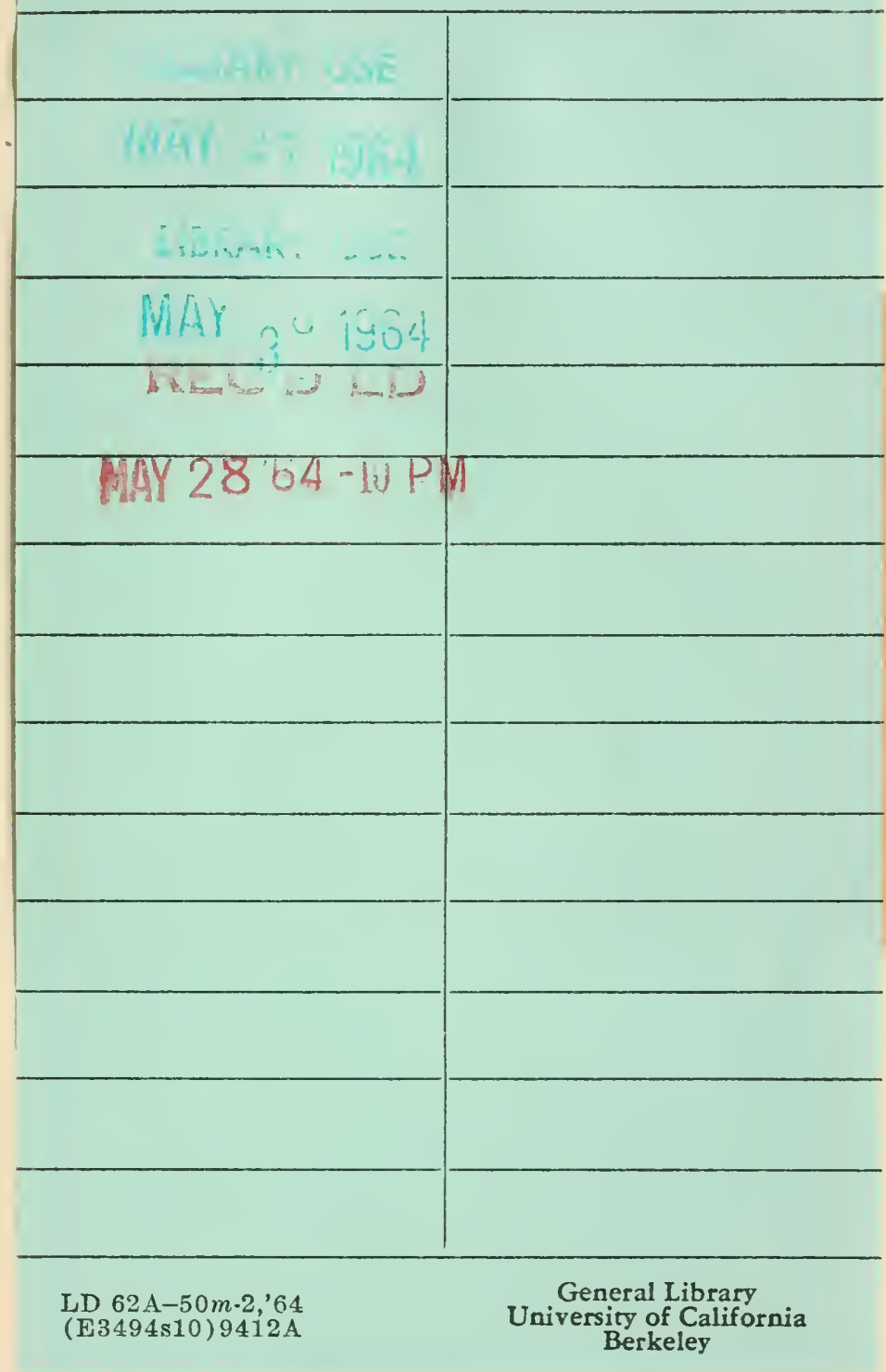


